\title{
Regulation of in vitro cell-cell and cell-substrate adhesion
}

Remy W.F. Wiertz 
Samenstelling van de promotiecommissie:

Voorzitter en Secretaris

Prof. dr. ir. A.J. Mouthaan (voorzitter)

Universiteit Twente

Promotoren:

Prof. dr. E. Marani (promotor)

Universiteit Twente

Prof. dr. W.L.C. Rutten (promotor)

Universiteit Twente

Leden:

Dr. Vleggeert-Lankamp

Leids Universitair Medisch

Centrum/RU Leiden

Dr. A.A. Poot

Universiteit Twente

Prof. dr. A. Offenhäusser

Forschungszentrum Jülich

Prof. dr. W. Kruijer

Universiteit Twente

Prof. dr. ir. P.H.Veltink

Universiteit Twente

ISBN: 978-90-365-3049-1

(C) R.W.F. Wiertz, Hengelo, The Netherlands, 2010 


\title{
REGULATION OF IN VITRO \\ CELL-CELL AND CELL- SUBSTRATE ADHESION
}

\section{PROEFSCHRIFT}

\author{
ter verkrijging van \\ de graad van doctor aan de Universiteit Twente, \\ op gezag van de rector magnificus, \\ prof. dr. H. Brinksma, \\ volgens besluit van het College van Promoties \\ in het openbaar te verdedigen \\ op donderdag 24 juni 2010 om 16.45 \\ door \\ Remy Willem Frederik Wiertz
}

Geboren op 22 november 1974

Te Hengelo, Nederland 
Dit proefschrift is goedgekeurd door de promotoren:

Prof. dr. E. Marani

Prof. dr. W.L.C. Rutten 


\section{Contents}

Chapter 1

General Introduction

Chapter 2

Impedance Sensing for monitoring neuronal coverage

and comparison with microscopy

Chapter 3

Inhibition of neuronal cell-cell adhesion measured by microscopic aggregation assay and impedance sensing

Chapter 4

The inhibition of neuronal aggregation on Fibronectin,

Poly-L-Lysine and Laminin coated substrates in culture

Chapter 5

Neural cell-cell and cell-substrate adhesion

through N-Cadherin, N-CAM and L1

Chapter 6

General Discussion

Summary

Nederlandse samenvatting 
Chapter 1

General Introduction 


\subsection{Neural engineering}

\subsubsection{Neuronal adhesion and the cultured probe}

The key topic of this thesis is the enhancement of cell-substrate adhesion of cultured neurons to artificial (flat electrode array) surfaces accompanied by measures to weaken the cell-cell adhesion among these neurons. The latter is necessary in order to suppress the strong drive to aggregate to three-dimensional conglomerates of two dimensionally plated neurons.

An improved control over the structure of neuronal cultures would be important in the development of a more intimate, selective and durable contact between implanted 2D electrode systems and neural tissue. The ensemble of cultured neurons on electrode arrays is called a 'cultured probe'.

In this chapter we will introduce the key players of this hybrid interface probe: neural interfaces, cell culturing/assays, neural tissue, cultured probes, cellular adhesion, cell signalling, impedance testing and microscopic evaluation.

\subsubsection{Neuro-electronic interfacing}

Stimulation or recording of neural activity in the brain or the spinal cord can be effectuated by interfacing the nervous system with electrodes. Depending on the application, electrodes with various designs and made of different materials have been developed for stimulation and recording. A relatively simple example is the surface electrode, which is attached to the skin. Other electrodes need to be implanted through a surgical intervention, like the intra-neural wire electrode [1] and cuff (multi) electrodes, which surround nerve fibers like a cylinder [2-4], a spiral [5] or a helix [6]. Another type of electrode design is the multi-electrode array, which is a set of needles that are penetrated into fibre bundles. The electrodes can be arranged in a 2D configuration with needles of equal length [7] or in 3D with needles of different length [8].

The functionality of any type of neuroprosthesis depends on the ability to create effective, selective and stable neuro-electronic interfaces. A neuron cultured probe is a hybrid type of interfacing. The development of a neuron cultured probe is an attempt to further miniaturize electrodes to a cellular dimension and enhance selectivity and effectivity. The 'cultured probe' reverses the mechanism of interfacing by guiding axons to neuron probed electrodes on multi electrode arrays (MEAs, figure 1), rather then bringing the electrodes to the axons [9]. Such a precultured interfacing device will have to meet special requirements regarding overall design, micro design, electrical properties, biocompability of the used material, and the quality and stability of the neuronal "pre-culture". This thesis is focussed on the improvement of the stability of the neuronal pre-culture. 


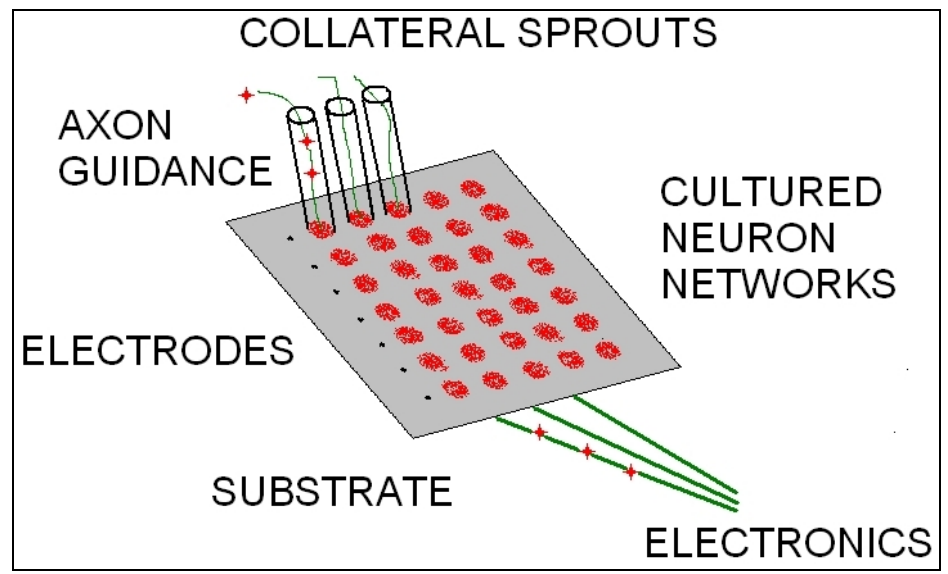

Figure 1. Schematic impression of a neuron cultured probe, for a stimulatory prosthesis. Collateral sprouts from an in vivo system are guided to the pre-cultured islands. These circular islands (red) are cultured neuronal networks covering and surrounding micro-electrodes electrodes (black dots), which are further connected to an electronic system. (Courtesy: W.L.C. Rutten).

\subsubsection{Neuronal culturing}

The cultivation of cells from animals is a lab technique that became a major tool in many clinical and research fields. Eukariotic cells can be isolated form nearly any type of animal tissue by mechanical dissociation and/or enzymatic digestion. Once isolated, these primary cells can be maintained and grown under controlled conditions, which vary widely for each cell type. Cells can only be cultured in a precisely supportive liquid culturing medium bath. Culturing media can vary in $\mathrm{pH}$, glucose concentration, growth factors, and many other nutrients. The culturing of eukaryotic cell has found numerous applications in research, the manufacturing of viral vaccines, hormones, enzymes, immunobiologicals (monoclonal antibodies, interleukins, lymphokines), and anticancer agents.

The culturing of neuronal cells differs from that of most other cell types. The main differences are their ability to process and transmit electrochemical signals and the inability of neurons to divide. This non-dividing character means that neuronal cells can only be obtained by isolation from tissue. On the favorable side, the lack of dividing capacity makes neuronal cultures relatively stable over time. They can be kept in culture for months, enabling long term in vitro experiments.

Some cell lines are widely used as a model for a neuronal cell line. For example, PC12 cells derive from rat adrenal pheochromocytoma and can proliferate in growth media. However, in the presence of nerve growth factor (NGF) they stop proliferating and differentiate into neuron-like cells which express neuronal function in vitro [10]. The result is a culture representing a single cell type. The major disadvantage of neuronal cell line models is their genomic abnormality, resulting in both genotype and phenotype variations [11]. 
Because of its complexity and importance for the human body, studies on the nervous system and its disorders are numerous. The use of in vitro models can simplify research [12-14].

Cultures of neuronal cells are very helpful for studying the nervous system on several levels under controlled conditions. Neuronal cultures have been applied for the study of hypothermia [15], differentiation [16], learning [17, 18], degeneration [19], regeneration [20], neurotoxicity [21] and neural circuits [22]. Neuronal cultures have also been applied in neuro-electronic interfacing [23].

The initial composition of neuronal cultures is dependent on the neuronal tissue used as a source. Such tissue consists of both neurons and glial cells. Using isolation and separation techniques it is possible to increase the relative content of a certain type of neuron. The use of selective growth media in cell cultures can ensure the survival or proliferation of cells with certain properties. For example, the chemically defined R12 culturing medium is developed and optimised to sustain neurons in culture, but to minimise the glial content $[24,25]$.

\subsubsection{Neurons and glia}

Nervous tissue is composed of two main cell types in an 1 to 1 ratio: neurons and glial cells [26]. Neurons are cells with electrical signalling properties, enabling them to receive, transmit and process information. Bota et al qualitatively estimated that the mammalian nervous system is constructed ontogenetically from 2500 to 5000 subclasses of neurons [27]. These subclasses of neurons are all part of the 3 major classes of neurons; afferent neurons (sensory neurons), efferent neurons (motor neurons) and interneurons. Afferent neurons conduct afferent impulses from the periphery to the central nervous system. These impulses from the periphery are activated by physical phenomena like sound, light, mechanical pressure, etc. Efferent neurons conduct efferent signals from the central nervous system to effectors, such as muscles and glands.

The most abundant neurons in the nervous system are interneurons, which can only be found in the central nervous system (CNS). Interneurons only connect with other neurons and are involved in intermediate processing of afferent to efferent signals. However, large networks of interneurons in the cortex also enable analysis and interpretation of information received from other parts of the brain or the body. The interconnection among the cortical neurons can convert these interpretations into thoughts and concrete operations of the body.

The rest of the cells in the nervous systems are for the greater part of glial origin. This diverse group mainly consists of astrocytes, oligodendrocytes, microglia and Schwann cells. Unlike neurons, glial cells do not conduct electrochemical pulses. Glial cells serve as connective tissue in the CNS, forming complex interrelationships with neuronal cells and supporting a wide range of processes [28]. 


\subsubsection{Neuronal cultured probe}

The neuron cultured probe is based on the connections between micro electrodes and regenerating axons [9]. For the contact between collateral sprouts and microelectrodes, axons need to be branched from fibres and guided toward an implantable micro-electrode array. In an in vitro study by Mouveroux et al [29] the guiding of spinal axons over a grid micro-patterned with polyethylene imine (PEI) lanes was shown. A recent study by Wieringa et al indicated the possibility of guiding neurites through micro channels and even separation of neurites in bifurcating micro channels [30].

A regenerating axon can only maintain itself and pass on electrical information when it finds a target cell or dendrite [31], so bare micro-electrodes will have to be covered with 2D islands of neurons to host collateral sprouts. These small islands of neurons can act both as recognition target and focal points for collateral sprouts as well as sealing layers for micro electrodes. The adhesion of these islands to substrates can, for example, be promoted or inhibited by chemical modification of electrode areas with various coatings. Ruardij et al managed to create a surface "patterned" with neuronal cells (figure 2) using a combination of PEI and fluorocarbon (FC) as substrates [32]. Nonetheless, natural tendencies to migrate and cluster into $3 \mathrm{D}$ eventually disturb the desired stability of a neuronal culture, resulting in the loss of all predefined 2D structures. Better control over cell-cell and cell-substrate adhesion could delay or prevent this aggregation.

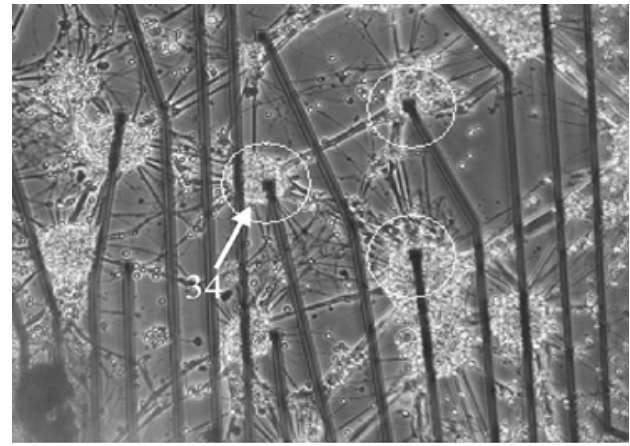

(a)

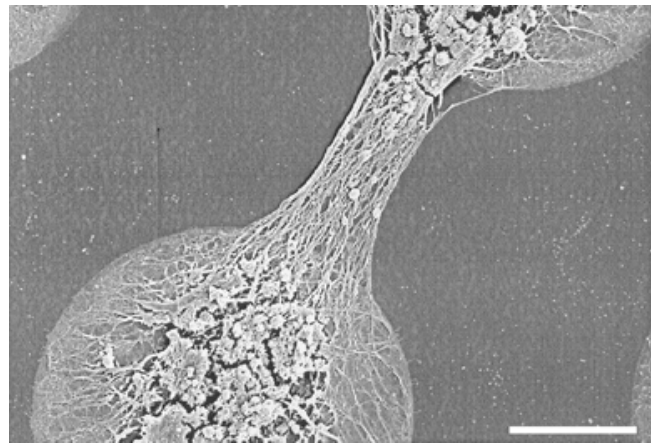

(b)

Figure 2. (a) Morphological appearance of neuronal tissue adhering on microprinted PEI circles. PEI borders are indicated by the drawn white circles. (b) Scanning electron micrograph of cortical neuronal tissue (30 days) present on a circular pattern of PEI circles microprinted onto an fluorocarbon substrate. Diameter is $150 \mu \mathrm{m}$. Spacing distance between circles is $90 \mu \mathrm{m}$. Scaling bar $=50 \mu \mathrm{m}$.(Courtesy: Ruardij, 2000 ). 


\subsection{Neuronal adhesion}

\subsubsection{Cell-substrate adhesion}

For the promotion of long term positioning of neuronal cells a neuronal cell culturing environment should have specific properties. Inert culturing substrates like glass are not suited for neuronal adhesion, unless chemically modified by coating with specific or non-specific neuro-adhesive agents. The neuron-adhesive properties of these chemical agents should be strong enough to inhibit migration of neuronal cells. Poor cell-substrate adhesion will cause the loss of any predefined structure due to aggregation. Aggregates may even cross the boundaries of neurophilic patterns. To avoid or delay this, strong neuron repellent area's can enhance the stability of neuro-adhesive regions [32-35]. Another way is to tackle the aggregation tendency itself by inhibition of cell-cell adhesion. Cell-cell adhesive forces are the main competition for cell-substrate adhesive forces, disturbing cell-substrate immobilization. Cell-substrate adhesion has to be optimal, while cell migration and aggregation caused by cell-cell adhesion should be reduced to a minimum.

Several types of (bio)chemicals are applicable as substrate coatings. They vary in origin, binding mechanism, binding strength and other properties. Synthetic polymers like PEI and poly-1-lysine (PLL) provide strong adhesiveness through positively charged functional groups that enable attachment to the negatively charged membrane of the neuronal cells [36]. Another widely applied type of surface coating are proteins from the extracellular matrix. The extracellular matrix consists of supportive material surrounding cells in all types of tissue. Surface coatings based on ECM-molecules like fibronectin and laminin bind specifically to cell adhesion molecules such as integrins [37]. Besides adhesive properties, ECM molecules are known to have functions in cell signalling as well. Processes like proliferation, differentiation, axonal outgrowth and survival are promoted when using ECM derived molecules that specifically bind neuronal cells [38-40]. This makes ECM molecules like fibronectin and laminin interesting as a surface coating for neuronal cultures. However, major disadvantages of ECM molecules in comparison to non-specific coatings are their weaker adhesive strength [41, 42]. Polymers of organic compound like lysine and ethanolamine have stronger neuron adhesives properties, but have probably no direct receptor mediated signalling effects on neuronal cells. 
Table 1. A list of the most common neuronal substrate coatings and their properties. ${ }^{*} R G D$ represents the one letter abbreviations for the amino acids: arginine $(R)$, glycine $(G)$, and aspartate $(D)$. The $R G D$ motif is the recognition site in fibronectin for the integrin adhesion molecule.

\begin{tabular}{c|c|c|c|c}
\hline Substrate & Synthetic & Natural & $\begin{array}{c}\text { Biologic } \\
\text { active }\end{array}$ & $\begin{array}{c}\text { Neuron-adhesive } \\
\text { Properties }\end{array}$ \\
\hline Polyethyleneimine (PEI) & $\mathrm{X}$ & & & good \\
Poly-L lysine (PLL) & $\mathrm{X}$ & & & good \\
Poly-D lysine (PDL) & $\mathrm{X}$ & & & good \\
Polyethyleneoxide (PEO) & $\mathrm{X}$ & & & good \\
RGD-peptide & $\mathrm{X}$ & & $\mathrm{X}$ & moderate \\
Fibronectin & & $\mathrm{X}$ & $\mathrm{X}$ & poor \\
Gelatine & & $\mathrm{X}$ & $\mathrm{X}$ & poor \\
Collagen & & $\mathrm{X}$ & $\mathrm{X}$ & moderate \\
Laminin & & $\mathrm{X}$ & $\mathrm{X}$ & poor \\
\hline
\end{tabular}

\subsubsection{Cell-cell adhesion}

The integrity of tissues is maintained by cell-cell adhesion and cell-ECM adhesion. Control over regulatory mechanism in neuronal cell-cell adhesion would be of great interest for the control over neuronal cultures. Neurons in culture start to aggregate into the third dimension over time, limiting cell-survival and disturbing the two-dimensional structure. By controlling the culture topography (the overall structure of a culture) it could be possible to create pre-designed structures that are stable over long periods of time, such as islands or networks. An important tool for regulation of cell cultures lies in the cell-substrate and the cell-cell adhesion. Cell adhesion molecules on the cell surface regulate the binding of cells to cells or to the extracellular matrix. Intervention in cell-cell adhesion in vitro through blocking of CAMs could provide a better control over neuronal adhesion. A wide range of CAMs are involved in neuronal adhesion.

\section{Immunoglobuline superfamily}

The immunoglobuline superfamily is a family of adhesion molecules with a wide diversity in function and structure. This protein family is one of the largest in vertebrate genomes, with over 750 genes encoding for Ig-like domain containing proteins [43]. Most of the molecules in the Ig superfamily are transmembrane molecules with a short tail into the cytoplasma. Members of the Ig superfamily can be characterised by the presence of one or more Ig related domains at the extracellular site of the molecule [44]. Several members of the immunoglobine superfamily, like N-CAM and L1, have an important role in the development of the nervous system, especially during embryonic development, where they regulate cell migration, neurite extension, and fasciculation, and possibly formation of synapses in the brain [45-48]. The most common member of the superfamily, NCAM, has a major role in preserving the integrity of the nervous system. There are at least 27 types of N-CAM mRNAs, all generated by alternative splicing of an 
RNA transcript produced from a single gene. There are three major isoforms of NCAM, which vary in their cytoplasmatic domain. N-CAM-120kDa is anchored to the exterior leaflet of the cell membrane through glycophosphatidylinositol (GPI). In contrast, N-CAM-140kDa and N-CAM-180kDa are both transmembrane proteins with cytoplasmic domains [49]. After translation, N-CAM can be posttranslationally modified by addition of polysialic acid (PSA) particularly onto the fifth Ig loop [46]. PSA is thought to discard N-CAMs homophilic binding properties and can lead to reduced cell adhesion [50]. It has been suggested that this reduction is caused by the negative charge of PSA. It forms stable connections with water and occupies a large volume in the extracellular space. This will keep plasma membranes sufficiently far apart from other N-CAMs.

\section{Cadherins}

Like the members of the Ig superfamily the cadherins play a major role in the adhesion between cells. The binding between cadherins is calcium-ion dependent. Between each pair of repeats there are $\mathrm{Ca}^{2+}$-binding sites, each binding site is capable of binding a calcium ion [51]. Binding of $\mathrm{Ca}^{2+}$ causes the $\mathrm{N}$-Cadherin molecule to assume a rigid conformation and orients the adhesive regions of the cadherin molecule in such a way that the cadherin from one cell can interact with the same kind of cadherin from an adjacent cell [52]. The cytoplasmic tail of the cadherins interacts indirectly with actin filaments through adaptor molecules called catenins. The serine-rich domain of the cytoplasmic tail of $\mathrm{N}$-Cadherin is capable of binding $\beta$ - and $\gamma$-catenins. These catenins associate with $\alpha$-catenin, which in turn connects the cadherin-catenin complex to the actin filaments [53]. This association with actin is critical for the formation of stable adhesion through cadherin [54].

Cadherin binding is mostly homotypical. However, some cases of heterotypical adhesions are known. The family of the cadherins contains about 50 members, all with a comparable structure, but with different adhesive properties. The cadherins have a typical structure of 5 homologous domains, a transmembrane domain and a domain in the cytoplasma. Results of several in vivo and in vitro studies suggest cis-binding of the extracellular region among cadherins in order to enable binding of cadherins among neighbouring cells [55]. Clustering of cadherins seems to be an important factor for cadherin mediated cell-cell adhesion.

\section{Integrin family}

Integrins play a key role in organogenesis, development of tissue, thrombosis and leucocyte migration. The integrin structure comprises 2 transmembrane units, $\alpha$ and $\beta$, that bind heterotypically to peptides in the extracellular matrix. However, some integrins bind to adhesion molecules from the Ig superfamily and some to cadherins. Integrins can be divided in subcategories based on the $\beta$ subunit, with comparable physiologic properties within the subunits. B1 integrins are involved in the organisation of muscle, nervous tissue, epithelium and endothelium. B2 integrins enable leucocytes to migrate and bind to endothelial cells. The B3 
subgroup is found on platelets and is responsible for cross-linking platelets in fibrin within a developing blood clot. In the nervous system integrins are known to be expressed in neural and glial cells of developing and adult brain. Several studies indicated the role of integrins in migration of neuroblasts, neural crest cells and cortical neurons [56].

\subsection{CAM activated signalling}

Besides their functions in physical cell to cell adhesion, CAMs also demonstrate receptor functions for neuronal cell signalling. The cytoplasmic domain of NCadherin, N-CAM and L1 all interact with proteins that are involved in several cell-signalling pathways. These direct pathways have been hard to discover. The indirect effects of ligation among CAMs are many, making it difficult to distinguish them from effects caused by direct signalling. A study by C. Schrick et al [57] suggests a role of hippocampal N-Cadherin in cytoskeletal IQGAP1/Erk signalling pathways, which is thought to be involved in memory consolidation. Recent studies have shown the involvement of N-Cadherin in regulation of calcium influx through voltage-activated calcium currents and organization of synaptic structure by signaling via small Rho guanosine triphosphatase [58]. N-Cadherin seems to have a functional signalling overlap with NCAM and L1 in other pathways. All three CAMs are crucial for neurite formation through activation of FGF receptor (fibroblast growth factor receptors). The induction of neurite outgrowth has been shown to be activated by the MAPK (mitogen-activated protein kinase) pathway in response on N-Cadherin, N-CAM and L1 [59].

$\mathrm{N}-\mathrm{CAM}$ has been shown to be involved in several other signalling pathways: NCAM has the ability to act as a glial cell-line derived neurotrophic factor (GDNF) receptor in the absence of the GDNF receptor tyrosine kinase. The polysialylated form of N-CAM is involved in the regulation of brain-derived neurotrophic factor (BDNF) and platelet-derived growth factor.

Besides having a stimulating effect on neurite outgrowth, N-Cadherin, N-CAM and L1 have also shown to be involved in signaling pathways that prevent neuronal cell death [59-62].

\subsection{Impedance Sensing (IS) and Microscopy}

For the monitoring of cell-substrate- and cell-cell adhesion mediation one can use IS and compare it with microscope-evaluation of cell coverage. In IS cells are cultured on micro electrodes and submitted to an AC current. During cell attachment and cell spreading on an electrode, cells progressively constrain the electrical current and force it to flow through decreasing intercellular spaces among neighbouring cells, resulting in progressively higher AC impedances. Change in cell adhesion will have effect on the dimension of extracellular space and consequently on current flow patterns and total impedance $[63,64]$. 
The effect of intervention on CAM-mediated cell-cell adhesion on the impedance of the neuron covered electrode was then compared with changes in the neuronal coverage of the culturing surface.

The percentage of surface coverage can be determined by analysis of phasecontrast microscopy images. Digital color photographs can be converted into 8-bit grayscale photographs using imaging software. The contrast between the neuronal cells and the culturing surface can be subsequently used for segmentation of the grayscale picture into a black-and-white image. Pixels within a pre-defined upper and lower grey tone threshold, representative for somas and cell delineation, can be set to black or white pixels (black in this study). The pixels in between dark somas or dark cell delineation are then consequently set to white. The ratio of the number of black to white pixels is the percentage of the electrode area covered by cells. Figure 3 is an example of the conversion from color image to grayscale image and from a grayscale image to a black and white image.
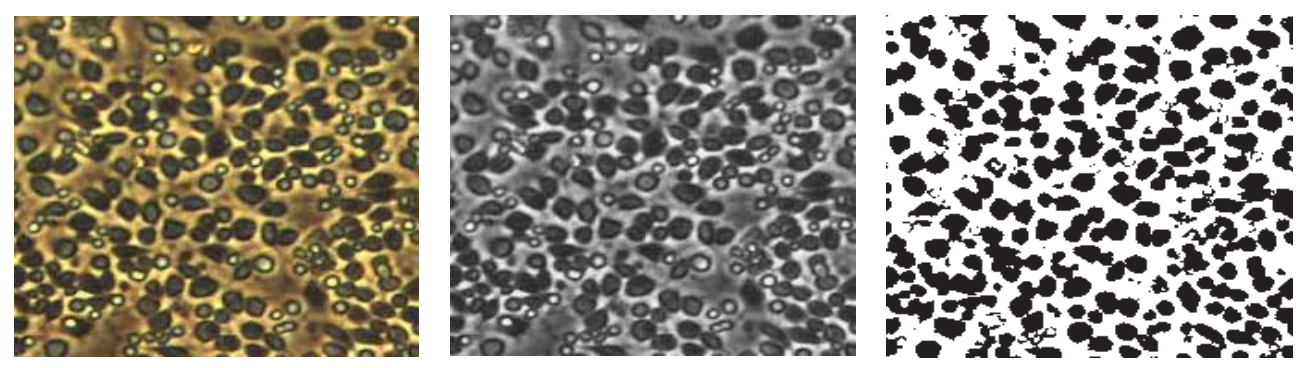

Fig 3. Conversion of a color image into a 1-bit black and white photograph.

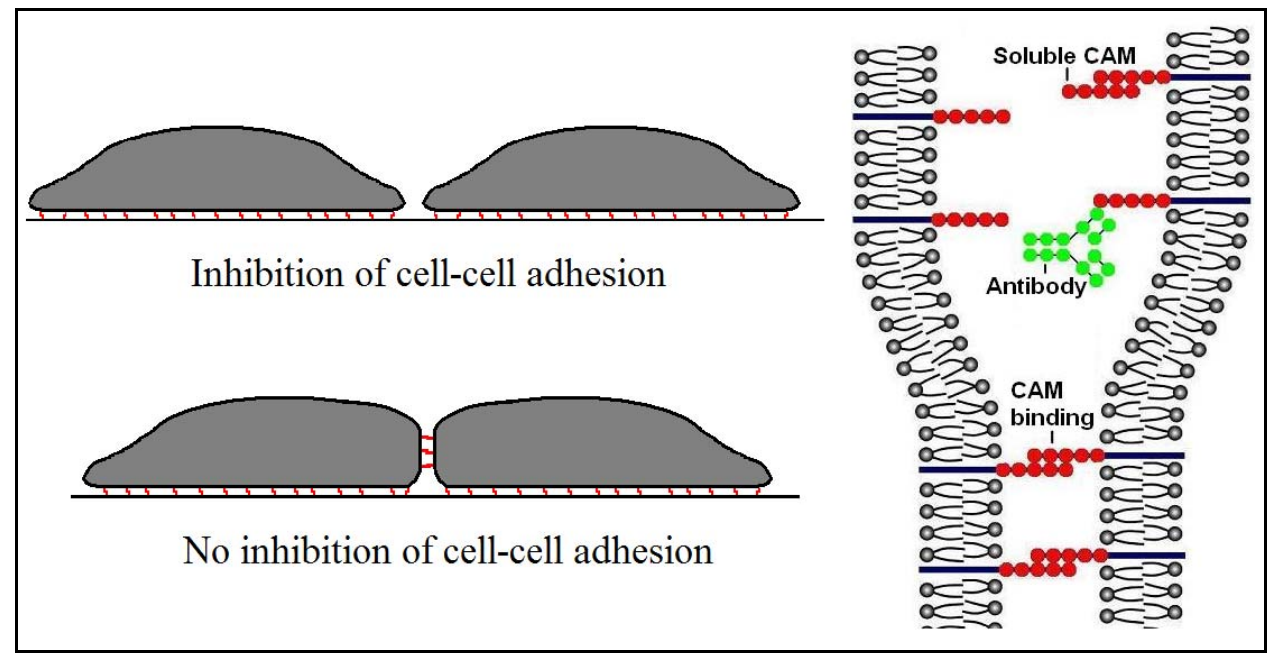

Figure 4. Inhibition of cell cell adhesion. Binding of antibodies or peptides to CAMs obstructs binding of CAMs on neighbouring cells, thereby inhibiting cell-cell adhesion. 


\subsection{Outline of this thesis}

This thesis aims to provide a better understanding of neuron-substrate adhesion and neuron-neuron adhesion in vitro, which should contribute to a better control of neuron culture topography. In chapter 2 , we investigated the applicability of IS for the monitoring of neuronal adhesion in culture. The IS technique was optimized for frequency and electrode size. Fitting of models to measured data yielded a simple model which was used for identification of the interface components, such as the spreading resistance $R_{\text {spread }}$ and the electrode-electrolyte interface parameter $\mathrm{K}$. Long term monitoring of neuronal cultures revealed detailed information on changes during the development of such cultures. The most appropriate electrode properties for the impedance sensing of neuronal cells were applied in the protocols of the experiments described in the subsequent chapters.

In chapter 3, we explored the use of soluble CAMs and CAM antibodies for inhibition of neuron to neuron adhesion on a PEI coated surface (figure 4), applying the optimized IS setup. L1, NCAM and N-Cadherin on neuronal cells were blocked by adding soluble peptide and antibody antagonists to the culturing medium. N-Cadherin peptide and antibody showed to be most effective in overcoming migration and aggregation of neuronal cells by inhibiting neuron to neuron adhesion. Some of the applied inhibitory additives showed little or no effect on cell-cell adhesion.

In chapter 4 we compared inhibition of cell-cell adhesion among neuronal cells cultured on several other substrates. Neurons were cultured on laminin, fibronectin and PLL coated surfaces, all exhibiting different properties as a culturing substrate. On laminin, fibronectin and PLL, migration of neuronal cells caused formation of neuronal aggregates within a few days. However, in the presence of N-Cadherin peptide or antibody, aggregation of neurons was inhibited or stopped.

In chapter 5, CAMs were investigated on their suitability as cell culturing substrate coatings. Soluble L1, NCAM and N-Cadherin peptides and their antibody antagonists were immobilized on electrode areas by chemical crosslinking. Immobilization of both N-CAM and N-Cadhering peptides or antibodies on surfaces resulted in better neurophilic properties of the modified surface. Especially N-Cadherin antibody showed to be applicable as a surface modificator. In the second part of chapter 5 the effect of adding CAM protein or antibody to the medium, on neurons cultured on surfaces modified with immobilized CAMs was investigated. Neurons cultured on immobilized antibodies were less affected by addition of soluble CAM blockers compared to neurons cultured on immobilized proteins, indicating that antibody-protein bonds are more stable compared to protein-protein bonds. 


\section{References}

[1] Nannini N, Horch K 1991 Muscle recruitment with intrafascicular electrodes IEEE Trans. Biomed. Eng. 38 769-76

[2] Stein R B, Nichols T R, Jhamandas J, Davis L and Charles D 1977 Stable long-term recordings from cat peripheral nerves Brain Res. 128 21-38

[3] Barone F C, Wayner M J, Aguilar-Baturoni H U and Guevara-Aguilar R 1979 A bipolar electrode for peripheral nerve stimulation Brain Res. Bull. 4 $421-2$

[4] Sauter J F, Berthoud H R and Jeanrenaud B 1983 A simple electrode for intact nerve stimulation and/or recording in semi-chronic rats Pflligers Arch. Eur. J. Physiol. 397 68-9

[5] Naples G G, Mortimer J T, Scheiner A, Sweeney J D 1988 A spiral nerve cuff electrode for peripheral nerve stimulation IEEE Trans. Biomed. Eng. 35 905-916

[6] Naples G G, Mortimer J T, Yuen T G H 1990 Overview of peripheral nerve electrode design and implantation Neural Prostheses: Fundamental studies. 107-45.

[7] Smit, J P A, Rutten,W L C and Boom H B K 1999 Endoneural selective stimulation using wire-microelectrode arrays IEEE trans. Rehabil. Eng. 4 399-412

[8] Rutten W L C, Frieswijk T A, Smit J P A, Rozijn T H, Meier J H 1995 3D Neuro-electronic interface devices for neuromuscular control: Design studies and realisation steps Biosens. Bioelectrons. 10 141-153.

[9] Rutten, W L C, Ruardij T G, Marani E and Roelofsen B H 2007 Neural networks on chemically patterned electrode arrays: towards a cultured probe Acta Neurochirurgica Supplementum 97 547-554

[10] Greene L A and Tischler A S 1976 Establishment of a noradrenergic clonal line of rat adrenal pheochromocytoma cells which respond to nerve growth factor. Proc. Natl. Acad. Sci. USA. 73 2424-8

[11] Mutayama K, Singh N N, Helmrich H and Barnes D 2001 Neural Cell Lines Prot. Neural Cell Culture. 219-28

[12] Suuronen E J, Sheardown H, Newman K D, McLaughlin C R, Griffith M 2005 Building in vitro models of organs Int. Rev. Cytol. 244 137-73

[13] Culot M, Lundquist S, Vanuxeem D, Nion S, Landry C, Delplace Y, Dehouck M, Berezowski V, Fenart L and Cecchelli R 2008 An in vitro blood-brain barrier model for high throughput (HTS) toxicological screening Toxicol. in Vitro 22 799-811

[14] Privat A, Marson A M, Drian M J 1979 In vitro models of neural growth and differentiation_Prog. Brain Res. 51 335-56

[15] Rubinsky L, Raichman N, Baruchi I, Shein M, Lavee J, Frenk H and BenJacob E. 2007 Study of hypothermia on cultured neuronal networks using multi-electrode arrays J. Neurosci. Methods. 160 288-93 
[16] $\mathrm{Su} \mathrm{H}, \mathrm{Chu} \mathrm{T}$ and $\mathrm{Wu} \mathrm{W} 2007$ Lithium enhances proliferation and neuronal differentiation of neural progenitor cells in vitro and after transplantation into the adult rat spinal cord Exp. Neurol. 206 296-307

[17] Stegenga J, Le Feber J, Marani E and Rutten W L C 2009 The effect of learning on bursting IEEE Trans. Biomed. Eng. 56 1220-7

[18] le Feber J, Rutten W L C, Stegenga J, Wolters P S, Ramakers G and van Pelt J 2007 Conditional firing probabilities in cultured neuronal networks: a stable underlying structure in widely varying spontaneous activity patterns J. Neural Eng. 4 54-67

[19] Lim H, Lee S, Chu K, Joo K, Kang L, Im W, Park J, Kim S U, Kim M, Cha C 2008 Neuroprotective effect of neural stem cell-conditioned media in in vitro model of huntington's decease Neurosci. Lett. 435 175-80

[20] Fayaz I, Tator C H 2000 Modelling axonal injury in vitro: injury and regeneration following acute neuritic trauma J. Neurosci. Methods. 102 699

[21] Figiel I, Jaworski J and Kaczmarek L 2007 Hippocampal Cells in Culture as a Model to Study Neuronal Apoptosis New Developments and New Applications in Animal Cell Technology Proceedings of the $15^{\text {th }}$ ESACT Meeting

[22] Claverol-tinture E, Babestany J, Resell X 2007 Multisite recording of extracellular potentials produced by microchannel-confined neurons invitro IEEE Trans. Biomed. Eng. 54 331-35

[23] Buitenweg J R, Rutten W L C, Willems W P, van Nieuwkasteele J W 1998 Measurement of sealing resistance of cell-electrode interfaces in neuronal cultures using impedance spectroscopy Med. Biol. Eng. Comput. 36 630-37

[24] Romijn H J, Van Huizen F and Wolters P S 1984 Towards an improved serum free, chemically defined medium for long term culturing of cerebral cortex tissue Neurosci. Biobehav. Rev. 8 301-344

[25] Marani E, Corino M, van den Berg R J, Rietveld W J, Deenen M, Windhorst W 1988 Ionic conductances in cultured pre-infundibular cells from the hypothalamic arcuate region Neuroendocrinology 48 445-52

[26] Azevedo F A, Carvalho L R, Grinberg L T, Farfel J M, Ferretti R E, Leite R E, Jacob Filho W, Lent R, Herculano-Houzel S 2009 Equal numbers of neuronal and nonneuronal cells make the human brain an isometrically scaled-up primate brain J. Comp. Neurol. 513 532-41

[27] Bota M, Dong H and Swanson L W 2003 From gene networks to brain networks Nature Neuroscience. 6 795-9

[28] Barres B A 2008 The mystery of glia: A perspective on Their Roles in Heath and diseases Neuron. 60 430-40

[29] Mouveroux J M P, Lakke E A J F, Marani E, Stelztle M 2001 Profuse and selective growth in vitro of rat spinal axons on a micro-patterned poly (ethylene imine) grid Engineering in Medicine and Biology Society, Proceedings of the 23rd Annual International Conference of the IEEE. 1 745- 8 
[30] Wieringa P A, Wiertz R W F, de Weerd E and Rutten W L C 2010 Bifurcating Microchannels as a scaffold to induce seperation of regenerating neurites J. Neural. Eng. 716001

[31] O'Leary D D M, Terashima T 1988 Cortical axons branch to multiple subcortical targets by interstitial axon budding: Implications for target recognition and "waiting periods" Neuron. 1 901-10

[32] Ruardij T G, Goedbloed M H and Rutten W L C 2000 Adhesion and patterning of cortical

neurons on polyethylenimine and fluorocarbon-coated surfaces IEEE Trans. Biomed. Eng 47 1593-9

[33] Makohliso S A, Giovangrandi L, Leonard D, Mathieu M J, Ilegems M, Aebischer P A 1998 Application of Teflon-AF(R) thin films for biopatterning of neural cell adhesion Biosens. Bioelectrons 13 1227-35

[34] Ruardij T G, van den Boogaart M A F and Rutten W L C 2002 Adhesion and growth of Electrically active cortical neurons on polyethyleneimine patterns microprinted on PEO-PPO-PEO triblockcopolymer-coated hydrophobic surfaces IEEE Trans on Nanobiosci. 1 1-8

[35] Ruardij T G, Goedbloed M H and Rutten W L C 2003 Long-term adhesion and survival of dissociated cortical neurons on miniaturized chemical patterns Med. Biol. Eng. Comp. 41 227-32.

[36] Yavin E and Yavin Z 1974 Attachment and culture of dissociated cells from rat embryo cerebral hemispheres on polylysine-coated surfaces $J$. Cell. Biol. 62 540-6.

[37] Hynes R O 1999 Cell Adhesion: old and new questions Trends Cell Biol. 9 33-7

[38] Chen C S, Tan J and Tien J 2004 Mechanotransduction at cell-matrix and cell-cell contacts Ann. Rev. Biomed. Eng. 6 275-302

[39] Venstrom K A and Reichardt L F 1993 Extracellular matrix 2: Role of extracellular matrix

molecules and their receptors in the nervous system". FASEB J. 7 9961003.

[40] Smalheiser N R, Crain S M and Reid L M 1984 Laminin as a substrate for retinal axons in

Vitro Dev.. Brain Res. 12 136-140

[41] Heiduschka P, Romann I, Ecken H, Schöning M, Schuhmann W and Thanos S 2001 Defined

adhesion and growth of neurons on artificial structured substrates Electrochim. Acta. 7 299-307

[42] Liang S and Crutcher K A Neural migration on laminin in vitro $1992 \mathrm{Dev}$. Brain.Res. 66 127-32

[43] E.S. Lander., et al. 2001 linitial sequencing and analysis of the human genome nature 15 860-921 
[44] Barclay A N 2003 Membrane proteins with immunoglobin-like domains-a master superfamily of interaction molecules Seminars in Immunology. 15 215-23

[45] Saffel J L, Williams E J, Mason I J, Walsh F S, Doherty P 1997 Expression of a Dominant Negative FGF Receptor Inhibits Axonal Growth and FGF Receptor Phosphorylation Stimulated by CAMs Neuron. 18 123-32

[46] Rønn L C B, Hartz B P and Bock E 1998 The neural cell adhesion molecule (NCAM) in development and plasticity of the nervous system Exp. Gerontology. 33 853-64

[47] Crossin K L and Krushel L A 2000 Cellular signaling by neural cell adhesion molecules of the immunoglobulin superfamily Dev. Dyn. 218 260-279

[48] R S Schmid and P F Maness 2008 L1 and NCAM adhesion molecules as signaling coreceptors in neuronal migration and process outgrowth Curr. Opin. Neurobiol. 18 245-50

[49] Kiselyov V V, Soroka V, Berezin V, Bock E 2005 Structural biology of NCAM homophilic binding and activation of FGFR J. Neurochem. 94 1169-79

[50] Rutishauser U, Acheson A, Hall A K, Mann D M and Sunshine J 1988 The neural cell adhesion molecule (NCAM) as a regulator of cell-cell interactions Science 240 53-7

[51] Ferreira-Cornwell C M, Veneziale R W, Grunwald G B and Menko S A $2000 \mathrm{~N}$-Cadherin Function Is Required for Differentiation-Dependent Cytoskeletal Reorganization in Lens Cells in Vitro Exp. Cell. Res. 256 23747

[52] Prozialeck W C, Fay M J, Lamar P C, Pearson C A, Sigar I and Ramsey K H 2002 Chlamydia trachomatis Disrupts N-Cadherin-Dependent Cell-Cell Junctions and Sequesters ß-Catenin in Human Cervical Epithelial Cells Infection and Immunity.70 2605-13

[53] Shun C T, Wu M S, Lin M T, Chang M C, Lin J T, Chuang S M 2001 Immunohistochemical evaluation of cadherin and catenin expression in early gastric carcinomas: correlation with clinicopathologic characteristics and Helicobacter pylori infection Oncology 60 339-45.

[54] Imamura Y, Itoh M, Maeno Y, Tsukita S and Nagafuchi A 1999 Functional Domains of $\alpha$-Catenin Required for the Strong State of Cadherin-based Cell Adhesion J. Cell. Biol. 144 1311-22

[55] Zhang Y, Sivasankar S, Nelson J W and Chu S 2009 Resolving cadherin interactions and binding cooperativity at the single-molecule level Proc. Natl. Acad. Sci. U S A. 106 109-14

[56] Clegg D O 2000 Novel Roles for Integrins in the Nervous System Mol. Cell. Biol. Res. Commun. 3 1-7

[57] Schrick C, Fischer A, Srivastava D P, Tronson N C, Penzes P and Radulovic J 2007 N-Cadherin Regulates Cytoskeletally Associated IQGAP1/ERK Signaling and Memory Formation Neuron. 55 786-98 
[58] Marrs G S, Theisen C S and Brusés J L 2009 N-cadherin modulates voltage activated calcium influx via RhoA, p120-catenin, and myosin-actin interaction Molecular and Cellular Neuroscience. 40 390-400

[59] Skaper S D, Facci L, Williams G, Williams E, Walsh F S and Doherty P 2004 A dimeric version of the short N-cadherin binding motif HAVDI promotes neuronal cell survival by activating an N-cadherin/fibroblast growth factor receptor signalling cascade Mol. Cell. Neurosci. 26 17-23

[60] Ditlevsen D K, Køhler L B, Pedersen M V, Risell M, Kolkova K, Meyer M, Berezin V, Bock E 2003 The role of phosphatidylinositol 3-kinase in neural cell adhesion molecule-mediated neuronal differentiation and survival J. Neurochem. 84 546-56

[61] Chen S, Mantei N, Dong L, Schachner M 1999 Prevention of neuronal cell death by neural adhesion molecules L1 and CHL1 j. neurobiol. 38 428-39

[62] Loers G, Chen S, Grumet M and Schachner M 2005 Signal transduction pathways implicated in neural recognition molecule L1 triggered neuroprotection and neuritogenesis J. Neurochem. 92 1463-76

[63] Giaever I and Keese C R 1991 Micromotion of mammalian cells measured electrically," Proc. Natl. Acad. Sci. 88 7896-7900

[64] Wegener J, Giaever I and Keese C R 2000 Electric cell-substrate impedance sensing (ECIS) as a noninvasive means to monitor the kinetics of cell spreading to artificial surfaces Exp. Cell. Res. 259 158-66 


\title{
Chapter 2
}

\section{Impedance Sensing for monitoring neuronal coverage and comparison with microscopy}

\author{
R.W.F.Wiertz, E. Marani and W.L.C.Rutten
}

Neurotechnology Group/BSS, MIRA Institute, University of Twente, Enschede, The Netherlands 


\begin{abstract}
We investigated the applicability of electric impedance sensing to monitor the adhesion of dissociated neuronal cells on glass substrates with embedded electrodes. IS is a sensitive method for the quantification of changes in cell morphology and cell mobility, making it suitable to study aggregation kinetics. Various sizes of electrodes were compared for the real time recording of the impedance of adhering cells, at eight frequencies (range: $5 \mathrm{~Hz}-$ $20 \mathrm{kHz}$ ). The real part of the impedance showed to be most sensitive at frequencies of 10 and $20 \mathrm{kHz}$ for the two largest electrodes $\left(7850 \mathrm{um}^{2}\right.$ and $\left.125600 \mathrm{um}^{2}\right)$. Comparison of microscope-evaluation of cell coverage and cell spreading with simultaneous impedance measurements showed the superiority of the latter method.
\end{abstract}




\subsection{Introduction}

To assay the attachment of cells to artificial surfaces several techniques have been used. Most quantitative studies involve employing forces like centrifugal acceleration and laminar shear flow [1,2]. These techniques are laborious and noncontinuous. Another technique is microscopy, often in combination with immunocytochemical staining, direct cell counting or time lapse cinematography [3-5]. Impedance Sensing (IS) is a continuous method, providing quantitative data on several cultures simultaneously with a relatively high time resolution [6-10].

In IS cells are cultured on micro electrodes and submitted to an AC current. Current can flow through cell membranes and via openings between tightly adhered, but not totally confluent cells.

The impedance measured depends on a number of variables, such as adhesion tightness, cell type, surface area of the electrode, frequency and confluency of cells. Depending on the application an optimal set of variables has to be chosen. In the methods section this will be further elaborated on.

Assuming that cells are firmly adhered (sealed) to the substrates, and stay adhered when openings between cells grow or shrink, changes in cell confluency will affect mainly the intercellular resistance (spreading resistance, or constriction resistance). Due to low resistivity of the culturing fluid, compared to the membrane impedance and sealing resistance, even slight changes in the openings have very large effects on the impedance, as shown in $[9,10]$.

Impedance sensing has proven valuable [7, 8, many others] for study of the cell or tissue interface and monitoring of changes in mammalian cell culture morphology $[9,10]$. Several electric models of electrode-fluid-cell/tissue have been developed [7-10]. Changes in cell shape caused by various biochemicals like $\alpha$-thrombin [11] and prostaglandine E [12] have been monitored as well as changes caused by cytotoxic agents [13], virus infections [14] or even very small changes in morphology caused by periodic injection of $\mathrm{CO}_{2}$ in cell culture incubators [15].

So far no research has been reported in which IS was applied on dissociated primary neuronal cells. IS has been reported in studies involving mammalian cell types with tight intracellular clefts, whereas neurons have far less defined cell-cell contacts and do not divide. In a study by Bieberich et al [16], the neuronal differentiated cancer cell line PC-12 showed an almost 3\% higher impedance compared to non-differentiated PC-12 cells. Another study demonstrated a significant increase in impedance during the attachment of neuroblastoma cells on an electrode [17].

In this study neuronal cultures were investigated during normal development, in two ways, impedance sensing and microscopy. Directly after plating the neurons start to spread and make contact with surrounding cells, leading to a rather confluent monolayer of neurons. Both methods were compared to test whether impedance sensing shows more details than standard microscopy. 


\subsection{Methods}

\subsubsection{Electrodes}

Figure 1 shows an overview of the four electrodes used for impedance sensing. Dimensions of the electrodes were $78 \mu \mathrm{m}^{2}, 1962 \mu \mathrm{m}^{2}, 7850 \mu \mathrm{m}^{2}$ and $125600 \mu \mathrm{m}^{2}$. Electrodes were patterned on $1 \mathrm{~cm}^{2}$ glass plates. Each glass plate contained 19 electrode of one size. Glass was used as a substrate in order to have transparency between electrodes. Gold electrode structures were created by photolithography and reactive ion etching. An isolation sandwiched layer combination of $\mathrm{SiO}_{2}$ $\mathrm{Si}_{3} \mathrm{~N}_{4}-\mathrm{SiO}_{2}$ was deposited by plasma enhanced chemical vapor deposition.
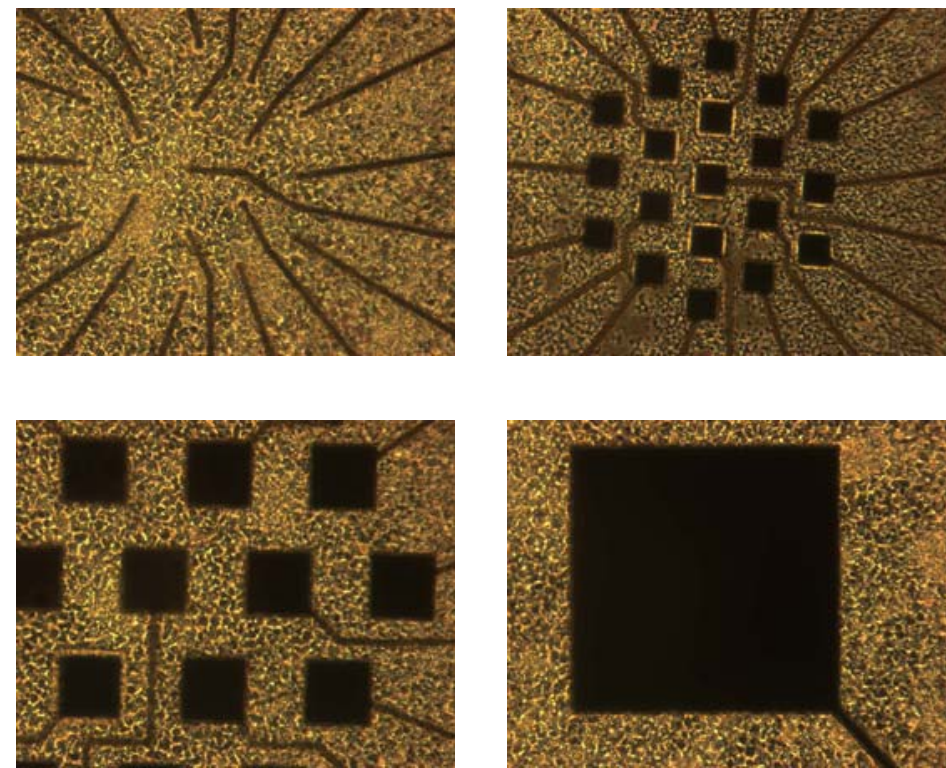

Figure 1. Cell covered gold electrodes $\left(78 \mu \mathrm{m}^{2}, 1962 \mu \mathrm{m}^{2}, 7850 \mu \mathrm{m}^{2}\right.$ and $\left.125600 \mu \mathrm{m}^{2}\right)$.

Neurons were plated and cultured on electrode areas. The electrode glass plates were precoated with $50 \mu \mathrm{g} / \mathrm{ml}$ poly-ethylene-imine (Fluka, Buchs, Switzerland). For the positioning of a neuronal culture a glass ring was placed on the substrate during cell plating. In between impedance measurements, cultures were gently shaken to check for non adhering cells and remove them from the electrode area. 


\subsubsection{Impedance model}

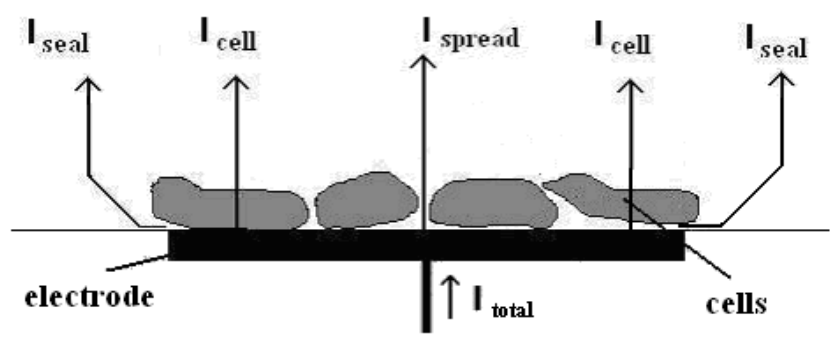

Figure 2. Schematic view of an electrode covered with neurons. The total current $I_{\text {total }}$ splits up into a current $I_{\text {spread }}$ finding its way 'easy'" through the small spaces between the cells, $I_{\text {seal }}$, the leakage current through the gaps between the substrate and the cells and $I_{\text {cell }}$, the current through the cells.

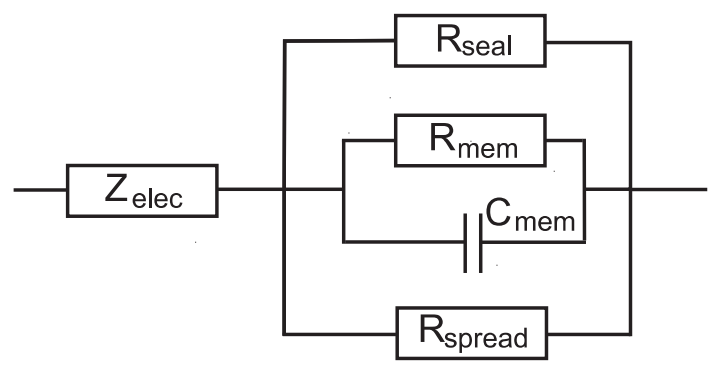

Figure 3. The equivalent circuit. $Z_{\text {elec }}$ is the impedance of the electrode-electrolyte interface (Helmholtz double layer), $R_{\text {spread }}$ is the resistance of the intercellular open spaces and the culturing medium and $R_{\text {seal }}$ the sealing resistance between the cells and substrate. The $R_{\text {mem }} C_{\text {mem }}$ part accounts for the neuronal cell membranes.

Figure 2 shows a schematic view of an electrode covered by neurons. The impedance spectrum of this system can be analyzed using an equivalent RC-circuit (figure 3). Assuming that cells are firmly adhered to the substrates, so $\mathrm{R}_{\text {seal }}$ is very high, and stay adhered when openings between the cells grow or shrink, changes in cell confluency will affect mainly the intercellular resistance (spreading resistance $\mathrm{R}_{\text {spread }}$ ). Due to low resistivity of the culturing fluid, compared to the membrane impedance and $\mathrm{R}_{\text {seal }}$, even slight changes in the openings have very large effects on the impedance, as shown in $[9,10]$. (for proof, see last two paragraphs of this section).

Therefore, this model can be simplified to only $Z_{\text {elec }}$ in series with $R_{\text {spread, }}$ (figure 4).

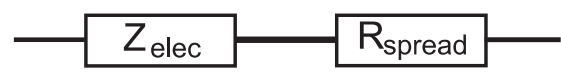

Figure 4. Simplified equivalent circuit for an electrode 


$$
Z=Z_{\text {elec }}+R_{\text {spread }}=\frac{K}{(i \omega)^{m}}+R_{\text {spread }}
$$

The first term represents the equivalent impedance of the electrode-electrolyte interface $[19,8]$ which is frequency dependent. $\mathrm{K}$ is a size dependent constant. Power $\mathrm{m}$ usually takes values around $0.6-0.7$, indicating the non-truly capacitive nature of the Helmholtz layer.

$\mathrm{R}_{\text {spread }}$ can be modeled as the resistance of a fluid conductor, seen by a small source with "electrode" radius $r_{e}$,

$$
R_{\text {spread }}=\frac{\sqrt{2}}{2 \pi \sigma r_{e}} \approx \frac{1}{4.44 \sigma r_{e}}
$$

with $\sigma$ the conductivity of the culturing medium $(\sigma=1.65 \mathrm{~S} / \mathrm{m})$. Electrode coverage with neurons will have a main effect on the second term, as corridors will shrink vanish when cells attach more firmly to each other, until complete confluence is reached. The neurons now impede the passage of current, thereby increasing the total impedance.

The model approach chosen is certainly not the only possible one. A number of other, but usually more complex, models exist in literature $[6,8]$. However, given the purpose of analysis of development of confluency of cells, the proposed model has the strength of simplicity, with only three parameters.

We still have to check numerically whether our simplification of the electrical circuit model is justified, so whether the ratio of $R_{\text {spread }}$ and membrane impedance is sufficiently low. For parameters $\mathrm{C}_{\mathrm{m}}$ and $\sigma_{\mathrm{m}}$ we have cellular membrane capacitance $\mathrm{C}_{\mathrm{m}}=1 \mu \mathrm{F} / \mathrm{cm}^{2}$, membrane conductance $\sigma_{\mathrm{m}}=0.3 \mathrm{mS} / \mathrm{cm}^{2}$ [9].

Assuming full confluency and regarding now all cells as one giant cell, with surface dimensions the same as the four electrodes areas $(78,1962,7850,125600$ $\mu \mathrm{m}^{2}$ ) one calculates $\mathrm{C}_{\mathrm{m} \text { all cells }}=0.39,9.81,39.25$ and $628 \mathrm{pF}$ respectively. And $\mathrm{R}_{\mathrm{m}}$ all cells $=4270,170,42.5$ and $2.65 \mathrm{M} \Omega$ respectively. Together, they determine the membrane real impedance for each frequency. For example, for the $7850 \mu \mathrm{m}^{2}$ surface, and at $10 \mathrm{kHz}$, one calculates $\mathrm{R}_{\mathrm{m}}=42.5 \mathrm{M} \Omega$, in parallel with $\mathrm{Z}_{\mathrm{C}}$ (real part $)=406 \mathrm{k} \Omega$. So the membranes form together a real impedance of about 400 $\mathrm{k} \Omega$, or less (when less cells present, i.e. not completely confluent). On the other hand, voids between the cells of $0.1 \%, 1 \%$, or $10 \%$ yield $\mathrm{R}_{\text {spread }}$ values of 123,40 and $12.2 \mathrm{k} \Omega$, respectively, equation (2). Combining these values, one may conclude that at voids of $1 \%$ and $10 \%$ the circuit simplification is justified, as $\mathrm{R}_{\text {spread }}$ is 10 to 32 times smaller than the membrane real impedance, respectively. At $0.1 \%$ open space, the simplification is a bit too strong for the $7850 \mu \mathrm{m}^{2}, 10 \mathrm{kHz}$ combination, but will get better justified for lower frequencies or smaller electrodes. 


\subsubsection{Cell Culturing}

Cerebral cortical neurons from newborn rats (P2) were used for all experiments in this study. Brains were taken out after decapitation, the meninges of the cortices were removed and the basal ganglia as well as the hippocampus were prepared free. The remaining cortices were collected in a tube with chemically defined R12 culture medium [20] and trypsin for chemical dissociation. After removal of trypsin (45 min), $150 \mu \mathrm{l}$ of soybean trypsin inhibitor and $125 \mu \mathrm{l}$ of DNAse I (20.000 units, Life Technology, Carlsbad, United States) were added. A solution of single neurons was obtained by mechanical dissociation of the cortical tissue. The neuron solution was centrifuged at $1200 \mathrm{rpm}$ for 5 minutes. The supernatant was removed and the pellet of neurons resuspended. Neurons were plated and cultured on the described electrodes precoated with $50 \mu \mathrm{g} / \mathrm{ml}$ poly-ethylene-imine (Fluka, Buchs, Switzerland). Cells were kept in serum-free R12 medium under standard conditions of $37^{\circ} \mathrm{C}$ and $5 \% \mathrm{CO}_{2}$ in air. A cell concentration of approximately $10^{6}$ cells $/ \mathrm{cm}^{2}$ was used in all experiments. During measurements the neuron cultures were placed into a small incubator keeping the temperature at $37^{\circ} \mathrm{C}$.

\subsubsection{Measurement Setup}

All impedance measurements were carried out using a programmable signal source (HP 4194A), a home-built impedance measuring circuit and a data acquisition system in a Labview environment $[9,10]$. This setup was used in combination with cell culturing chambers containing the electrodes. The cultures were kept at $37^{\circ} \mathrm{C}$ under sterile conditions during measurements on a NIKON DIAPHOT inverted microscope. Applied frequencies were 5, 10, 50, 100, 500, 1000, 10000 and 20000 $\mathrm{Hz}$. The measurements were controlled by the same computer that recorded and saved the real and imaginary impedance.

Cultures were monitored during their development, starting shortly before cell plating of the electrodes, until cultures formed compact monolayers of neurons and aggregation was just starting. In the first 12 hours the electrodes were monitored by a set of measurements done every 3 hours in which 6 impedance spectra were obtained with an interval of 2 minutes on all 4 devices $(\mathrm{N}=5)$. After 12 hours the cultures were measured every 24 hours ending the experiment after 144 hours.

Measurement sessions ended on day 6 by the addition of trypsin while monitoring its effect on the impedance of the cell-covered electrode. During trypsin digestion the time interval between measurements was 5 minutes until electrodes appeared to be free of neurons.

\subsubsection{Imaging Technique}

The neuronal coverage of the electrodes was determined by taking the visible area directly surrounding the electrodes as representative for the electrode area itself (which lacked the transparency for direct optical monitoring). Percentage of coverage was determined by converting digital color photographs into an 8-bit grayscale photograph using CorelDraw software. The histogram of the grayscale photograph was used for segmentation of the picture into a black-and-white photo. 
The ratio of the number of black to white pixels is the percentage of the electrode area covered by cells. Pictures of the electrode areas were made after every impedance measurement. During the impedance experiments areas of $40000 \mu \mathrm{m}^{2}$ (ex. non-transparent electrodes and leads) were photographed. The average percentage of coverage at these 4 areas was calculated.

\section{Results}

\subsubsection{Electrodes}

In the first experiment the optimum electrode size of planar electrodes for neuronal coverage was investigated at frequencies of 5, 10, 100, 500, 1000, 10000 and $20000 \mathrm{~Hz}$. The sensitivity of these electrodes for cell coverage was calculated as a percentage of the increase in impedance after maximum coverage of the electrodes with neuronal cells. Maximum electrode coverage was accomplished by culturing at a cell density of $1 \times 10^{6}$ cells $/ \mathrm{cm}^{2}$, during 6 days, before the period that at some parts of the culture aggregates were developing. The track of changes of the real and imaginary part of the impedance during these six days development of a neuronal culture is plotted in figure 5 and 6 together with the change in cell coverage in the electrode area. Directly after cell seeding a clear rise in the real part of the impedance at a frequency of $10 \mathrm{kHz}$ is seen due to attachment and spreading of the neuronal cells. After 6 hours the increase flattens, but progresses slowly. This effect on the real impedance is not seen at a frequency of $100 \mathrm{~Hz}$ (figure 5). Figure 7 a-d shows the impedance loci for all electrode sizes for both non-covered electrodes and electrodes covered with a 6 day old neuronal culture.

As can be seen in figure 8 the impedance of the applied electrodes at low frequencies show a small rise of impedance (below $500 \mathrm{~Hz}$ ). Standard deviations are relatively high.

Strongest effects with the larger electrodes were obtained using the $7850 \mu \mathrm{m}^{2}$ electrodes at frequencies of $10 \mathrm{kHz}$ and $20 \mathrm{kHz}$. At these frequencies the cellcoverage of electrodes alters the real impedance with more than $250 \%$ (figure 8 ). In contrast, effects on the imaginary part of the impedance were low at all frequencies, with a maximum change in imaginary impedance of $14 \%$ at $10 \mathrm{~Hz}$ (1962 $\mu \mathrm{m}^{2}$ electrode, data not shown). Also, impedances at frequencies of $1000 \mathrm{~Hz}$ or lower showed a high variability. This makes the imaginary part of the impedance less attractive for future use in electric cell sensing. So, for further monitoring of neuronal development in culture the electrode with a size of 7850 $\mu \mathrm{m}^{2}$ was used to record the real impedance at a frequency of $10000 \mathrm{~Hz}$. 


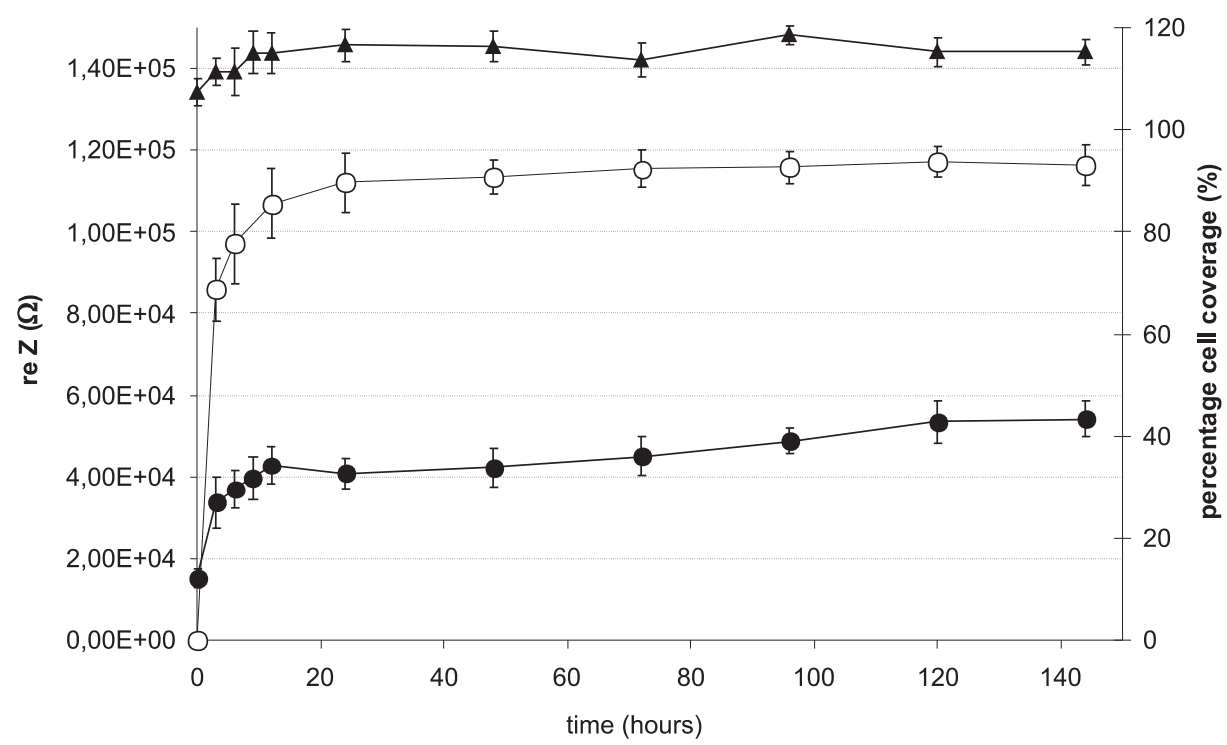

Figure 5 Real impedance during the development of a neuronal cell culture after cell seeding at frequencies of $100 \mathrm{~Hz}\left(-\boldsymbol{\Lambda} \longrightarrow\right.$ ) and $10 \mathrm{kHz}\left(\longrightarrow\right.$ (Electrode size $\left.7850 \mu^{2}\right)$. Percentage cell coverage $(\longrightarrow$ on the right axis. $N=5$.

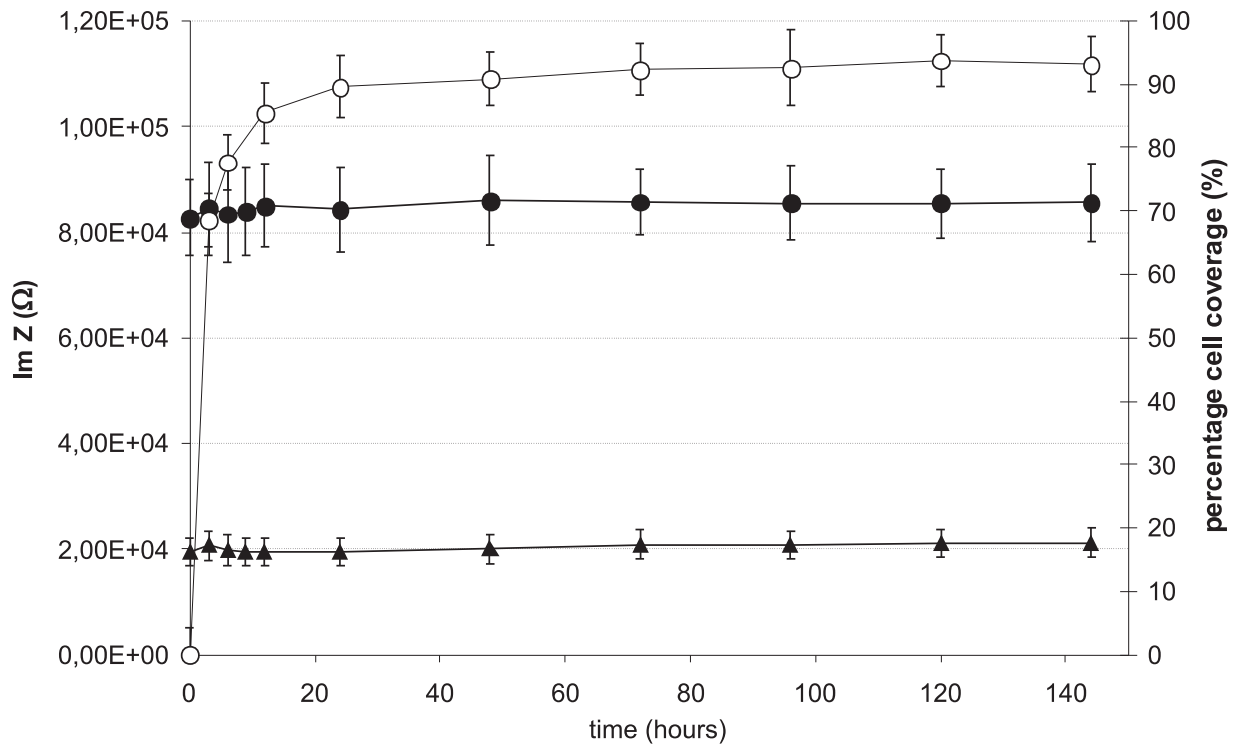

Figure 6. Imaginary impedance during the development of a neuronal cell culture after seeding at frequencies of $100 \mathrm{~Hz}(\longrightarrow)$ and $10 \mathrm{kHz}\left(-\boldsymbol{\Lambda} \longrightarrow\right.$ (Electrode size $\left.7850 \mu^{2}\right)$. Percentage cell coverage (-○) on the right axis. $N=5$. 
$7 a$.

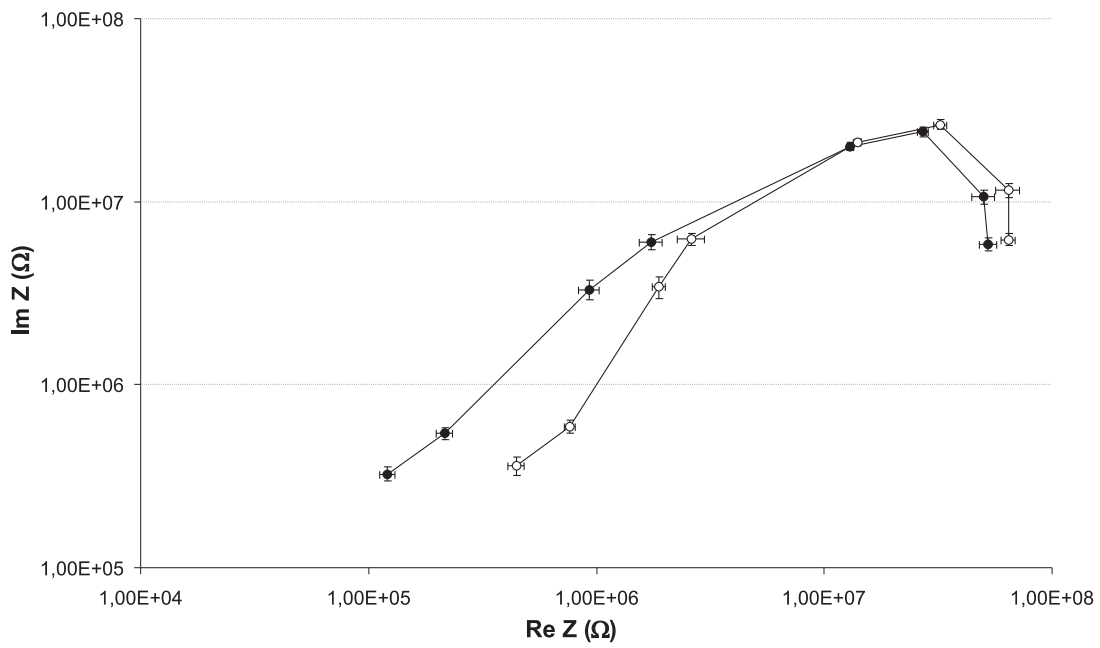

$7 b$.

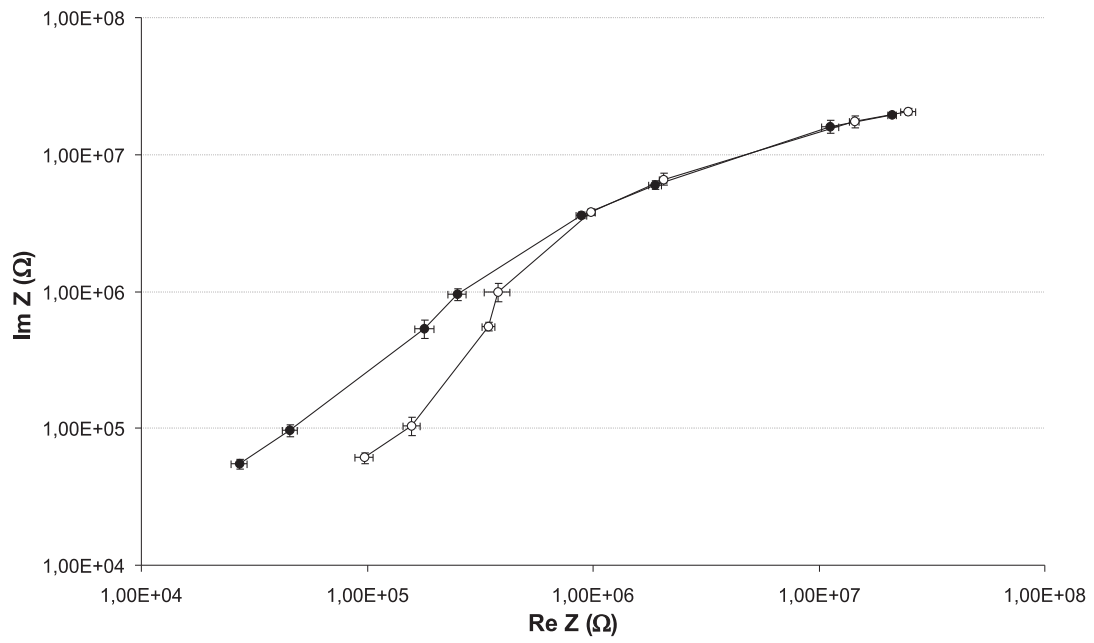


$7 \mathrm{c}$.

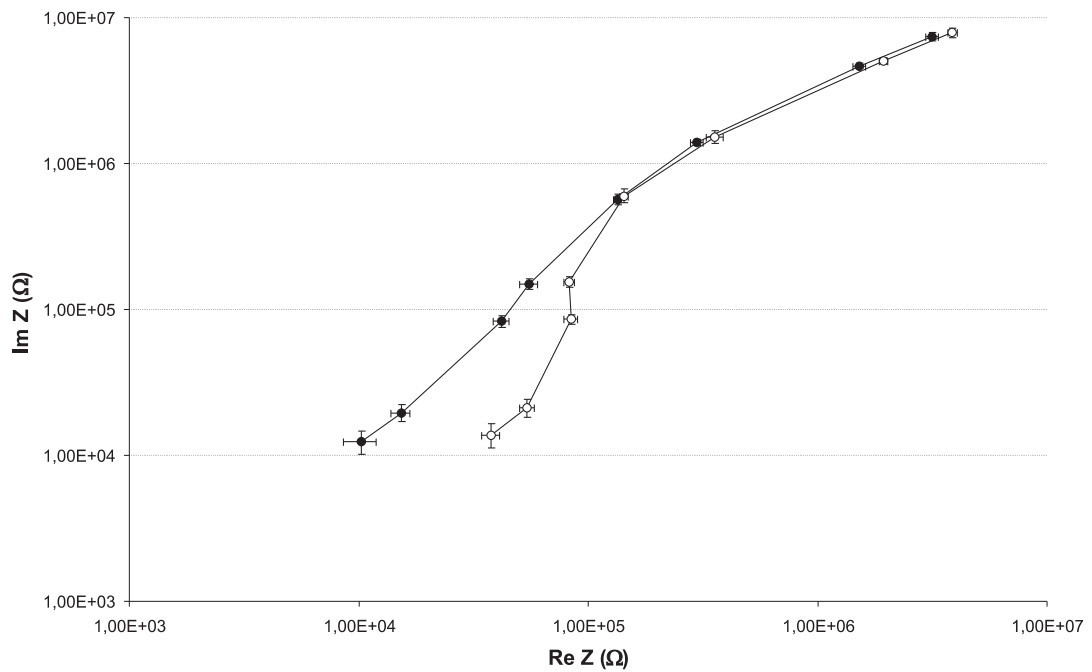

$7 \mathrm{~d}$.

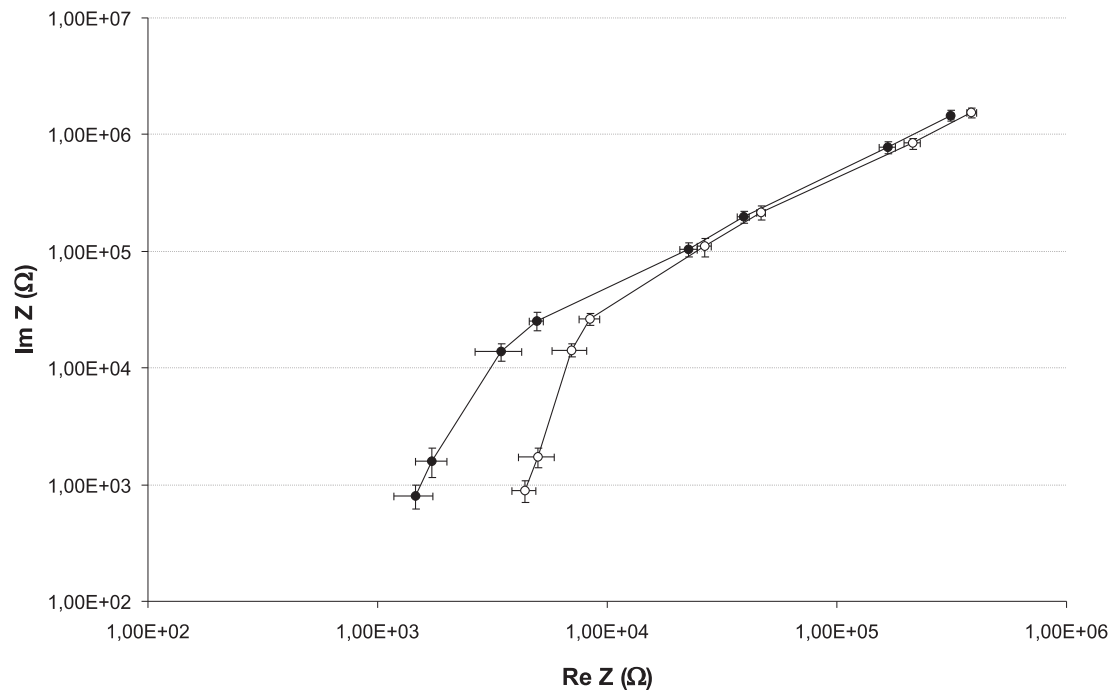

Figure 7 a-d Impedance locus of electrodes with full cell coverage and without cells (-०— and - -respectively) at 5, 10 50, 100, 500, 1000, 10000 and $20000 \mathrm{~Hz}$. Electrodes sizes: $A=78 \mu \mathrm{m}^{2}, B=1962$ ${\mu \mathrm{m}^{2}}^{2}, C=7850 \mu \mathrm{m}^{2}$ and $D=125600 \mu \mathrm{m}^{2} . N=5$. 


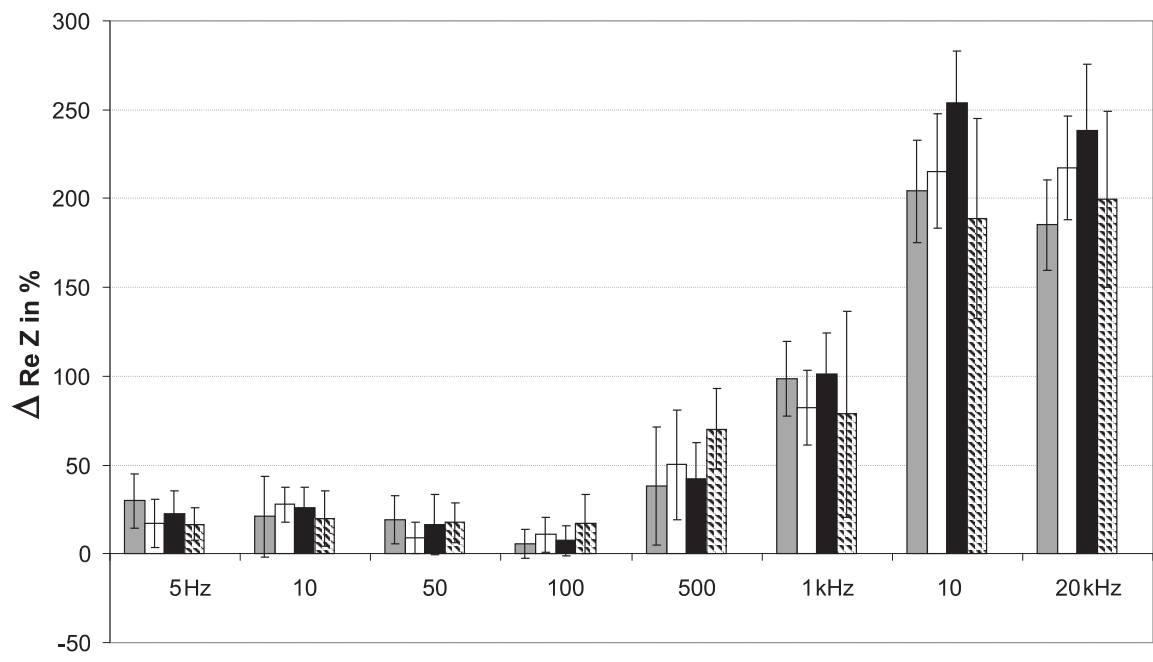

frequency $(\mathrm{Hz})$

Figure 8. Percentage of change in real impedance before and after complete coverage with neuronal cells on electrodes with various sizes $\left(78 \mu \mathrm{m}^{2}=\right.$ gray, $1962 \mu \mathrm{m}^{2}=$ white $7850 \mu^{2}=$ black and 125600 $\mu m^{2}=$ hatched). $N=5$.

After 6 days the experiments were finalized by the addition of trypsin, serving as a control to see if the impedance was effected by anything else then culture development. Impedances decreased to the non-covered value in about 40 minutes (figure 9).

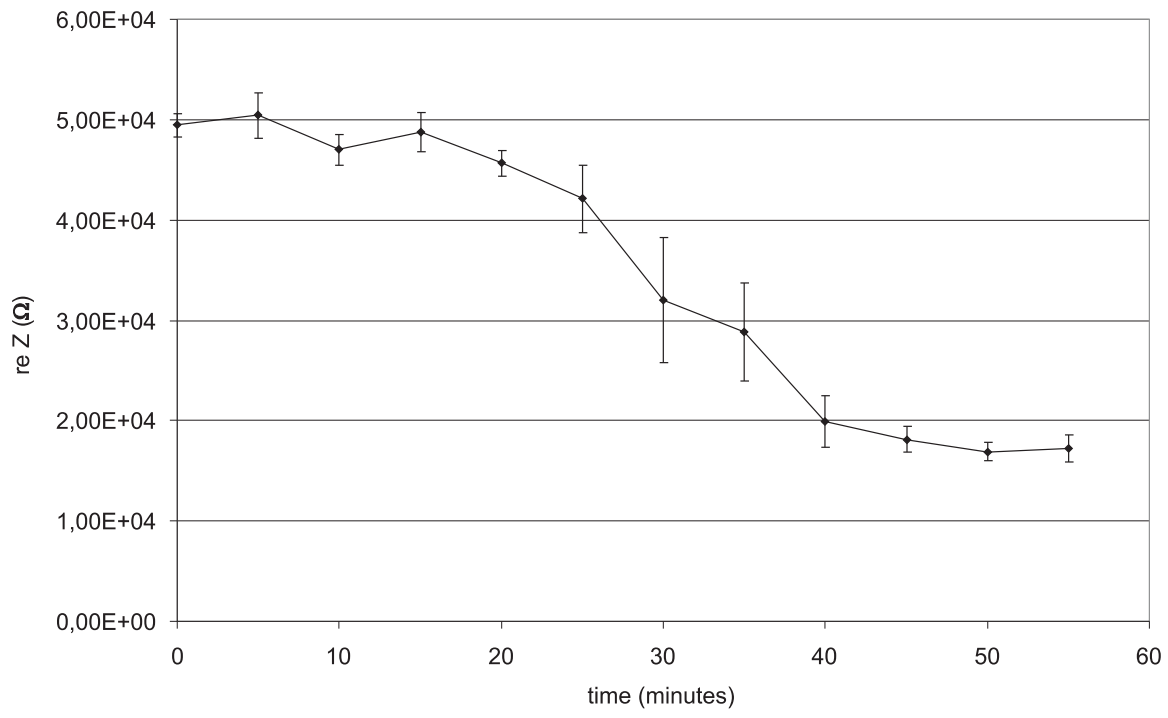

Figure 9. Real impedance during trypsin digestion of a neuronal cell culture (electrode size 7850um ${ }^{2}$, frequency $10 \mathrm{kHz}$. 


\subsubsection{Model fit}

Impedance loci of electrodes have been simulated by fitting equation 1 to the measured impedance loci. Figure 10 represents the measured and fitted loci of both $7850 \mu \mathrm{m}^{2}$ and $125600 \mu \mathrm{m}^{2}$ electrodes, before and during cell coverage at frequencies of 5, 10, 100,500,1000, 10000 and $20000 \mathrm{~Hz}$. The highest frequencies are plotted in the lower left corner of the graph. As the frequency decreases, both real $\mathrm{Z}$ and imaginary $\mathrm{Z}$ increase. The impedance loci could be fitted by a multi variable least-squares-fit selection procedure of values for the parameters $\mathrm{K}$, $\mathrm{m}$ and $\mathrm{R}_{\text {spread. }}$ The values are listed in table $1 \mathrm{a}$ (non-covered electrodes) and table $1 \mathrm{~b}$ (neuron covered electrodes). The tables and plotted impedance loci show that neuron coverage mainly affects the real valued $\mathrm{R}_{\text {spread }}$.

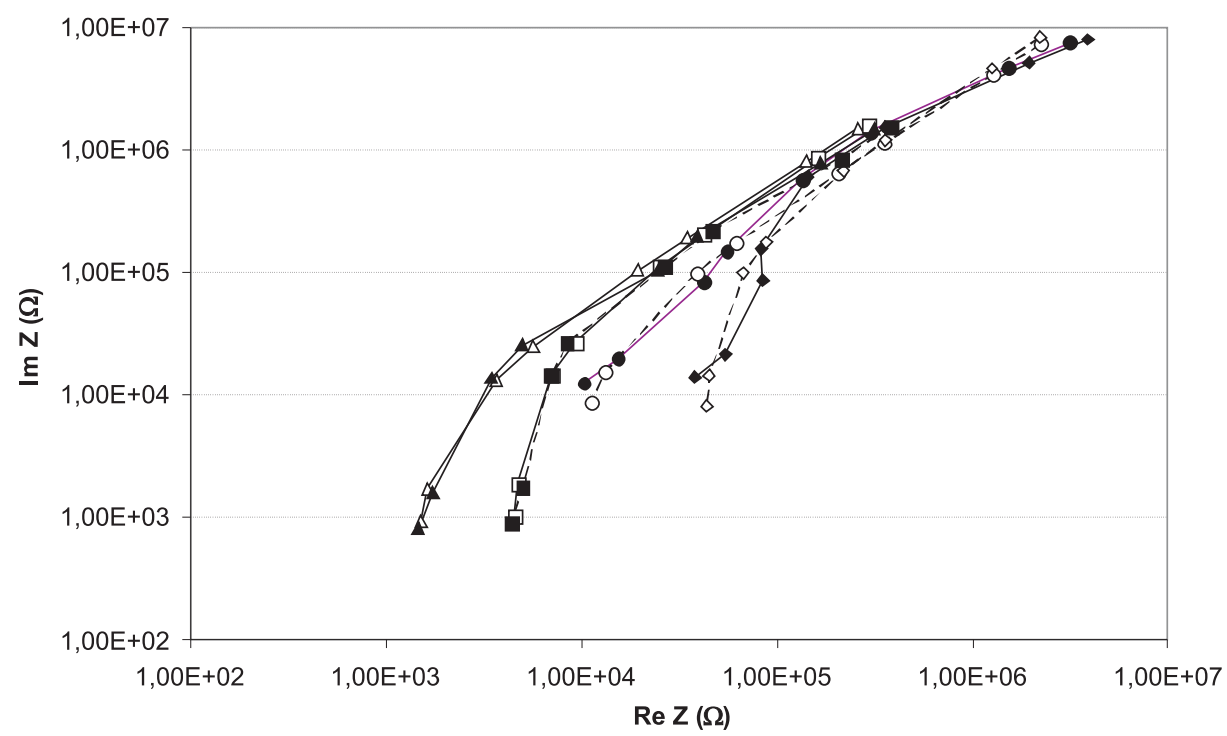

Figure 10. Example of two impedance loci (7850 $\mu^{2}$ and $125600 \mu^{2}$ electrodes) before and after neuron coverage with the modeled loci fitted to the measured data. $-\longrightarrow=7850 \mu^{2}$ non-covered measured, $\longrightarrow-=7850 \mu^{2}$ non-covered fit, $\longrightarrow-=7850 \mu^{2}$ covered measured, $\longrightarrow-=7850$ $\mu \mathrm{m}^{2}$ covered fit, $-\mathbf{\Delta}-=125600 \mu^{2},-\Delta-=125600 \mu \mathrm{m}^{2}$ non-covered fit, non-covered measured, $\longrightarrow-=125600 \mu^{2}$ covered measured, $\longrightarrow \square=125600 \mu^{2}$ covered fit.

Table 1a. Model parameters, fitted to the experimental impedance spectra of non-covered electrodes.

\begin{tabular}{c|ccc}
\hline $\begin{array}{c}\text { electrode size } \\
\mu \mathrm{m}^{2}\end{array}$ & $\begin{array}{c}\mathrm{R}_{\text {spread }} \\
{[\mathrm{Ohm}]}\end{array}$ & $\mathrm{m}$ & $\mathrm{K}$ \\
\hline 78 & 0.00 & 0.76 & $2.60^{*} 10^{9}$ \\
1962 & $1.19 * 10^{3}$ & 0.74 & $3.86^{*} 10^{8}$ \\
7850 & $8.46^{*} 10^{3}$ & 0.81 & $1.24 * 10^{8}$ \\
125600 & $1.34 * 10^{3}$ & 0.89 & $3.23 * 10^{7}$ \\
\hline
\end{tabular}


Table $1 b$. Model parameters, fitted to the experimental impedance spectra of electrodes covered with a neuron culture. For each electrode size, parameters $m$ and $K$ do not change much after neuron coverage. The spreading resistance however increases drastically after coverage.

\begin{tabular}{c|ccc}
\hline $\begin{array}{c}\text { electrode size } \\
\mu \mathrm{m}^{2}\end{array}$ & $\begin{array}{c}\mathrm{R}_{\text {spread }} \\
{[\mathrm{Ohm}]}\end{array}$ & $\mathrm{m}$ & $\mathrm{K}$ \\
\hline 78 & $3.04 * 10^{5}$ & 0.72 & $2.24 * 10^{9}$ \\
1962 & $7.92 * 10^{4}$ & 0.73 & $3.98 * 10^{8}$ \\
7850 & $4.13 * 10^{4}$ & 0.83 & $1.51 * 10^{8}$ \\
125600 & $4.36 * 10^{3}$ & 0.88 & $3.34 * 10^{7}$ \\
\hline
\end{tabular}

\subsubsection{Calculation of change in impedance based on microscopy}

In figure 11 the increase of the real impedance (equal to $R_{\text {spread, }}$, filled circles) of the $7850 \mu \mathrm{m}^{2}$ electrode during culture development is plotted, together with the percentage of electrode coverage, as determined from microscopy and image analysis (open circle symbols). The experimental $R_{\text {spread }}$ data (filled circles) in figure 11 are derived from figure 5 by subtracting the real impedance in the uncovered condition, obtained from figure 7 (10 kHz data). (In contrast to the real impedance, there is nearly no change in imaginary impedance at high frequency between uncovered and fully covered electrode condition). On the other hand, change in real impedance can be derived from the optical coverage data using the following equation.

$R_{\text {spread }}=\frac{\sqrt{2}}{2 \pi \sigma r_{e}} \approx \frac{1}{4.44 \sigma r_{e}}$

As conductivity we used $1.65 \mathrm{~S} / \mathrm{m}$. The radius $r_{e}$ is the equivalent radius of the electrode surface which is not covered by cells and can be calculated from the optically determined electrode coverage $\mathrm{A}_{\mathrm{e}}$.

$r_{e}=\sqrt{\left(A_{e} / \pi\right)}$

This "optically inferred" change in impedance $\mathrm{R}_{\text {spread }}$ is also plotted in figure 11 , triangle symbols. The difference between the two curves (measured versus optically inferred one) is striking. The absolute values differ considerably, but also the detailed course over time, the IS-measured curve showing the most detail. 


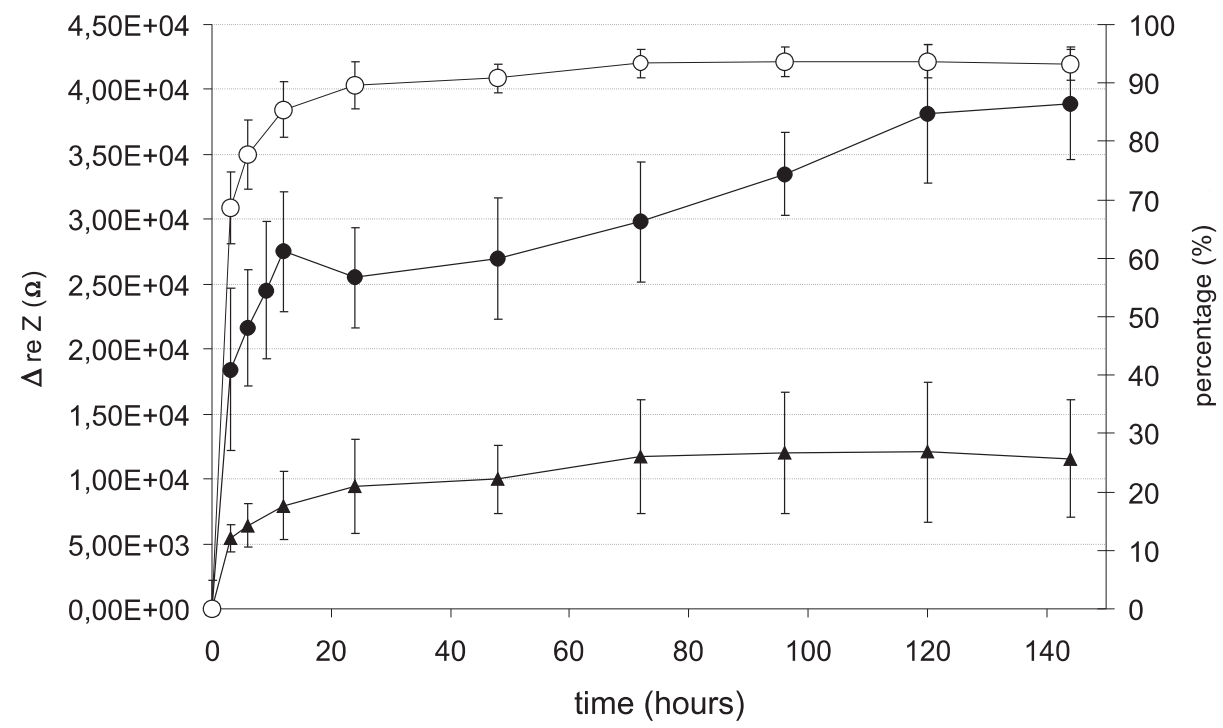

Figure 11. Measured change $\Delta R e Z$ during the development of a neuronal cell culture after seeding at $10 \mathrm{kHz}(-\bullet-)$ on the left y-axis. Change $\Delta$ ReZ calculated from the cell coverage, determined by image analysis $(-\mathbf{\Lambda} \longrightarrow$ on the left axis. Percentage cell coverage obtained by microscopy, right y-axis $\left(\longrightarrow-N=5\right.$. Electrode size $=7850 \mu^{2}$.

\subsection{Discussion}

Impedance sensing of cellular systems has shown to be effective in monitoring cell spreading and adhesion. Change in impedance is mainly caused by the progressive "insulating" properties of cells. So far impedance sensing has been applied on cell types proliferating in 2 dimensional monolayers with tight intercellular spaces, like epithelial and endothelial cells. However, neurons do not proliferate and cell junctions are far less tight. Electrodes were applied in neuronal cell sensing to study the applicability of IS in the monitoring of neuronal cell cultures. Four sizes of electrodes were compared. For all electrodes a clear effect of neuronal cell covering on the electrode impedance has been demonstrated, the maximal effect was seen for an electrode with size 7850. Increase of real impedance after cell coverage was $254 \%$ at $10 \mathrm{kHz}$. Wegener et al [7] indicated a frequency of $40 \mathrm{kHz}$ as measured optimum for cell sensing (but for epithelial cells, electrode surface $50000 \mu \mathrm{m}^{2}$ ).

Neuronal cultures that are kept longer than 6 days in vitro have a denser morphology compared to the final state of the cultures measured in this study. Aggregation of neurons in such cultures however, causes non-homogeneous covering of electrodes and is therefore less interesting for this study. 
An increase of $14 \%$ in the imaginary part of the impedance was seen at a frequency of $10 \mathrm{~Hz}$ with the $1962 \mu \mathrm{m}^{2}$ electrode probably caused by the capacitive effect of the neurons on the electrodes.

We also tested interdigitated electrodes (results not shown). They were reported as more applicable for IS [18] because of better sensitivity and reproducibility. The results obtained in this study do not support this conclusion for neuronal cultures. Possible reason is the larger intercellular space in neuronal cultures, resulting in a lower $\mathrm{R}_{\text {spread, }}$, outshining the capacitive effect. After completely removing neuronal cultures by trypsin digestion, electrode impedance turned back to the initial impedance of empty electrodes.

Monitoring of neuronal cultures in development is presented in figure 5 . At $10 \mathrm{kHz}$ over $50 \%$ of the increase in real impedance is caused by attachment and spreading of neurons in the first 3 hours. The percentage of electrode coverage (optical) demonstrates a similar increasing trend as the real impedance during the first 24 hours. No further increase in neuronal coverage of the electrode is seen after 24 hours. The real impedance however increase further after 24 hours. This indicates that IS can detect changes in neuronal cultures which are undetectable using normal microscopy.

The impedance derived from optically determined cell coverage is plotted in figure 11 (triangles). This calculated impedance is considerably less than the measured impedance (closed circles). Image analysis shows cell coverage with a maximum of $92 \%$. The impedance discrepancy arises because of the limited value of microscopy when compared to IS. Only an on-top view of a culture can be achieved, making it difficult to obtain data from the cell-substrate area. At high cell densities neurons are at close proximity. At these small distances the halo effect caused by phase-contrast microscopy [21] obscures a small part of the clear vision on the soma's distal regions (which consist of very thin lamellae) and cellular processes. The halo effect makes it also hard to distinguish somas from axonal outgrowth, cell debris and non-covered substrate. At cell coverage of $92 \%$ the extent of cell-cell contacts seem to be poor. However, when detached from the substrate we observed a floating "monopiece" sheet of tissue, which does indicate a much better than poor extent of cell-cell contact in dense neuronal cultures. The conclusion can be drawn that IS is very sensitive for the coverage with neurons. IS can monitor small changes in developing cultures, which are not revealed by microscopy and image analysis. It is also a relatively simple technique, yet yielding quantitative data on culture development.

\section{References}

[1] Crouche C F, Fowler H W and Spier R E 1985 The adhesion of animal cells to surfaces: the measurement of critical surface shear stress permitting attachment or causing detachment J Chem. Tech. Biotechnol. 35 273-81 
[2] Chanavajjala L S, Eidsath A and Saxinger W 1997 A simple method for measurement of cell-substrate attachment forces: application to HIV-1 Tat J. Cell. Sci. 110 249-56

[3] Hedin V, Bottger B A, Luthman J, Johansson S and Thyberg J 1989 A substrate of the cell-attachment sequence of fibronectin is a sufficient to promote transition of arterial smooth muscle cells from a contractile to a synthetic phenotype Develop. Bio. 133 489-501

[4] Edelman G M 1984 Modulation of cell adhesion during induction, histogenesis, and perinatal development of the nervous system Annu. Rev. Neurosci. 7 339-77

[5] Dillner L, Dickerson K, Manthrope M, Ruoslahti E and Engvall E 1988 The neuritepromoting domain of human laminin promotes attachment and induces characteristic morphology in non-neuronal cells Exp Cell Res $\mathbf{1 7 7}$ $186-98$

[6] Giaever I and Keese C R 1991 Micromotion of mammalian cells measured electrically Proc. Natl. Acad Sci. 88 7896-7900

[7] Wegener J, Giaever I and Keese C R 2000 Electric cell-substrate impedance sensing (ECIS) as a noninvasive means to monitor the kinetics of cell spreading to artificial surfaces Exp. Cell. Res. 259 158-66

[8] Duan Y Y, Clark G M and Cowan R S C 2004 A study of intra-cochlear electrodes and tissue interface by electrochemical impedance methods in vivo Biomat. 25 3813-28

[9] Buitenweg J R, Rutten W L C, Willems W P A and van Nieuwkasteele J W 1998 Measurement of sealing resistance of cell-electrode interfaces in neuronal cultures using impedance spectroscopy Med. Biol. Eng. Comput. 36, 630-637.

[10] Buitenweg J R, Rutten W L C and Marani E 2003 Geometry based finiteelement modeling of the electrical contact between a culture neuron and a microelectrode IEEE Trans. Biomed. Eng. 50 501-10

[11] Tiruppathi C, Malik A B, Del Vecchio P J, Keese C R and Giaever I 1992 Electrical method for detection of endothelial cell shape change in real time: assessment of endothelial barrier function Proc. Natl. Acad. Sci. U. S. A. 89 7919-23

[12] Reddy L, Wang H S, Keese C R, Giaever I and Smith T J 1998 Assessment of rapid morphology changes associated with cAMP levels in human orbital fibroblasts Exp. Cell. Res. 245 360-7

[13] Xiao C, Lachance B, Sunahara G and Luong J 2002 Assessment of cytotoxicity using electric cell-substrate impedance sensing: concentration and time response function approach Anal. Chem. 74 5748-53

[14] McCoy M and Wang E 2005 Use of electrical cell-substrate impedance sensing as a tool for quantifying cytophatic effect in influenza A virus infected MDCK cells in real-time J. Virol. Methods. 130 157-61

[15] Lo C M, Keese C R and Giaever I pH changes in pulsed CO2 incubators cause periodic changes in cell morphology Exp. Cell. Res. 213 391-7 
[16] Bieberich E and Guiseppi-Elie A 2004 Neuronal differentiation and synapse formation of PC12 and embryonic stem cells on interdigitated microelectrode arrays: contact structures for neuron-to-electrode signal transmission (NEST) Biosen. Bioelectrons. 19 923-31

[17] Sharma K V, Koenigsberger C, Brimijoin S, Bigbee J W 2001 Direct evidence for an adhesive function in the noncholinergic role of acetylcholinesterase in neurite outgrowth $J$. Neurosci. Res. 63 165-75

[18] Ehret R, Baumann W, Brischwein M, Schwinde A and Wolf B 1998 Online control of cellular adhesion with impedance measurements using interdigitated electrode structures Med. Biol. Eng. Comput. 36 365-70

[19] de Boer R W and van Oosterom A 1978 Electrical properties of platinum electrodes: impedance measurements and time-domain analysis Med. Biol. Eng. Comp. 16 1-10

[20] Romijn H J, Van Huizen F and Wolters P S 1984 Towards an improved serum free, chemically defined medium for long term culturing of cerebral cortex tissue Neurosci. Biobehav. Rev. 8 301-44

[21] Zernike F 1942 Phase contrast, a new method for the microscopic observation of transparent objects Physica. 10 974-86 


\section{Chapter 3}

\section{Inhibition of neuronal cell-cell adhesion measured by microscopic aggregation assay and impedance sensing}

R.W.F.Wiertz, E. Marani and W.L.C.Rutten

Neurotechnology Group/BSS, MIRA Institute, University of Twente, Enschede, The Netherlands 


\begin{abstract}
Microscopic aggregation assay and impedance sensing IS were used to monitor change of in vitro neuron-neuron adhesion in response to blocking of cell adhesion molecules. By blocking neuron-neuron adhesion, migration and aggregation of neuronal cells can be inhibited. This leads to a better control of spatial arrangement of cells in culture.

In literature N-CAM, N-Cadherin and L1 proteins are pointed out as main regulators of neuronal adhesion. In this study, these three main cell adhesion molecules were used to inhibit neuron-to-neuron adhesion and to control culture topography. Both, soluble extracellular domains and antigen antibodies were investigated on their ability to block these adhesion molecules on neuronal cells in cultures.

First, in a 96 hour aggregation assay on a low-adhesive substrate, the effect of inhibition of the three proteins on aggregation of cortical neurons was investigated optically. Both the L1 antibody and the L1 soluble protein had no effect on the degree of aggregation. The NCadherin antibody however was shown to be effective in aggregation inhibition at concentrations of 1 and $3 \mu \mathrm{g} / \mathrm{ml}$. Up to 96 hours no aggregation occurred. A similar effect was achieved by the N-Cadherin protein, although less distinct. N-CAM blocking revealed no inhibition of aggregation.

Second, results from IS corresponded to those of aggregation assays. In these experiments neuron-neuron adhesion was also inhibited by blocking N-CAM, N-Cadherin and L1. Cortical neurons were cultured in small wells containing circular $100 \mu \mathrm{m}$ diameter gold electrodes, so small changes in cell-cell interactions in monolayers of neurons could be monitored by IS. Impedances of neuron covered electrodes were significantly lower in presence of $\mathrm{N}$-Cadherin antibody and protein at concentrations of 1,3 and $10 \mu \mathrm{g} / \mathrm{ml}$, indicating a less profound binding between adjacent neurons.

The results from both aggregation assays and impedance measurements demonstrate the applicability of blocking cell adhesion molecules for inhibition of cell-cell adhesion and aggregation.
\end{abstract}




\subsection{Introduction}

The effectiveness of neuronal interfacing with micro-electrode arrays, for in vitro research applications or for development of neuro-prosthetic devices like the "neuron cultured probe", depends largely on the quality of the neuro electronic interface. Creating the right properties of the actual interface between electrodes and neurons is crucial. These properties include pre-designed neuronal structures that are stable over long periods of time, such as islands or networks.

An important tool for regulation of cell cultures lies in the cell-substrate and the cell-cell adhesion. Over time, neuronal cells cultured on flat substrates tend to migrate and rearrange into 3 dimensional aggregates like in the in vivo situation. In a study by Ruardij et al, control over neuronal culture topography by chemical modification of culturing substrates was extensively studied [1-3]. They showed, like many other studies, that formation of aggregates can be slowed down by improving neurophilic and neurophobic capabilities of patterned substrates. However, despite the use of strong neurophilic surfaces like PEI, PLL or laminin, cells maintain a certain degree of mobility, enabling the clustering of neurons. A significant part of that mobility is mediated through cell-cell adhesion. Preventing adhesion between neuronal cells can suppress the strong drive of two dimensionally plated neuronal cultures to aggregate to three-dimensional conglomerates.

In this study we focused on the cell-cell adhesion for further improvement in the inhibition of aggregation. We investigated the effect of blocking cell adhesion molecules on cell-cell adhesion, using aggregation assays and impedance sensing, each in its most sensitive cell-substrate adhesive regime. This implies that for aggregation assays neurons have to be cultured on relatively weak adhesive substrates, while for impedance sensing, neurons have to be adhered more strongly to the substrate.

Adhesion molecules are involved in a number of important regulatory processes in the brain, including cell growth, migration and regeneration [4-6]. Cells in tissues can adhere directly to one another through specialized integral membrane proteins called cell-adhesion molecules (CAMs), which often cluster into specialized cell junctions. Cells also adhere indirectly (cell-matrix adhesion) through binding to adhesive proteins in the extra-cellular matrix (ECM). These two basic types of interactions not only allow cells to aggregate into distinct tissues, but also form a signaling pathway between the exterior and the interior of cells. There are four principal classes of membrane-anchored CAMs: Cadherins, the immunoglobulin (Ig) superfamily, selectins and integrins. All four CAM classes participate in cell adhesion. The members of the Cadherin family, the immunoglobulin (Ig) superfamily and selectins are involved in the adhesion among cells. Integrins interact with extracellular matrix (ECM) components like fibronectin, collagen and laminin and are found on a wide variety of cells, including neuronal cells. Selectins play an important role in inflammatory response and are expressed by leucocytes, platelets and endothelial cells. However, selectins are not involved in neuronal cell 
adhesion. In this study we focused on adhesion molecules that participate in neuronal cell-cell adhesion, which are members of the Cadherins or the immunoglobulin (Ig) superfamily.

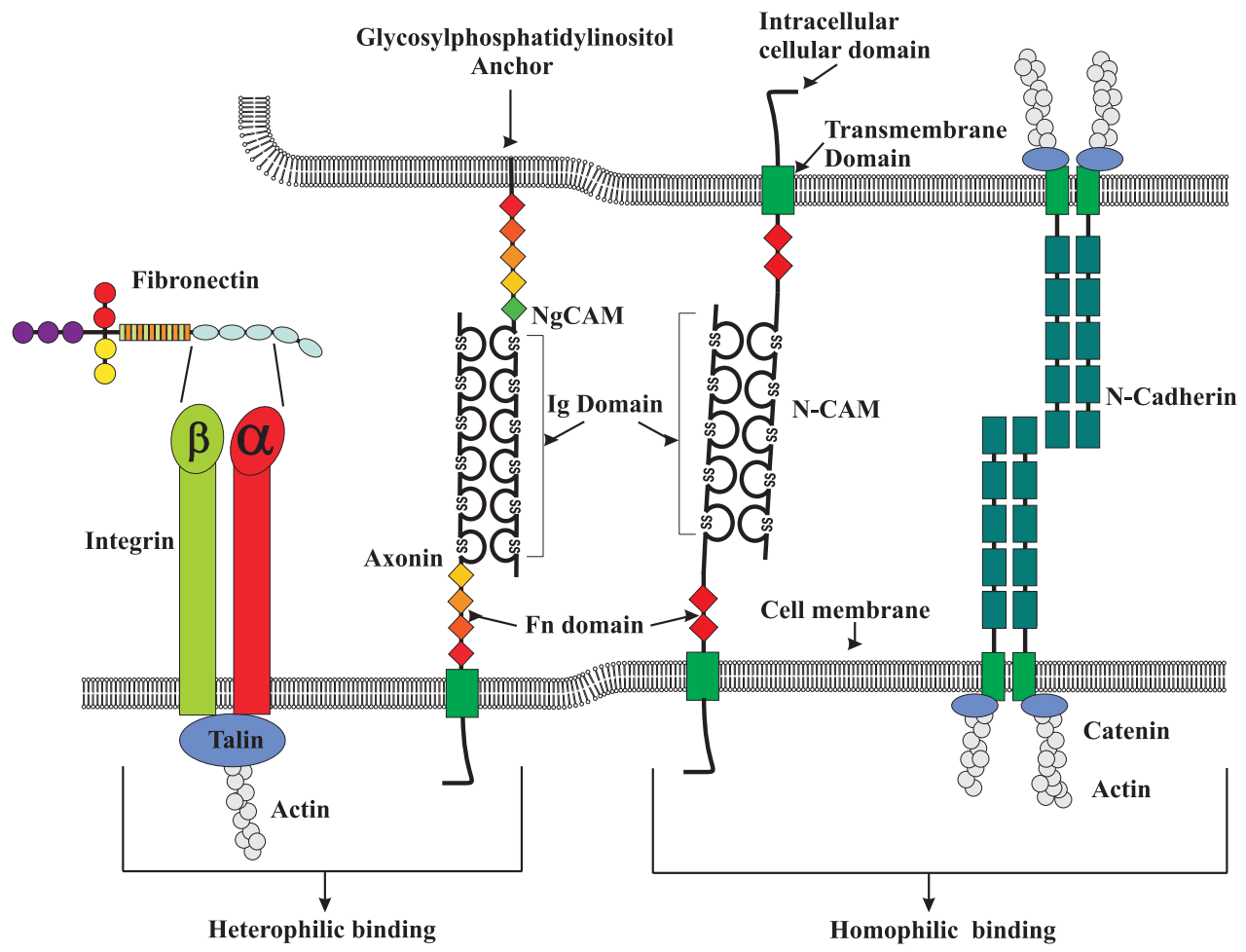

Fig. 1. Schematic drawing of heterophilic and homophilic binding between cells. For adhesion to other neuronal cells or to the extracellular matrix, cortical neurons express various cell adhesion molecules. Integrin binds to fibronectin or other components of the extracellular matrix. The second example from the left represents heterophilic binding between $\mathrm{NgCAM}$ and Axonin. On the right we show the binding between two N-CAM molecules and two $\mathrm{N}$-Cadherin molecules. Both are examples of homophilic binding. Note that integrins and $\mathrm{N}$-Cadherin are bound to the cytoskeleton through specific intracellular molecules, integrin binds to actin via talin, $N$-cadherin binds via catenin to actin.

\subsubsection{Neural cell adhesion molecules}

Three important CAMs in the central nervous system (CNS) are neural cell adhesion molecule (N-CAM), neural (N)-Cadherin and L1-CAM. N-CAM and NCadherin mediate cell adhesion through homotypic binding (figure 1) between extracellular domains [7]. L1 can bind to other L1 molecules (homotypical) or to CAMs that have a different structure, like $\mathrm{NgCAM}$ (heterotypical).

From the Ig superfamily, N-CAM is the most important CAM in the CNS. N-CAM is involved in neural development, regeneration and synaptic plasticity [8]. The extracellular domain of N-CAM consists of five Ig loops followed by two 
fibronectin type III (FNIII) repeats. There are at least 27 different spliced N-CAM mRNAs, all generated by alternative splicing of an RNA transcript produced from a single gene. The three major isoforms of N-CAM vary only in their cytoplasmic domain. These three isoforms are N-CAM-120kDa (glycophosphatidylinositol (GPI) anchored), N-CAM-140kDa (short cytoplasmic domain), N-CAM-180kDa (long cytoplasmic domain) [7]. After translation, N-CAM can be posttranslationally modified by addition of polysialic acid (PSA) to the fifth Ig loop. PSA is thought to discard N-CAMs homophilic binding properties and can lead to reduced cell adhesion. The function of N-CAM also includes induction of intracellular signaling by heterophilic interaction with various binding partners. An important example is N-CAM induced neurite outgrowth by heterophilic binding with fibroblast growth factor receptor (FGFR) [9].

L1 is also a member of the immunoglobulin superfamily of CAMs. It exhibits both homophilic and heterophilic binding [10]. L1 can mediate cell-cell adhesion through $\mathrm{Ca}^{2+}$-independent homophilic binding at the cell surface. Each member of the L1 subfamily contains six Ig loops linked to five FNIII repeats on the extracellular surface, a single-pass transmembrane domain and a short cytoplasmic tail [11]. The primary function of L1 appears to be formation of axon bundles [12]. L1 can bind to several other membrane molecules and receptors, which include F2/F11/contactin, DM1-GRASP and Axonin-1 (TAG-1) [9, 13]. Both, DM1GRASP and Axonin-1 are known to promote neurite outgrowth through a signaling cascade initiated by binding to L1.

The $\mathrm{N}$-Cadherins are $\mathrm{Ca}^{2+}$-dependent and are involved in embryonic development and play a critical role during tissue differentiation [14]. The brain expresses the largest number of different Cadherins, presumably due to the necessity of forming very specific cell-cell contacts. N-Cadherin is a transmembrane cell surface protein with homophilic binding activity. The extracellular domain of $\mathrm{N}$-Cadherin consists of five Cadherin repeats. Between each pair of repeats there are $\mathrm{Ca}^{2+}$-binding sites, each binding site is capable of binding a calcium ion. Binding of $\mathrm{Ca}^{2+}$ causes the NCadherin molecule to assume a rigid conformation and orients the adhesive regions in such a way that the Cadherin from one cell can interact with the same kind of Cadherin from an adjacent cell [15]. The cytoplasmic tail of the Cadherins interacts indirectly with actin filaments through adaptor molecules called catenins. The serine-rich domain of the cytoplasmic tail of N-Cadherin is capable of binding $\beta$-, and $\gamma$-catenins. These catenins associate with $\alpha$-catenin, which in turn connects the cadherin-catenin complex to actin filaments [16]. This association with actin is critical for the formation of stable adhesions [17]. N-Cadherin is, like N-CAM and L1, involved in activation of signaling pathways that induce neurite outgrowth [18].

In various studies the effect of N-CAM, L1 and N-Cadherin blocking or their knock-out was studied both in vitro and in vivo. 
For example, of the presence of N-CAM and N-Cadherin antibodies in the midbrain neural tube causes abnormalities in the neural tube and neural crest and limits neural crest cell migration [14].

The inhibitory effect of ethanol on L1-mediated cell-cell adhesion is antagonized by neuroprotective proteins [19]. Another study showed strong inhibition of aggregation in ARM, 2B2, MCF-7/AZ and PL $\beta 2$ cell cultures in the presence of NCadherin antibody [20]. Aggregation of $\mathrm{PC} 12 \mathrm{~h}$ cells is also significantly inhibited in the presence of N-Cadherin antibody [21]. Further, aggregation of cortical neurons was strongly inhibited when $\mathrm{N}$-Cadherin was absent on the surface of these cells [22]. The same effect was obtained with N-CAM negative cells. Cortical neurons lacking N-CAM showed no aggregation in culture [23].

\subsubsection{Impedance Sensing}

IS is a technique for quantitative and real-time monitoring of cell attachment, spreading and confluency. In short: the method is based on measuring changes in impedance of gold micro electrodes to AC current flow when covered by cells (figure 2). The impedance spectrum of an electrode covered by cells can be analyzed using the equivalent RC-circuit of figure $3 \mathrm{a}$.

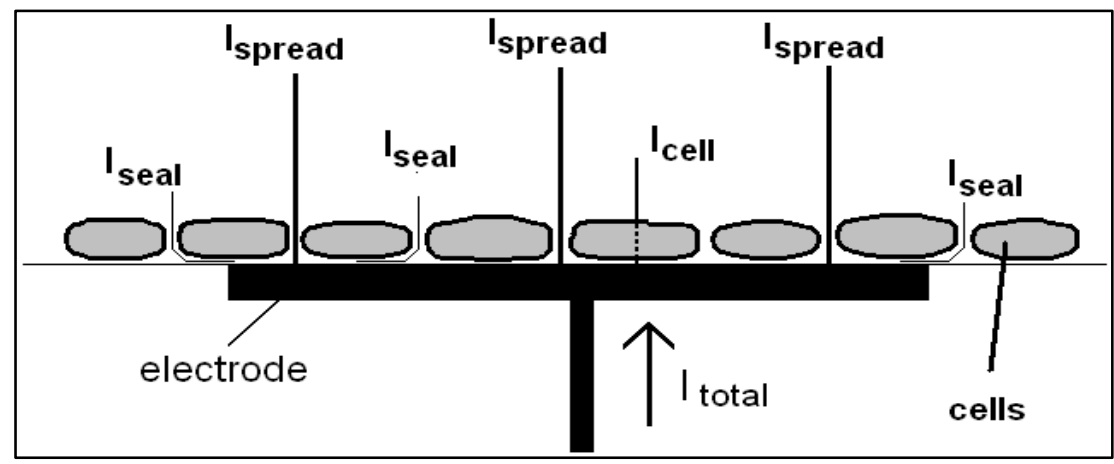

Figure 2. Schematic view of an electrode covered with neurons. The total current $I_{\text {total }}$ is split up into a current $I_{\text {spread }}$ finding its way trough the small spaces between the cells, $I_{\text {seal }}$, a leakage current through the gap between the substrate and the cells and the current through the cells $I_{\text {cell }}$. 

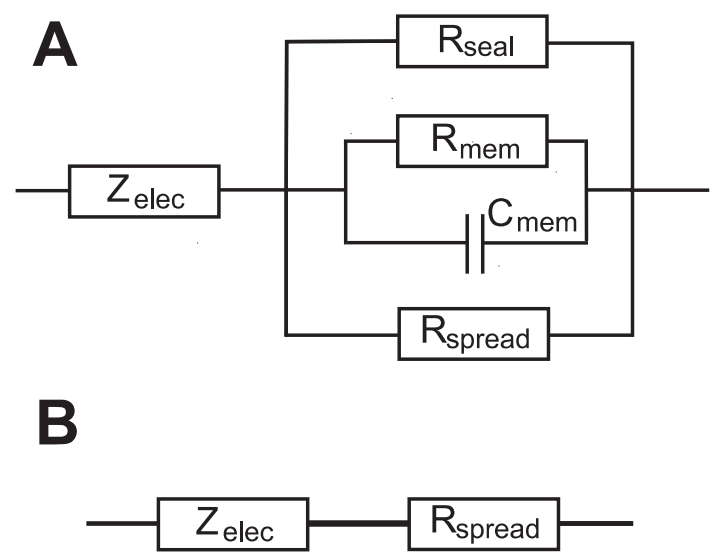

Figure $3 a$. The equivalent circuit of the impedance measured with gold electrodes (with a large counter electrode at a large distance). $Z_{\text {elec }}$ is the impedance of the electrode-electrolyte interface (Helmholtz double layer), $R_{\text {spread }}$ is the resistance of the intercellular open spaces and bulk fluid and $R_{\text {seal }}$ the sealing resistance between the cells and the substrate. The $R C_{\text {mem }}$ part accounts for the neuronal cell membranes.

b. Simplified equivalent circuit, see text.

Current can flow through the cell membranes and via openings between tightly adhered, but not totally confluent cells. Assuming that cells are firmly adhered to the substrates, so $\mathrm{R}_{\text {seal }}$ is very high, and stay adhered when openings between cells grow or shrink, changes in cell confluency will affect mainly the intercellular resistance (spreading resistance $R_{\text {spread, }}$, or constriction resistance). Due to low resistivity of the culturing fluid, compared to the membrane impedance and $\mathrm{R}_{\text {seal }}$, even slight changes in the openings have very large effects on the impedance, as shown in [24, 25].

Therefore, this model can be simplified to only $Z_{\text {elec }}$ in series with $R_{\text {spread, }}$ (figure 3b):

$$
Z=Z_{\text {elec }}+R_{\text {spread }}=\frac{K}{(i \omega)^{m}}+R_{\text {spread }}
$$

The first term represents the equivalent impedance of the electrode-electrolyte interface [26]. $\mathrm{K}$ is a size dependent constant. Power $\mathrm{m}$ usually takes values around $0.6-0.7$, indicating the non-truly capacitive nature of the Helmholtz layer. The second term $R_{\text {spread }}$ represents the spreading resistance of the summed openings between cells. 


\subsection{Methods}

\subsubsection{Planar electrode structure}

Figure 4 shows an overview of electrodes used for impedance sensing. Diameters of the circular electrodes are 50,100 and $200 \mu \mathrm{m}$. In this study only the $100 \mu \mathrm{m}$ diameter electrodes were measured. Electrodes were patterned in 8 groups on a 25 $\mathrm{cm}^{2}$ square glass plate. Each group contained two electrodes of each size, so 6 electrodes. Glass was used as a substrate in order to have transparency between electrodes. Gold electrode structures were created by photolithography and reactive ion etching. An isolation layer consisting of a sandwiched $\mathrm{SiO}_{2}-\mathrm{Si}_{3} \mathrm{~N}_{4}-\mathrm{SiO}_{2}$, combination was deposited by plasma enhanced chemical vapor deposition (PECVD). A $6 \mathrm{~mm}$ thick "overlay" block of PDMS with 8 round holes was let to adhere on the glass surface of the electrode device to create 8 wells for the cell cultures (wells are $7 \mathrm{~mm}$ in diameter).

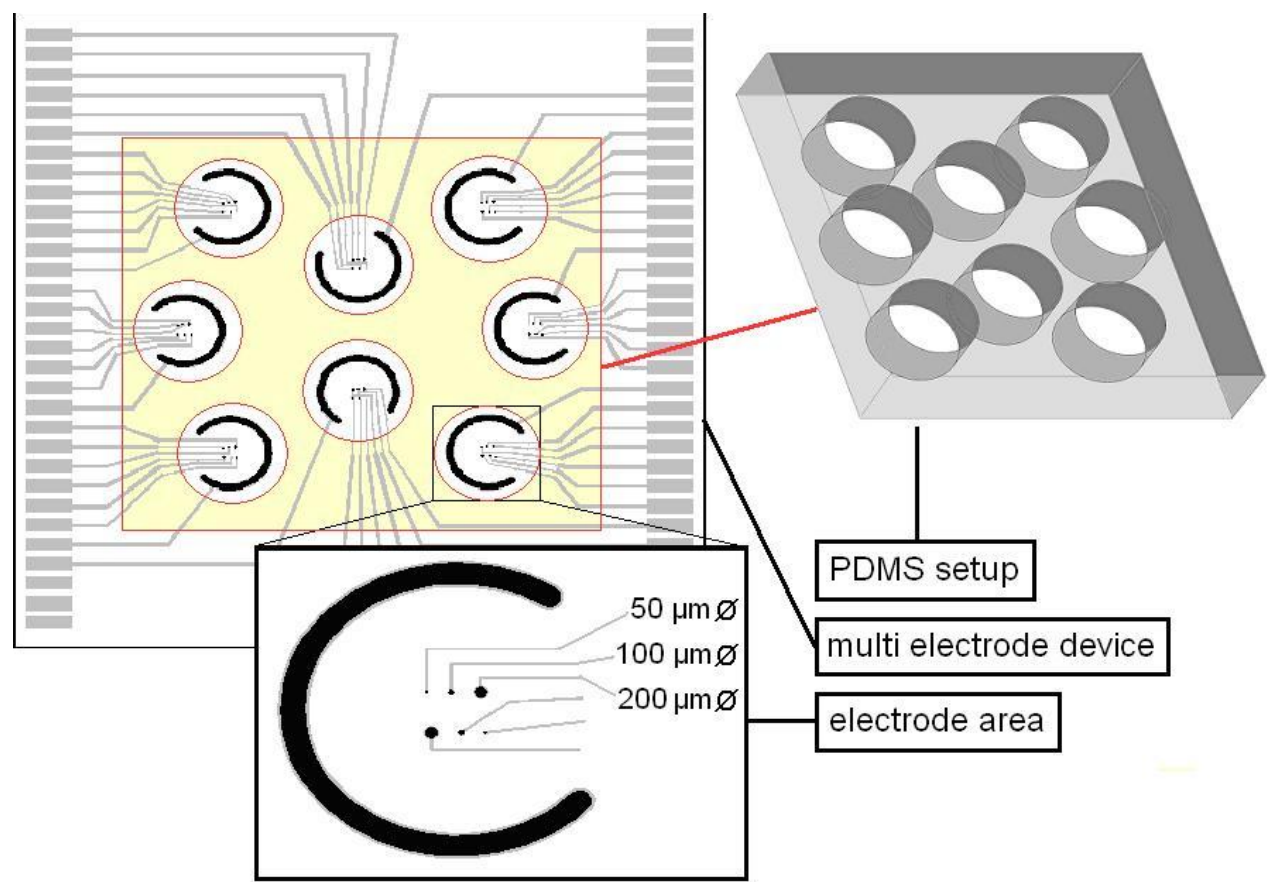

Fig 4. IS device (left) with 8 electrode areas (magnification shown in the lower insert) and a PDMS overlay with 8 wells (right). Each well contains 6 electrodes with a diameter of 50, 100 and $200 \mu \mathrm{m}$ in diameter (two of each).

\subsubsection{Cell Culturing}

Cerebral cortical neurons from newborn rats (P2) were used for all experiments in this study. Brains were taken out after decapitation, the meninges of the cortices were removed. Finally the cortex was prepared free and cut in small pieces. The remaining cortices were collected in a tube with chemically defined R12 culture medium [27] which strongly inhibits the proliferation of glial cells. Trypsin was 
added for chemical dissociation (45 minutes). After removal of trypsin, $150 \mu \mathrm{l}$ of soybean trypsin inhibitor and $125 \mu$ of DNAse I (20.000 units, Life Technology, Carlsbad, United States) were added. A solution of single neurons was obtained by mechanical dissociation of the cortical tissue. The neuron solution was centrifuged at $1200 \mathrm{rpm}$ for 5 minutes. The supernatant was removed and the pellet of neurons resuspended. Neurons were plated and cultured on the electrodes, which were precoated with poly-ethylene-imine (PEI, Fluka, Buchs, Switzerland) at a concentration of $0.05 \mu \mathrm{g} / \mathrm{ml}$ for the aggregation assays and $50 \mu \mathrm{g} / \mathrm{ml}$ for the impedance experiments. PEI is a strong cell-substrate adhesive. Cells were kept in serum-free R12 medium under standard conditions of $37^{\circ} \mathrm{C}$ and $5 \% \mathrm{CO}_{2}$ in air. A cell concentration of approximately $10^{6}$ cells $/ \mathrm{cm}^{2}$ was used in all experiments. During measurements the neuron cultures were placed into a small incubator at a constant temperature of $37^{\circ} \mathrm{C}$.

\subsubsection{Aggregation assay}

To inhibit homotypic interaction between N-Cadherin molecules, a polyclonal antibody to N-cadherin (H-63, Santa Cruz Biotechnology, Santa Cruz, United States) or a soluble N-Cadherin protein, fused to the Fc region of human IgG via a peptide linker ( $\mathrm{R} \& \mathrm{D}$ systems, Minneapolis, United states), were used. NCAM interactions were inhibited with a monoclonal antibody to N-CAM (antiCD56; BD Pharmingen, New Jersey, United States) or a soluble N-CAM protein (R \& D systems). Also L1 molecules were blocked using an antibody (anti-L1, BD Pharmingen) or a soluble L1 protein fused to the Fc region of human IgG (R \& $\mathrm{D}$ systems). To enhance aggregation the PEI concentration was set at a low concentration of $0.05 \mu \mathrm{g} / \mathrm{ml}$. After isolation, neurons were allowed to adhere onto the surfaces in the presence of one of the chosen blockers. After this the neurons were rinsed with DMEM (Dulbecco's modified Eagle's medium; Invitrogen), to remove non-adherent cells. Fresh R12 medium, again with the chosen blockers, was added $(\mathrm{t}=0)$. The samples were incubated with the following concentrations of antibodies or proteins 1) 0.1 till $10 \mu \mathrm{g} / \mathrm{ml}$ anti-N-Cadherin or $\mathrm{N}$-Cadherin protein/Fc region, 2) 0.1 till $10 \mu \mathrm{g} / \mathrm{ml}$ anti-N-CAM or N-CAM protein and 3) 0.3 till $30 \mu \mathrm{g} / \mathrm{ml} \mathrm{L1}$ antibody or L1 protein/Fc region. At 6, 24 and 96 hours, neuronneuron aggregation was determined. Six pups from three rats (two pups per rat) were used to perform the experiments. From each pup 6 assay platings were made, as described above ( 5 different concentrations and 1 control). This was done for each antibody or peptide.

\subsubsection{Imaging technique}

The neuronal coverage of electrodes was determined by taking the visible area directly surrounding the electrodes as representative for the electrode area itself (which lacked the transparency for direct optical monitoring). Percentage of coverage was determined by converting digital color photographs into an 8-bit grayscale photograph using CorelDraw software. The histogram of the grayscale photograph was used for segmentation of the picture into a black-and-white photo. 
The ratio of the number of black to white pixels is the percentage of the electrode area covered by cells. Pictures of the electrode surround areas were made after every impedance measurement. During IS experiments areas of 200 x $200 \mu \mathrm{m}$ were taken at 4 different positions on each photograph. The average percentage of coverage at these 4 areas was calculated. During the aggregation assays pictures were taken at the center of each culture. The average percentage of coverage of the whole picture was calculated. The area size of the images are $600 \times 480 \mu \mathrm{m}$, with a pixel size of $0.5 \times 0.5 \mu \mathrm{m}$.

\subsubsection{IS Measurement Setup}

All impedance measurements were carried out using a programmable signal source (HP 4194A), a home-built impedance measuring circuit [25] and a data acquisition system in a Labview environment. This setup was used in combination with cell culturing chambers containing the planar gold electrodes. Cultures were kept in culturing chambers at $37^{\circ} \mathrm{C}$ under sterile conditions during measurements, while positioned under a NIKON DIAPHOT inverted microscope. Applied frequencies were $5,10,50,100,500,1000,10000$ and $20000 \mathrm{~Hz}$. The measurements were controlled by the same computer that recorded and saved the real and imaginary part of the impedance.

Cultures were monitored during their development, starting shortly before cell plating $(\mathrm{t}=0)$, until cultures formed compact monolayers of neurons and aggregation was just starting ( $\mathrm{t}=144$ hours). From 0 hours on, electrodes were monitored every 12 hours in which 5 repeated impedance measurements were carried out with an interval of 1 minute. Six pups from three rats (two pups per rat) were used to perform experiments. From each pup 6 well-platings were made, as described above ( 5 different concentrations and 1 control). This was done for each antibody or peptide.

\subsubsection{Inhibition of cell-cell adhesion during IS measurements}

Neuron to neuron adhesion was inhibited by adding the soluble extracellulair domain of N-Cadherin, N-CAM or L1. In case of N-Cadherin and L1, these proteins were fused to a $\mathrm{Fc}$ region of human $\mathrm{IgG}$ via a peptide linker. Antibodies targeting the adhesive regions of the mentioned cell adhesion molecules were also used for the inhibition of the adhesion.

$\mathrm{N}-$ Cadherin and N-CAM antibodies as well as N-Cadherin and N-CAM peptide were added at resulting end concentrations of $0.1,0.3,1.0,3.0$ and $10.0 \mu \mathrm{g} / \mathrm{ml}$ in the culturing solution after the second data point at 12 hours.

L1 antibody and peptide was added after 12 hours in a concentration range of 0.3 , $1.0,3.0,10.0,30.0 \mu \mathrm{g} / \mathrm{ml}$. As a control the buffer solutions of the protein and of the antibodies were used as a control. 


\subsection{Results}

\subsubsection{Aggregation assay using blocking agents}

The inhibitory effect of CAM blockers on neuronal cell-cell adhesion was investigated by means of an aggregation assay. In this assay, neurons were cultured on a relatively weak adhesive $(0.05 \mu \mathrm{g} / \mathrm{ml} \mathrm{PEI})$ and aggregation promoting surface. Microscopic images were used to determine the surface coverage and aggregation. Neuronal cells were plated in the presence of CAM blockers and allowed to adhere. The cell-substrate adhesion was set at a minimum by presenting cells to a lowadhesive substrate. A low-adhesive substrate promotes aggregation and limits the duration of the experiment. The blockers were added to the cell suspension at the moment of plating to check for possible effects of blockers on cell-substrate adhesion. The moment all cells adhered to the substrate was set to $\mathrm{t}=0 \mathrm{hrs}$. At $\mathrm{t}=0$, $\mathrm{t}=24$ and $\mathrm{t}=96 \mathrm{hrs}$ pictures were made. The percentage of surface area covered by cells was then determined for all images.

Figures 5 a-f represent the change of area coverage in the presence of CAM blockers. In the absence of CAM blockers (blank) a clear decrease of surface area covered by cells can be seen. This decrease of surface coverage is caused by aggregation of neuronal cells. For both L1 antibody and L1 protein there is no significant effect on surface coverage for any concentration (fig 5a-b). Neither did the topography of any L1 inhibitor containing culture differ from that of cultures lacking blockers.

The effect of $\mathrm{N}$-Cadherin antibody (figure $5 \mathrm{c}$ ) is more distinctive. For the 1.0 $\mu \mathrm{g} / \mathrm{ml}$ and $3.0 \mu \mathrm{g} / \mathrm{ml}$ concentration the decrease of surface coverage is less definite compared to the control. After 24 hours and 96 hours the surface is better covered and images of the cultures show no aggregates. A concentration of $10.0 \mu \mathrm{g} / \mathrm{ml}$ led to cell death after 96 hours resulting in a lower surface coverage. A concentration of $10 \mu \mathrm{g} / \mathrm{ml} \mathrm{N}$-Cadherin protein has the same deleterious effect on neuronal cultures. A concentration of $3.0 \mu \mathrm{g} / \mathrm{ml}$ also results in cell death, but moderate (fig $5 \mathrm{~d}$ ). The surface coverage at $1.0 \mu \mathrm{g} / \mathrm{ml}$ does not differ from the control, neither does any lower concentration of $\mathrm{N}$-Cadherin protein. However, the culture topography at $1.0 \mu \mathrm{g} / \mathrm{ml}$ lacks the presence of aggregates, indicating the inhibitory effect on neuronal cell-cell adhesion (figure 6, c1-c3).

No effect is seen of N-CAM antibody on neuronal cultures (figure 5e). Both the surface coverage and the culture topography are not affected by any applied concentration of N-CAM antibody. Like the N-Cadherin blockers the N-CAM protein induces cell death at a concentration of 3.0 and $10.0 \mu \mathrm{g} / \mathrm{ml}$. N-CAM protein concentrations of $3.0 \mu \mathrm{g} / \mathrm{ml}$ and $1.0 \mu \mathrm{g} / \mathrm{ml}$ seem to slightly alter the surface coverage after 24 hours, but these differences are not significant (fig $5 \mathrm{f}$ ).

In figure 6 some pictures of culture development are presented. Figures 6, a1-a3 show aggregation without any blockers during 96 hours. The inhibition of aggregation by $\mathrm{N}$-Cadherin antibody is shown in figures 6, b1-b3. N-Cadherin 
protein shows a less profound inhibitory effect on aggregation of neuronal cells (c1-c3). Cells do migrate towards each other but form flat islands rather than large aggregates. High concentrations of N-CAM protein led to cell death within 96 hours (d1-d3).
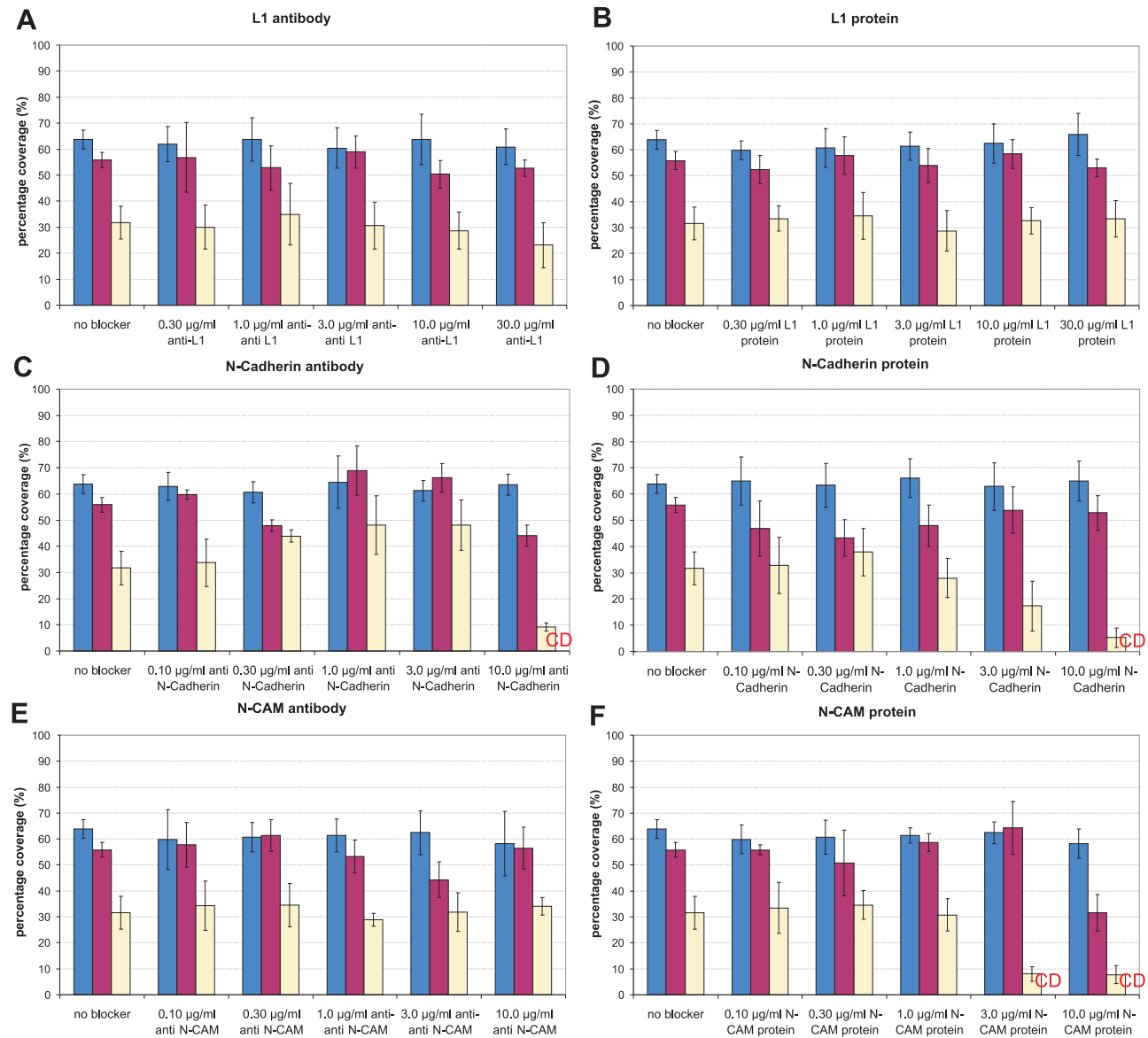

Figure 5. Microscopic observation results (average and standard deviation; $n=6$ ) from aggregation assays concerning the attachment of rat cortical neurons on a glass substrate. This table represents the course of the substrate covering, under influence of L1 antibody (a) and L1 peptide (b) at a concentration range of $0.3,1.0,3.0,10.0,30.0 \mu \mathrm{g} / \mathrm{ml}$. N-Cadherin (c) and $\mathrm{N}$-CAM antibody (e) as well as $\mathrm{N}$-Cadherin (d) and $\mathrm{N}$-CAM (f) protein were applied at concentrations of 0.1, 0.3, 1.0, 3.0 and $10.0 \mu \mathrm{g} / \mathrm{ml}$. At zero hours the different concentrations of CAM blockers were added to the medium. At

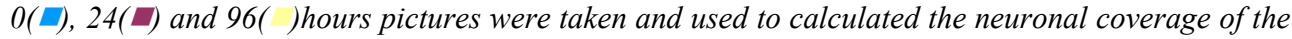
glass substrate. $C D=$ cell death. 

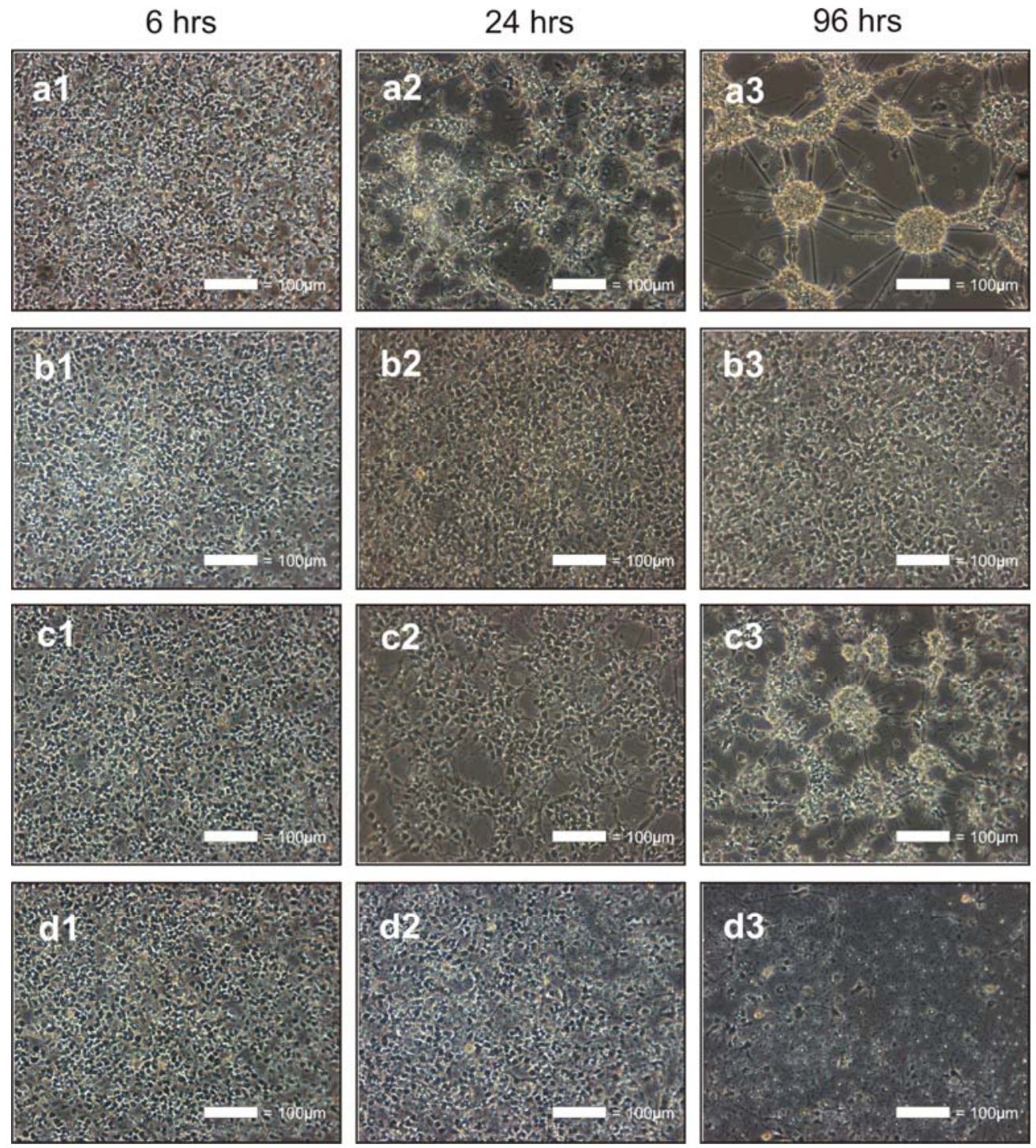

Figure 6. Attachment of rat cortical neurons on a glass substrate. Examples of pictures taken at $t=0$, 24 and 96 hrs. Without blocking agents the neuronal cells aggregate already after 24 hrs (al-a3). With $1.0 \mu \mathrm{g} / \mathrm{ml} \mathrm{N}$-Cadherin antibody (b1-b3) cell aggregation is inhibited even up to 96 hours. The $\mathrm{N}$-Cadherin protein (c1-c3) also inhibits aggregation up to 24 hours although not as well as $N$ Cadherin antibody. A concentration of $10.0 \mu \mathrm{g} / \mathrm{ml} \mathrm{N}$-CAM protein causes cell death after 96 hours (d3). 


\subsubsection{Impedance measurements during inhibition of cell-cell adhesion}

Impedance measurements were used to monitor the effect of CAM blockers on cell-cell adhesion among neuronal cells. In contrast to aggregation assays, neurons were cultured on surfaces with relatively strong neuron adhesive properties (50 $\mu \mathrm{g} / \mathrm{ml}$ PEI). During 144 hours, the impedance of neuron-covered gold electrodes was monitored at frequencies of 5, 10,50,100,500,1000, 10.000 and $20.000 \mathrm{~Hz}$ and plotted as Bode plots of amplitude and phase, or as impedance locus of real and imaginary part. The real part of the impedance at $10000 \mathrm{~Hz}$ showed to be most affected by cell coverage and change in culture topography. Therefore, we will limit the presentation of all impedance results to the real part of the impedance at $10 \mathrm{kHz}$.

In time, the presence of L1 antibody has no effect on the real impedance at any of the applied concentrations (figure 7). A comparable result was seen for L1 protein (figure 8). In contrast, concentrations of $1.0 \mu \mathrm{g} / \mathrm{ml} \mathrm{N}$-Cadherin antibody (and higher) significantly decrease the real impedance of the neuron-covered electrodes after 60 hours (figure 9). However, no difference in optical coverage could be measured (the right axis displays the surface coverage). Only the highest $\mathrm{N}$ Cadherin antibody concentration of $10.0 \mu \mathrm{g} / \mathrm{ml}$ shows a clearly lower trend line. The surface coverage is less, but only significantly at 24 hours.

Like N-Cadherin antibody, N-Cadherin protein decreases the real impedance. Yet, the decrease is only seen between 48 and 72 hours, after which the real impedance approaches the level of a "non-blocked" culture (figure 10). Besides the effect on the real impedance, a significant lower surface coverage is seen at 36 and 48 hours for a concentration of $10.0 \mu \mathrm{g} / \mathrm{ml}$. For $3.0 \mu \mathrm{g} / \mathrm{ml}$ and lower concentrations this effect on surface coverage was not seen (data not presented).

Comparable to both the L1 blockers, N-CAM antibody displays no effect on the impedance of neuron covered electrode or on the surface coverage (figure 11). In contrast, the decrease of real impedance caused by high N-CAM protein concentrations is eminent (figure 12). After the addition of the blocker ( $\mathrm{t}=12$ hours) at concentrations of $3.0 \mu \mathrm{g} / \mathrm{ml}$ and $10.0 \mu \mathrm{g} / \mathrm{ml}$ the real impedance and the surface coverage stay on a rather constant level up till 48 hours, after which both impedance and surface coverage decrease drastically. This effect is caused by cell death of neuronal cells. Among all CAM blockers, N-CAM protein was the only compound that altered cultures topography. For all other blockers, no obvious changes like aggregation, cell death, or change in single cell morphology could be observed. 


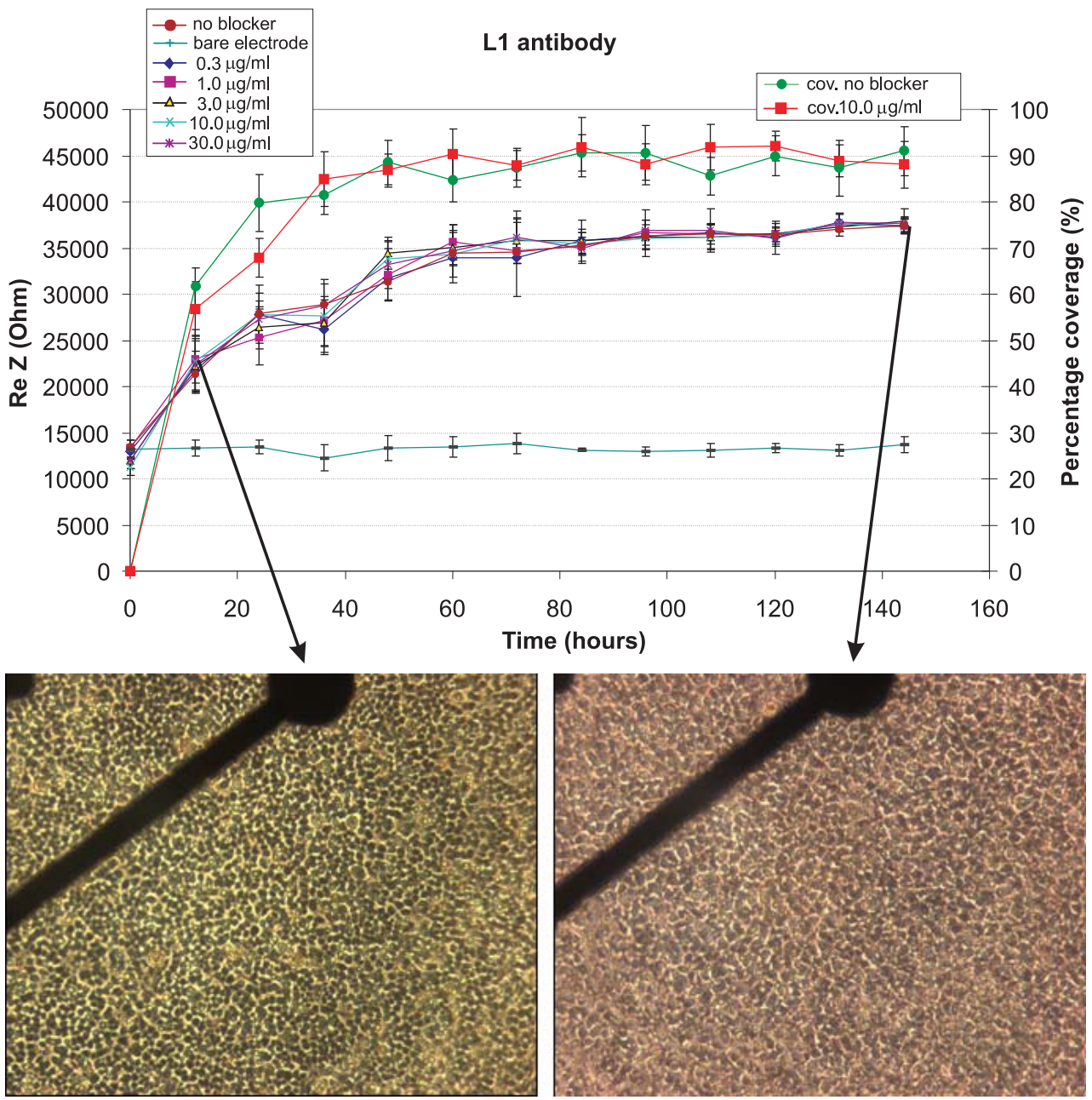

Figure 7, upper part. Real part of the impedance during development of a neuronal culture on top of an $7850 \mu^{2}$ gold electrode under influence of L1 antibody at concentration of 0, 0.3, 1.0, 3.0, 10.0 and $30.0 \mu \mathrm{g} / \mathrm{ml}$. Percentage cell coverage is indicated on the right vertical axis and the real impedance (at $10 \mathrm{kHz}$ ) on the left axis. $N=6$. Lower part left $=$ no blocking at 12 hours and lower part right $=$ blocking with $10.0 \mu \mathrm{g} / \mathrm{ml} \mathrm{L1}$ ab at 144 hours. 

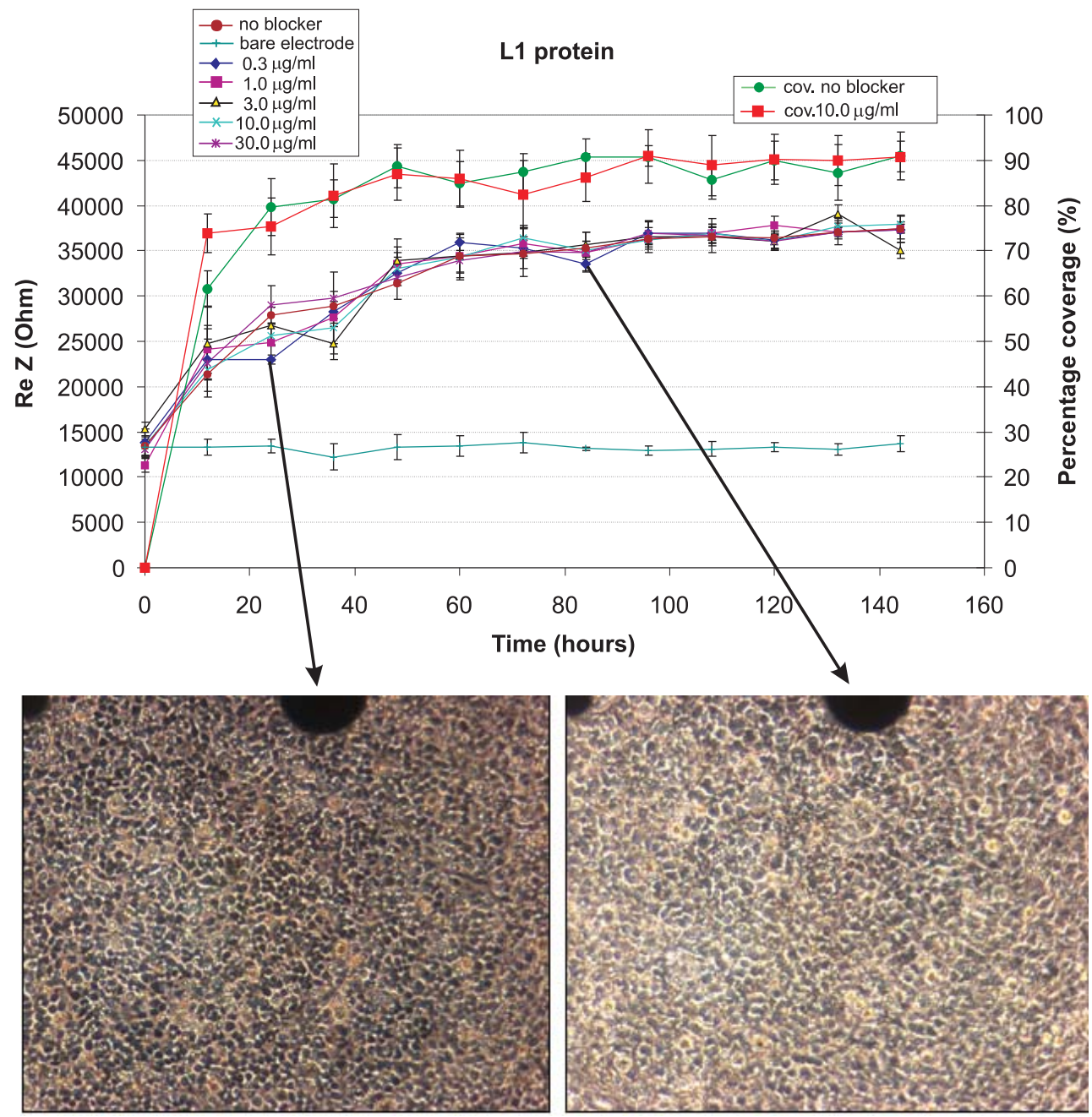

Figure 8, upper part. Real part of the impedance during development of a neuronal culture on top of an $7850 \mu^{2}$ gold electrode under influence of L1 protein at concentration of 0, 0.3, 1.0, 3.0, 10.0 and $30.0 \mu \mathrm{g} / \mathrm{ml}$. Percentage cell coverage is indicated on the right vertical axis and the real impedance (at $10 \mathrm{kHz}$ ) on the left axis. $N=6$. Lower part left $=$ blocking with $0.3 \mu \mathrm{g} / \mathrm{ml} \mathrm{L1}$ protein at 24 hours and lower part right $=$ blocking with $0.3 \mu \mathrm{g} / \mathrm{ml} \mathrm{L1}$ protein at 84 hours. 

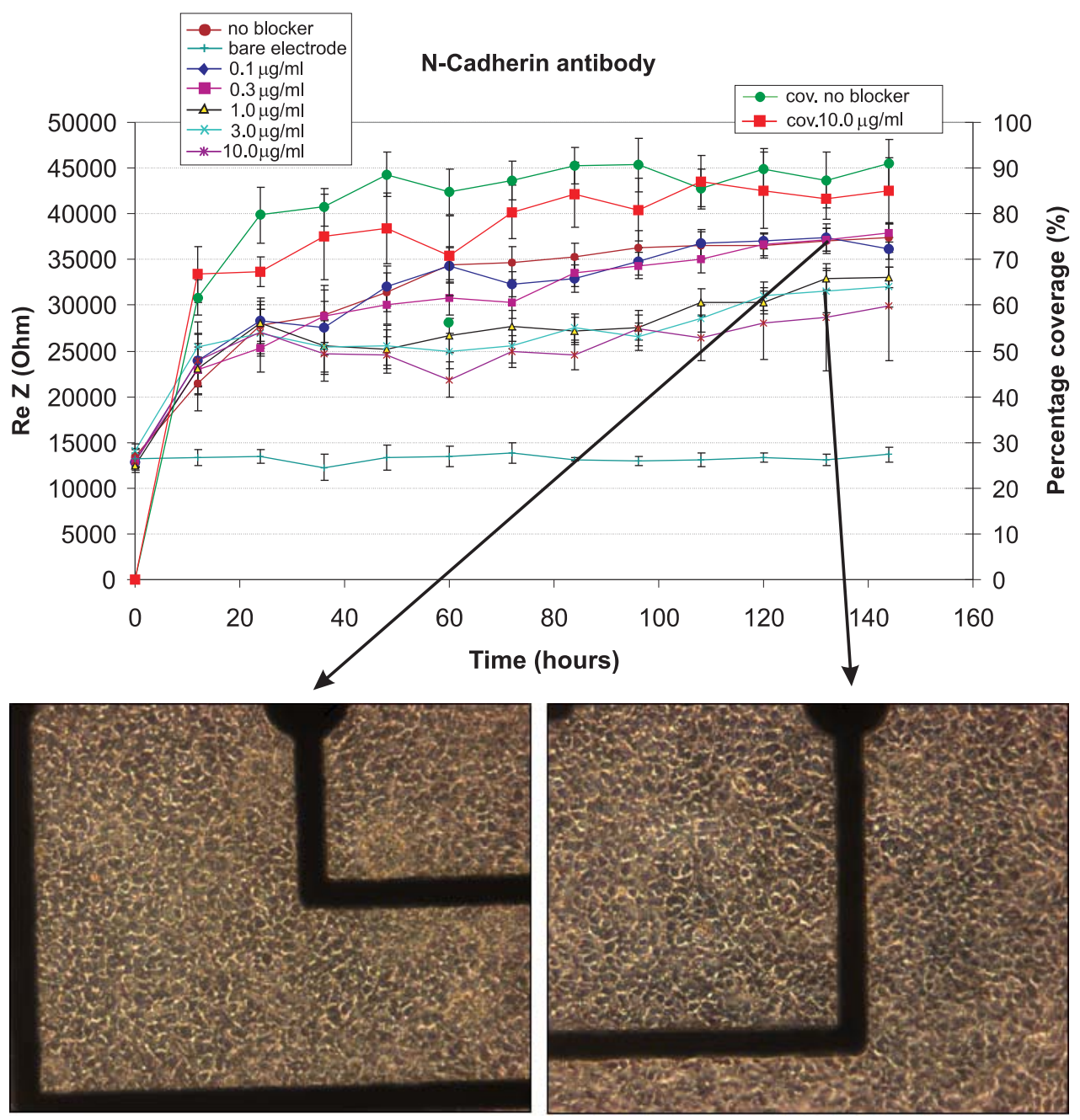

Figure 9, upper part. Real part of the impedance during development of a neuronal culture on top of an $7850 \mu^{2}$ gold electrode under influence of $\mathrm{N}$-Cadherin antibody at concentration of 0, 0.1, 0.3, 1.0, 3.0 and $10.0 \mu \mathrm{g} / \mathrm{ml}$. Percentage cell coverage is indicated on the right vertical axis and the real impedance (at $10 \mathrm{kHz}$ ) on the left axis. $N=6$. Lower part left $=$ no blocker at 132 hours and lower part right $=$ blocking with $3.0 \mu \mathrm{g} / \mathrm{ml} \mathrm{N}$-Cadherin ab at 132 hours. 

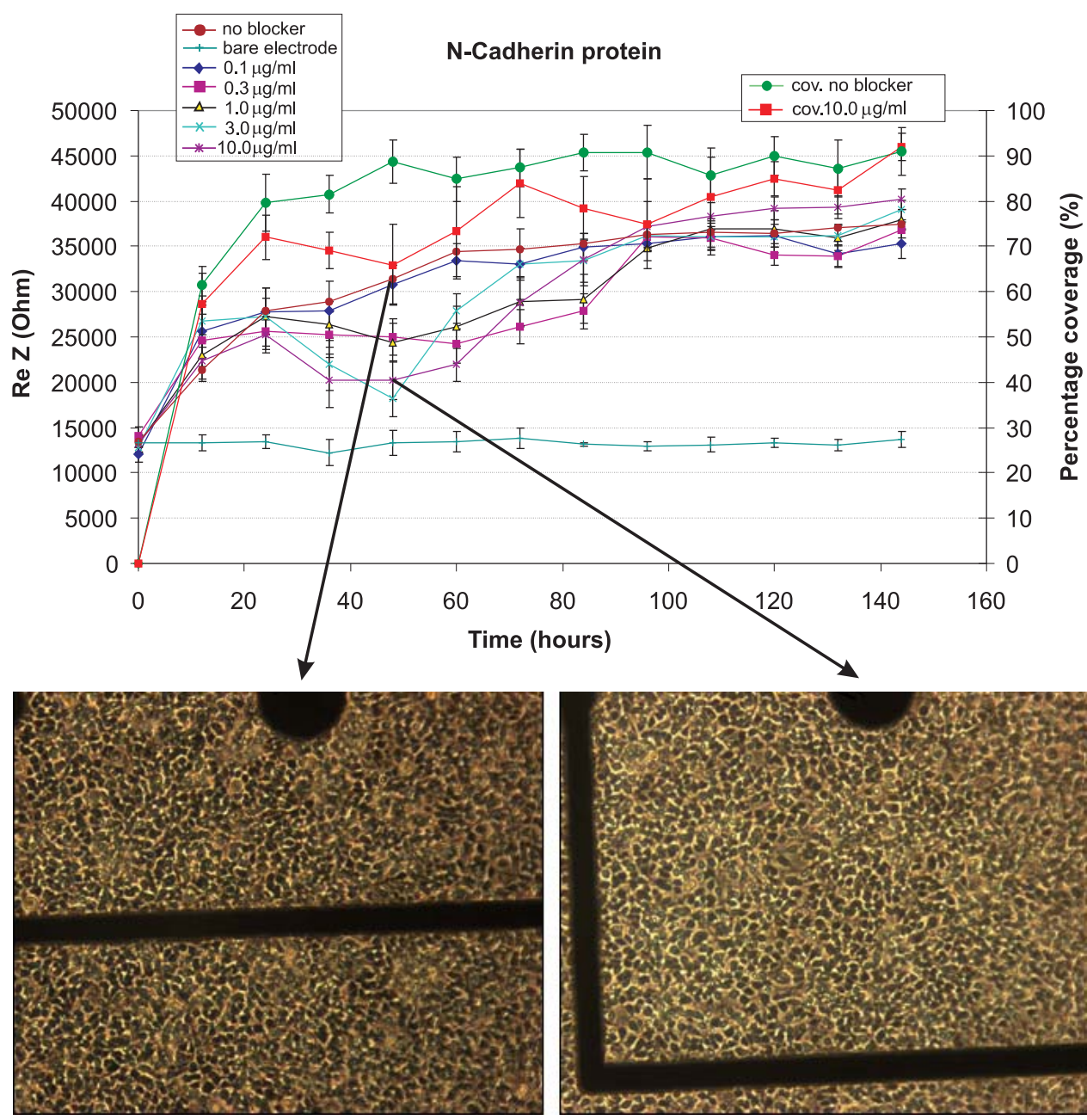

Figure 10, upper part. Real part of the impedance during development of a neuronal culture on top of an $7850 \mathrm{\mu m}^{2}$ gold electrode under influence of $\mathrm{N}$-Cadherin protein at concentration of 0, 0.1, 0.3, 1.0, 3.0 and $10.0 \mu \mathrm{g} / \mathrm{ml}$. Percentage cell coverage is indicated on the right vertical axis and the real impedance (at $10 \mathrm{kHz}$ ) on the left axis. $N=6$. Lower part left $=$ no blocker at 48 hours and lower part right $=$ blocking with $10.0 \mu \mathrm{g} / \mathrm{ml} \mathrm{N}$-Cadherin protein at 48 hours. 

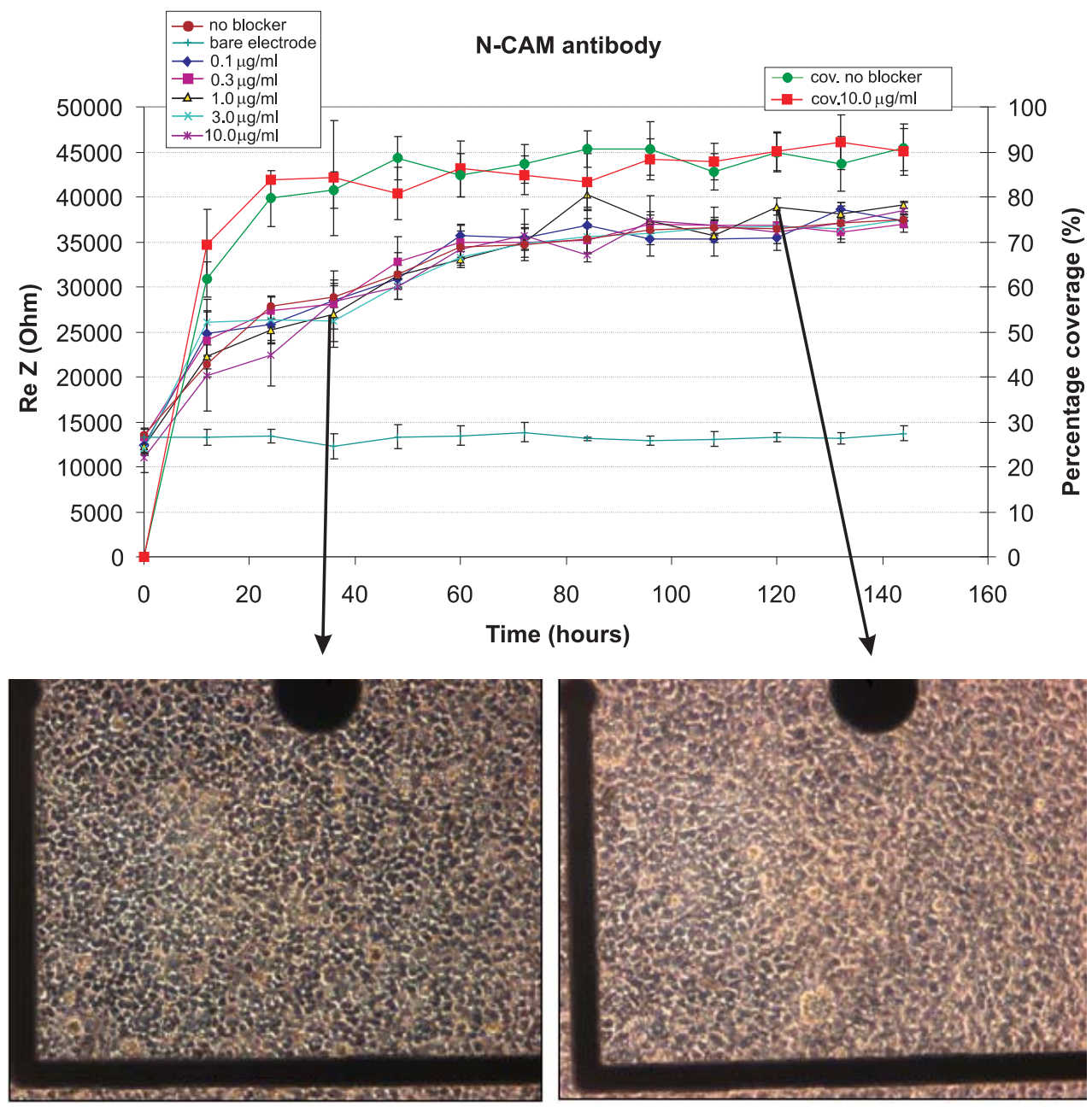

Figure 11, upper part. Real part of the impedance during development of a neuronal culture on top of an $7850 \mu^{2}$ gold electrode under influence of $\mathrm{N}-\mathrm{CAM}$ antibody at concentration of $0,0.1,0.3,1.0$, 3.0 and $10.0 \mu \mathrm{g} / \mathrm{ml}$. Percentage cell coverage is indicated on the right vertical axis and the real impedance (at $10 \mathrm{kHz}$ ) on the left axis. $N=6$. Lower part left = blocking with $10.0 \mu \mathrm{g} / \mathrm{ml} \mathrm{N}-\mathrm{CAM}$ ab at 36 hours and lower part right $=$ blocking with $10.0 \mu \mathrm{g} / \mathrm{ml} \mathrm{N}-\mathrm{CAM}$ ab at 120 hours. 

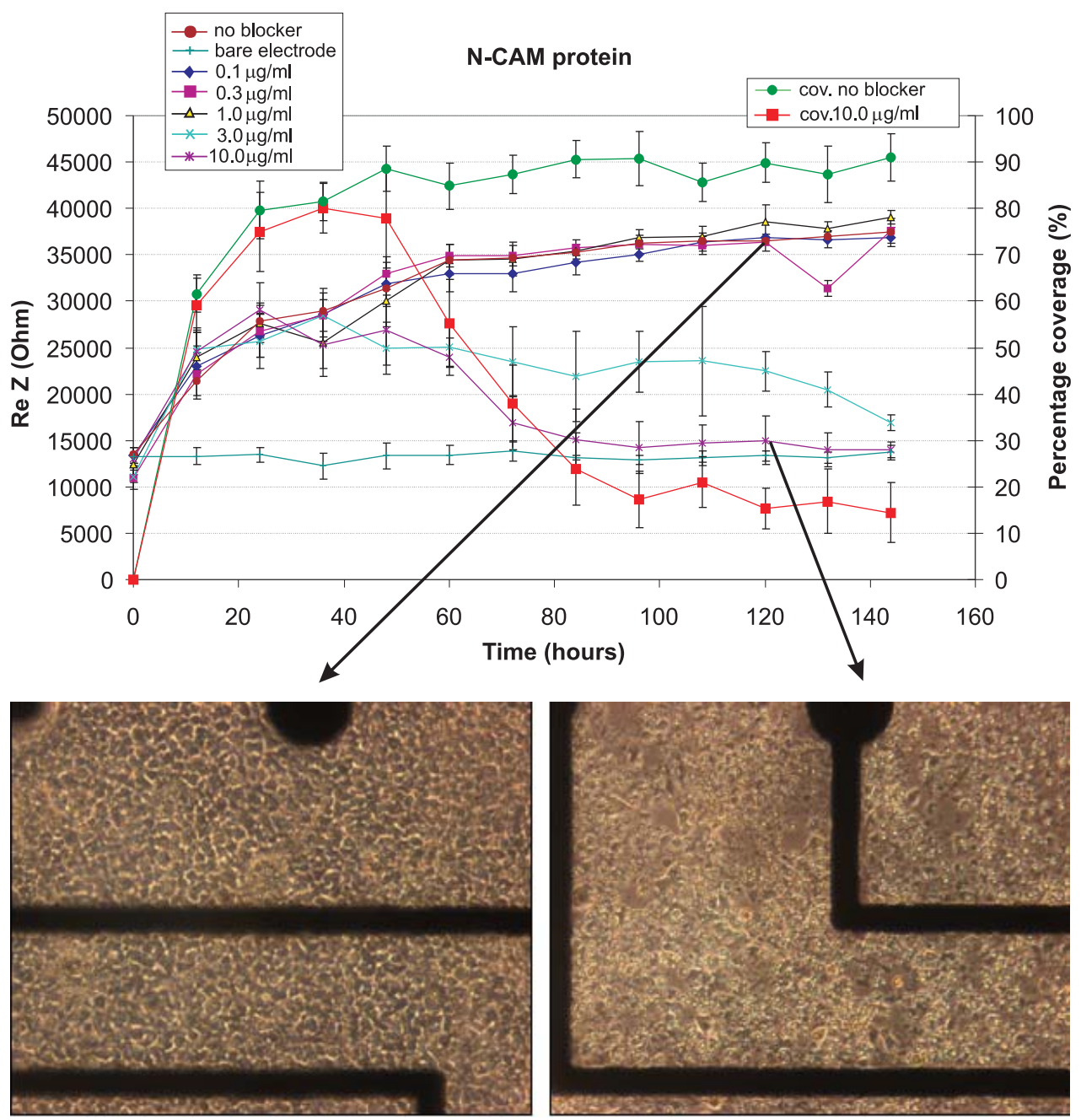

Figure 12, upper part. Real part of the impedance during development of a neuronal culture on top of an $7850 \mu^{2}$ gold electrode under influence of $\mathrm{N}-\mathrm{CAM}$ protein at concentration of $0,0.1,0.3,1.0,3.0$ and $10.0 \mu \mathrm{g} / \mathrm{ml}$. Percentage cell coverage is indicated on the right vertical axis and the real impedance (at $10 \mathrm{kHz}$ ) on the left axis. $\mathrm{N}=6$. Lower part left $=$ blocking with $0.1 \mu \mathrm{g} / \mathrm{ml} \mathrm{N}-\mathrm{CAM}$ protein at 120 hours and lower part right = blocking with $10.0 \mu \mathrm{g} / \mathrm{ml} \mathrm{N}$-CAM protein at 120 hours.

\section{Discussion}

This study describes the effect of CAM blockers on neuronal cell-cell adhesion and aggregation.

During aggregation assays, where changes were monitored with microscopy only, 3 of the 6 applied biochemicals showed to affect cell cultures in an aggregation promoting environment. The addition of N-CAM protein to a neuronal culture could not prevent the forming of aggregates. At high concentrations of N-CAM 
protein the culture topography was changed by cell death. High concentrations of $\mathrm{N}$-Cadherin antibody and N-Cadherin protein also led to cell death. However, at right concentrations, both $\mathrm{N}$-Cadherin antibody and protein were able to inhibit neuronal aggregation.

The findings of impedance measurements are in accordance with those of aggregation assays. In these assays, neurons are cultured in an aggregation promoting environment. Some of the CAM blockers caused an inhibitory effect on the cell-cell adhesion, resulting in less neuronal aggregation. The same inhibitory effect influences the impedance (where cells are cultured as a dense monolayer on a stronger neuron adhesive surface). Impedance is lowered, due to increased intercellular space. L1 antibody, L1 protein and the N-CAM antibody had no effect on the impedance of the cell covered electrode. N-Cadherin antibody and $\mathrm{N}$ Cadherin protein both led to a decrease of real impedance at higher concentrations. This indicates more extracellular space caused by inhibition of cell-cell adhesion. The blocking capacity of the N-Cadherin antibody appears to be better than the peptide blocking in both the impedance experiments and the aggregation assays. This difference can have several causes. We think the most plausible cause for the difference in blocking capacity between N-Cadherin peptide and antibody is a difference in affinity for the cell's CAMs, with a higher affinity by the antibodies. A second plausible cause could be the size and more voluminous shape of the antibody, making it harder for neighboring CAMs to make junctions with CAMs on neighboring cells. Another important factor that could influence the blocking capacity of soluble peptides is the affinity among the soluble peptides in the solution. Unlike antibodies, soluble peptides can not only bind to cell adhesion molecules on cell membranes, but also to each other. However, immediately after the addition of the N-Cadherin protein there is a clear effect on blocking the cellcell adhesion that fades during the course of the experiment (figure 10), making extensive binding among soluble peptides at the beginning of the experiment improbable. The effect of both $\mathrm{N}$-Cadherin antibody and protein are similar to results found in previous studies [21,22].

The inhibition of N-CAM and L1 mediated cell adhesion was less effective than the inhibition of N-Cadherin mediated cell adhesion. Immunocytological staining carried out in a pilot study (data not shown) indicated the presence of both N-CAM and $\mathrm{N}$-Cadherin (the antibodies in the blocking studies were also used as primary antibodies in immunocytological experiments). Cortical neurons in culture showed low immuno-reactivity for L1, which most probably explains why no inhibition of cell-cell adhesion and aggregation was detected when blocking L1. The most obvious cause for the effect of Cadherin is the adhesive property of N-Cadherin. The homophilic bond between Cadherins is stronger than any other known protein to protein bond in adhesive interaction [28]. Several other causes for the different blocking properties of N-Cadherin and N-CAM protein can also be put forward. Post-translational modification by addition of polysialic acid (PSA) reduces the adhesive properties of N-CAM. PSA is present on N-CAM molecules to enable 
migration in the developing central nervous system [29]. The amount of PSA on NCAM of P2 cortical rat neurons is not known, but could have diminished the adhesive properties of $\mathrm{N}-\mathrm{CAM}$ in this experiment. The contribution of $\mathrm{N}-\mathrm{Cadherin}$ in neuron to neuron adhesion is most probably larger than that of N-CAM.

Apart from acting as physical anchors, N-CAM, N-Cadherin and L1 are involved in transmembrane signaling, affecting the behavior and fate of cells in several ways [30-32]. Also, several possible binding conformations for N-CAM, N-Cadherin and L1 are possible. For example, homophilic binding between two N-CAM or two L1 molecules involves the affinity between immunoglobin-like domains. Earlier studies indicated several conformations between these immunoglobin-like domains with each conformation having its own effect on cell adhesion and signaling events. The effect of possible signaling responses on a neuronal culture caused by $\mathrm{N}-\mathrm{CAM}, \mathrm{N}-\mathrm{Cadherin}$ and $\mathrm{L} 1$ is uncertain.

Soluble proteins bind to CAMs on the cell membrane in the same way as CAMs of adjacent cells bind to each other. The signal inducing properties of antibodies depend on to what extent antibodies can mimic homophilic binding between CAMs. Although binding to the same receptor, signaling events might be cancelled out by antibodies. Antibodies bind to antigens on CAMs, but it seems less likely that antibodies can induce a similar signaling effect, since their structure is completely different from the CAMs. This could explain the different effects of NCAM antibody and N-CAM protein on the culture's fate. The cell death of the neuronal cells at high concentrations caused by N-CAM peptide during the IS experiments could be caused by a signaling response. At this point N-CAM antibody was apparently unable to trigger this signal response. This difference in signaling effect (or the lack of it) might not be valid for all antibodies (depending on the antigens position on the cell adhesion molecule). A study by Azizeh et al [33] revealed significant cell death 24 hours after the addition of soluble antiNCAM monoclonal antibodies $(3 \mu \mathrm{g} / \mathrm{ml})$.

In the aggregation assay cell death was also observed for the highest concentration of N-Cadherin protein and antibody. Cell death at high concentrations of these CAMs is most likely not the actual outcome of the signaling response under normal conditions, but rather a consequence of an extreme signal cascade caused by the high concentration of CAM blockers.

The sudden dose response effect (figure 12) between $1 \mu \mathrm{g} / \mathrm{ml}$ and $3 \mu \mathrm{g} / \mathrm{ml} \mathrm{N}-\mathrm{CAM}$ protein is surprising. In case of an inhibitory effect on cell-cell adhesion a less distinct change between $1 \mu \mathrm{g} / \mathrm{ml}$ and $3 \mu \mathrm{g} / \mathrm{ml} \mathrm{ml} \mathrm{N-CAM} \mathrm{protein} \mathrm{would} \mathrm{be}$ expected. Instead, signaling effects are known to exhibit threshold effects. For example, NCAM-dependent neurite outgrowth exhibits such a threshold effect, whereas $\mathrm{N}$-Cadherin dependant outgrowth is essentially linear [18].

In this study, the blocking of some specific cell adhesion molecules has shown to have an inhibitory effect on cell-cell adhesion and aggregation of neuronal cell cultures. Also, electric impedance sensing proved to be sensitive enough to detect 
small changes in cell cultures caused by biochemical intervention, where no change could be observed using standard imaging.

$\mathrm{N}$-Cadherin antibodies and peptides proved to be applicable in the regulation of neuronal cell-cell adhesion, over a time period of 6 days. Further fine tuning of blocking over a longer period of time should lead to a helpful tool in maintaining patterned neuronal cultures vital and stable over long periods.

\section{References}

[1] Ruardij T G, Goedbloed M H and Rutten W L C 2000 Adhesion and patterning of cortical neurons on polyethylenimine and fluorocarboncoated surfaces IEEE trans. Biomed. eng. 47 1593-9

[2] Ruardij T G, van den Boogaart M A F, and Rutten W L C 2002 Adhesion and growth of electrically-active cortical neurons on polyethyleneimine patterns microprinted on PEO-PPO-PEO triblockcopolymer-coated hydrophobic surfaces IEEE Trans. Nanobiosci. 1 1-8

[3] Ruardij T G, Goedbloed M H and Rutten W L C 2003 Long-term adhesion and survival of dissociated cortical neurons on miniaturized chemical patterns Med. Biol. Eng. Comp. 41 227-32

[4] Ditlevsen D K, Køhler L B, Pedersen M V, Risell M, Kolkova K, Meyer M, Berezin V, Bock E 2003 The role of phosphatidylinositol 3-kinase in neural cell adhesion molecule-mediated neuronal differentiation and survival $J$. Neurochem. 84 546-56

[5] Walsh F S, and Doherty P 1996 Cell adhesion molecules and neuronal regeneration Curr. Opin. Cell. Biol. 8 707-13

[6] Petruzzelli L, Takami M and Humes H D 1999 Structure and function of cell adhesion molecules Am. J. Med. 106 467-76

[7] Kiselyov V V, Soroka V, Berezin V and Bock E $J 2005$ Structural biology of NCAM homophilic binding and activation of FGFR Neurochem. 94 1169-79

[8] Ronn L C, Berezin V and Bock E 2000 The neural cell adhesion molecule in synaptic plasticity and ageing Int. J. Dev. Neurosci. 18 193-9

[9] Saffel J L, Williams E J, Mason I J, Walsh F S, Doherty P 1997 Expression of a Dominant Negative FGF Receptor Inhibits Axonal Growth and FGF Receptor Phosphorylation Stimulated by CAMs Neuron. 18 123-32

[10] Bates C A, Becker C G, Miotke J A and Meyer R L 1999 Expression of polysialylated NCAM but not L1 or N-cadherin by regenerating adult mouse optic fibers in vitro Exp. Neurol. 155 128-39

[11] Kenwrick S, Watkins A and De Angelis E, 2000 Neural cell recognition molecule L1: relating biological complexity to human disease mutations Hum. Mol. Genet. 9 879-86 
[12] Landmesser L, Dahm L, Schultz K and Rutishauser U 1988 Distinct roles for adhesion molecules during innervation of embryonic chick muscle Dev. Biol. 130 645-70

[13] Kuhn T B, Stoeckli E T, Condrau M A, Rathjen F G and Sonderegger P 1991 Neurite outgrowth on immobilized axonin-1 is mediated by a heterophilic interaction with L1(G4) J. Cell. Biol. 115 1113-26

[14] Norgren R B, Jr. And Brackenbury R 1993 Cell adhesion molecules and the migration of LHRH neurons during development Dev. biol. 160 377-87

[15] Prozialeck W C, Grunwald G B, Dey P M, Reuhl K R and Parrish A R 2002 Cadherins and NCAM as potential targets in metal toxicity Toxicol. Appl. Pharmacol. 182 255-65

[16] Shun C T, Wu M S, Lin M T, Chang M C, Lin J T and Chuang S M 2001 Immunohistochemical evaluation of cadherin and catenin expression in early gastric carcinomas: correlation with clinicopathologic characteristics and Helicobacter pylori infection Oncology. $60339-45$

[17] Rhee J, Mahfooz N S, Arregui C, Lilien J, Balsamo J and Van Berkum M F 2002 Activation of the repulsive receptor Roundabout inhibits Ncadherin-mediated cell adhesion Nat. Cell. Biol. 4 798-805

[18] Doherty P, Skaper S D, Moore S E, Leon A and Walsh F S 1992 A developmentally regulated switch in neuronal responsiveness to NCAM and N-cadherin in the rat hippocampus Development. 115 885-92

[19] Wilkemeyer M F, Menkari C E, Spong C Y and Charness M E 2002 Peptide Antagonists of Ethanol Inhibition of L1-Mediated Cell-Cell Adhesion J. Pharmacol. Exp. Ther. 303 110-6

[20] Willems J, Bruyneel E, Noe V, Slegers H, Zwijsen A, Mege R.M and Mareel M 1995 Cadherin-dependent cell aggregation is affected by decapeptide derived from rat extracellular super-oxide dismutase FEBS Letters. 363 289-92

[21] Bayarsaikhan M, Takino T, Gantulga D, Sato H, Ito T and Yoshioka K 2007 Regulation of N-cadherin-based cell-cell interaction by JSAP1 scaffold in PC12h cells Biochem. Biophys. Res. Commun. 353 357-62

[22] Kwon Y T, Gupta A, Zhou Y, Nikolic M, Tsai L H 2000 Regulation of Ncadherin-mediated adhesion by the p35-Cdk5 kinase Curr. Biol. $10363-72$

[23] Gago N, Avellana-Adalid V, Evercooren A.B, Schumacher 2003 Control of cell survival and proliferation of postnatal PSA-NCAM(+) progenitors Mol. Cell. Neurosci. 2 162-78

[24] Buitenweg J R, Rutten W L C and Marani E 2003 Geometry based finiteelement modeling of the electrical contact between a culture neuron and a microelectrode IEEE Trans. Biomed. Eng. 50 501-10

[25] Buitenweg J R, Rutten W L C, Willems W P A and van Nieuwkasteele J W 1998 Measurement of sealing resistance of cell-electrode interfaces in neuronal cultures using impedance spectroscopy Med. Biol. Eng. Comput. 36 630-637. 
[26] de Boer R W and van Oosterom A 1978 Electrical properties of platinum electrodes: impedance measurements and time-domain analysis Med. Biol. Eng. Comp. 16 1-10

[27] Romijn H J, Van Huizen F, and Wolters P S 1984 Towards an improved serum free, chemically defined medium for long term culturing of cerebral cortex tissue Neurosci. Biobehav. Rev. 8 301-44

[28] Zhernosekov D D, Nerush P A 2004 Role of Neuronal Cell Adhesion Molecules and N-Cadherin in Passive Avoidance Training of Rats Neurophysiology. 32 368-70

[29] Gascon E, Vutskits L, Kiss J Z 2008 The Role of PSA-NCAM in Adult Neurogenesis Neurochem Res.

[30] Suyama K, Shapiro I, Guttman M, Hazan R B 2002 A signaling pathway leading to metastasis is controlled by N-cadherin and the FGF receptor Cancer Cell. 2 301-14

[31] Paratcha G, Ledda F. Ibáñez C F 2003 The neural cell adhesion molecule NCAM is an alternative signaling receptor for GDNF family ligands Cell. 27 867-79

[32] Kamiguchi H, Lemmon V 1998 Neural cell adhesion molecule L1: Signaling pathways and growth cone motility $J$. Neurosci. Res. 49 1-8

[33] Azizeh B Y, Cribbs D H, Kreng V M and Cotman C W 1998 Cross-linking of NCAM receptors on neurons induces programmed cell death Brain Res. 796 20-6 


\section{Chapter 4}

\section{The inhibition of neuronal aggregation on Fibronectin, Poly-L-Lysine and Laminin coated substrates in culture}

R.W.F.Wiertz, E. Marani and W.L.C.Rutten

Neurotechnology Group/BSS, MIRA Institute, University of Twente, Enschede, The Netherlands 


\begin{abstract}
In this study we used Impedance Sensing (IS) to investigate and reduce the aggregation of neuronal cells by blocking the cell adhesion molecules N-CAM, N-Cadherin and L1.

The soluble extracellular domains of the cell adhesion molecules (CAMs) and antibodies (directed against CAMs) were investigated on their blocking abilities in neuronal cultures, which were adhered to the glass substrate using laminin, fibronectin or poly-L-lysine.

Laminin, fibronectin and poly-L-lysine are bioactive substrates, but possess limited neuron adhesive properties causing neuronal cells to adhere better to each other rather than to the substrate. This makes these biochemicals very suitable as substrates to study the inhibition of cell-cell adhesion in a neuronal culture.

Small changes in cell-cell interactions in neuronal monolayers could be monitored using impedance sensing and microscopy. Impedances of electrodes, coated with laminin and fibronectin, remained low over 144 hours of the experiment because of extensive aggregate formation. However, in the presence of $\mathrm{N}$-Cadherin antibody and protein at concentrations of 3 and $10 \mu \mathrm{g} / \mathrm{ml}$ the formation of aggregates is inhibited, causing the impedance to increase over time when neurons are allowed to adhere and spread on the substrate. The highest concentration of N-CAM antibody $(10.0 \mu \mathrm{g} / \mathrm{ml})$ also inhibits aggregation of neuronal cells cultured on laminin and fibronectin. Neurons cultured on PLL adhere better to the substrate compared to fibronectin and laminin. After 72 hours the impedance started to decrease, caused by migration and aggregation on PLL. In the presence of high concentrations of N-Cadherin antibody $(1.0,3.0$ and $10.0 \mu \mathrm{g} / \mathrm{ml})$ the impedance remains stable over the whole duration of the experiment because of the inhibitory effect on neuronal cell-cell adhesion and therefore on neuronal aggregation.
\end{abstract}




\subsection{Introduction}

Long term positioning of neuronal cells on micro-electrodes is crucial for the development of implantable neuronal probes or for electrical recording and monitoring in in vitro learning and memory studies. The success of the use of cultured neural probes depends largely on the quality of the neuron-electrode interfaces and the long term positioning of neurons on specific sites. To keep neuronal cells on predestined positions or in patterns on electrodes, it is important that neuronal cells remain as immobile as possible. The cell-substrate adhesion has to be optimal, while cell migration and aggregation caused by cell-cell adhesion should be reduced to a minimum.

In many studies the chemical modification of culturing substrates for control over neuronal migration has been investigated. For example, Ruardij et al applied neurophilic and neurophobic agents to substrates, making it possible to immobilise neuronal cells on predestined areas over a longer period of time [1-3]. However, in general, neuronal cells in culture form aggregates eventually, despite the substrate coating applied. In a previous study (chapter 3) we have chosen PEI as the neurophilic cell-substrate adhesive. In that study we investigated the effect of blocking L1, N-CAM and N-Cadherin on cell-cell adhesion and aggregation of cultured neurons (blocking with protein or antibody). By weakening cell-cell adhesion, the balance between cell-substrate and cell-cell adhesive forces can be changed. Inhibition of cell-cell adhesion will give cell-substrate adhesion a more dominant position, reducing aggregation of neuronal cells. However, several inhibitory additives showed little or no effect on cell-cell adhesion, like L1 and NCAM blockers. This may have been caused by the strong adhesive strength of PEI. In this study we replaced PEI by poly-L-lysine and the weaker adhesives fibronectin and laminin $[7,8]$. We expect that these weaker cell-substrate forces will make it easier to observe possible changes in cell-cell adhesion caused by blocking L1 and N-CAM. The difference in cell-substrate adhesiveness when comparing fibronectin and laminin with PEI and PLL is caused by the mechanism by which these biochemicals bind cells. ECM molecules bind specifically to cell adhesion molecules such as integrins [10], whereas the positively charged functional groups on PEI and PLL enable attachment of the negatively charged membrane of the neuronal cells [11]. By choosing PLL, fibronectin and laminin we are also able to compare effects of the cell-substrate binding mechanism (PEI and PLL versus fibronectin and laminin). We chose for laminin, fibronectin and PLL (besides PEI, which was investigated in a previous study), since these biochemicals are commonly applied as substrate coatings in neuronal cultures and in cultures of many other cell types. Besides, extracellular matrix molecules (laminin and fibronectin) are known to promote several cellular processes like proliferation, differentiation, axonal outgrowth and survival [4-6], also when applied as a culturing surface. These bioactive properties make it interesting to elongate the stability of the culture's topography on laminin and fibronectin through blocking of CAMs. 
From the Ig superfamily, N-CAM is the most important CAM in the CNS. N-CAM is involved in neural development, regeneration and synaptic plasticity [12]. L1 is also a member of the immunoglobulin superfamily of CAMs. [13]. The primary function of L1 appears to be formation of axon fascicles [14].

The N-Cadherins are involved in embryonic development and play a critical role during tissue differentiation [15]. The brain expresses the largest number of different cadherins, presumably due to the necessity of forming very specific cellcell contacts. The cell adhesion molecules N-CAM, N-Cadherin and L1 can be considered the three most important CAMs in the central nervous system (CNS) involved in neuron-neuron adhesion.

The blocking or knock-out of these adhesion molecules directly affects cell coherency in tissues and cell cultures. We therefore used CAM blocking as the main tools in this study for the inhibition of cell-cell adhesion. In various studies the role of N-CAM, L1 and N-Cadherin was studied both in vitro and in vivo. The in vivo blocking of CAMs in neural tissue with N-CAM and N-Cadherin antibodies seriously affects the development of that tissue [15]. Also, the blocking of L1, NCadherin or N-CAM in cultures of several different neuronal cell types shows significant inhibition of cell aggregation [16-20]. In this study we investigated the inhibition of neuronal aggregation on fibronectin, PLL and laminin by blocking L1, $\mathrm{N}-\mathrm{CAM}$ and $\mathrm{N}-\mathrm{Cadherin}$ with peptides and antibodies.

\subsubsection{Impedance Sensing}

In Impedance Sensing (IS), cells are seeded on gold micro electrodes and are subjected to AC micro currents, at several frequencies. Changes in cell-cell and cell-substrate adhesion change the electrode impedance.

The resulting impedance spectrum of a neuron-covered electrode can be analyzed using the equivalent RC-circuit of figure 1a. 

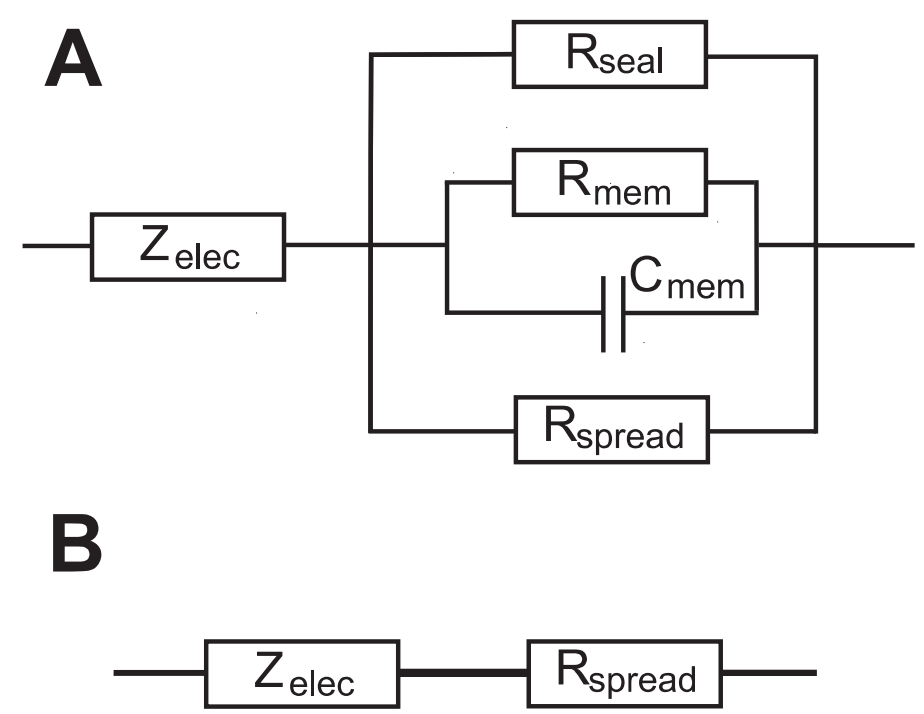

Figure 1a. The equivalent circuit of electrodes covered by cells. $Z_{\text {elec }}$ is the impedance of the electrode-electrolyte interface (Helmholtz double layer), $R_{\text {spread }}$ is the resistance of the intercellular open spaces and bulk fluid and $R_{\text {seal }}$ the sealing resistance between electrode and cell. The $R C_{\text {mem }}$ part accounts for the neuronal cell membranes. $1 \mathrm{~b}$. Simplified equivalent circuit.

This model can be modified to a simpler version, by taking the relative values of the various components into account. The relatively high membrane impedance may be neglected with respect to $R_{\text {seal }}$ and $R_{\text {spread. }}$. Also, $R_{\text {seal }}$ is very high when cells adhere tightly. The resulting circuit then only has $Z_{\text {elec }}$ in series with $R_{\text {spread }}$, resulting in the equivalent circuit in figure $1 \mathrm{~b}$.

So, finally the circuit can be modeled by

$$
Z=\frac{K}{(i \omega)^{m}}+R_{\text {spread }}
$$

In a previous study we investigated in more details the course of the impedance of several types and sizes of electrodes over time when covered with a developing neuronal culture. We showed that measurements of the real impedance at $10 \mathrm{kHz}$ were optimal for the detection of changes in cell-cell adhesion (with an electrode surface of $7850 \mu \mathrm{m}^{2}$ ).

\subsection{Methods}

\subsubsection{Planar electrode structure}

16 gold electrodes, each with a surface of $7850 \mu \mathrm{m}^{2}$, were patterned as 8 pairs on a $25 \mathrm{~cm}^{2}$ square glass plate. Glass was used as a substrate in order to have 
transparency between electrodes. Gold electrode structures were created by photolithography and reactive ion etching. An isolation layer consisting of a sandwiched $\mathrm{SiO}_{2}, \mathrm{Si}_{3} \mathrm{~N}_{4}, \mathrm{SiO}_{2}$, combination was deposited by plasma enhanced chemical vapor deposition (PECVD). A $6 \mathrm{~mm}$ thick block of PDMS with 8 round holes was adhered to the glass surface of the electrode device to create 8 wells (each $7 \mathrm{~mm}$ in diameter) for the cell cultures.

\subsubsection{Substrate coating}

The glass culturing surface, containing the gold micro electrodes, was coated with laminin, fibronectin and poly-L-lysine at concentrations of $25 \mu \mathrm{g} / \mathrm{ml}$.

\subsubsection{Cell Culturing}

Cerebral cortical neurons from newborn rats (P2) were used for all experiments in this study. Brains were taken out after decapitation, the meninges of the cortices were removed and the cortex was prepared free. The remaining cortices were collected in a tube with chemically defined R12 culture medium [21] and trypsin for chemical dissociation. After removal of trypsin $(45 \mathrm{~min}), 150 \mu \mathrm{l}$ of soybean trypsin inhibitor and $125 \mu \mathrm{l}$ of DNAse I (20.000 units, Life Technology, Carlsbad, United States) were added. A suspension of single neurons was obtained by mechanical dissociation of the cortical tissue. The neuron suspension was centrifuged at $1200 \mathrm{rpm}$ for 5 minutes. The supernatant was removed and the pellet of neurons resuspended. Neurons were plated and cultured in wells, containing the described electrodes. The neuronal cultures were kept in serum-free R12 medium under standard conditions of $37^{\circ} \mathrm{C}$ and $5 \% \mathrm{CO}_{2}$ in air. A cell concentration of approximately $10^{6}$ cells $/ \mathrm{cm}^{2}$ was used in all experiments. During measurements the neuron cultures were placed into a small incubator keeping the temperature at $37^{\circ} \mathrm{C}$.

\subsubsection{Inhibition of cell-cell adhesion}

Neuron to neuron adhesion was inhibited by adding the soluble extracellulair domains of N-Cadherin, N-CAM or L1. In case of N-Cadherin and L1, these proteins were fused to the $\mathrm{Fc}$ region of human $\mathrm{IgG}$ via a peptide linker. Antibodies targeting the adhesive regions of mentioned cell adhesion molecules were also used for the inhibition of the adhesion.

$\mathrm{N}$-Cadherin and N-CAM antibody as well as N-Cadherin and N-CAM peptide were added to the culturing solution after 6 hours (when cells adhered well to the culturing substrate) at resulting end concentrations of $0.1,0.3,1.0,3.0$ and 10.0 $\mu \mathrm{g} / \mathrm{ml}$. L1 antibody and peptide were added at the same time in a concentration range of $0.3,1.0,3.0,10.0,30.0 \mu \mathrm{g} / \mathrm{ml}$. Buffer solutions of the peptides and of the antibodies were used as control.

Six pups from three rats (two pups per rat) were used to perform the experiments. From each pup 6 well-platings were made, as described above (5 different concentrations and 1 control). This was done for each antibody or peptide. 


\subsubsection{IS Measurement Setup}

All impedance measurements were carried out using a programmable signal source (HP 4194A), a home-built impedance measuring circuit and a data acquisition system in a Labview environment. This setup was used in combination with cell culturing chambers containing the planar gold electrodes. The cultures were kept at $37^{\circ} \mathrm{C}$ under sterile conditions during measurements on a NIKON DIAPHOT inverted microscope. Applied frequencies were chosen at $10.000 \mathrm{~Hz}$. The measurements were controlled by the same computer that recorded and saved the real and imaginary part of the impedance.

Cultures were monitored during their development, starting shortly before cell plating $(\mathrm{t}=0)$ of the electrodes, until 144 hours. From 0 hours on, electrodes were monitored every 12 hours in which 5 repeated impedance spectra were obtained with an interval of 1 minute, on all devices $(\mathrm{N}=6)$.

\subsubsection{Imaging technique}

The neuronal coverage of the electrodes was determined by taking the visible area directly surrounding the electrodes as representative for the electrode area itself (which lacked the transparency for direct optical monitoring). Percentage of coverage was determined by converting digital color photographs into 8-bit grayscale photographs using CorelDraw software. The histogram of the grayscale photograph was used for segmentation of the picture into a black-and-white photo. The ratio of the number of black to white pixels is the percentage of the electrode area covered by cells. Pictures of the electrode areas were made after every impedance measurement. Areas of $200 \times 200 \mu \mathrm{m}$ were taken at 4 different positions. The average percentage of coverage at these 4 areas was calculated.

\subsection{Results}

\subsubsection{Impedance measurements during inhibition of cell-cell adhesion}

During 144 hours, the impedance of neuron covered gold electrodes was monitored at frequencies of $5,10,50,100,500,1000,10.000$ and $20.000 \mathrm{~Hz}$. The real impedance at $10.000 \mathrm{~Hz}$ showed to be most affected by cell coverage and change in culture morphology.

In figure 2 comparison between PEI, laminin, PLL and fibronectin can be seen. PEI has better neurophilic properties, especially over longer periods. The brown line represents the real impedance of fibronectin coated electrodes covered by developing cultures (at a frequency of $10.000 \mathrm{~Hz}$ ). In the first 12 hours of the experiment, neuronal cells attached randomly on the surface and spread out. The impedance of the electrode rises when being increasingly covered by neuronal cells. After the first 12 hours the impedance decreases immediately, reaching the same impedance of a non covered electrode after 48 hours. This effect is caused by the aggregation of neuronal cells leaving the electrodes partially or completely uncovered. When laminin is used as a substrate coating (figure 2), the course of the impedance resembles that of fibronectin coated electrodes. Impedance increases, 
but less than fibronectin. After 60 hours the impedance equaled that of a non covered electrode. The coverage of the electrode area reaches approximately $60 \%$ for both fibronectin and laminin coated substrates. This decreases to a level between 35 and $45 \%$ coverage for fibronectin (figure 3-8, green line) and around $35 \%$ for laminin (figure $15-20$, green line). This coverage is not equally dispersed over the substrate, but more clustered, caused by aggregation of neurons (data not shown). Neurons cultured on PLL (figure 2) don't cluster before 120 hours. Impedance of electrodes coated with PLL increases from the moment of cell seeding until 72 hours. After 72 hours the impedance decreases. The substrate coverage starts to decrease after 96 hours.

The presence of L1 antibody had no effect on the real impedance or the substrate coverage for any of the substrate coatings (figure 3, 9 and 15). Figures 4, 10 and 16 display a comparable result for L1 protein. In contrast, concentrations of 3.0 and $10.0 \mu \mathrm{g} / \mathrm{ml} \mathrm{N}$-Cadherin protein significantly increase the real impedance of fibronectin coated electrodes covered with neurons. This is not always represented by substrate coverage (right axis displays surface coverage). On PLL, neurons have less effect on the impedance in the presence of $\mathrm{N}$-Cadherin protein at concentrations of 1.0 and $3.0 \mu \mathrm{g} / \mathrm{ml}$ between 48 and 72 hours (figure 12). Surprisingly, the presence of N-Cadherin protein at a concentration of $10.0 \mu \mathrm{g} / \mathrm{ml}$ causes cell death after 36 hours, causing the impedance and the substrate coverage to decrease drastically. On laminin the effect is opposite (figure 18). The impedance remains higher at $10.0 \mu \mathrm{g} / \mathrm{ml} \mathrm{N}$-Cadherin protein. Cells don not adhere to one another, preventing aggregation, which causes better electrode coverage.

Like N-Cadherin protein, high concentrations of N-Cadherin antibody affect the impedance of neuron covered electrodes. The impedances of PLL coated electrodes remain rather constant in the presence of $\mathrm{N}$-Cadherin antibody at concentrations of 3.0 and $10.0 \mu \mathrm{g} / \mathrm{ml}$. Until 72 hours, low concentrations of N-Cadherin antibody cause higher impedances when comparing to high concentrations of $\mathrm{N}$-Cadherin antibody. However, at low concentration of N-Cadherin antibody the impedance drops substantially after 84 hours, while the impedances at higher concentrations remain constant. Aggregation of neuronal cells is inhibited by high concentrations of N-Cadherin antibody, causing a higher impedance and cell coverage after 84 hours (figure 11). On fibronectin and laminin the effect of soluble N-Cadherin antibody is similar to that of $\mathrm{N}$-Cadherin protein, only stronger (figure 5 and 17). High concentrations of $\mathrm{N}$-Cadherin antibody inhibit neuronal aggregation, resulting in higher impedance and substrate coverage.

Comparable to both the L1 blockers, N-CAM antibody displays no effect on the impedance of neuron covered electrode or on the surface coverage when applied in combination with one of the 3 substrate coatings (figure 7, 13 and 19). In contrast, decrease of real impedance caused by high N-CAM protein concentrations is eminent in combination with PLL. After addition of the blocker at concentrations of $3.0 \mu \mathrm{g} / \mathrm{ml}$ and $10.0 \mu \mathrm{g} / \mathrm{ml}$ the real impedance and the surface coverage stay on a relatively constant level up till 48 hours, after which both the real impedance and the surface coverage decrease drastically. This effect is caused by neuronal cell 
death. On both laminin and fibronectin a concentration of $10.0 \mu \mathrm{g} / \mathrm{ml} \mathrm{N}-\mathrm{CAM}$ protein caused a slight inhibition of neuronal aggregation. Table 1 gives an overview of the blocking effect of L1, N-Cadherin and N-CAM (highest concentration peptides and antibodies) on PLL, fibronectin, laminin and PEI coated surfaces.

\section{PEI vs laminin, PLL and fibronectin}

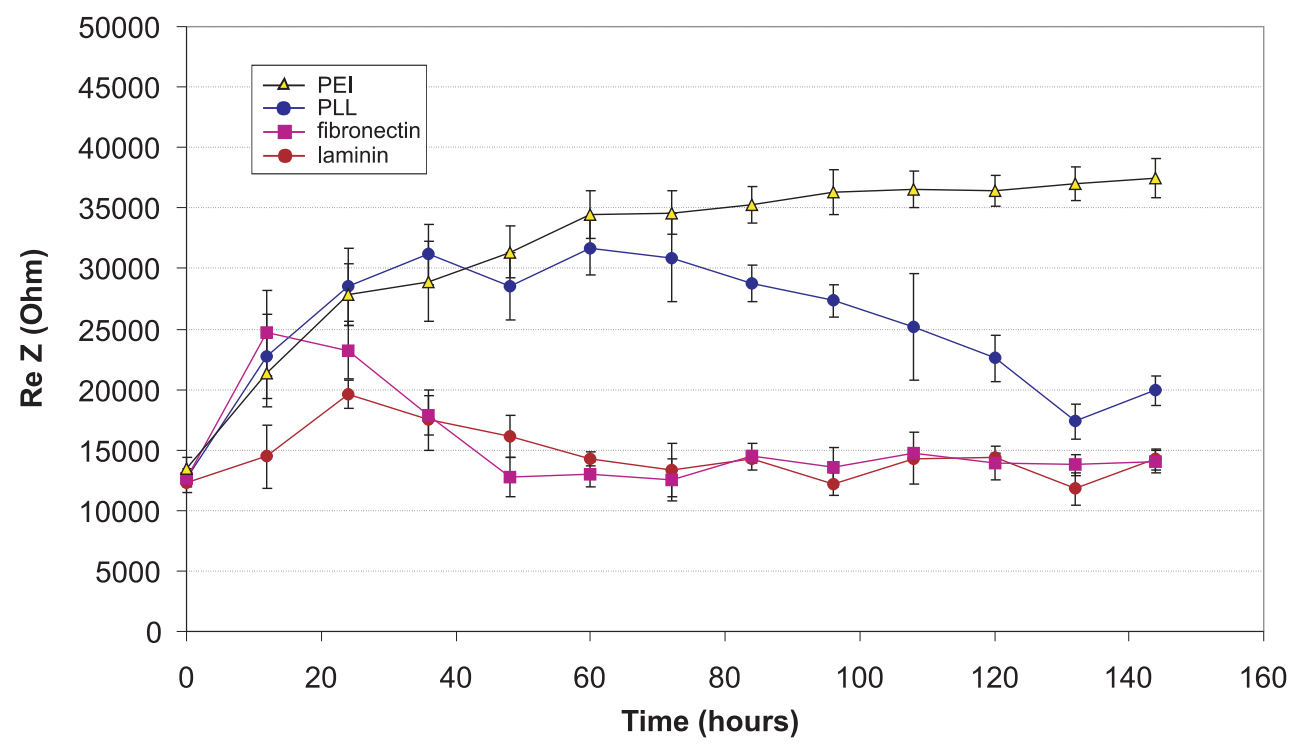

Figure 2. The real impedance during development of neuronal cultures on top of $7850 \mu^{2}$ gold electrodes measured at a frequency of $10 \mathrm{kHz}$. Comparison between PEI, Laminin, PLL and fibronectin as substrate coatings. $N=6$. 


\section{Fibronectin}
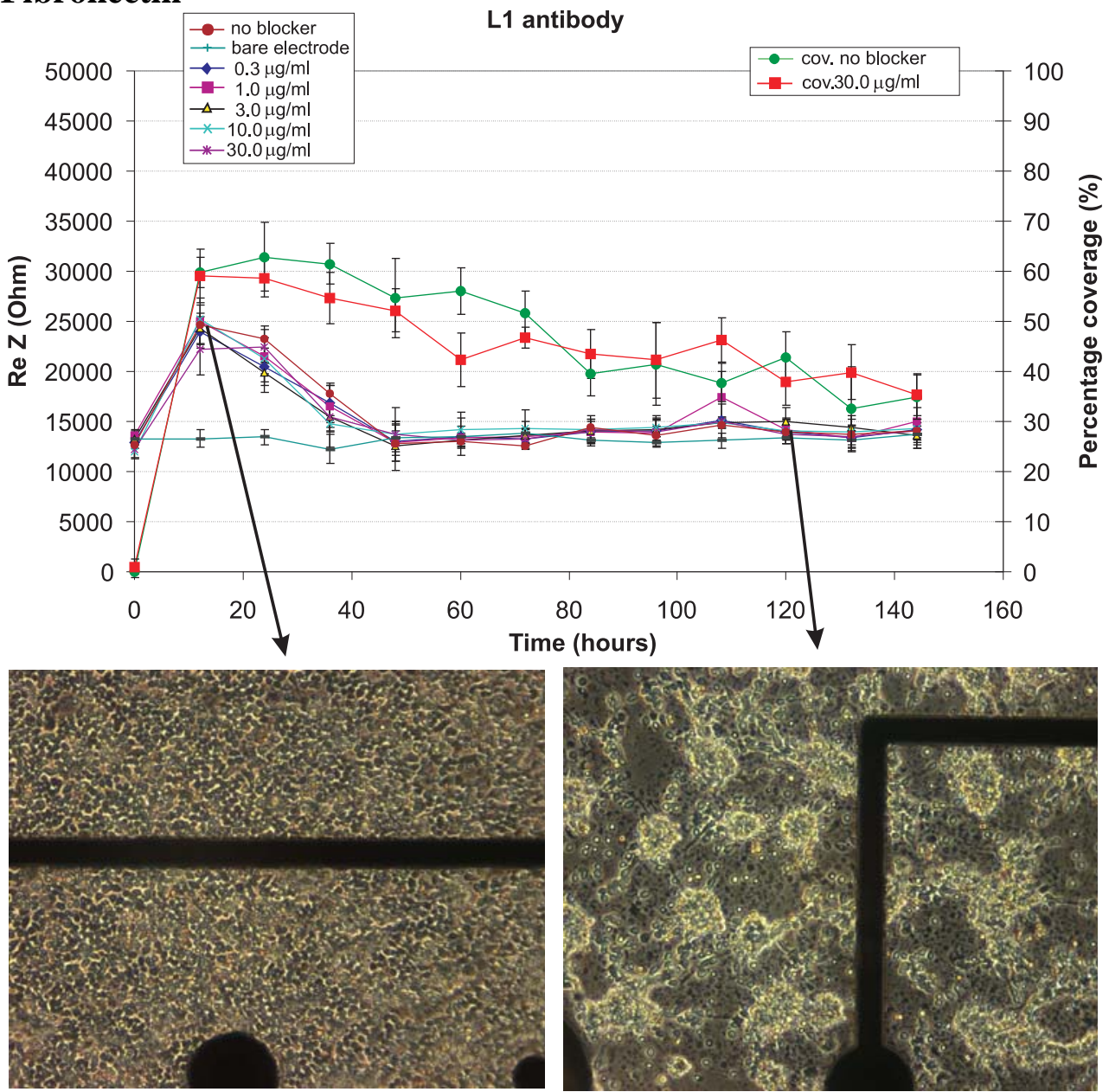

Figure 3, upper part. Real impedance during development of a neuronal culture on top of an 7850 ${\mu \mathrm{m}^{2}}^{2}$ gold electrode coated with fibronectine in the presence of L1 antibody at concentrations of $0,0.3$, 1.0, 3.0, 10.0, and $30.0 \mu \mathrm{g} / \mathrm{ml}$. Percentage cell coverage on right axis and real impedance on left axis at a frequency of $10 \mathrm{kHz} . N=6$. Lower part left $=$ no blocker, 12 hours. Lower part right $=$ no blocker 120 hours. 
Fibronectin

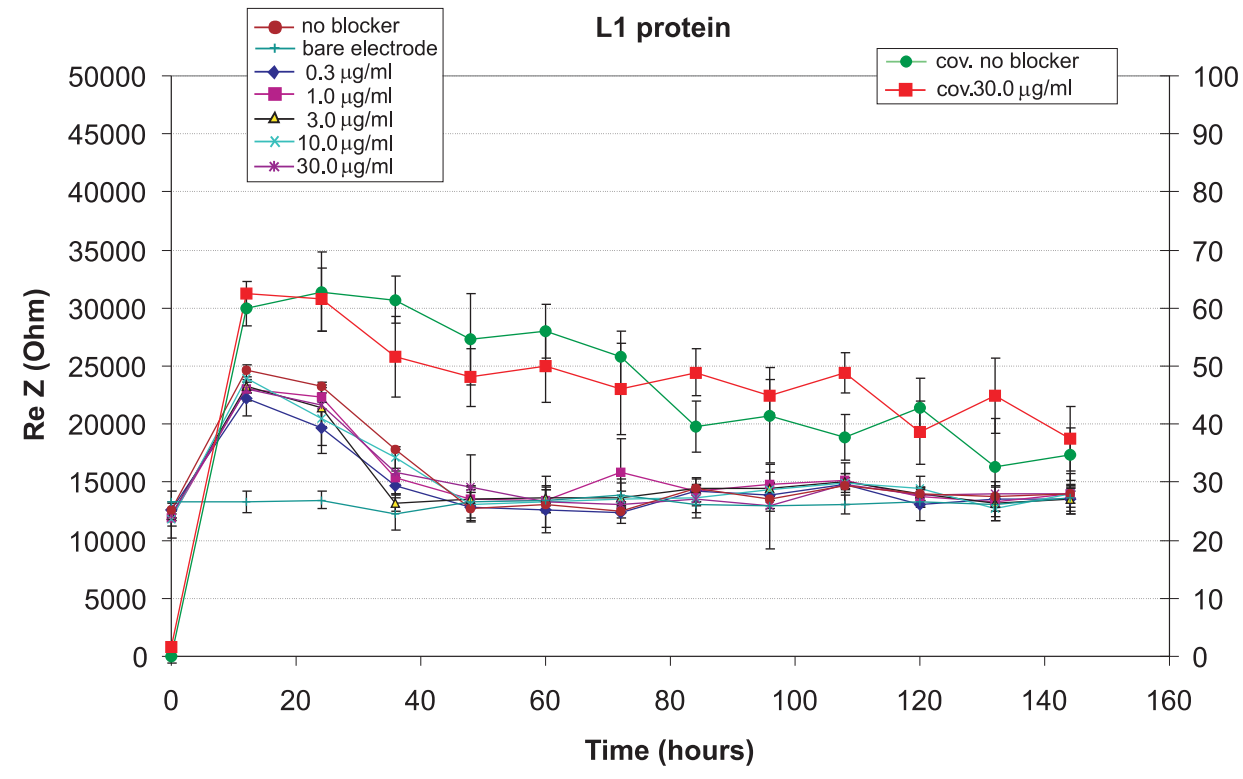

Figure 4. Real impedance during development of a neuronal culture on top of an $7850 \mu^{2}$ gold electrode coated with fibronectin in the presence of L1 protein at concentrations of 0, 0.3, 1.0, 3.0, 10.0 , and $30.0 \mu \mathrm{g} / \mathrm{ml}$. Percentage cell coverage on right axis and real impedance on left axis at a frequency of $10 \mathrm{kHz} . \mathrm{N}=6$. 


\section{Fibronectin}
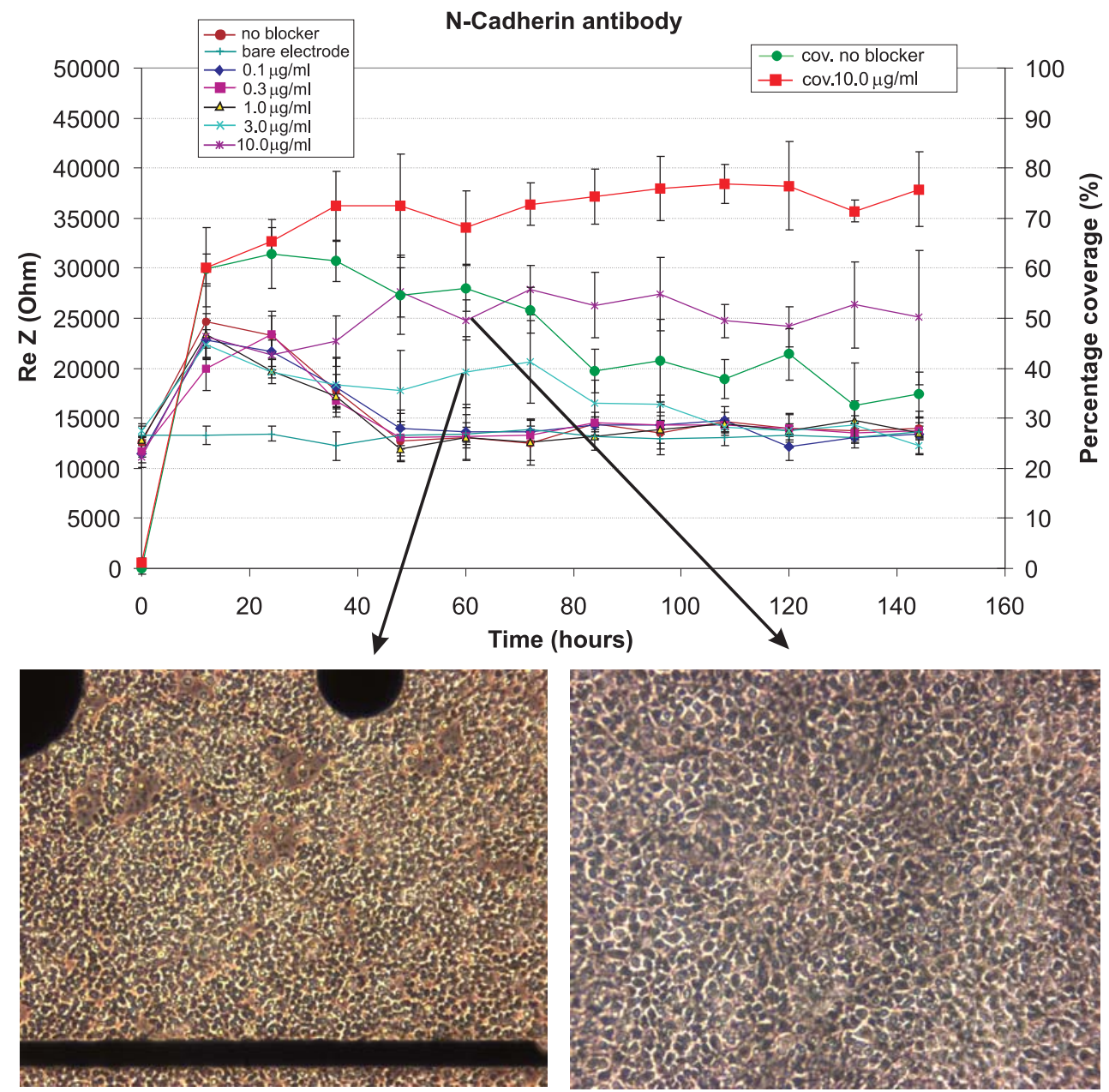

Figure 5, upper part. Real impedance during development of a neuronal culture on top of an 7850 $\mu^{2}$ gold electrode coated with fibronectin in the presence of $\mathrm{N}$-Cadherin antibody at concentrations of $0,0.1,0.3,1.0,3.0$ and $10.0 \mu \mathrm{g} / \mathrm{ml}$. Percentage cell coverage on right axis and real impedance on left axis at a frequency of $10 \mathrm{kHz} . N=6$. Lower part left = blocking with $3.0 \mu \mathrm{g} / \mathrm{ml} \mathrm{N-Cad} \mathrm{ab,60}$ hours and lower part right $=$ blocking with $10.0 \mu \mathrm{g} / \mathrm{ml} \mathrm{N}$-Cad ab at 60 hours. 
Fibronectin

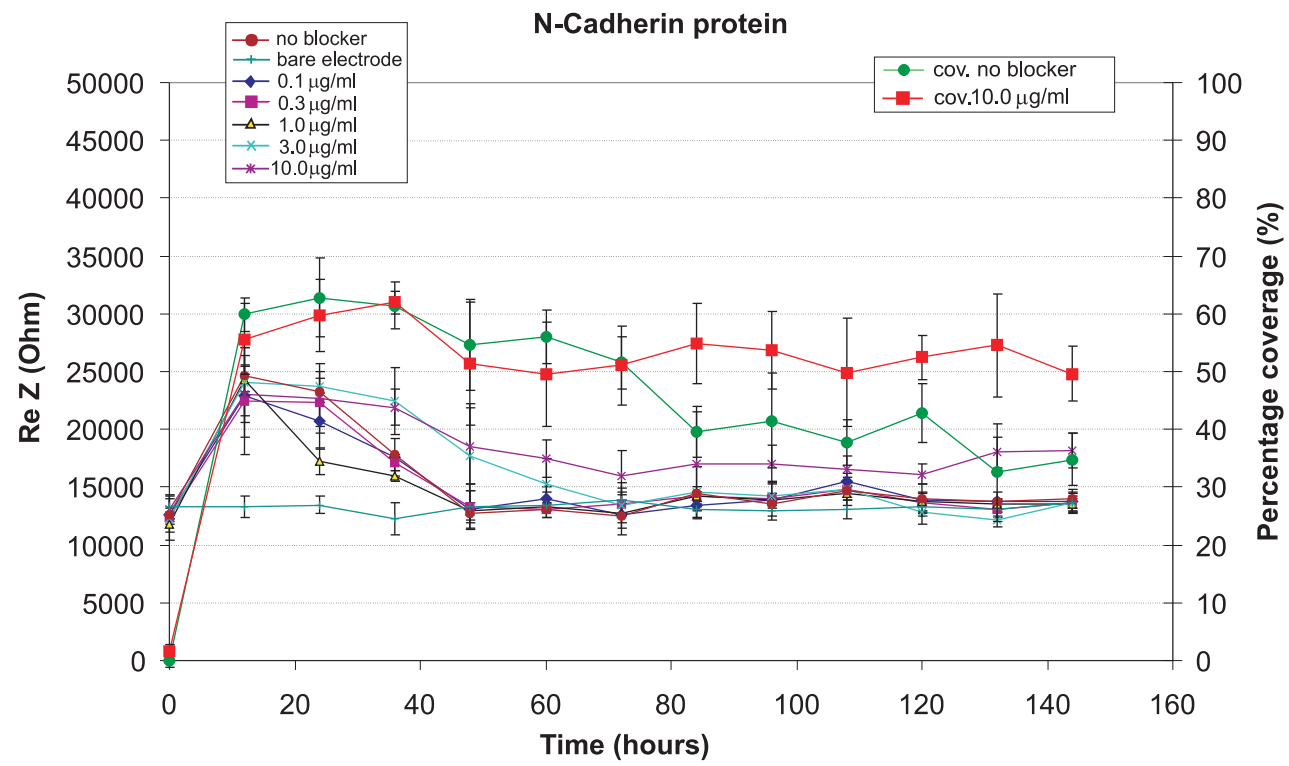

Figure 6. Real impedance during development of a neuronal culture on top of an $7850 \mu^{2}$ gold electrode coated with fibronectin in the presence of $\mathrm{N}$-Cadherin protein at concentrations of $0,0.1$, $0.3,1.0,3.0$ and $10.0 \mu \mathrm{g} / \mathrm{ml}$. Percentage cell coverage on right axis and real impedance on left axis at a frequency of $10 \mathrm{kHz} . \mathrm{N}=6$. 


\section{Fibronectin}
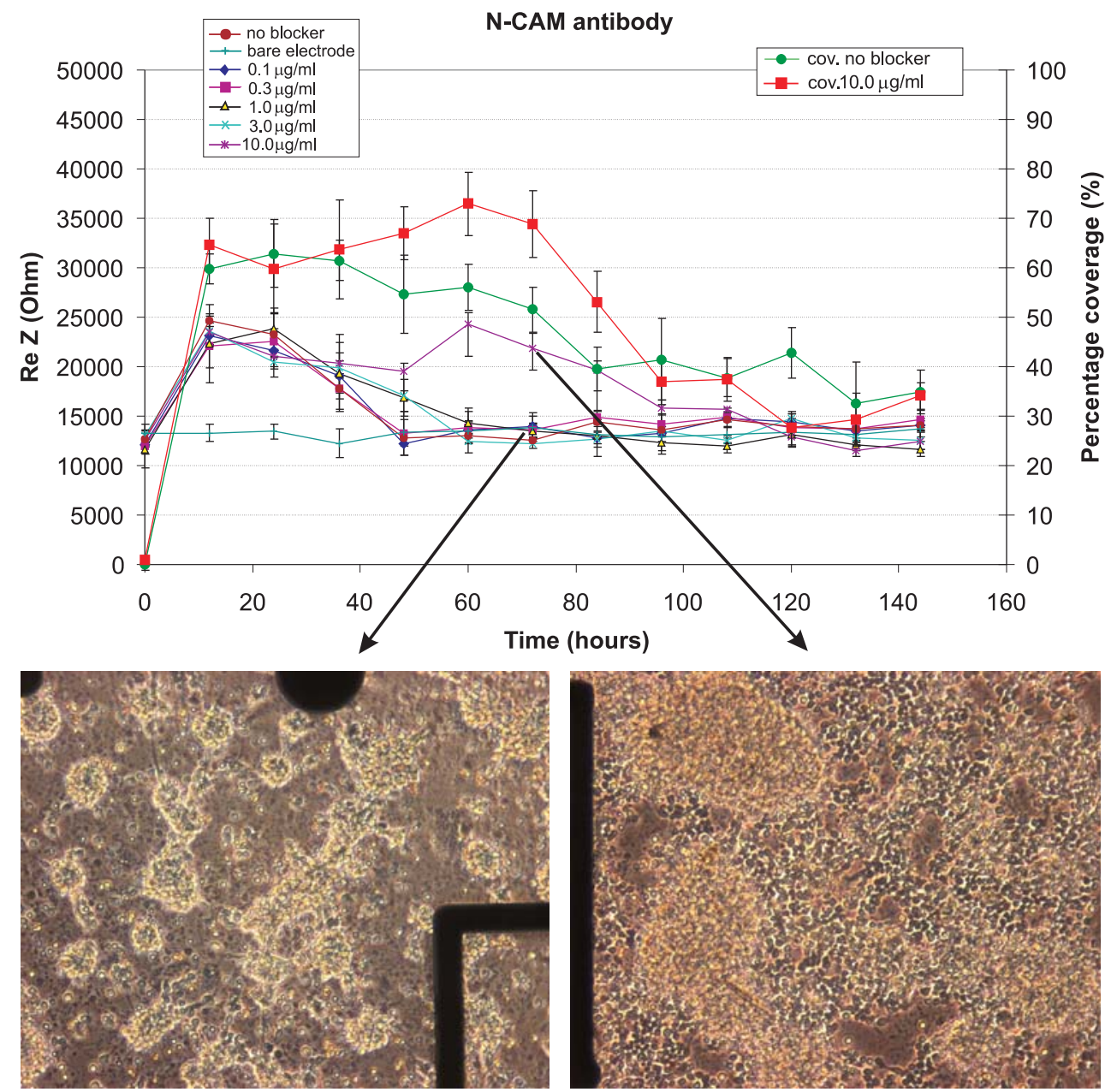

Figure 7, upper part. Real impedance during development of a neuronal culture on top of an 7850 $\mathrm{\mu m}^{2}$ gold electrode coated with fibronectin in the presence of $\mathrm{N}$-CAM antibody at concentrations of 0 , $0.1,0.3,1.0,3.0$ and $10.0 \mu \mathrm{g} / \mathrm{ml}$. Percentage cell coverage on right axis and real impedance on left axis at a frequency of $10 \mathrm{kHz} . N=6$. Lower part left = blocking with $1.0 \mu \mathrm{g} / \mathrm{ml} \mathrm{N}-\mathrm{CAM} \mathrm{ab}, 72$ hours and lower part right $=$ blocking with $10.0 \mu \mathrm{g} / \mathrm{ml} \mathrm{N-CAM} \mathrm{ab}$ at 72 hours. 
Fibronectin

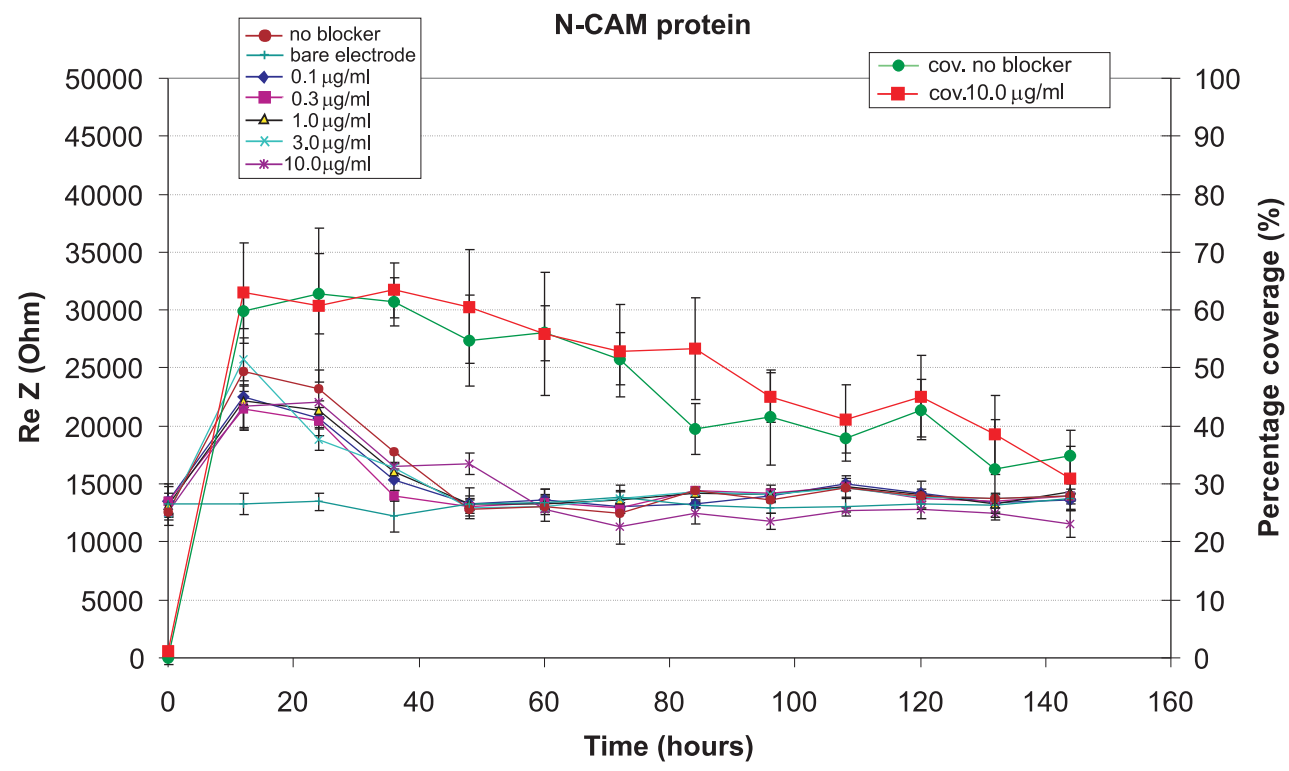

Figure 8. Real impedance during development of a neuronal culture on top of an $7850 \mu^{2}$ gold electrode coated with fibronectin in the presence of $N$-CAM protein at concentrations of $0,0.1,0.3$, $1.0,3.0$ and $10.0 \mu \mathrm{g} / \mathrm{ml}$. Percentage cell coverage on right axis and real impedance on left axis at a frequency of $10 \mathrm{kHz} . \mathrm{N}=6$. 


\section{Poly-L-Lysine}
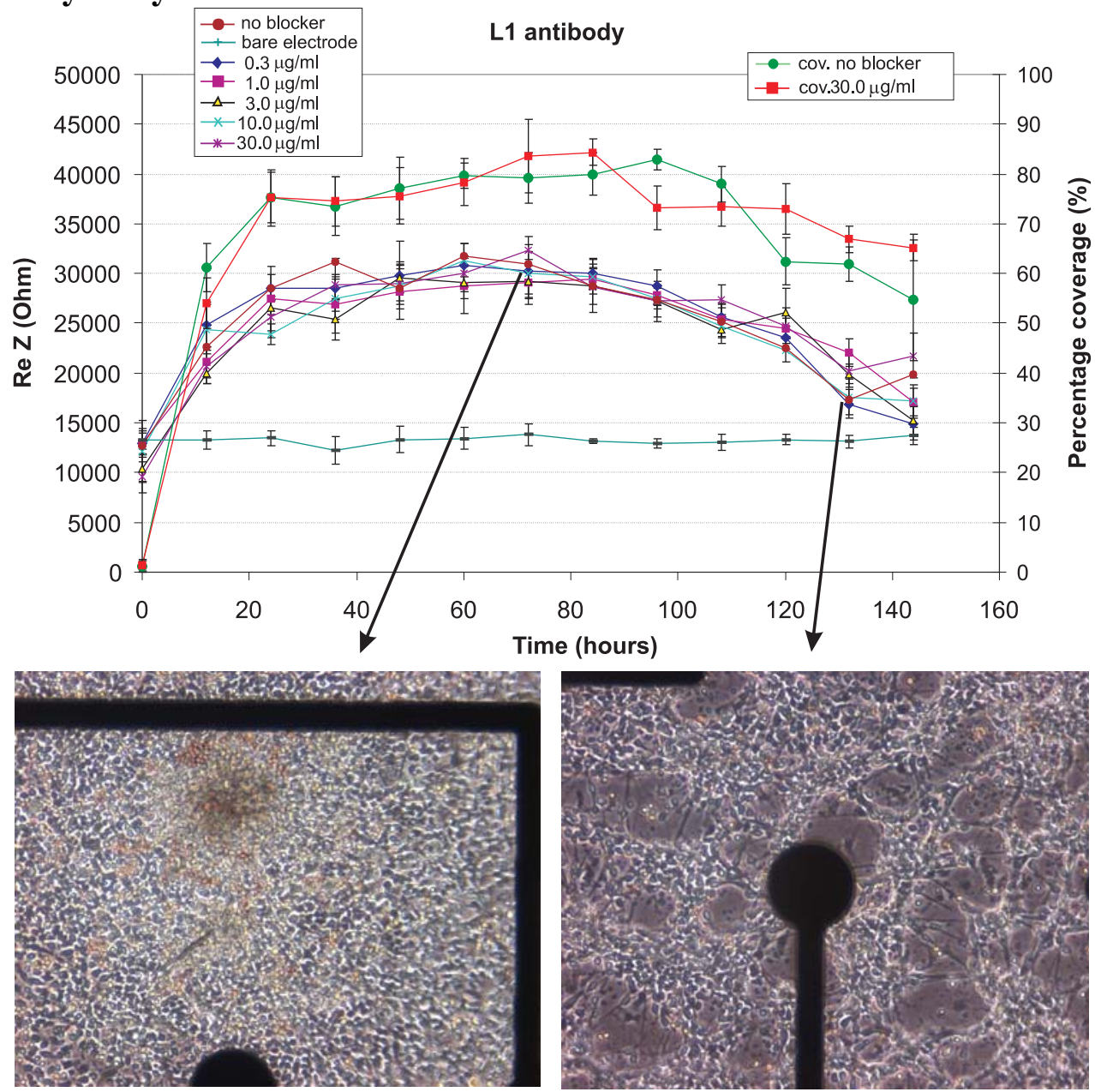

Figure 9, upper part. Real impedance during development of a neuronal culture on top of an 7850 $\mu^{2}$ gold electrode coated with poly-L-lysine in the presence of L1 antibody at concentrations of 0 , $0.3,1.0,3.0,10.0$, and $30.0 \mu \mathrm{g} / \mathrm{ml}$. Percentage cell coverage on right axis and real impedance on left axis at a frequency of $10 \mathrm{kHz} . N=6$. Lower part left $=$ no blocker, 72 hours and lower part right $=$ no blocker 132 hours. 


\section{Poly-L-Lysine}

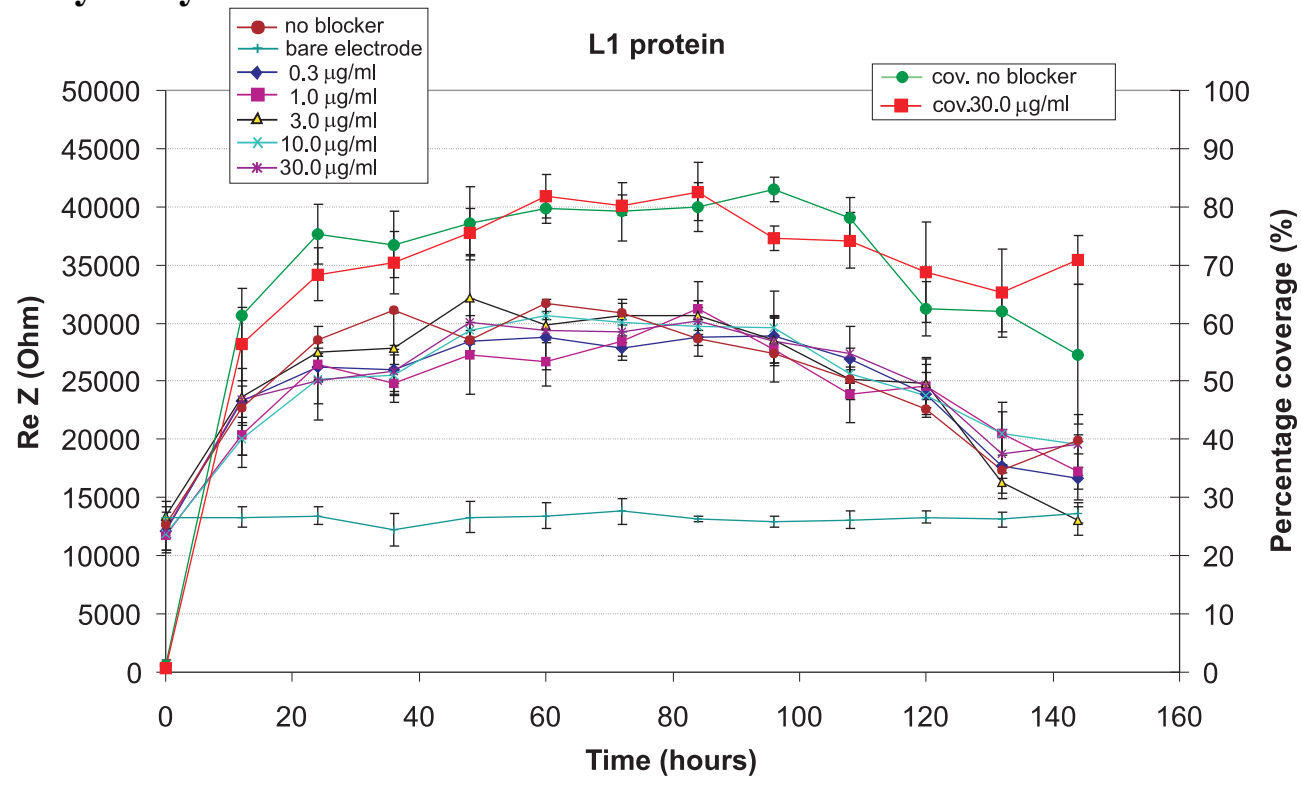

Figure 10. Real impedance during development of a neuronal culture on top of an $7850 \mu^{2}$ gold electrode coated with poly-L-lysine in the presence of L1 protein at concentrations of 0, 0.3, 1.0, 3.0, 10.0 , and $30.0 \mu \mathrm{g} / \mathrm{ml}$. Percentage cell coverage on right axis and real impedance on left axis at a frequency of $10 \mathrm{kHz} . \mathrm{N}=6$. 


\section{Poly-L-Lysine}
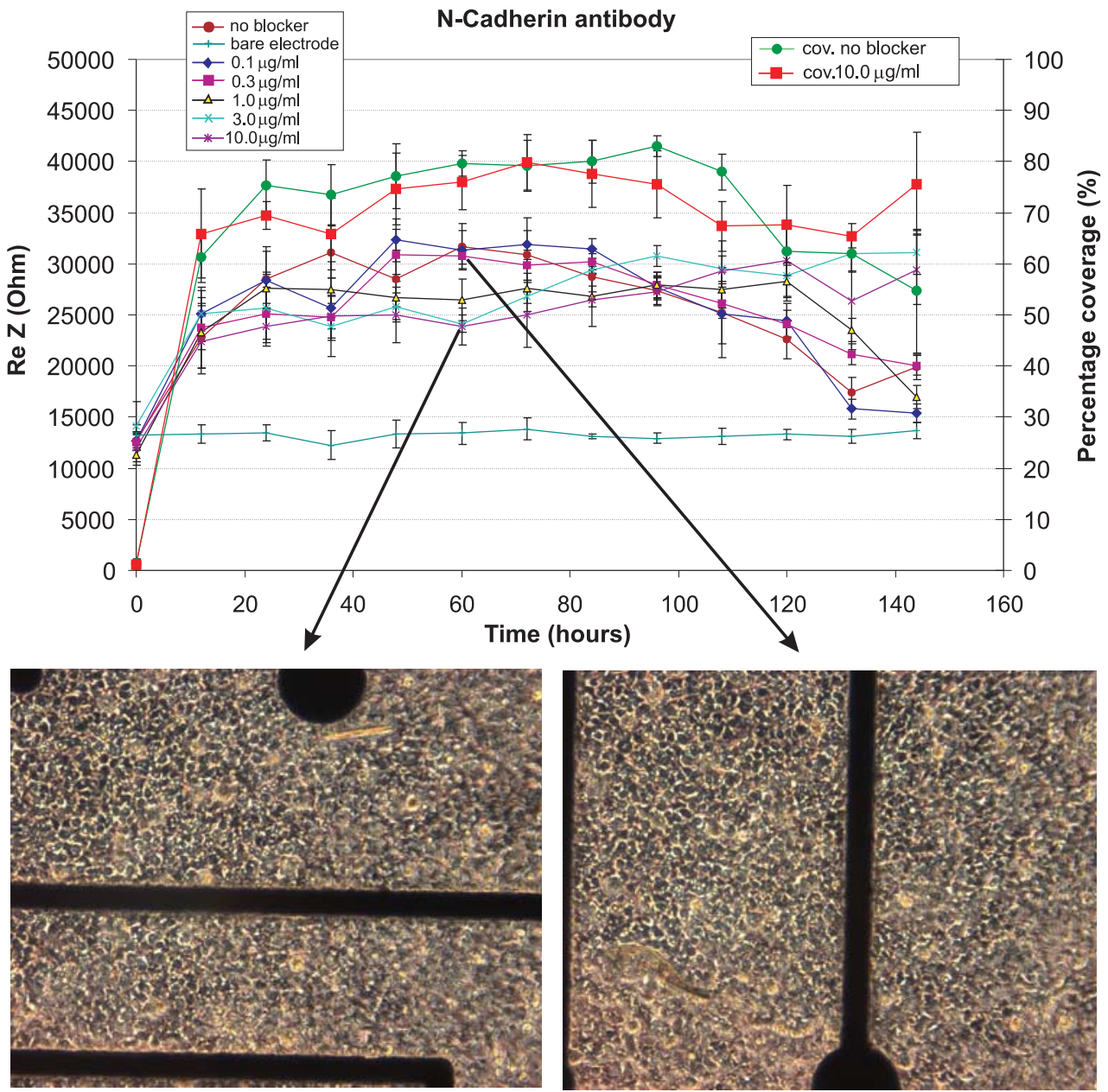

Figure 11, upper part. Real impedance during development of a neuronal culture on top of an 7850 $\mu^{2}$ gold electrode coated with poly-L-lysine in the presence of $N$-Cadherin antibody at concentrations of $0,0.1,0.3,1.0,3.0$ and $10.0 \mu \mathrm{g} / \mathrm{ml}$. Percentage cell coverage on right axis and real impedance on left axis at a frequency of $10 \mathrm{kHz} . \mathrm{N}=6$. Lower part left $=$ blocking with $10.0 \mu \mathrm{g} / \mathrm{ml} \mathrm{N}$ Cad ab, 60 hours and lower part right $=$ no blocker at 60 hours. 


\section{Poly-L-Lysine}
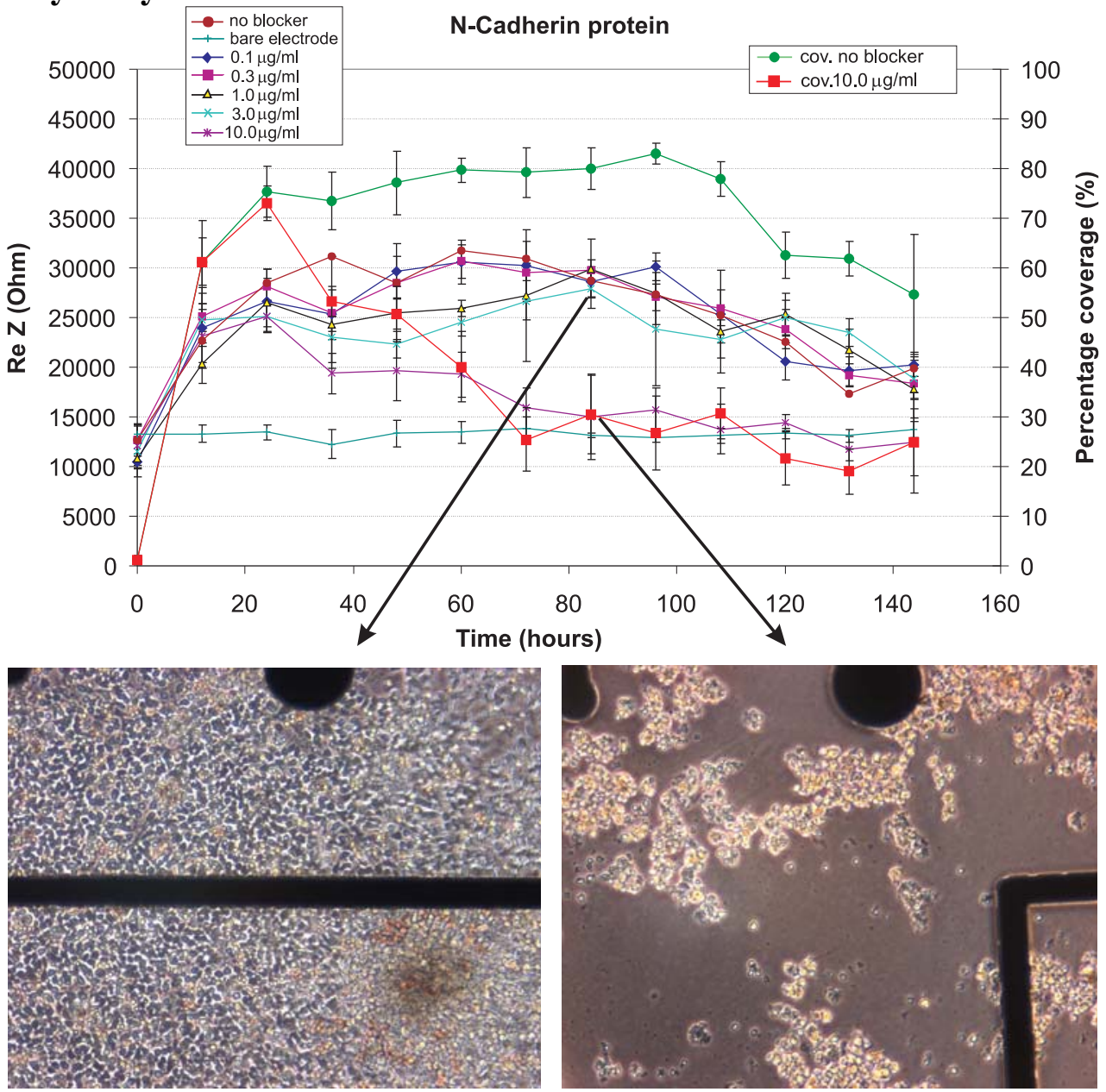

Figure 12, upper part. Real impedance during development of a neuronal culture on top of an 7850 ${\mu \mathrm{m}^{2}}^{2}$ gold electrode coated with poly-L-lysine in the presence of $\mathrm{N}$-Cadherin protein at concentrations of $0,0.1,0.3,1.0,3.0$ and $10.0 \mu \mathrm{g} / \mathrm{ml}$. Percentage cell coverage on right axis and real impedance on left axis at a frequency of $10 \mathrm{kHz} . N=6$. Lower part left $=$ blocking with $3.0 \mu \mathrm{g} / \mathrm{ml} \mathrm{N}$-Cad protein, 84 hours and lower part right $=$ blocking with $10.0 \mu \mathrm{g} / \mathrm{ml} \mathrm{N}$-Cad protein at 84 hours. 


\section{Poly-L-Lysine}

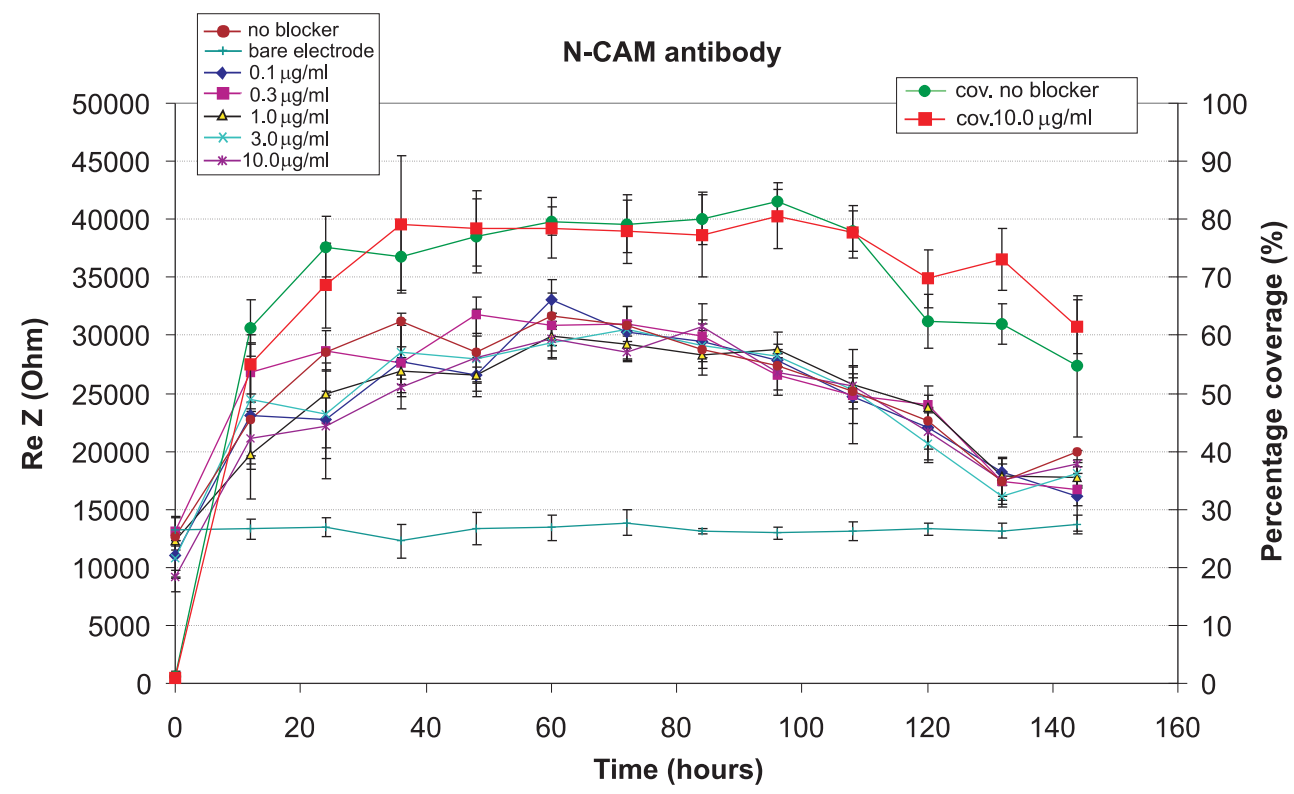

Figure 13. Real impedance during development of a neuronal culture on top of an $7850 \mu^{2}$ gold electrode coated with poly-L-lysine in the presence of $N$-CAM antibody at concentrations of $0,0.1$, $0.3,1.0,3.0$ and $10.0 \mu \mathrm{g} / \mathrm{ml}$. Percentage cell coverage on right axis and real impedance on left axis at a frequency of $10 \mathrm{kHz} . \mathrm{N}=6$. 


\section{Poly-L-Lysine}
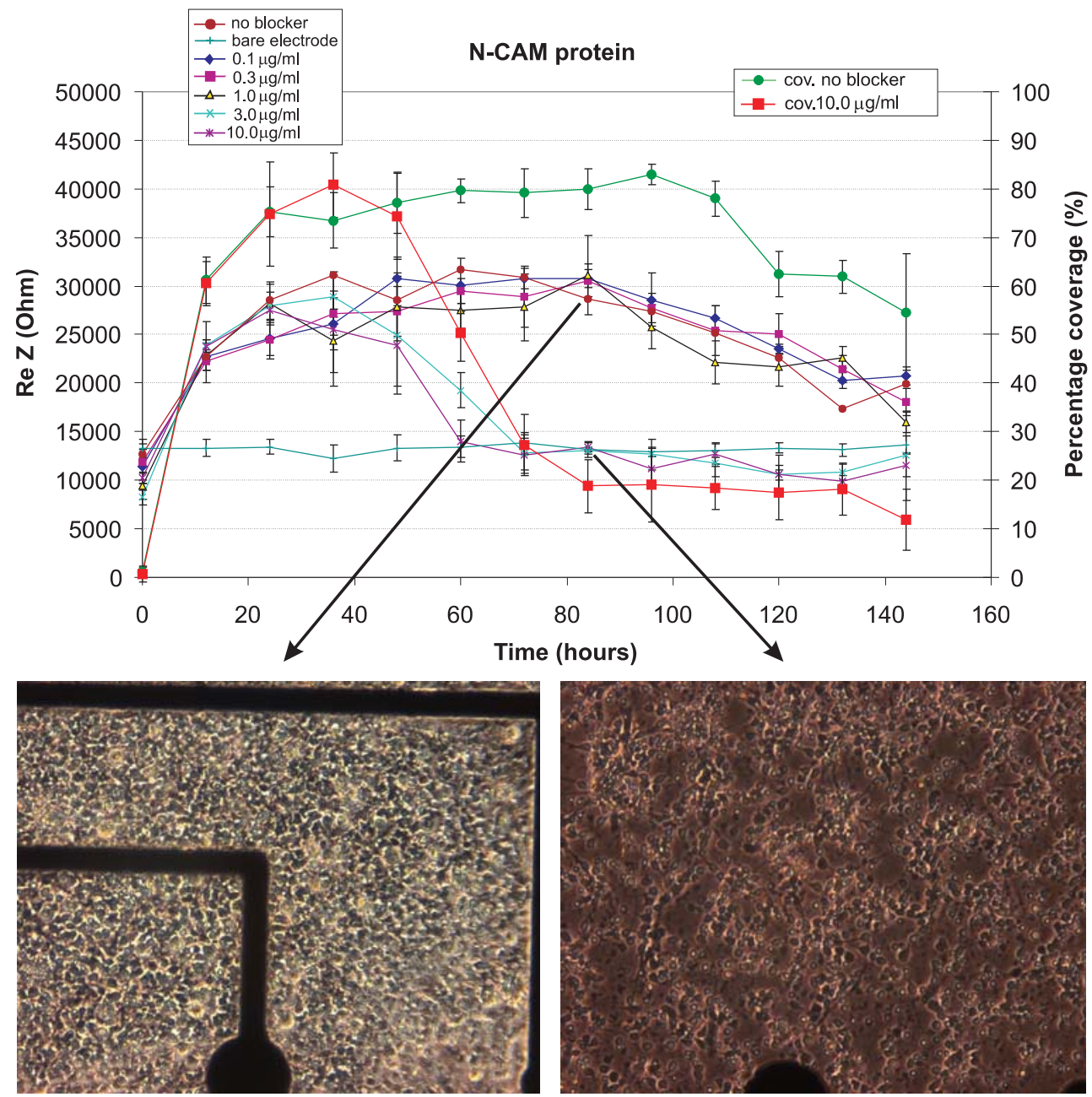

Figure 14, upper part. Real impedance during development of a neuronal culture on top of an 7850 ${\mu \mathrm{m}^{2}}^{2}$ gold electrode coated with poly-L-lysine in the presence of $\mathrm{N}-\mathrm{CAM}$ protein at concentrations of $0,0.1,0.3,1.0,3.0$ and $10.0 \mu \mathrm{g} / \mathrm{ml}$. Percentage cell coverage on right axis and real impedance on left axis at a frequency of $10 \mathrm{kHz}$. N=6. Lower part left $=$ no blocker, 84 hours and lower part right $=$ blocking with $10.0 \mu \mathrm{g} / \mathrm{ml} \mathrm{N}-\mathrm{CAM}$ ab at 84 hours. 


\section{Laminin}
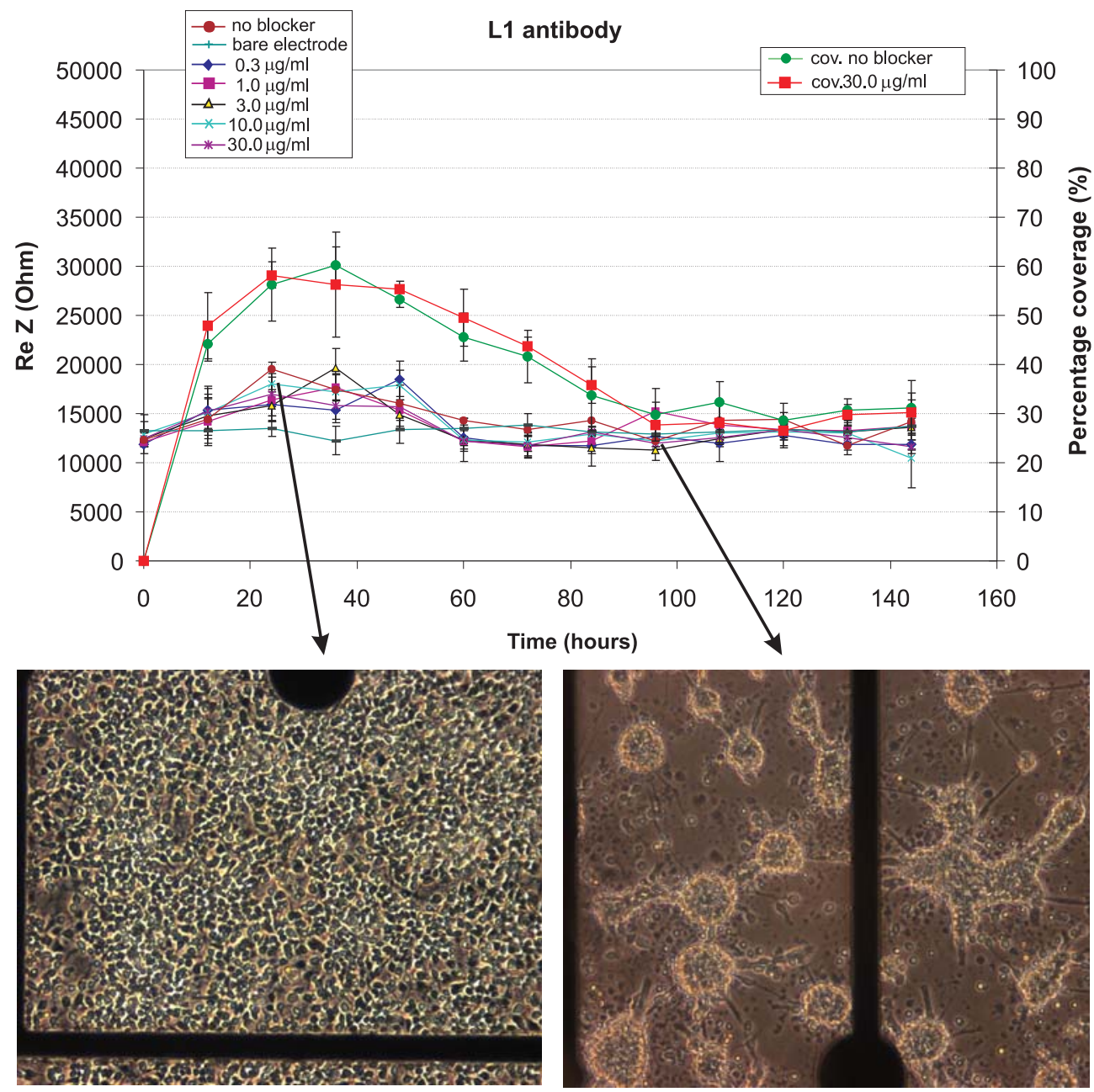

Figure 15, upper part. Real impedance during development of a neuronal culture on top of an 7850 $\mu^{2}$ gold electrode coated with laminin in the presence of L1 antibody at concentrations of 0, 0.3, 1.0, $3.0,10.0$, and $30.0 \mu \mathrm{g} / \mathrm{ml}$. Percentage cell coverage on right axis and real impedance on left axis at a frequency of $10 \mathrm{kHz} . N=6$. Lower part left $=$ no blocker, 24 hours and lower part right $=$ blocking with $10.0 \mu \mathrm{g} / \mathrm{ml} \mathrm{L1}$ ab at 96 hours. 


\section{Laminin}

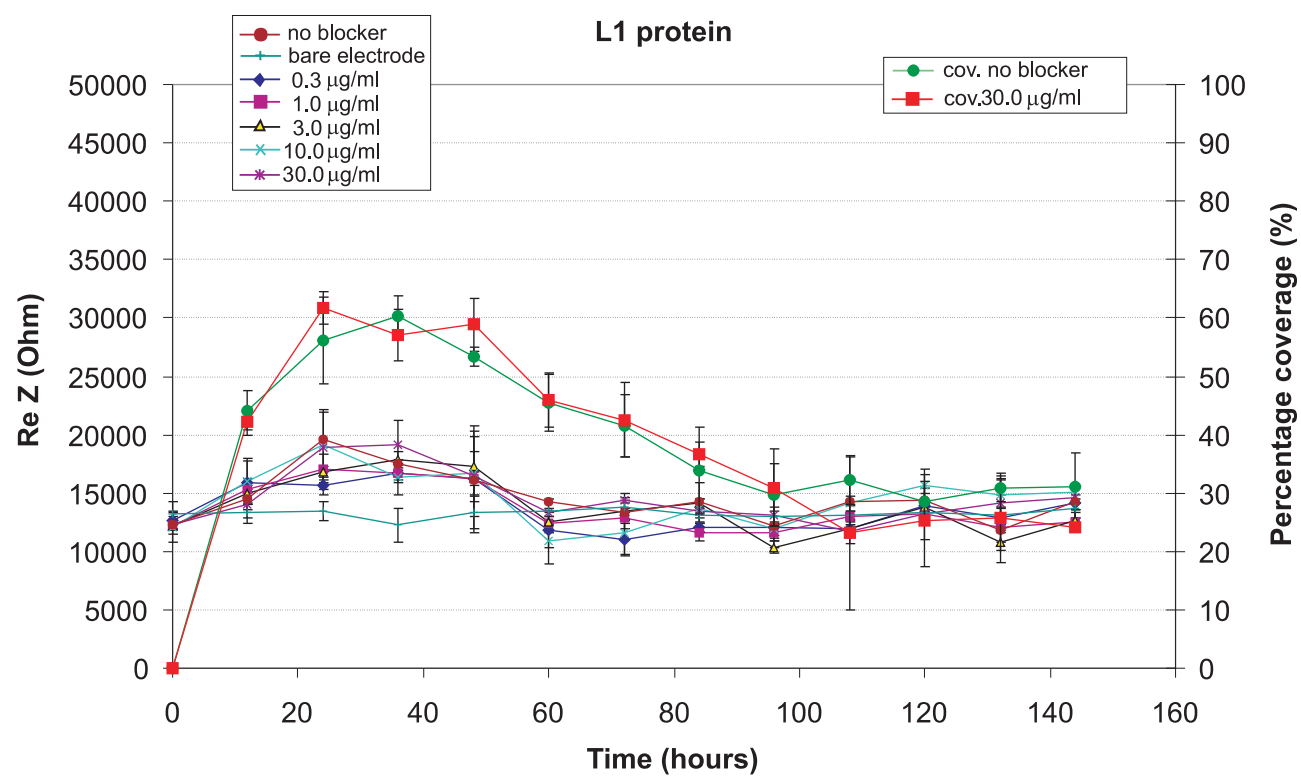

Figure 16. Real part of the impedance during development of a neuronal culture on top of an 7850 $\mu^{2}$ gold electrode coated with laminin under influence of L1 protein at concentration of $0,0.3,1.0$, 3.0, 10.0, and $30.0 \mu \mathrm{g} / \mathrm{ml}$. Percentage cell coverage on right axis and real impedance on left axis at frequencies of $10 \mathrm{kHz} . \mathrm{N}=6$. 


\section{Laminin}
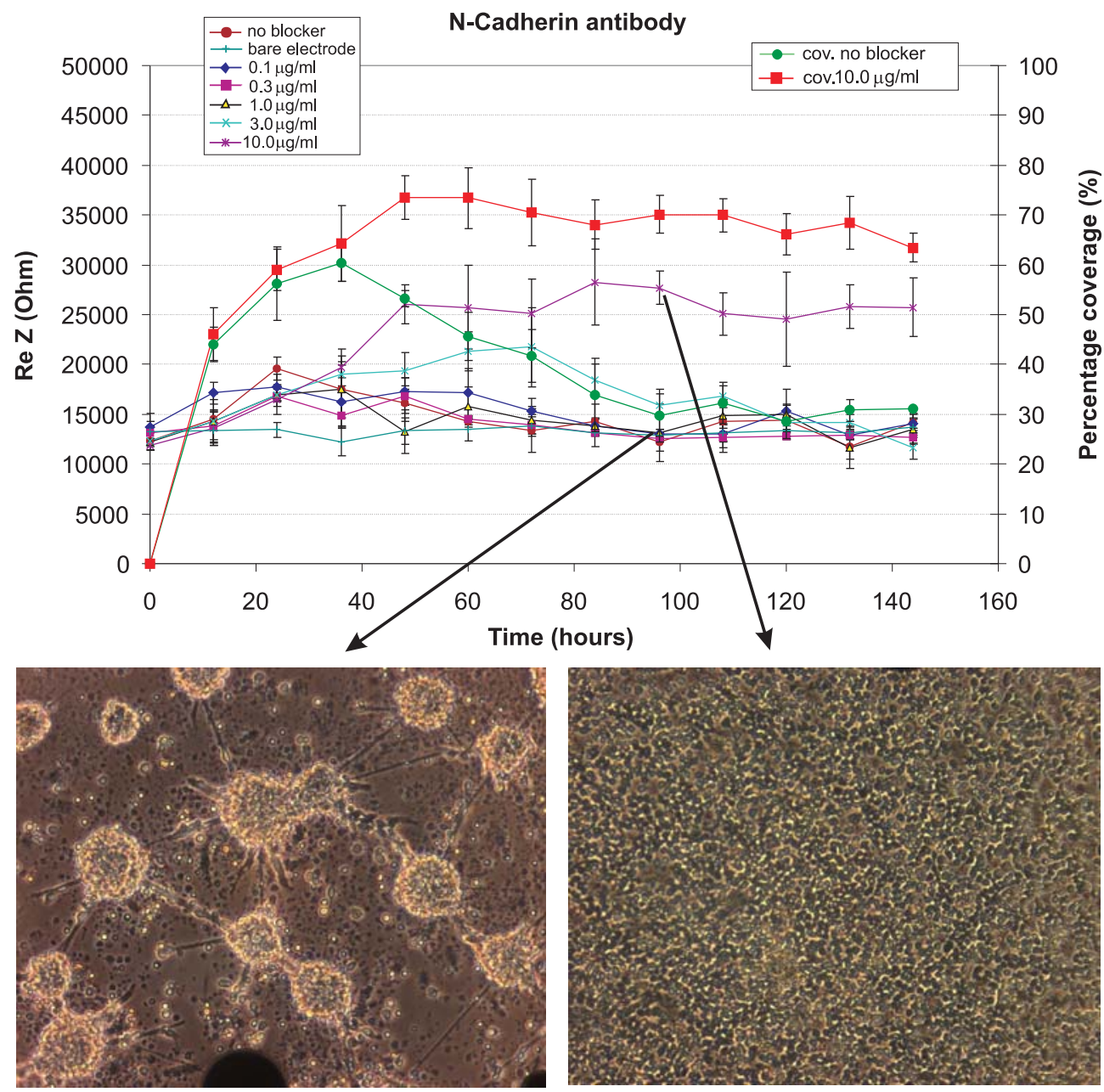

Figure 17, upper part. Real impedance during development of a neuronal culture on top of an 7850 $\mu^{2}$ gold electrode coated with laminin in the presence of $N$-Cadherin antibody at concentrations of $0,0.1,0.3,1.0,3.0$ and $10.0 \mu \mathrm{g} / \mathrm{ml}$. Percentage cell coverage on right axis and real impedance on left axis at a frequency of $10 \mathrm{kHz} . N=6$. Lower part left = blocking with $0.1 \mu \mathrm{g} / \mathrm{ml} \mathrm{N}$-Cad ab, 96 hours and lower part right $=$ blocking with $10.0 \mu \mathrm{g} / \mathrm{ml} \mathrm{N}$-Cad ab at 96 hours. 


\section{Laminin}
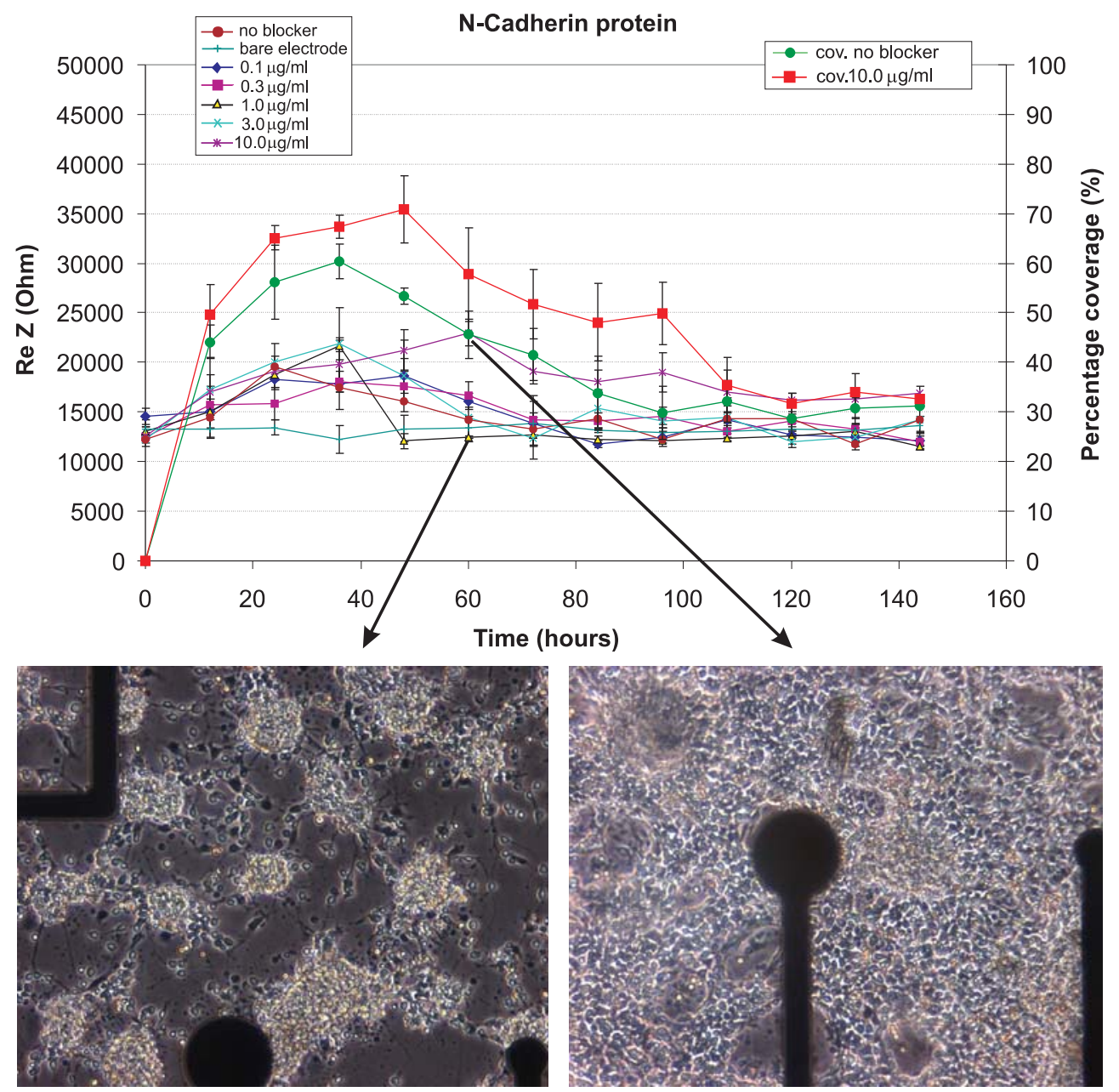

Figure 18, upper part. Real impedance during development of a neuronal culture on top of an 7850 $\mu^{2}$ gold electrode coated with laminin in the presence of $\mathrm{N}$-Cadherin protein at concentration of 0 , $0.1,0.3,1.0,3.0$ and $10.0 \mu \mathrm{g} / \mathrm{ml}$. Percentage cell coverage on right axis and real impedance on left axis at a frequency of $10 \mathrm{kHz} . N=6$. Lower part left = blocking with $1.0 \mu \mathrm{g} / \mathrm{ml} \mathrm{N}$-Cad protein, 60 hours and lower part right = blocking with $10.0 \mu \mathrm{g} / \mathrm{ml} \mathrm{N}$-Cad protein at 60 hours. 


\section{Laminin}
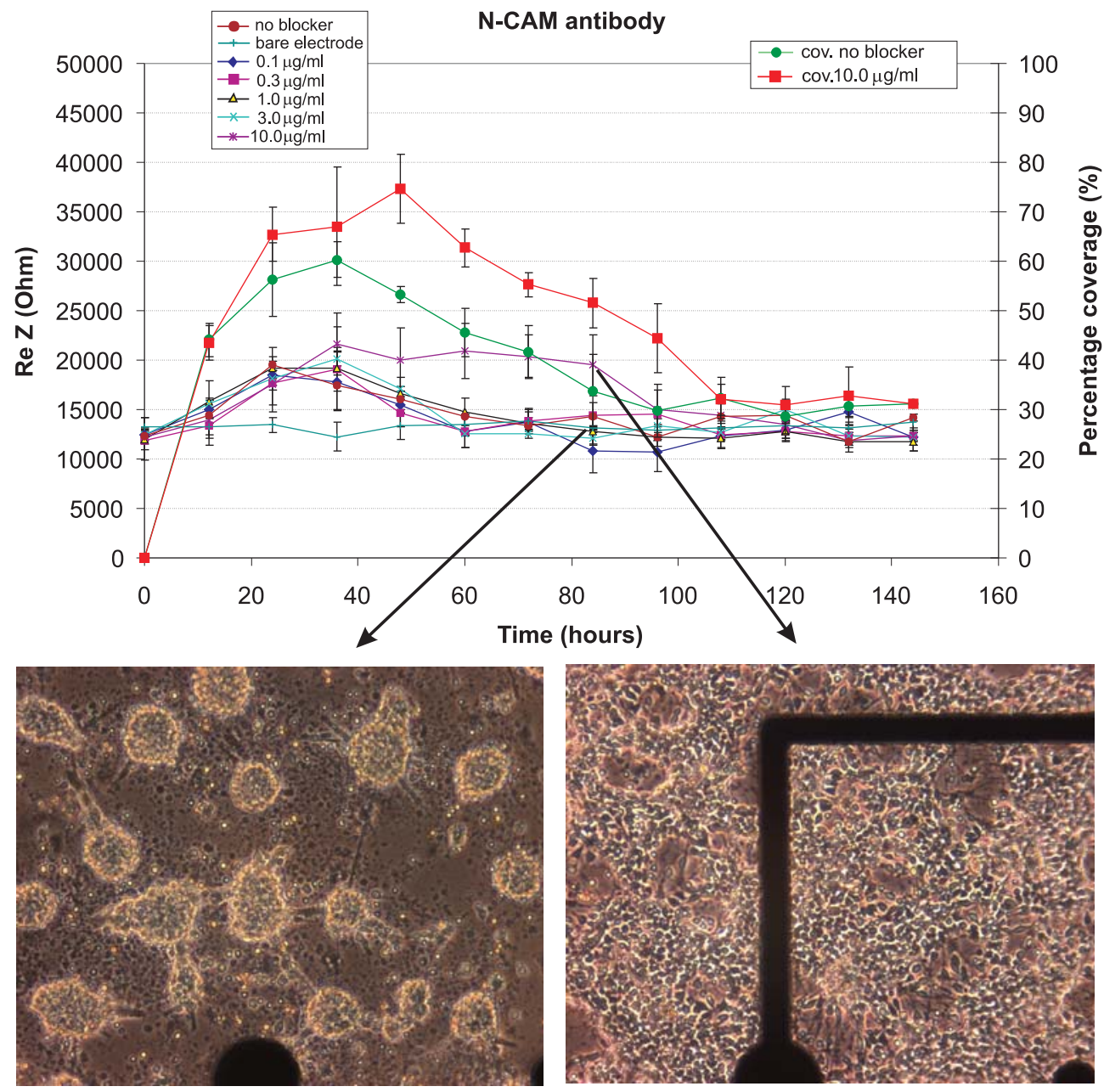

Figure 19, upper part. Real impedance during development of a neuronal culture on top of an 7850 $\mu^{2}$ gold electrode coated with laminin under influence of N-CAM antibody at concentration of 0 , $0.1,0.3,1.0,3.0$ and $10.0 \mathrm{ug} / \mathrm{ml}$. Percentage cell coverage on right axis and real impedance on left axis at a frequency of $10 \mathrm{kHz}$. $N=6$. Lower part left = blocking with $1.0 \mu \mathrm{g} / \mathrm{ml} \mathrm{N}$-CAM ab, 84 hours and lower part right $=$ blocking with $10.0 \mu \mathrm{g} / \mathrm{ml} \mathrm{N}-C A M$ ab at 84 hours. 


\section{Laminin}

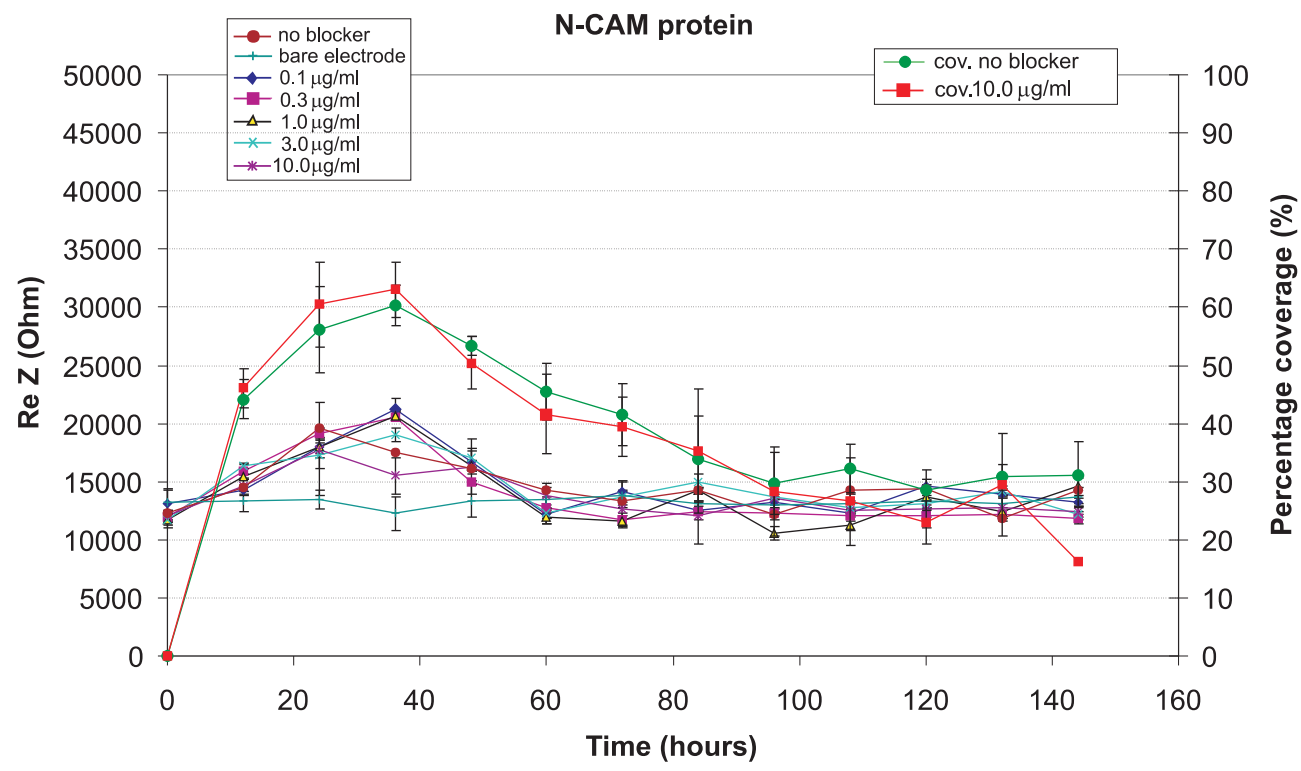

Figure 20, upper part. Real impedance during development of a neuronal culture on top of an 7850 $\mu^{2}$ gold electrode coated with laminin under influence of $\mathrm{N}$-CAM protein at concentration of $0,0.1$, $0.3,1.0,3.0$ and $10.0 \mu \mathrm{g} / \mathrm{ml}$. Percentage cell coverage on right axis and real impedance on left axis at a frequency of $10 \mathrm{kHz} . \mathrm{N}=6$.

Table 1. Overview of the blocking effect of L1, N-Cadherin and N-CAM (highest concentration peptides and antibodies) on neurons culturen on PEI, PLL, fibronectin and laminin. $-=$ no effect, $+=$ moderate blocking effect, $++=$ strong blocking effect, $c . d .=$ cell death (" results from previous study, $N=6$ ).

\begin{tabular}{l|c|cccccc}
\hline $\begin{array}{l}\text { Substrate } \\
\downarrow\end{array}$ & $\begin{array}{c}\text { Blockers } \\
\rightarrow\end{array}$ & $\begin{array}{c}\text { L1 } \\
\text { antibody }\end{array}$ & $\begin{array}{c}\text { L1 } \\
\text { protein }\end{array}$ & $\begin{array}{c}\text { N-Cad } \\
\text { antibody }\end{array}$ & $\begin{array}{c}\text { N-Cad } \\
\text { protein }\end{array}$ & $\begin{array}{c}\text { N-CAM } \\
\text { antibody }\end{array}$ & $\begin{array}{c}\text { N-CAM } \\
\text { protein }\end{array}$ \\
\hline PEI $^{*}$ & & - & - & ++ & + & - & c.d. \\
Fibronectin & & - & - & ++ & + & + & - \\
PLL & & - & - & ++ & c.d. & - & c.d. \\
Laminin & & - & - & ++ & + & + & - \\
\hline
\end{tabular}

\subsection{Discussion}

Fibronectin, PLL and laminin were applied as coatings for glass substrates for the culturing of neuronal cells. Fibronection and laminin, both components of the extracellular matrix, initiate receptor mediated binding to neuronal cells. Fibronectin and laminin are known to promote several cellular processes like proliferation, differentiation, axonal outgrowth and survival. The mechanism behind PLL binding is of a nonspecific electrostatic nature. The three applied substrate coatings are known for decreasing adhesive properties over time. Neurons 
tend to migrate and aggregate only several days after cell seeding. In figure 2 PEI has been compared with fibronectin and laminin. PEI and PLL have stronger neuro-adhesive properties than fibronectin and laminin. This can be explained by the difference in binding mechanism and binding force. The electrostatic force in case of PEI and PLL makes use of an abundant amount of positively charged amine groups on the PEI coated surface and all negatively charged groups on the cell membrane. In contrast, the specific bonds between integrins and fibronectin or laminin are limited by the amount of specific adhesion molecules, in this case the integrins on the cell membrane. This difference in quantity apparently is not compensated by the quality of this specific bond. Fibronectin and laminin show almost an identical course of impedance development, except at 12 hours. The difference at that time can be caused by both the expression in integrins subtypes and the combination of integrin subtypes present on the cell surface (fibronectin and laminin both bind to several subtypes of integrins). Figure 2 also shows a remarkable difference in cell adhesive properties between PEI and PLL. It may be that PEI holds a higher density of amine groups. Other possibilities are differences in the degree of branching and the degradability of PLL. The last might explain why neurons adhere as well on PLL as they do on PEI until 60 hours, but not longer (figure 2).

In this study soluble N-Cadherin protein, N-CAM protein, L1 protein, anti-NCadherin antibody, anti-N-CAM antibody and L1 antibody were used as blockers of CAMs on neuronal cells, cultured on fibronectin, PLL or laminin. The inhibition of neuron-neuron adhesion (and aggregation) on fibronectin, PLL and laminin could not be achieved for the whole duration (144 hours) of the experiment. Only the highest concentrations of N-Cadherin antibody $(3 \mu \mathrm{g} / \mathrm{ml}$ and $10 \mu \mathrm{g} / \mathrm{ml})$ could stabilize the culture's topography on PLL during 144 hours, which is comparable to results obtained in a previous study on PEI. The temporarily effect of CAM blocking can not be attributed to the cell adhesion blockers, since the effect on neurons cultured on PEI or PLL (in combination with N-Cadherin antibody) is present for 144 hours. Therefore, the fading of the blocking effect on fibronectin, laminin and in some cases PLL, can only be caused by changes in cell-substrate adhesion during the experiment. This is plausible since fibronectin, laminin and PLL are all biodegradable. Nonetheless, cell-cell adhesion can be inhibited on fibronectin, laminin and PLL coated substrates, although only temporarily on fibronectin and laminin.

In a previous study the addition of soluble L1 protein, L1 antibody and N-CAM antibody had no effect on the development of neuronal cells cultured on PEI. We assumed that the strong neuron adhesive properties of PEI 'overruled' the effect of blocking L1 protein, L1 antibody and N-CAM antibody. Any possible effect of blocking cell-cell adhesion would have been clearer on laminin, fibronectin or PLL, because of their lower neuron adhesive properties. No significant change in substrate coverage or impedance was measured for L1 antibody or L1 protein (figures 3, 4, 9, 10, 15 and 16). L1 antibody and L1 protein don't seem to have an 
effect on neuronal cell-cell adhesion. However, a slight inhibition of aggregate forming on fibronectin and laminin was seen in the presence of N-CAM protein at concentrations of $10 \mu \mathrm{g} / \mathrm{ml}$ (figure 7 and 19).

The effect of N-Cadherin protein on neurons cultured on PLL was somewhat surprising. At a concentration of 3 and $10 \mu \mathrm{g} / \mathrm{ml}$, most of the neurons became subject of cell death, whereas the rest started to aggregate (figure 12). The impedance on PEI also decreases drastically at high concentrations of N-Cadherin protein, but no cell death is seen (previous study). The inferior adhesive properties of PLL probably create a more critical environment for neuronal cells. The outcome in combination with fibronectin and laminin is contrary. A concentration of $10 \mu \mathrm{g} / \mathrm{ml} \mathrm{N}$-Cadherin protein substantially delayed formation of aggregates, causing higher impedance (figure 5 and 17). Specific binding of cells through integins somehow prevents cell death caused by N-Cadherin protein, despite the low neuron adhesive properties of fibronectin and laminin. The mechanism behind this effect is unclear.

Results obtained using N-Cadherin antibody as a blocker are more univocal. At a concentration of $10 \mu \mathrm{g} / \mathrm{ml}$ the aggregation of neurons on fibronectin and laminin is clearly inhibited. The impedance is more then double compared to cultures having no blocker at all on both fibronectin and laminin (figures 5 and 17). The influence on neurons cultured on PLL (figure 11) and PEI (previous study) is less profound and opposite, which indicates that blocking neuronal cell-cell adhesion has a different effect on a low adhesive substrate. There is no significant difference in courses of the substrate coverage when comparing neurons cultured on PLL with or without the presence of $\mathrm{N}$-Cadherin antibody, although no aggregation is seen after 108 hours in the presence of N-Cadherin antibody. The impedance between 48 and 84 hours is significantly lower in the presence of 1,3 and $10 \mu \mathrm{g} / \mathrm{ml} \mathrm{N}$-Cadherin antibody, indicating an inhibition of neuron-neuron adhesion. This same inhibition of neuron-neuron adhesion causes inhibition of aggregation after 108 hours (figure 11). A high concentration of N-Cadherin antibody has a stabilizing effect on neuronal culture topography (when cultured on PLL).

When culturing on laminin or fibronectin, addition of N-CAM antibody displays a moderate effect at a concentration of $10 \mu \mathrm{g} / \mathrm{ml}$ (figures 5 and 17). Comparable to $\mathrm{N}$-Cadherin protein, cell death of neurons is observed on PLL in combination with $10 \mu \mathrm{g} / \mathrm{ml} \mathrm{N}$-CAM protein (figure 14). The same effect is seen when PEI is used as a substrate (previous study). No effect by N-CAM protein is seen when fibronectin and laminin were used as substrate coatings. However, cell death is hard to detect within aggregates formed on fibronectin and laminin.

The adhesive properties of fibronectin and laminin are poor. The adhesive properties of PLL displayed a much better neuron attachment and spreading of cells, however temporarily. The presence of $10 \mu \mathrm{g} / \mathrm{ml} \mathrm{N}$-Cadherin antibody causes a distinct inhibition of the aggregation of neurons on fibronectin and laminin. However, this inhibitory effect was temporarily. On PLL the N-Cadherin antibody is able to decrease the impedance, meaning less neuron-neuron adhesion. N- 
Cadherin protein, N-CAM protein and N-CAM antibody all displayed moderate effects in combination with one or two substrates, but the blocking abilities of these three were not as convincing as those of $\mathrm{N}$-Cadherin antibody. We believe that $\mathrm{N}$ Cadherin antibody can be applied as a effective but simple tool to inhibit migration and aggregation of neuronal cells on the tested substrate coatings.

\section{References}

[1] Ruardij T G, Goedbloed M H and Rutten W L C 2000 Adhesion and patterning of cortical neurons on polyethylenimine and fluorocarboncoated surfaces IEEE Trans. Biomed. Eng. 47 1593-9

[2] Ruardij T G, van den Boogaart M A F and Rutten W L C 2002 Adhesion and growth of electrically-active cortical neurons on polyethyleneimine patterns microprinted on PEO-PPO-PEO triblockcopolymer-coated hydrophobic surfaces IEEE Trans. Nanobiosci. 1 1-8

[3] Ruardij T G, Goedbloed M H and Rutten W L C 2003 Long-term adhesion and survival of dissociated cortical neurons on miniaturized chemical patterns Med. Biol. Eng. Comp. 41 227-32

[4] Chen C S, Tan J and Tien J 2004 Mechanotransduction at cell-matrix and cell-cell contacts Ann. Rev. Biomed. Eng. 6 275-302

[5] Venstrom K A and Reichardt L F 1993 Extracellular matrix 2: Role of extracellular matrix molecules and their receptors in the nervous system FASEB J. 7 996-1003

[6] Smalheiser N R, Crain S M and Reid L M 1984 Laminin as a substrate for retinal axons in vitro Develop. Brain. Res. 12 136-40

[7] Heiduschka P, Romann I, Ecken H, Schöning M, Schuhmann W and Thanos S 2001 Defined adhesion and growth of neurons on artificial structured substrates Electrochim. Acta. 47 299-307

[8] Liang S and Crutcher K A 1992 Neuronal migration on laminin in vitro Develop. Brain. Res. 66 127-132

[9] Park K S, Kim S M, Kim M S, Lee I, Rhee J M, Lee H B, Khang G 2007 Effect of cell-adhesive-molecule-coated poly(lactide- $c o$-glycolide) film on the cellular behaviors of olfactory ensheathing cells and Schwann cells $J$. Appl. Polymer. Sci. 107 1243-51

[10] Hynes RO 1999 Cell adhesion: old and new questions Trends. Genets. 15 m33-7

[11] Yavin E and Yavin Z 1974 Attachment and culture of dissociated cells from rat embryo cerebral hemispheres on polylysine-coated surfaces $J$. Cell. Biol. 62 540-6

[12] Ronn L C, Berezin V and Bock E 2000 The neural cell adhesion molecule in synaptic plasticity and ageing Int. J. Dev. Neurosci 18 193-199

[13] Bates C A, Becker C G, Miotke J A and Meyer R L 1999 Expression of polysialylated NCAM but not L1 or N-cadherin by regenerating adult mouse optic fibers in vitro Exp. Neurol. 155 128-39 
[14] Landmesser L, Dahm L, Schultz K and Rutishauser U 1988 Distinct roles for adhesion molecules during innervation of embryonic chick muscle Dev. Biol. 130 645-70

[15] Norgren R B Jr and Brackenbury R 1993 Cell adhesion molecules and the migration of LHRH neurons during development Dev. biol. 160 377-87

[16] Wilkemeyer M F, Menkari C E, Spong C Y and Charness M E 2002 Peptide Antagonists of Ethanol Inhibition of L1-Mediated Cell-Cell Adhesion J. Pharmacol. Exp. Ther. 303 110-6

[17] Willems J, Bruyneel E, Noe V, Slegers H, Zwijsen A, Mege R M and Mareel M 1995 Cadherin-dependent cell aggregation is affected by decapeptide derived from rat extracellular super-oxide dismutase FEBS Letters. 363 289-92

[18] Bayarsaikhan M, Takino T, Gantulga D, Sato H, Ito T and Yoshioka K 2007 Regulation of N-cadherin-based cell-cell interaction by JSAP1 scaffold in PC12h cells Biochem. Biophys. Res. Commun. 353 357-62

[19] Kwon Y T, Gupta A, Zhou Y, Nikolic M and Tsai L 2000 Regulation of Ncadherin-mediated adhesion by the p35-Cdk5 kinase Curr. Biol. 10 363-72

[20] Gago N, Avellana-Adalid V, Baron-Van Evercooren A and Schumacher M 2003 Control of cell survival and proliferation of postnatal PSA-NCAM ${ }^{+}$ progenitors Mol. Cell. Neurosci. 22 162-78

[21] Romijn H J, Van Huizen F and Wolters P S 1984 Towards an improved serum free, chemically defined medium for long term culturing of cerebral cortex tissue Neurosci. Biobehav. Rev. 8 301-44 


\section{Chapter 5}

\section{Neuronal cell-cell and cell-substrate adhesion through N-Cadherin, N-CAM and L1}

R.W.F.Wiertz, E. Marani and W.L.C.Rutten

Neurotechnology Group/BSS, MIRA Institute, University of Twente, Enschede, The Netherlands 


\begin{abstract}
In this study we investigated the applicability of N-Cadherin, N-CAM and L1 protein as well as N-Cadherin, N-CAM and L1 antibody for the regulation of cell-substrate and cellcell adhesion in vitro. The cell adhesion molecules (CAMs) and antibodies were covalently immobilized on glass to form a neuron adhesive layer. In a combinatorial experiment we used these same antibodies and proteins as medium-additives to inhibit cell-cell adhesion between neurons. Impedance Sensing (IS) and image analysis of assays were used to monitor effects of these CAMs. Their neuron adhesive properties were compared to those of polyethylene-imine (PEI).

The results of the cell-substrate study demonstrate the applicability of some of the investigated CAM proteins and antibodies as substrate coatings. Immobilization of high concentrations of both $\mathrm{N}$-Cadherin protein and antibody led to a good adhesion of neurons to the modified surface. The surfaces treated with N-CAM protein and antibody had poor neuron adhesive properties, which caused forming of aggregates. Only the highest concentration of $100.0 \mu \mathrm{g} / \mathrm{ml}$ and $30.0 \mu \mathrm{g} / \mathrm{ml} \mathrm{N}$-CAM protein showed better neuron coverage. L1 antibody and protein coating revealed no significant effect on neuronal cellsurface adhesion, compared to non-treaded surfaces.

Adhesion of neurons cultured on a N-Cadherin protein or antibody-modified surface was inhibited by addition of soluble N-Cadherin protein and antibody to the culturing medium. Under these conditions neurons start to aggregate after 36 hours. The presence of soluble $\mathrm{N}-\mathrm{CAM}$ antibody or protein had no effect on the adhesion of neuronal cells on a $\mathrm{N}$ Cadherin protein modified surface. On N-Cadherin antibody coated surface, addition of soluble N-CAM protein led to cell death of neurons after 48 hours, while N-CAM antibody had no effect. In the presence of soluble N-Cadherin protein and antibody, aggregation of neurons was inhibited on both N-CAM protein and N-CAM antibody modified surfaces. Neurons cultured on immobilized antibodies were less affected by addition of soluble CAM blockers compared to neurons cultured on immobilized proteins, indicating that antibodyprotein bonds are more stable compared to protein-protein bonds.
\end{abstract}




\subsection{Introduction}

Control over cell responses to material surfaces is important for cellular engineering in neuronal cultures and could favour further development of neuroelectronic devices. The cultured probe interface is based on a planar electrodes array with patterns of small neuronal islands surrounding each micro-electrode. These small islands of neurons should serve as attractors and "hosts" for collateral sprouts from the in vivo system, resulting in a very specific and efficient interfacing device.

Manipulation of neuronal cells in cultures is crucial for constructing neural networks with a specific design and a good cell-surface contact. In neural cultures, cells are subject to cell-substrate and cell-cell adhesion. The structural development of a two-dimensional neuronal culture depends considerably on the magnitudes of cell-cell and cell-substrate adhesive forces. Manipulation of cell-substrate or cellcell adhesion can strongly affect the structure and topography of a culture. For example, cell-cell adhesion studies demonstrate a strong inhibition of neuronal aggregation in the absence of neuron-neuron adhesion molecule, like N-Cadherin and N-CAM on the surface of neurons [1,2]. Also cell-surface adhesion in neural cultures has been investigated in several studies. By chemical surface modification it is possible to alter cell-surface adhesion [3-5]. Most synthetic surfaces are inert and have low or no neuron adhesive properties but are needed by their mechanical and/or physical properties, like transparency of culturing glass/plastics or gold electrodes. Organic, non-natural polymers like polylysine and polyethylene-imine (PEI) have cell adhesive properties based on electrostatic forces between their positive amino groups and the negatively charged cell membrane $[6,7]$. Ruardij et al, [8-10] applied these neurophilic agents in combination with neurophobic agents to create surfaces that contain neuron adhesive patterns surrounded by neurophobic areas, making it possible to immobilize neuronal cells on predestined areas over a longer period of time. Another class of cell adhesives is that of the extra cellular matrix (ECM) compounds like laminin, collagen and fibronectin [11]. In contrast to polymers like PEI and PLL, binding of neuronal cells to ECM compounds involves receptor mediated adhesion [12]. Besides adhesive properties, ECM molecules are known to promote several cellular processes like proliferation, differentiation, axonal outgrowth and survival, both in vitro [13] and in vivo [14]. In this study we used cell-cell adhesion molecules as a surface coating on glass slides containing gold electrodes and studied the neuron-neuron and neuronelectrode contact using electric impedance sensing (IS) and microscopy. In order to differentiate cell-substrate adhesion effects from cell-cell adhesion effects, we also inhibited cell-cell adhesion of neurons cultured on modified substrates. A wide variety of adhesion molecules are known to be involved in cell-cell adhesion. N$\mathrm{CAM}, \mathrm{N}-\mathrm{Cadherin}$ and $\mathrm{L} 1$ are the three main mediators in neuron to neuron adhesion. These molecules contribute to several cellular pathways, activating/regulating axonal guiding, neuronal tissue morphogenesis, tissue differentiation, regeneration and synaptic plasticity [15-18]. 
In several studies, CAMs have been immobilized on various surfaces to serve as bioactive culturing substrates for neural cells. Sorribas et al [19] cross-linked axonin-1 and $\mathrm{NgCAM}$, both neural cell adhesion molecules from the immunoglobin-superfamily, with a silicon oxide substrate in order to promote neural adhesion. Also L1 has been immobilized on silicon based materials. Neural electrode arrays coated with immobilized L1 showed enhanced levels of attachment of mouse cerebellum neuronal cells in vitro [20]. In another adhesion study an N-Cadherin-Fc chimera (an N-Cadherin molecule engineered on the tail region of an antibody) and N-Cadherin antibodies have been immobilized on beads. These beads bound specifically to several N-Cadherin expressing cancer cell lines, affecting both cytoskeletal reorganization and cytoplasmic signal mobilization by outside-in signalling [21]. Also, L1 and N-CAM were immobilized on beads [22]. Neurons adhered well on L1 treated surfaces, but not on N-CAM immobilized surfaces. Neurons adhered best to a surface containing both L1 and NCAM, even at a concentration that was 10 times lower than the lowest concentration of L1 found to promote adhesion.

In this study we compared immobilised extracellular parts of N-Cadherin, N-CAM and L1 proteins as well as N-Cadherin-, N-CAM- and L1 antibodies for their applicability as surface coatings. In a second combinatorial experiment, these same biomolecules were also added in their soluble form to the culturing medium. The addition of soluble CAM proteins and antibodies should inhibit cell-cell adhesion, reducing neuronal aggregation. However, in case of affinity between soluble CAMs and immobilized CAMs, it is likely that cell-substrate adhesion will be inhibited as well. Some of these conjoined effects could provide interesting tools for controlling the overall structure of neuronal cultures. The second experiment may also give some insight in the affinity among the different CAM proteins and antibodies.

The IS technique, used in this study, is a non-invasive technique to monitor cellcell and cell substrate adhesion [23, 24]. In IS cells are grown on planar micro electrodes and submitted to an AC current. The isolating properties of cell membranes progressively increase the electrode impedance when cultured neurons develop. In (almost confluent) cell layers the measured impedance is mainly determined by dimensions of the extracellular spaces between the cells in the cell layer on top of the electrode. When the shape or confluency of neuronal cells change, these void pathways for the $\mathrm{AC}$ currents consequently change the impedance. It is a relatively simple technique, revealing changes that are not seen under a light microscope. Moreover, several cultures can be monitored simultaneously with a relatively high time resolution $[25,26]$. IS has been applied for a whole range of studies on cytotoxicity [27], cell metabolism, cell morphology [28] and cell adhesion [29]. Also the development of a neuroblastoma cell line was monitored using IS [30]. In a study by Bieberich et al [31] IS was used to monitor differentiation of PC-12 cells into neuronal cells. The impedance showed a $3 \%$ increase after differentiation, indicating the sensitivity of the method. 


\subsection{Methods}

\subsubsection{Planar electrode structure}

16 gold electrodes, each with a surface of $7850 \mu \mathrm{m}^{2}$, were patterned as 8 pairs on a $25 \mathrm{~cm}^{2}$ square glass plate. Glass was used as device material in order to have transparency between electrodes. Gold electrode structures were created by photolithography and reactive ion etching. An isolation layer consisting of a sandwiched $\mathrm{SiO}_{2}-\mathrm{Si}_{3} \mathrm{~N}_{4}-\mathrm{SiO}_{2}$, combination was deposited by plasma enhanced chemical vapor deposition (PECVD). A $6 \mathrm{~mm}$ thick block of PDMS with 8 round holes was adhered to the glass surface of the electrode device to create 8 wells (each $7 \mathrm{~mm}$ in diameter) over the 8 pairs of electrodes for the cell cultures. Electrode glass plates were provided with neuron adhesive biochemicals. Neurons were plated and cultured in these wells.

\subsubsection{Substrate coating}

Glass culturing surfaces, containing IS electrode areas, were pre-coated with polyethylene-imine at a low concentration of $0.5 \mu \mathrm{g} / \mathrm{ml}$ (PEI, Fluka, Milwaukee, United States, ). Solutions of N-Cadherin protein (R\&D sytems, Minneapolis, United states), N-CAM protein (R\&D sytems), rabbit anti-N-Cadherin antibody (Santa Cruz Biotechnology) and mouse anti-N-CAM antibody (BD pharmingen) were prepared at concentrations of $1.0,3.0,10.0,30.0$ or $100.0 \mu \mathrm{g} / \mathrm{ml}$. Solutions of L1 protein (Chemicon, Temecula, United States) and rat anti-L1 antibody (R\&D sytems) were also prepared at concentrations of 1.0, 3.0 10.0, 30.0 and 100.0 $\mu \mathrm{g} / \mathrm{ml}$. The free amine groups on antibodies and proteins in these solutions were blocked using Fluorenylmethyloxycarbonyl (FMOC, Fluka). The resulting solutions of proteins-FMOC or antibody-FMOC complexes were applied to the PEI coated glass substrates. A concentration of $1 \mathrm{mM}$ 1-ethyl-3-(3dimethylaminopropyl) carbodiimide hydrochloride (EDC, Fluka) and 5mM (sulfo) N-hydroxysuccinimide (sulfo-NHS, Fluka) ) in solution was used to crosslink antibodies or proteins on the PEI layer (coated at $0.5 \mu \mathrm{g} / \mathrm{ml}$ )(figure 1). In a second crosslinking step linolenic acid (Sigma-Aldrich, St. Louis, United States) was crosslinked to the remaining free amine groups on the PEI polymer surface (figure 1). FMOC prevents the crosslinking of linolenic acid to aminogroups on antibodies or proteins. FMOC was removed from antibodies or proteins using $20 \%$ piperidine (Sigma-Aldrich) in DMF dimethylformamide (Fluka). As a control, neurons were culture on glass coated with a combination of PEI with linolenic acid. By blocking immobilized antibodies with secondary polyclonal antibodies (FITC labelled) the specific binding of immobilized antibodies was checked with fluorescence microscopy (chicken anti rat, with mouse and rabbit reactivity). Neurons were also cultured on PEI coated surface at a normal concentration of $50 \mu \mathrm{g} / \mathrm{ml}$.

\subsubsection{Cell Culturing}

Cerebral cortical neurons from newborn rats (P1-2) were used for all experiments in this study. Brains were taken out after decapitation, the meninges of the cortices 
were removed and the cortex was prepared free. The remaining cortices were collected in a tube with chemically defined R12 culture medium [32] and trypsin for chemical dissociation. After removal of trypsin (invitrogen), $150 \mu$ of soybean trypsin inhibitor (Cascade Biologies, Portland, United States) and $125 \mu 1$ of DNAse I (20.000 units, Life Technology, Carlsbad, United States) were added. A suspension of single neural cells was obtained by mechanical dissociation of cortical tissue. The neuron solution was centrifuged at $1200 \mathrm{rpm}$ for 5 minutes. The supernatant was removed and the pellet of neurons resuspended in R12 medium. Neurons were plated and cultured on the glass-electrode surfaces, precoated as described in the previous paragraph. Cell cultures were kept in serum-free R12 medium under standard conditions of $37^{\circ} \mathrm{C}$ and $5 \% \mathrm{CO}_{2}$ in air. A cell concentration of approximately $10^{6}$ cells $/ \mathrm{cm}^{2}$ was used in all experiments. During measurements, neuron cultures were placed into a incubator at a temperature of $37^{\circ} \mathrm{C}$. 

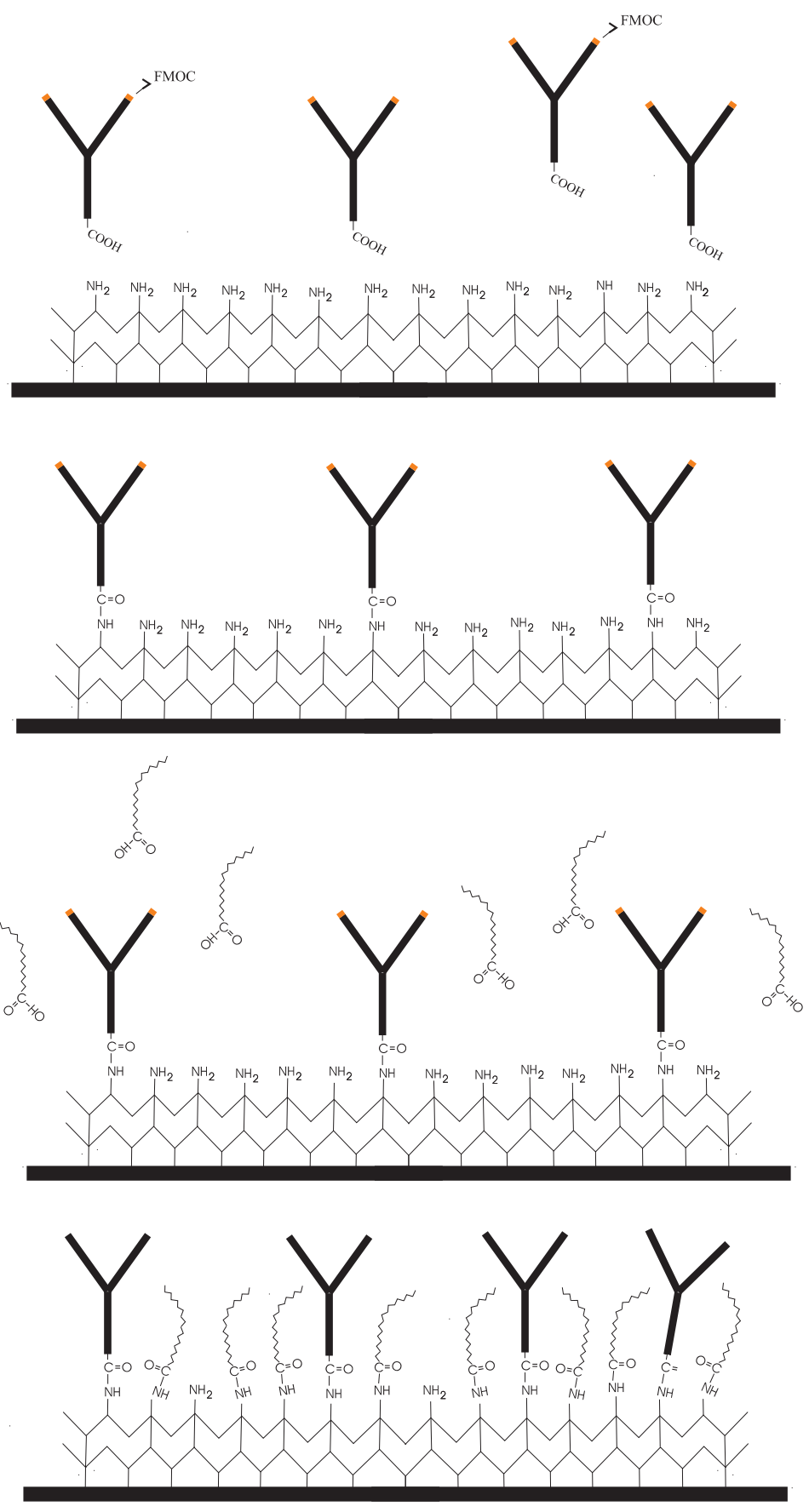

Figure 1. Free amine groups on antibodies and proteins ( $N$-Cadherin and $N$-CAM) were protected by FMOC. EDC and NHS were used to crosslink the antibodies or proteins to a PEI coated surface. In a second crosslinking step linolenic acid was bound to remaining free aminegroups on the PEI-coated surface. In the final step FMOC was removed using $20 \%$ Piperidine in DMF. 


\subsubsection{Inhibition of cell-cell adhesion}

To inhibit homotypic interaction between N-Cadherin molecules, a polyclonal antibody to N-Cadherin (H-63, Santa Cruz Biotechnology, Santa Cruz, United States) or a soluble N-Cadherin protein, fused to the Fc region of human IgG via a peptide linker ( $\mathrm{R} \& \mathrm{D}$ systems, Minneapolis, United states), was used. The N-CAM interactions were inhibited with a monoclonal antibody to N-CAM (antiCD56; BD Pharmingen, New Jersey, United States) or a soluble N-CAM protein (R \& D systems). Also L1 molecules were blocked using an antibody (anti-L1, BD Pharmingen) or a soluble L1 protein fused to the Fc region of human IgG (R \& D systems).

$\mathrm{N}-$ Cadherin and N-CAM antibodies as well as $\mathrm{N}-\mathrm{Cadherin} / \mathrm{Fc}$ and $\mathrm{N}-\mathrm{CAM}$ proteins were added at concentrations of $0.1,0.3,1.0,3.0$ and $10.0 \mu \mathrm{g} / \mathrm{ml}$ to the culturing solution after all neurons adhered well to the culturing substrate at 6 hours. L1 protein/Fc or L1 antibody was added after 6 hours at a concentration of $0.3,1.0,3.0$ 10.0 and $30.0 \mu \mathrm{g} / \mathrm{ml}$. As a control the buffer of the proteins and antibodies were taken along in the experiment.

Six pups from three rats (two pups per rat) were used to perform six experiments. 6 well-platings ( 5 different concentrations and 1 control, as described above) were made for each antibody or proteins, sacrificing one pup for a total of 36 platings for each experiment.

\subsubsection{IS Measurement Setup}

The circuit of a neural cell covered electrode can be modeled by $[33,34]$

$$
Z_{\text {tot }}=\frac{K}{(i \omega)^{m}}+R_{\text {spread }}
$$

The first term represents the equivalent impedance of the electrode-electrolyte interface [35] which is frequency dependent. $\mathrm{K}$ is a size dependent constant. Power $\mathrm{m}$ usually takes values around $0.6-0.7$, indicating the non-truly capacitive nature of the Helmholtz layer. The second term $\mathrm{R}_{\text {spread }}$ represents the spreading resistance of the summed openings between the cells.

All impedance measurements were carried out using a programmable signal source (HP 4194A), a home-built impedance measuring circuit [34] and a data acquisition system in a Labview environment. This setup was used in combination with cell culturing chambers containing the planar gold electrodes on a glass support. Cultures were kept at $37^{\circ} \mathrm{C}$ under sterile conditions during measurements on a NIKON DIAPHOT inverted microscope. The applied frequency were chosen at 5 , 10, 50, 100, 500, 1000, 10.000 and $20.000 \mathrm{~Hz}$. The measurements were controlled 
by the same computer that recorded and saved the real and imaginary part of the impedance.

Monitoring started shortly before cell plating $(\mathrm{t}=0)$ of electrodes, until 144 hours. Time between start and cell plating was $10 \mathrm{~min}$. From 0 hours on, electrodes were monitored every 12 hours in which 5 repeated impedance spectra were obtained with an interval of 1 minute.

\subsubsection{Imaging technique}

The neuronal coverage of electrodes was determined by taking the visible area directly surrounding electrodes as representative for the electrode area itself (lacking transparency for direct optical monitoring). Percentage of coverage was determined by converting digital color photographs into an 8-bit grayscale photograph using CorelDraw 11 software. The histogram of the grayscale photograph was used for segmentation of the picture into a black-and-white photo. The ratio of the number of black to white pixels is the percentage of the electrode area covered by cells. Pictures of the electrode areas were made after every impedance measurement. Images with areas of 200 x $200 \mu \mathrm{m}$ was used for analysis. The average percentage of coverage at these 4 areas was calculated. Each experiment was repeated 6 times.

\subsection{Results}

During 144 hours, the impedance of neuron-covered gold electrodes was monitored at frequencies of $5,10,50,100,500,1000,10.000$ and $20.000 \mathrm{~Hz}$ and plotted as Bode plots of amplitude and phase, or as impedance locus of real and imaginary part. The real part of the impedance at $10.000 \mathrm{~Hz}$ showed to be most affected by cell coverage and change in culture topography. Therefore, we will limit the presentation of all impedance results to the real part of the impedance at $10 \mathrm{kHz}$.

\subsubsection{Culture development on surfaces with immobilized CAM proteins or CAM antibodies}

In the first experiment cells were cultured on electrode areas modified with immobilized CAMs and anti-CAM antibodies. Soluble extracellular parts of NCadherin, N-CAM and L1 proteins as well as N-Cadherin-, N-CAM- and L1 antibodies were covalently bound to the PEI pre-coated substrate. In the second part of the results, modification of culturing surfaces was combined with inhibition of cell-cell adhesion, in order to differentiate cell-substrate adhesion from cell-cell adhesion.

On surfaces with immobilized L1 antibody or immobilized L1 protein no improvement of neuronal cell-substrate adhesion was observed, as no increase in impedance could be measured (data not shown) and no effect on surface coverage was seen. In contrast, immobilized N-Cadherin protein proved to be a good neural substrate at a concentration of $100.0 \mu \mathrm{g} / \mathrm{ml}$. Cells adhered well and the impedance increased from $12 \mathrm{kOhm}$ to $33 \mathrm{kOhm}$ (purple line, figure 2). At $30.0 \mu \mathrm{g} / \mathrm{ml}$, the 
impedance slowly decreased over time and was lower compared to the impedance at a concentration of $100.0 \mu \mathrm{g} / \mathrm{ml}$, especially after 84 hours. Spreading of neurons took longer and cell-cell adhesion partly overruled the cell-substrate adhesion, causing moderate aggregation, resulting in a lower substrate coverage (figure 2, red line) compared to that of substrates coated with PEI (figure 2, green line). Local clustering of neuronal cells causes small non covered substrate areas at $30.0 \mu \mathrm{g} / \mathrm{ml}$. The impedance measured at this concentration corresponded to the effect on cell surface coverage. Both cell surface coverage (not all data is shown) and impedance are significantly less at low concentrations of immobilized N-Cadherin protein. At a concentration of $1.0 \mu \mathrm{g} / \mathrm{ml}$ the cells don't manage to spread at all. Most cells detach from the substrate, while the remaining cells show strong aggregation shortly after seeding. This is confirmed by the impedance of the poorly covered electrodes, which is comparable to that of a bare electrode.

Results for N-Cadherin antibody are similar to that of N-Cadherin protein in the higher concentration range. However, low concentrations of immobilized NCadherin antibody still exhibit good cell-substrate adhesion. The impedance for all concentrations of immobilized antibody increases to $25 \mathrm{kOhm}$ or higher compared to a bare electrode (figure 3). Neurons adhering at the lowest concentration NCadherin antibody show a delay in cell spreading, seen both in impedance and cell substrate coverage and a moderate level of aggregation.

Both the immobilized N-CAM protein and antibody showed good neuron surface adhesion at high concentration (figure 4 and 5). However, the effect of N-CAM antibody was temporarily. Neurons initially attached and spread well at a concentration of $100.0 \mu \mathrm{g} / \mathrm{ml}$. Both the substrate coverage and the impedance increased in a comparable way to that of PEI. After 48 hours however, the substrate coverage and the impedance decreased drastically (figure 5). Neurons were able to attach to lower concentrations of N-CAM antibody. However, spreading of neurons was very poor with distinct aggregation.

The specific binding of neurons to antibodies and proteins was checked by blocking with antibody. Blocking of antibodies and proteins on the PEI-linolenic acid layer with FITC-labelled antibody caused strong inhibition of neuronal adhesion. In order to control for non-specific binding to the PEI-linolenic acid layer, neurons were cultured on PEI $(0.5 \mu \mathrm{g} / \mathrm{ml})$ coated surfaces crosslinked with linolenic acid only. The adhesive properties of a PEI/linolenic acid surfaces are comparable to that of a bare (non-coated) electrode. Neuron attachment was very poor under these conditions. Many cells detached and no cells were able to spread out on the layer of linolenic acid. As expected, neurons cultured on PEI only, at a normal concentration of $50 \mu \mathrm{g} / \mathrm{ml}$ showed very good substrate adhesion. Cells started to spread shortly after neural attachment. The impedance of neuron covered electrodes increases from $12 \mathrm{kOhm}$ to $35 \mathrm{kOhm}$ after 36 hours of culture development and the substrate coverage reached $90 \%$. 

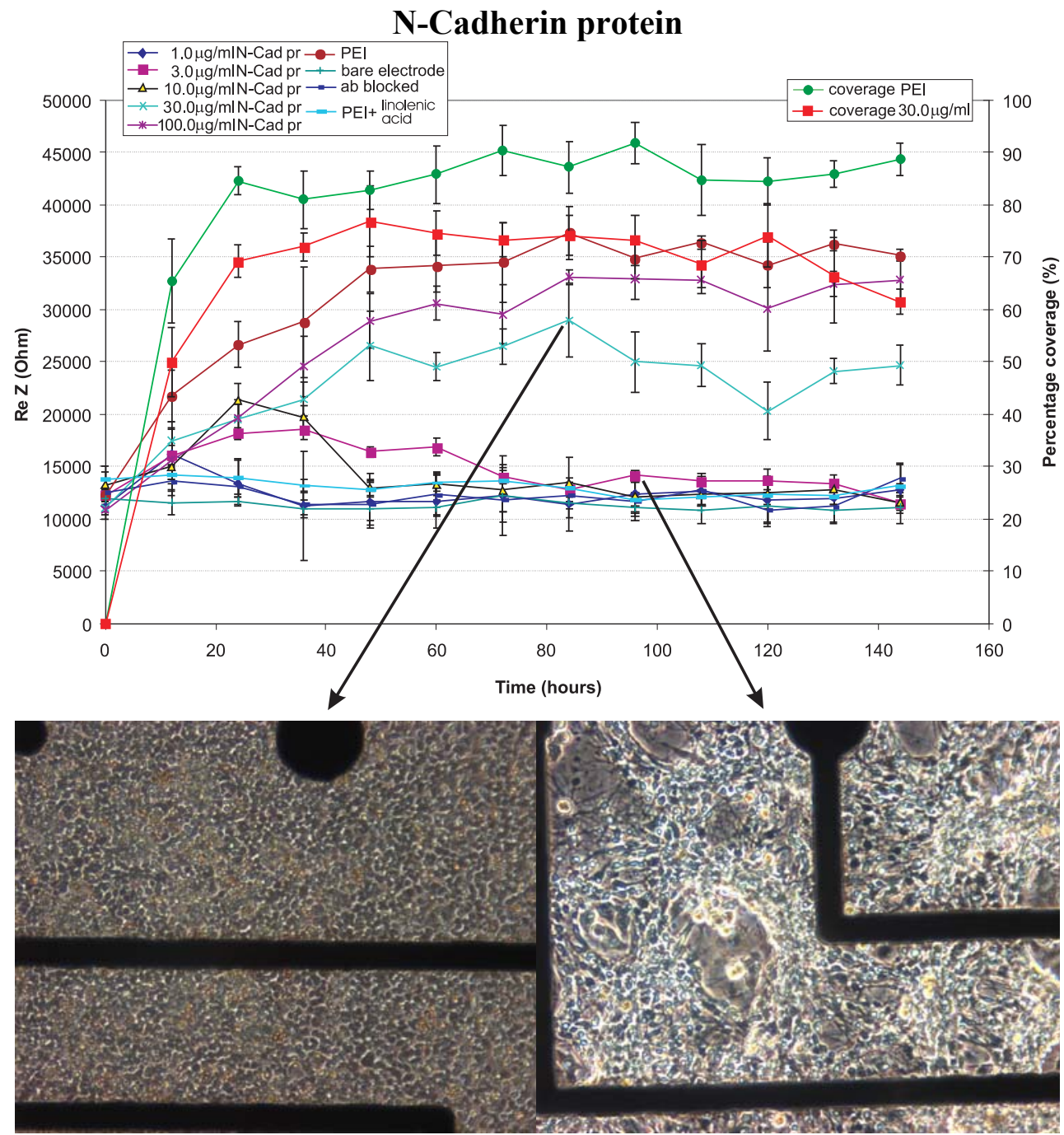

Figure 2, upper part. Real part of the impedance during development of a neuronal culture on top of an $7850 \mu^{2}$ gold electrode coated with immobilized $\mathrm{N}$-Cadherin protein at concentrations of $0,1.0$, 3.0, 10.0, 30.0 and $100.0 \mu \mathrm{g} / \mathrm{ml}$ (ab blocked = antibody blocked by secondary antibody). Percentage cell coverage is indicated on the right vertical axis and the real impedance (at $10 \mathrm{kHz}$ ) on the left axis. $N=6$. Lower part left $=30.0 \mu \mathrm{g} / \mathrm{ml} \mathrm{N}$-Cad protein, 84 hours and lower part right $=30.0 \mu \mathrm{g} / \mathrm{ml}$ $\mathrm{N}$-Cad protein at 96 hours. 


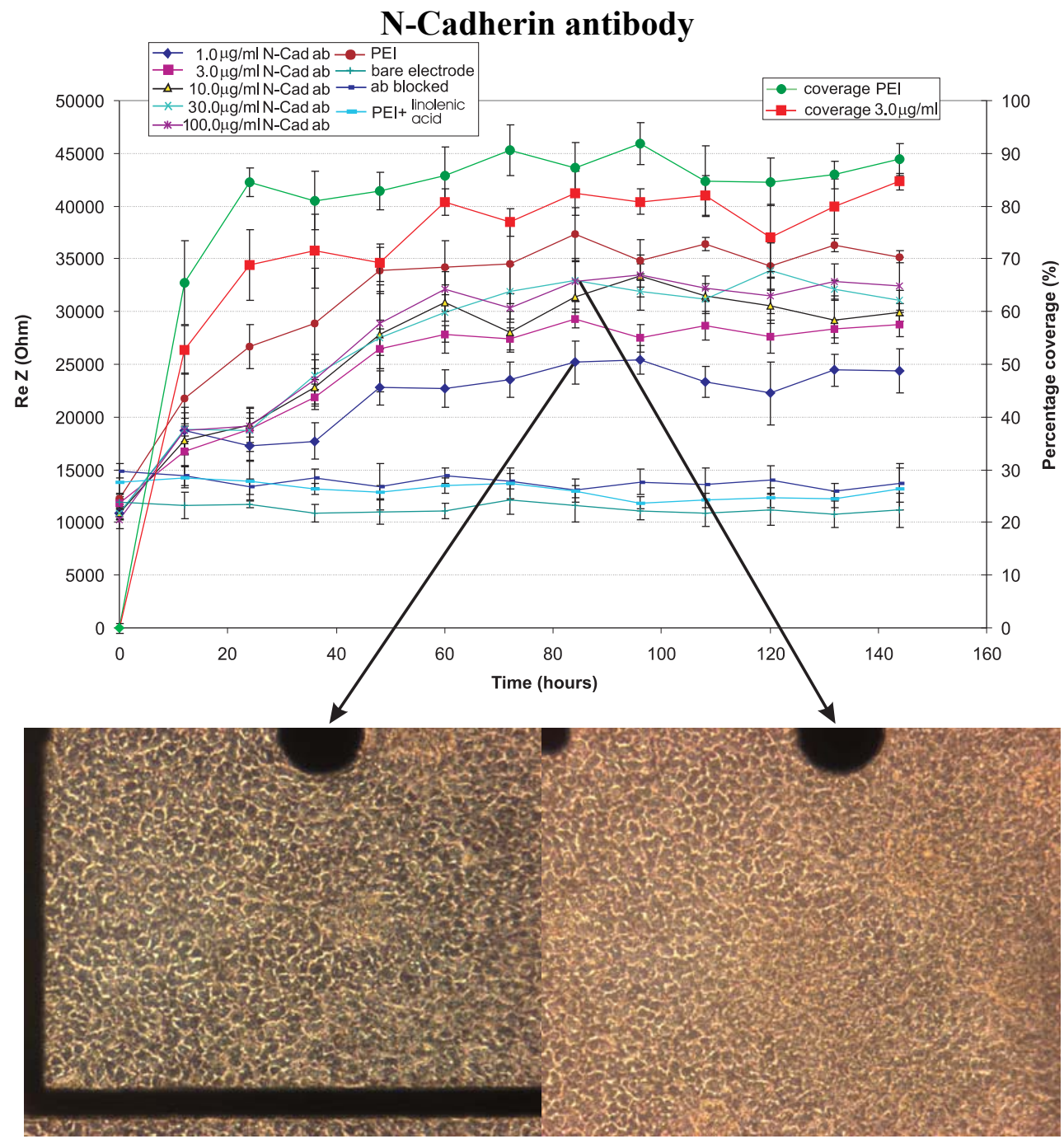

Figure 3, upper part. Real part of the impedance during development of a neuronal culture on top of an $7850 \mathrm{\mu m}^{2}$ gold electrode coated with immobilized $\mathrm{N}$-Cadherin antibody at concentrations of $0,1.0$, 3.0, 10.0, 30.0 and $100.0 \mu \mathrm{g} / \mathrm{ml}$ (ab blocked = antibody blocked by secondary antibody). Percentage cell coverage is indicated on the right vertical axis and the real impedance (at $10 \mathrm{kHz}$ ) on the left axis. $N=6$. Lower part left $=1.0 \mu \mathrm{g} / \mathrm{ml} \mathrm{N}$-Cad ab, 84 hours and lower part right $=100.0 \mu \mathrm{g} / \mathrm{ml} \mathrm{N}$-Cad ab at 84 hours. 

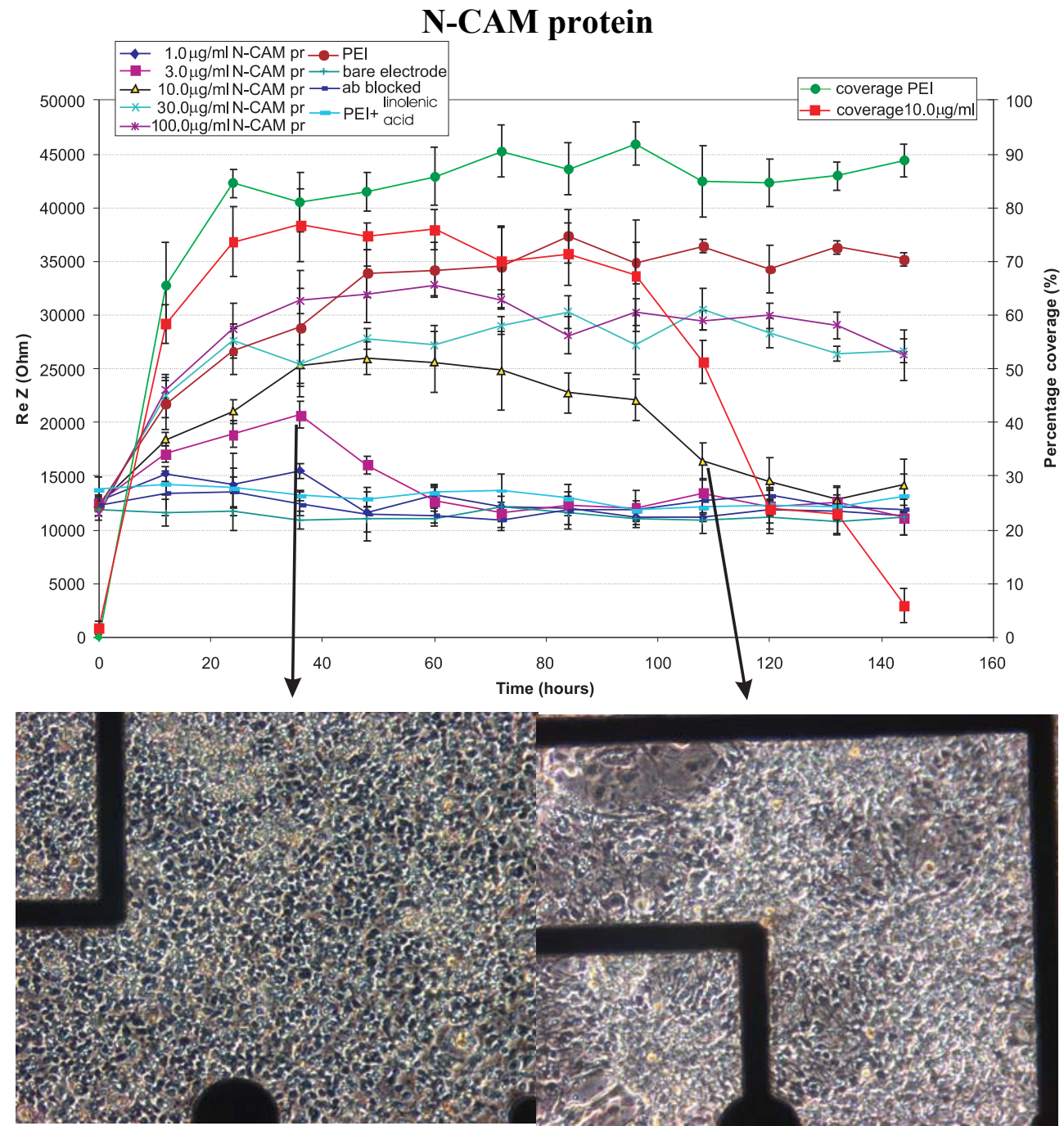

Figure 4, upper part. Real part of the impedance during development of a neuronal culture on top of an $7850 \mu^{2}$ gold electrode coated with immobilized $N$-CAM protein at concentrations of 0, 1.0, 3.0, 10.0, 30.0 and $100.0 \mu \mathrm{g} / \mathrm{ml} \mathrm{\mu g/ml} \mathrm{(ab} \mathrm{blocked} \mathrm{=} \mathrm{antibody} \mathrm{blocked} \mathrm{by} \mathrm{secondary} \mathrm{antibody).}$ Percentage cell coverage is indicated on the right vertical axis and the real impedance (at $10 \mathrm{kHz})$ on the left axis. $N=6$. Upper part left $=3.0 \mu \mathrm{g} / \mathrm{ml} \mathrm{N}$-CAM protein, 36 hours and lower part right $=10.0$ $\mu \mathrm{g} / \mathrm{ml} \mathrm{N}$-CAM protein at 36 hours. 

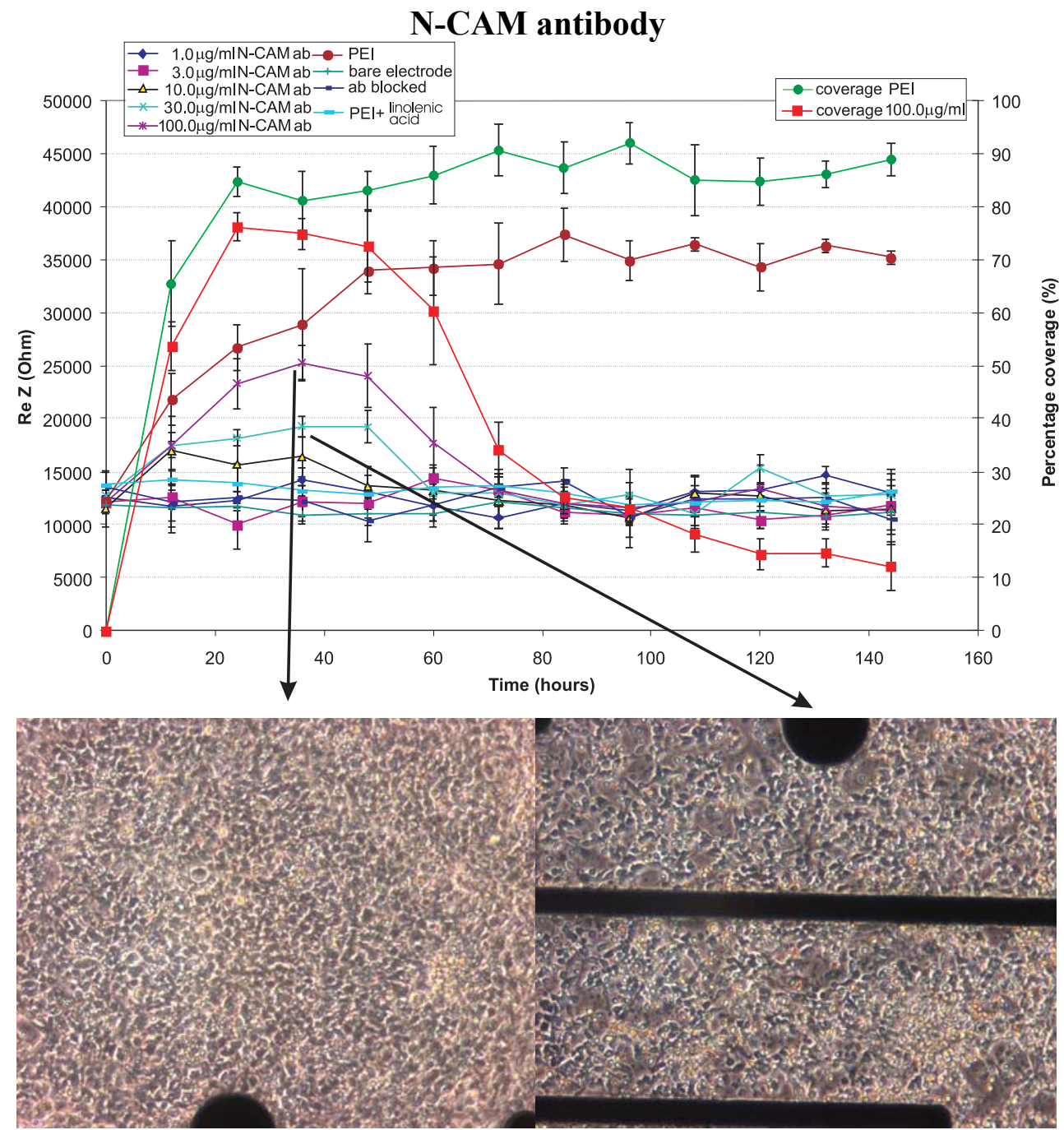

Figure 5, upper part. Real part of the impedance during development of a neuronal culture on top of an $7850 \mu^{2}$ gold electrode coated with immobilized N-CAM antibody at concentrations of 0, 1.0, 3.0, 10.0, 30.0 and $100.0 \mu \mathrm{g} / \mathrm{ml}$ (ab blocked = antibody blocked by secondary antibody). Percentage cell coverage is indicated on the right vertical axis and the real impedance (at $10 \mathrm{kHz}$ ) on the left axis. $N=6$. Lower part left $=100.0 \mu \mathrm{g} / \mathrm{ml} \mathrm{N}-C A M$ ab, 36 hours and lower part right $=30.0 \mu \mathrm{g} / \mathrm{ml} \mathrm{N-CAM}$ ab at 36 hours. 


\subsubsection{Blocking of neuron-neuron adhesion on surfaces with immobilized CAM proteins or CAM antibodies}

Like in the first experiment neurons were cultured on electrode areas modified with immobilized CAMs and anti-CAM antibodies. In this experiment however, soluble CAMs and anti-CAM antibodies were added to the cultures. Again the effect was monitored with image analysis and impedance measurements. Figures 6 through 9 present the effects of adding soluble CAM or anti-CAM antibodies, all at a concentration of $10.0 \mu \mathrm{g} / \mathrm{ml}$. From the first part of the experiment, in which we cultured neurons on immobilized CAMs and antibodies, one concentration of immobilized CAMs (proteins and antibodies) with moderate neuronal adhesion results was chosen. This way, positive and negative effects caused by soluble CAMs (proteins and antibodies) can be discriminated more effectively.

Addition of L1 protein or antibody did not have any inhibitory effects (data not shown). The dark blue line in figure 6 represents the impedance of an electrode with $30.0 \mu \mathrm{g} / \mathrm{ml}$ immobilized N-Cadherin protein. Addition of soluble N-CAM protein and antibody $(10.0 \mu \mathrm{g} / \mathrm{ml})$ had no large effect on the electrode impedance. Soluble N-Cadherin antibody and protein $(10.0 \mu \mathrm{g} / \mathrm{ml})$ both had a strong inhibitory effect on attachment and spreading of neurons on the $\mathrm{N}$-Cadherin protein surface substrate.

A substrate with $3.0 \mu \mathrm{g} / \mathrm{ml}$ immobilized N-Cadherin antibody (figure 7, blue line) is not affected by soluble N-CAM antibody $(10.0 \mu \mathrm{g} / \mathrm{ml})$. N-Cadherin protein and antibody inhibit the attachment and spreading of neurons during the whole experiment, causing lower impedances. Over time more and more small aggregates are formed. Addition of N-CAM protein causes strong aggregation and cell death after 48 hours, with low impedance as a result.

The presence of N-Cadherin protein on a N-CAM protein modified surface causes a slight decrease in impedance until 72 hours. This effect is not seen in the substrate coverage. The presence of N-Cadherin antibody shows no effect on a NCAM protein modified surface, except at 72 hours (figure 8). In contrast, N-CAM protein and antibody strongly decrease impedance and substrate coverage (data on coverage not shown).

Neurons initially adhere well when seeded on $100.0 \mu \mathrm{g} / \mathrm{ml}$ immobilized N-CAM antibody (figure 9). Nonetheless, after 48 hours neurons start aggregating, which is reflected in decreasing substrate coverage and impedance. The addition of soluble $\mathrm{N}-\mathrm{CAM}$ protein and antibody $(10.0 \mu \mathrm{g} / \mathrm{ml})$ amplifies this effect. In contrast, both the impedance and substrate coverage increase substantially in the presence of $\mathrm{N}$ Cadherin protein and antibody.

Neurons seeded on glass coated with a PEI-linolenic acid layer, but no antibodies or proteins, adhered very poorly. A comparable result is seen when the antibodies and proteins on the PEI-linolenic acid layer were blocked. 


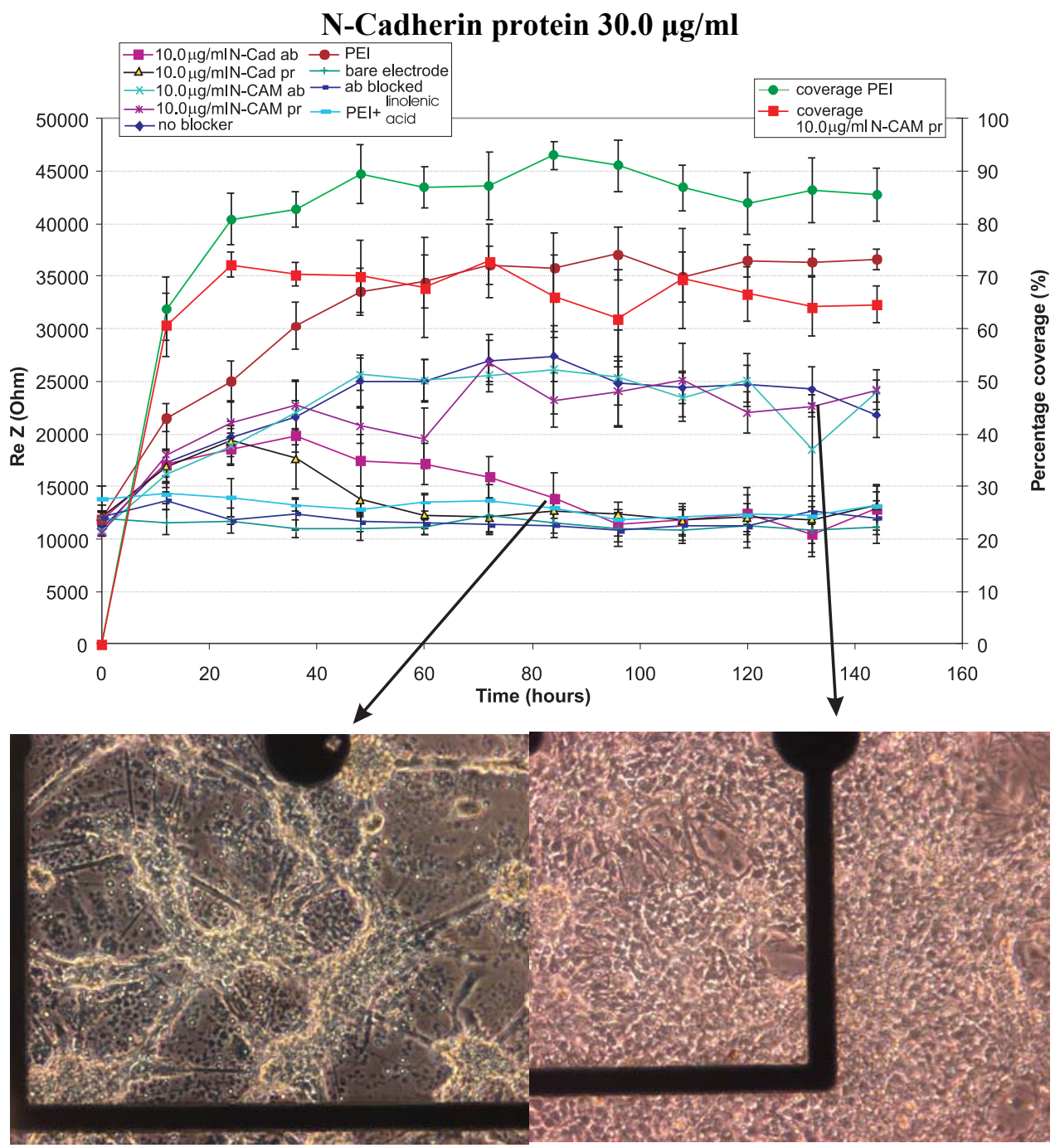

Figure 6, upper part. Real part of the impedance during development of a neuronal culture on top of an $7850 \mu^{2}$ gold electrode coated with immobilized $\mathrm{N}$-Cadherin protein at a concentrations of 30.0 $\mu \mathrm{g} / \mathrm{ml}$. The effect of soluble $\mathrm{N}$-Cadherin protein and antibody as well as $\mathrm{N}-\mathrm{CAM}$ protein and antibody at a concentrations of $10.0 \mu \mathrm{g} / \mathrm{ml}$ is presented (ab blocked = antibody blocked by secondary antibody). Percentage cell coverage is indicated on the right vertical axis and the real impedance (at $10 \mathrm{kHz}$ ) on the left axis . $N=6$. Lower part left $=$ blocking with $10.0 \mu \mathrm{g} / \mathrm{ml} \mathrm{N}$-Cad ab, 84 hours and lower part right $=$ blocking with $10.0 \mu \mathrm{g} / \mathrm{ml} \mathrm{N}$-CAM protein at 132 hours. 

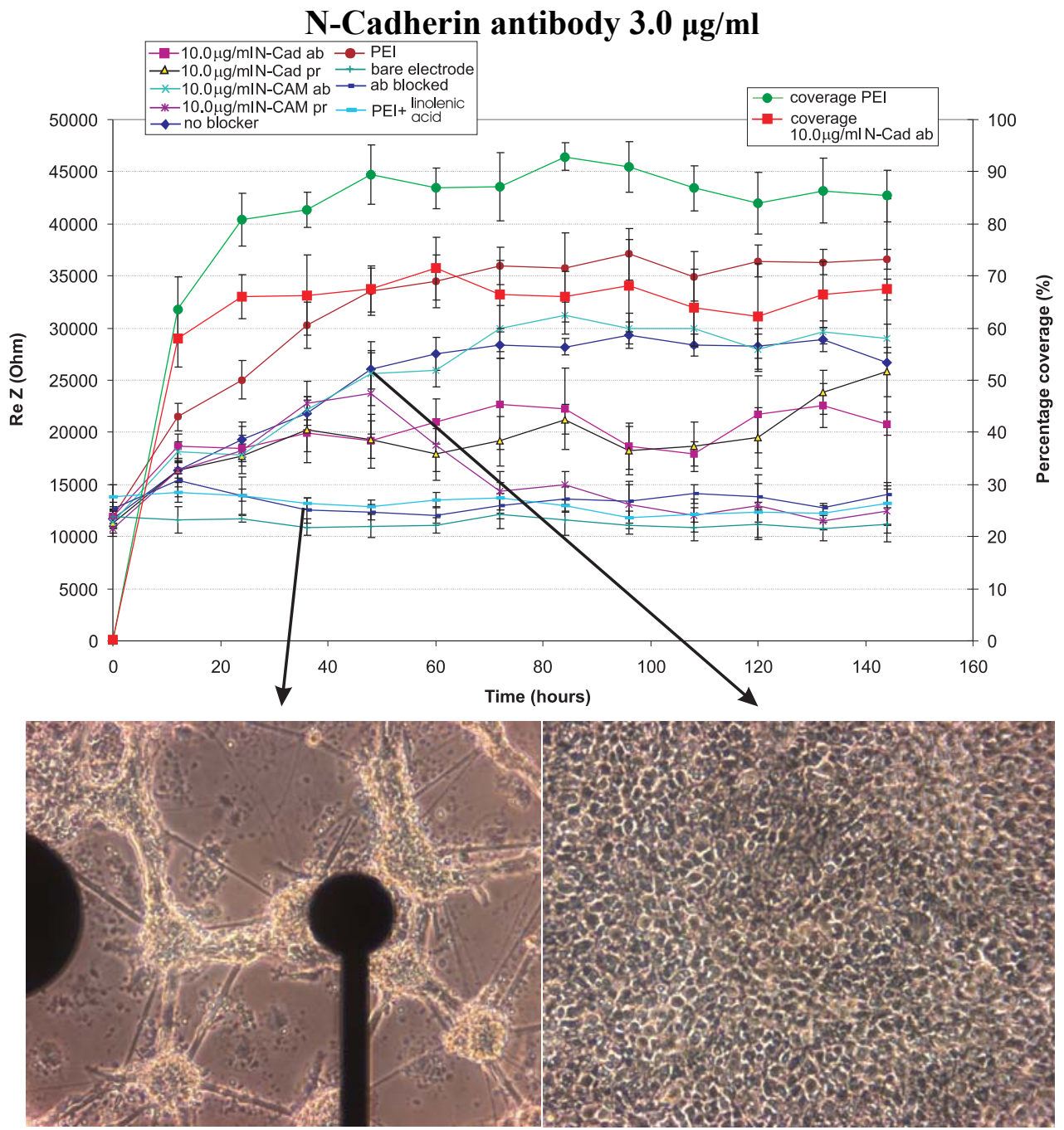

Figure 7, upper part. Real part of the impedance during development of a neuronal culture on top of an $7850 \mu^{2}$ gold electrode coated with immobilized N-Cadherin antibody at a concentrations of 3.0 $\mu \mathrm{g} / \mathrm{ml}$. The effect of soluble $\mathrm{N}$-Cadherin protein and antibody as well as $\mathrm{N}$-CAM protein and antibody at a concentrations of $10.0 \mu \mathrm{g} / \mathrm{ml}$ is presented (ab blocked = antibody blocked by secondary antibody). Percentage cell coverage is indicated on the right vertical axis and the real impedance (at $10 \mathrm{kHz}$ ) on the left axis . $\mathrm{N}=6$. Lower part left $=$ blocking with $10.0 \mu \mathrm{g} / \mathrm{ml} \mathrm{N}$-Cad ab, 36 hours and lower part right $=$ no blocker at 48 hours. 


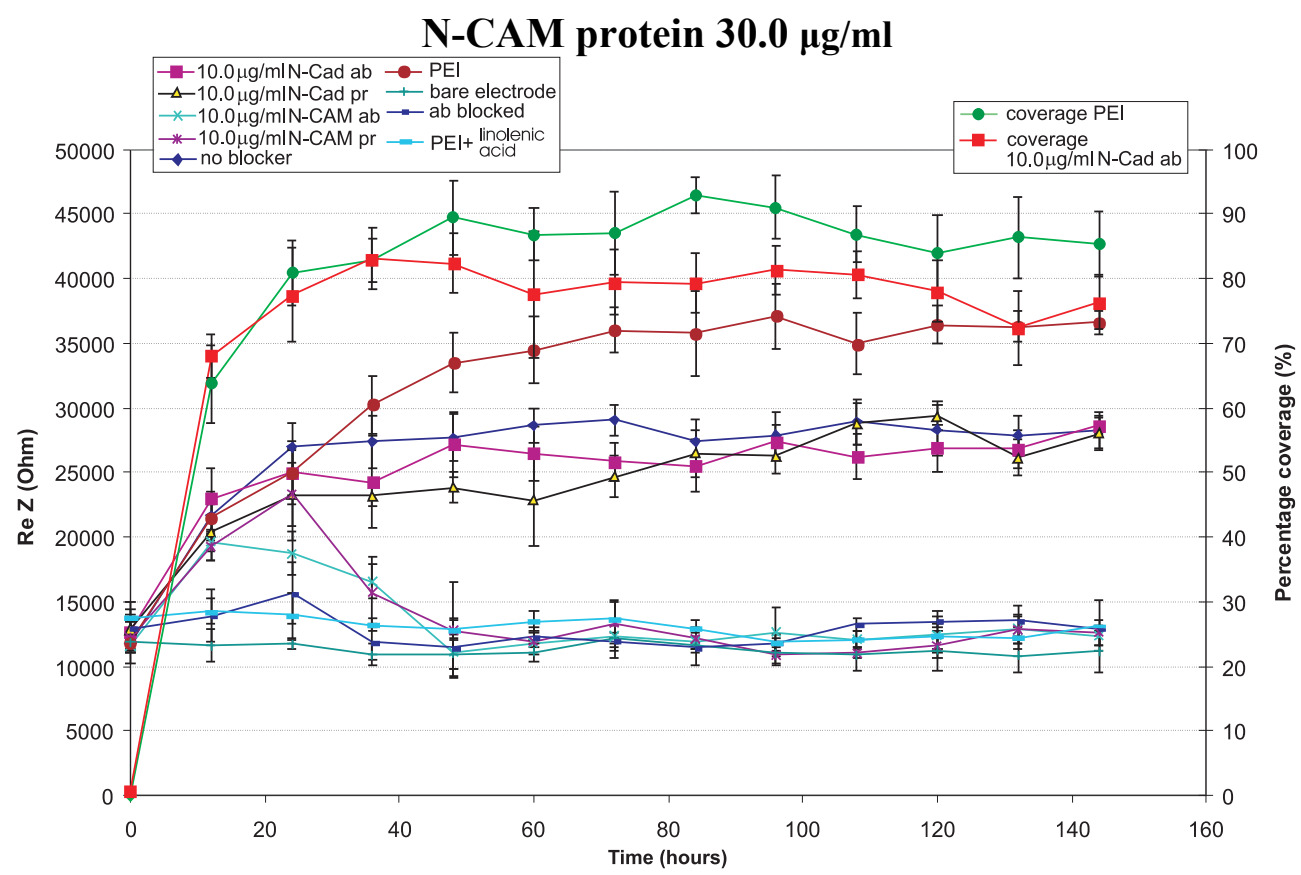

Figure 8. Real part of the impedance during development of a neuronal culture on top of an $7850 \mu^{2}$ gold electrode coated with immobilized $N$-CAM protein at a concentrations of $30.0 \mu \mathrm{g} / \mathrm{ml}$. The effect of soluble $N$-Cadherin protein and antibody as well as $N$-CAM protein and antibody at a concentrations of $10.0 \mu \mathrm{g} / \mathrm{ml}$ is presented (ab blocked = antibody blocked by secondary antibody). Percentage cell coverage is indicated on the right vertical axis and the real impedance (at $10 \mathrm{kHz})$ on the left axis . $N=6$. 


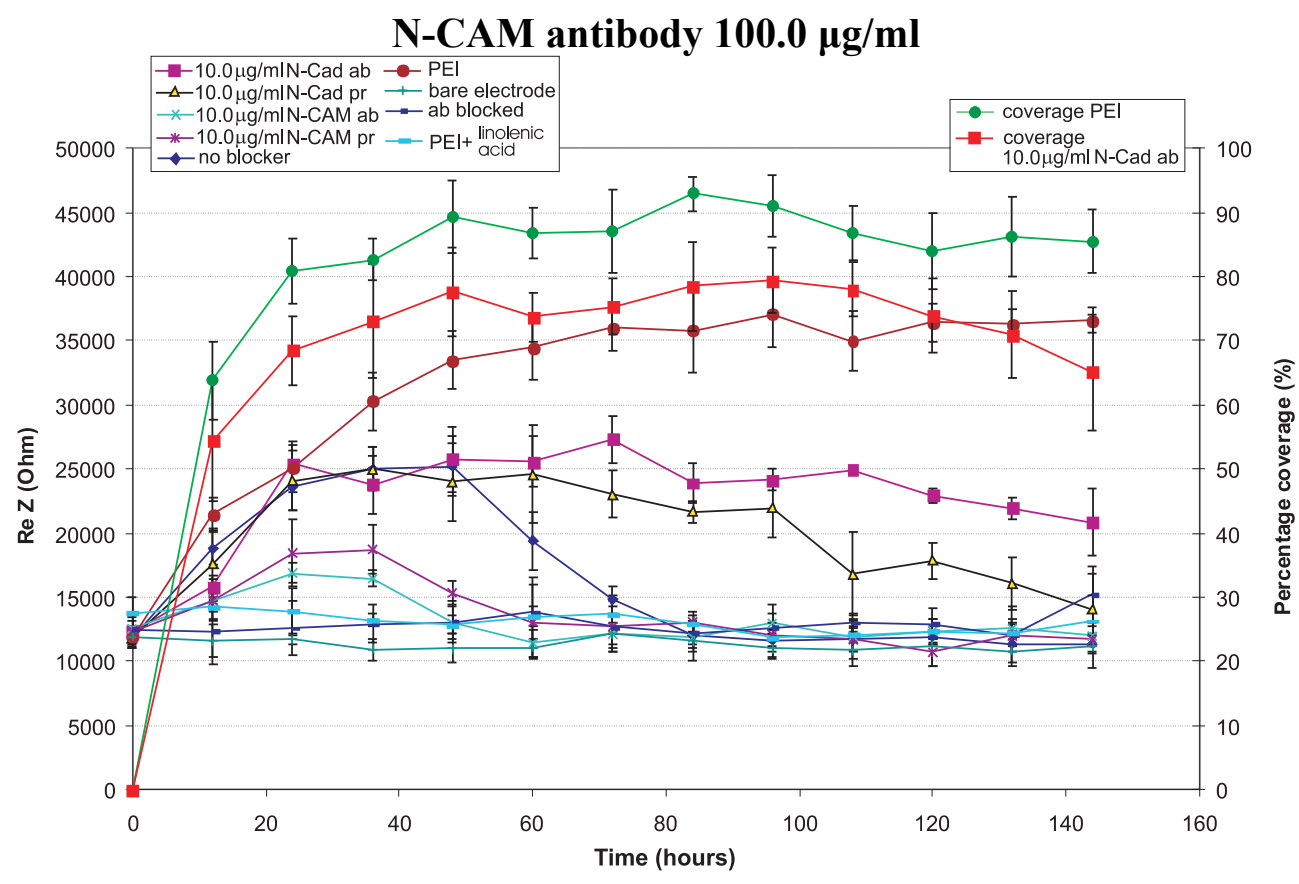

Figure 9. Real part of the impedance during development of a neuronal culture on top of an $7850 \mu^{2}$ gold electrode coated with immobilized N-CAM antibody at a concentrations of $100.0 \mu \mathrm{g} / \mathrm{ml}$. The effect of soluble $\mathrm{N}$-Cadherin protein and antibody as well as $\mathrm{N}$-CAM protein and antibody at a concentrations of $10.0 \mu \mathrm{g} / \mathrm{ml}$ is presented (ab blocked = antibody blocked by secondary antibody). Percentage cell coverage is indicated on the right vertical axis and the real impedance (at $10 \mathrm{kHz})$ on the left axis . $N=6$.

\section{Discussion}

In this study $\mathrm{N}-$ Cadherin protein, N-CAM protein, L1 protein, N-Cadherin antibody, N-CAM antibody and L1 antibody were immobilized on a glass substrate containing gold micro electrodes. PEI was used as and intermediate between the glass and the immobilized CAMs. Since PEI itself is a strong neuron adhesive, linolenic acid was immobilized together with CAM proteins and antibodies in order to cover remaining free positive amino groups on PEI. This technique cancels out the neuron adhesive properties of PEI. In order to avoid any crosslinking among CAMs and between CAMs and linolenic acid, FMOC was applied to protect the aminogroups on CAM proteins and antibodies. This limited cross linking possibilities for the carboxylic groups on the CAM proteins and antibodies to the amino groups of PEI.

The cell seeding density was chosen $1 \times 10^{6}$ cells $/ \mathrm{cm}^{2}$. At this cell concentration a maximum electrode coverage for a monolayer was accomplished. As a control neuronal adhesion on PEI-only was chosen. PEI exhibits very good neuron adhesive properties, also compared to laminin, fibronectin and poly-l-lysine. Changes of the culture's morphology were monitored with image analysis (of 
microscope pictures) and impedance measurements. IS showed to be a very useful monitoring technique in adhesion studies, adding to visual information. Together, the combination of optical evaluation with impedance measurement is a very powerful tool in adhesion studies.

As expected, neurons seeded on PEI coated surfaces $(50 \mu \mathrm{g} / \mathrm{ml})$ adhered very well. The impedance of the neuron covered electrodes increased from $12 \mathrm{kOhm}$ to 35 $\mathrm{kOhm}$. Substrate coverage by neuronal cells reached $92 \%$. Neurons cultured on immobilized linolenic (on PEI), did not spread on the substrate. This effect is caused by a long non-polar and "inert tail" sticking out towards the culturing medium. In combination with immobilized CAMs, this effect prevents any binding of neurons to the PEI rather than to the immobilized CAMs.

Neuronal cells cultured on immobilized L1 protein or anti-L1 antibody did not adhere. L1 is known to be involved in axonal guiding, but the adhesive properties of L1 did not seem to apply for neuronal somas (data not presented). Also, addition of soluble L1 did not have any effect on neuronal cultures at any concentration.

The adhesion of neuronal cells on immobilized $\mathrm{N}$-Cadherin protein is concentration dependent over the whole applied range. At a concentration of $100.0 \mu \mathrm{g} / \mathrm{ml}$ the impedance increases to $33 \mathrm{kOhm}$. This is comparable to that of a PEI coated electrode. At lower concentrations the spreading of neurons is delayed according to substrate coverage and impedance. The inferior cell-substrate adhesion at lower concentration becomes overruled by cell-cell adhesion, causing aggregation. The degree and rate of aggregation is also concentration dependent. The other immobilized CAM proteins and antibodies demonstrated concentration dependent neuronal adhesion. High concentrations of $\mathrm{N}$-Cadherin protein and anti-NCadherin antibody are most applicable as substrates for neuronal adhesion. However, lower concentrations of anti N-Cadherin antibody have better neuron adhesive properties compared to low concentrations of N-Cadherin protein. It's hard to say if this is due to a better or more stable connection between the neuronal cells and the substrate.

Neurons seeded on $100.0 \mu \mathrm{g} / \mathrm{ml}$ immobilized N-CAM antibody initially adhere well. After 48 hours both impedance and substrate coverage decrease drastically. In contrast to $\mathrm{N}$-Cadherin protein and antibody, the neuron adhesive property of immobilized N-CAM antibody is not capable to avoid aggregation of neurons over a longer period of time. Immobilized N-CAM protein at concentrations over 30.0 $\mu \mathrm{g} / \mathrm{ml}$ demonstrates good neuronal adhesion. A decrease in impedance is seen at $10.0 \mu \mathrm{g} / \mathrm{ml}$ especially after 96 hours. A less profound decrease in impedance was observed for $100.0 \mu \mathrm{g} / \mathrm{ml}$ after 72 hours.

In the second series of experiments, cell adhesion molecules on neuronal cells were blocked by adding the same CAM proteins and antibodies used to alter the substrate. The soluble CAM proteins and antibodies were added to cell populations growing on CAM protein or antibody immobilized substrates. Since all of the applied CAMs show homophilic binding, competition between soluble CAMs and CAMs on neurons for binding immobilized substrate CAMs was expected. The 
results obtained in the blocking experiments partly confirmed this presupposition. Soluble N-Cadherin protein and anti-N-Cadherin antibody strongly inhibited adhesion of neurons to immobilized N-Cadherin protein. However, the effect of soluble N-Cadherin protein and anti-N-Cadherin antibody on neurons cultured on immobilized N-Cadherin antibody was less profound. Connections between membrane bound N-Cadherin and immobilized N-Cadherin antibody are probably stable enough to overcome the formation of new connections with soluble $\mathrm{N}$ Cadherin protein or antibody.

Neurons cultured on immobilized N-CAM protein are only slightly affected by the addition of soluble N-Cadherin protein or N-Cadherin antibody (figure 8). The impedance decreased slightly. However, no significant difference in substrate coverage was observed, suggesting larger intercellular space, caused by inhibited cell-cell adhesion. The presence of N-CAM protein and antibody further inhibits the already poor adhesion of neurons to the N-CAM antibody substrate. Aggregation of neurons on immobilized N-CAM antibody is inhibited by both soluble N-Cadherin protein and N-Cadherin antibody (figure 9). These molecules seem to block membrane bound $\mathrm{N}$-Cadherin, thereby inhibiting N-Cadherin based cell-cell adhesion. The diminished cell-cell adhesion delays or prevents aggregation of neurons. The addition of N-CAM protein and antibody causes neurons to detach and aggregate strongly.

This study demonstrates the usability of immobilized cell adhesion molecules or their antibody counterparts as substrate coatings for neuronal cultures. The results of the blocking study display a competition mechanism among soluble CAMs and immobilized CAMs of the same type, revealing a stronger or more stable antibody-protein bond compared to protein-protein bonds. Also, N-Cadherin bonding (both antibody-protein and proteinprotein) seems to be stronger or more stable in comparison to N-CAM bonding.

\section{References}

[1] Kwon Y T, Gupta A, Zhou Y, Nikolic M and Tsai L 2000 Regulation of Ncadherin-mediated adhesion by the p35-Cdk5 kinase Curr. Biol. $10363-72$

[2] Gago N, Avellana-Adalid V, Baron-Van Evercooren A and Schumacher M 2003 Control of cell survival and proliferation of postnatal PSA-NCAM ${ }^{+}$ progenitors Mol. Cell. Neurosci. 22 162-78

[3] Craighead H G, Turner S W, Davis R C, James C, Perez A M, St. John P M, Isaacson M S, Kam L, Shain W, Turner J N and Banker G 1998 Chemical and topographical surface modification for control of central nervous system cell adhesion biom. microdev. 1 49-64 
[4] Nicolau D V, Taguchi T, Taniguchi H, Tanigawa H and Yoshikawa S 1999 Patterning neuronal and glia cells on light-assisted functionalised photoresists Biosens. Bioelectrons. 14 317-25

[5] Blau A, Weinl C, Mack J, Kienle S, Jung G and Ziegle C 2001 Promotion of neural cell

adhesion by electrochemically generated and functionalized polymer films J. Neurosci. Meth. 15 65-73

[6] Yavin E and Yavin Z 1974 Attachment and culture of dissociated cells from rat embryo cerebral hemispheres on polylysine-coated surfaces $J$. Cell. Biol. 62 540-6

[7] Liu B, Ma J, Gao E, He Y, Cui F and Xu Q 2008 Development of artificacial neuronal network network with post-mitotic rat fetal hippocampal cells by polyethyleneimine Biosens. Bioelectrons. 23 1221-8

[8] Ruardij T G, Goedbloed M H and Rutten W L C 2000 Adhesion and patterning of cortical neurons on polyethylenimine and fluorocarboncoated surfaces IEEE Trans. Biomed. Eng. 47 1593-9

[9] Ruardij T G, van den Boogaart M A F and Rutten W L C 2002 Adhesion and growth of electrically-active cortical neurons on polyethyleneimine patterns microprinted on PEO-PPO-PEO triblockcopolymer-coated hydrophobic surfaces IEEE Trans. Nanobiosci. 1 1-8

[10] Ruardij T G, Goedbloed M H and Rutten W L C 2003 Long-term adhesion and survival of dissociated cortical neurons on miniaturized chemical patterns Med. Biol. Eng. Comp. 41 227-32

[11] Federoff S and Richardson A Protocols for neural cell culture. pp 248-9 isbn 0-89603-902-1.

[12] Hynes RO 1999 Cell adhesion: old and new questions Trends. Genets. 15 $\mathrm{m} 33-7$

[13] Venstrom K A and Reichardt L F 1993 Extracellular matrix 2: Role of extracellular matrix molecules and their receptors in the nervous system FASEB J. 7 996-1003

[14] Heiduschka P, Romann I, Ecken H, Schöning M, Schuhmann W and Thanos S 2001 Defined adhesion and growth of neurons on artificial structured substrates Electrochim. Acta. 47 299-307

[15] Loers G, Chen S, Grumet M and Schachner M. 2005 Signal transduction pathways implicated in neural recognition molecule L1 triggered neuroprotection and neuritogenesis J. Neurochem. 92 1463-76

[16] Bates C A, Becker C G, Miotke J A and Meyer R L 1999 Expression of polysialylated NCAM but not L1 or N-cadherin by regenerating adult mouse optic fibers in vitro Exp. Neurol. 155 128-39

[17] Kenwrick S, Watkins A and De Angelis E 2000 Neural cell recognition molecule L1: relating biological complexity to human disease mutations Hum. Mol. Genet. 9 879-86 
[18] Landmesser L, Dahm L, Schultz K and Rutishauser U 1988 Distinct roles for adhesion molecules during innervation of embryonic chick muscle Dev. Biol. 130 645-70

[19] Sorribas H, Braun D, Leder L, Sonderegger P, Tiefenauer L 2000 Adhesion proteins for a thight neuron-electrode contact J. Neurosci. Meth. 104133 41

[20] Azemi E, Stauffer W R, Gostock M S, Lagnaur CF, and Cui XT 2008 Surface immobilization of neuronal adhesion molecule L1 for improving the biocompatibility of chronic neuronal probes: In vitro characterization Acta biomater. 4 1208-17

[21] Lambert M, Padilla F and Mege R M 2000 Immobilized dimers of Ncadherin-Fc chimera mimic cadherin-mediated cell contact formation: contribution of both outside-in and inside-out signals J. Cell. Sci. 113 2207-19

[22] Kadmon G, Kowitz A, Altevogt P and Schachner M 1990 The neural cell adhesion molecule N-CAM enhances L1-dependent cell-cell interactions J.Cell.Biol. 110 193-208

[23] Guan J, Miao Y and Zhang Q 2004 Impedimetric biosensors J. Biosci. Bioeng. 97 219-26

[24] Liu H, Plopper G, Early S, Chen Y,. Ferguson B and Zhang X. C 2007 Sensing minute changes in biological cell monolayers with $\mathrm{THz}$ differential time-domain spectroscopy Biosens. Bioelectron. 22 1075-80

[25] Lo C M, Keese C R and Giaever I $1994 \mathrm{pH}$ changes in pulsed CO2 incubators cause periodic changes in cell morphology Exp. Cell. Res. 213 391-7

[26] Ehret R, Baumann W, Brischwein M, Schwinde A and Wolf B 1998 Online control of cellular adhesion with impedance measurements using interdigitated electrode structures Med. Biol. Eng. Comput. 36 365-70

[27] Xiao C, Lachance B, Sunahara G and Luong J 2002 Assessment of cytotoxicity using electric cell-substrate impedance sensing: concentration and time response function approach Anal. Chem. 74 5748-53

[28] Wegener J, Giaever I and Keese C R 2000 Electric cell-substrate impedance sensing (ECIS) as a noninvasive means to monitor the kinetics of cell spreading to artificial surfaces Exp. Cell. Res. 259 158-66

[29] Luong J H T, Xiao C, Lachance B, Leabu S M, Li X, Uniyal S and Chan B M C 2004 Extended applications of electric cell-substrate impedance sensing for assessment of the structure-function of $\alpha 2 \beta 1$ integrin Anal. Chim. Acta. 501 61-9

[30] Sharma K V, Koenigsberger C, Brimijoin S, Bigbee J W 2001 Direct evidence for an adhesive function in the noncholinergic role of acetylcholinesterase in neurite outgrowth $J$. Neurosci. Res. 63 165-75

[31] Bieberich E and Guiseppi-Elie A 2004 Neuronal differentiation and synapse formation of PC12 and embryonic stem cells on interdigitated 
microelectrode arrays: contact structures for neuron-to-electrode signal transmission (NEST) Biosen. Bioelectrons. 19 923-31

[32] Romijn H J, Van Huizen F and Wolters P S 1984 Towards an improved serum free, chemically defined medium for long term culturing of cerebral cortex tissue Neurosci. Biobehav. Rev. 8 301-44

[33] Buitenweg J R, Rutten W L C and Marani E 2003 Geometry based finiteelement modeling of the electrical contact between a culture neuron and a microelectrode IEEE Trans. Biomed. Eng. 50 501-10

[34] Buitenweg J R, Rutten W L C, Willems W P A and van Nieuwkasteele J W 1998 Measurement of sealing resistance of cell-electrode interfaces in neuronal cultures using impedance spectroscopy Med. Biol. Eng. Comput. 36, 630-637.

[35] de Boer R W, van Oosterom A 1978 Electrical properties of platinum electrodes: impedance measurements and time-domain analysis Med. Biol. Eng. Comput. 16 1-10 
Chapter 6

General Discussion 


\subsection{Monitoring culture topography}

This research was carried out to understand the role of cell-cell adhesion and cellsubstrate adhesion in neuronal aggregation and the stability of neuronal culture topography. Impedance Sensing (IS) was used to monitor changes in neuronneuron and neuron-substrate adhesion and compared to microscopic evaluation of culture topography. After IS was described for the first time by Giaever and Keese in 1986 [1] it evolved into a biosensor that has been applied in a wide range of cell studies. However, no application for IS has been reported so far regarding monitoring of primary neuronal cells. Only neuronal cancer cell lines like PC-12 and neuroblastoma lines have been subject of studies involving IS [2].

In chapter 2 the IS monitoring technique was investigated and optimized for cultures of primary dissociated cortical neurons. The results from chapter 2 show that IS can effectively monitor changes in neuronal cultures under the right conditions. When IS is optimized for frequency, electrode size and electrode shape a $250 \%$ increase in impedance is measured after complete coverage of IS electrodes by neuronal cells. IS does monitor small changes in developing cultures, which are hardly detectable by microscopy and image analysis. IS is especially suitable for monitoring of an average state of a relatively large area in a culture, but is very limited in providing information on small irregularities within the monitoring area. IS is also a relatively easy technique for acquisition of quantitative data on culture dynamics. Due to the measuring setup the maximum applicable frequency was $20 \mathrm{kHz}$. A higher frequencies could probably further increase the sensitivity for neuron sensing. In a study by Wegener et al (2000) a frequency of $40 \mathrm{kHz}$ showed to be optimal for impedance sensing of epithelial cells [3].

Phase contrast microscopy is more suitable for detecting small irregularities, but for general characterization, time consuming image processing is necessary. Furthermore, phase contrast microscopy is only capable of providing an on-top over view of a culture, complicating data acquisition from the cell-substrate area.

\subsection{Cell substrate adhesion}

Several in vivo (cell engineered electrodes for prostheses) and in vitro applications (2D neuronal networks) in neuro-engineering involve contact between flat substrates and neuronal cells. In most cases an intimate and durable contact between electrode surfaces and neurons is a necessity.

A culturing surface can be modified for cell hosting in many ways. Physical obstruction with micro walls or micro pillars can keep cells in the desired position. However, these microstructures are hard to create and besides keeping cells in place, they do not enhance cell-substrate contact [4, 5]. In contrast, neuron adhesive coatings bind neuronal cells through a relatively strong cell-substrate interaction. In general, modification of culturing surfaces with neuron adhesive 
coatings is a rather straightforward technique that can also be combined with micro-patterning, enabling construction of patterned networks in culture [6]. In the past decades, numerous (bio)chemicals have been investigated on their ability to direct neuronal adhesion, using (synthetic) polymers [7-11], ECM proteins [6, 12, 13] and immobilized CAMs [14-16]. These individual studies focussed on (bio)chemicals from one and occasionally two of these three types. Also a variety of different neuronal cell types was used among the individual studies (dorsal root ganglion, ciliary ganglion, cortical neurons and cancer cell lines).

We chose to investigate several substrate coatings with different mechanisms of binding neuronal cells. As coatings, we compared PEI, PLL, fibronectin, laminin and 3 different neuronal cell adhesion molecules: N-Cadherin, N-CAM and L1. Figure 1 represents the impedance of electrodes covered with developing neuronal cultures.

PEI clearly represents the best neuron adhesive properties. Cells bind to positive charged amine groups in PEI through their negatively charged cell membrane. Cells bind to PLL coated surfaces in the same way in the first 60 hours of the experiment. However, a clear decline in impedance is seen over a longer period, indicating a decrease in cell-substrate adhesion. Several aspects are suspected to be involved in this difference of neuron adhesive property. The amount and distribution of positively charged amine groups is probably different. PEI might have a higher density of amine groups. A difference in the degree of branching of polymer chains might also cause a difference in neuron adhesive properties. Another likely option would be the degradability of PLL, which would explain the initially good adhesive properties of PLL.

Fibronection and laminin are both components of the extracellular matrix that connect to the membrane bound adhesion molecule integrin. Figure 1 shows relatively weak neuron adhesive properties for fibronectin and laminin. These limited adhesive properties can be caused by low binding forces between integrins and ECM molecules or by a limited amount of integrin molecules on the cell membrane. Fibronectin and laminin show an almost identical course of impedance development, except at 12 hours. The difference at that time may be caused by the fact that fibronectin and laminin bind to different integrin subtypes.

In contrast to fibronectin and laminin, N-Cadherin, N-CAM and L1 are membrane bound adhesion molecules, initiating homophilic binding. In this study culturing surfaces were coated with CAM peptides and CAM antibodies. Figure 1 displays the impedance of electrodes coated with N-Cadherin peptide, N-Cadherin antibody, N-CAM peptide and N-CAM antibody (L1 data are not shown). Only the N-CAM antibody coating shows relatively weak neuron adhesive properties. Immunohistologic staining did confirm attachment of N-CAM antibody to neuronal membrane bound N-CAM. These results suggest weaker binding forces between N-CAM antibody and membrane bound N-CAM when comparing with other N-CAM and N-Cadherin coatings.

$\mathrm{N}$-Cadherin peptide, N-Cadherin antibody and N-CAM peptide display slightly lower neuron adhesive properties compared to PEI, but better than PLL. Judging on 
neuron adhesive properties only, PEI would be the best choice to establish a long term neuron-substrate contact. However, depending on the purpose of a study or application, a bioactive surface coating might still be a better choice. Cell surface receptors like CAMs and integrins are also known to promote several cellular processes. For example, laminin and fibronectin promote proliferation, differentiation, axonal outgrowth and survival when binding to integrin [17-19], whereas N-CAM and L1 contribute to several cellular pathways that activate and regulate axonal guiding, neuronal tissue morphogenesis, tissue differentiation, regeneration and synaptic plasticity [20-22].

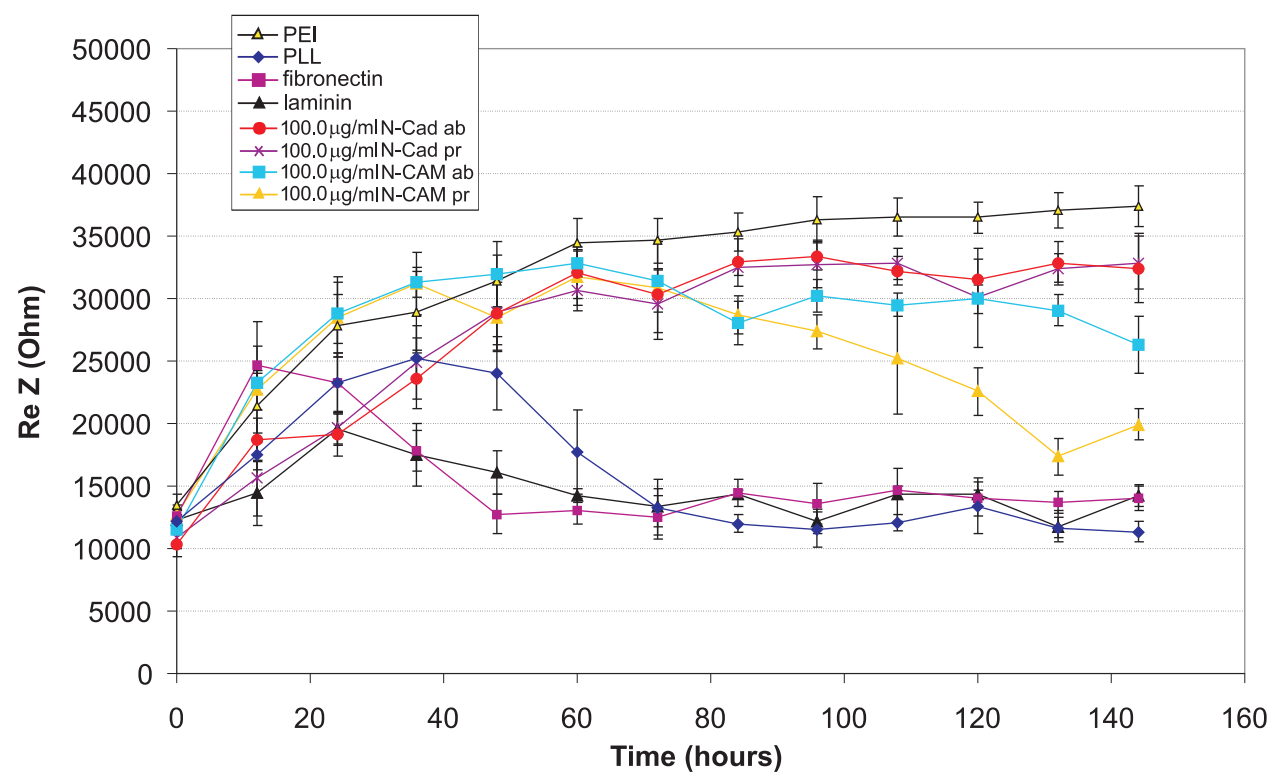

Figure 1. The real impedance during development of neuronal cultures on top of $7850 \mu^{2}$ gold electrodes measured at a frequency of $10 \mathrm{kHz}$. Comparison between PEI, Laminin, PLL, fibronectin, $N$-Cadherin antibody, $N$-Cadherin protein, $N$-CAM antibody and $N$-CAM protein as substrate coatings. $N=6$.

\subsection{Cell-cell adhesion}

Chemical modification of a culturing surface is a powerful tool to create a neuron adhesive substrate. Depending on a culture's purpose, one can choose among several chemical coatings, all with different properties. However, despite the use of neuron adhesive substrates, neuronal cells in culture can adhere to surrounding cells, using these nearby cells as a foothold for migration and aggregation. We focused on neuron adhesive properties of surface coatings, but also on how to prevent cell-substrate adhesion forces from being overruled by cell-cell adhesion forces. 
Several blocking studies demonstrated the importance of N-CAM, L1 and Ncadherin for the development of the nervous system. For example, microinjection of N-CAM and N-Cadherin antibodies into the midbrain neural tube causes abnormalities in the neural tube and neural crest and limited neural crest cell migration [23]. Studies on L1-knockout mice have confirmed that L1 is an important molecule for the development of the nervous system [24, 25]. Blocking or gene knock-out of one of these membrane molecules clearly affected cell adhesion between neurons. For example, absence of N-Cadherin or N-CAM on the cell surface of cortical neurons strongly inhibited aggregation of these cells [26, 27]. The same effect was obtained with N-CAM negative cells. L1-mediated cellcell adhesion can also be inhibited indirectly by a peptide antagonist of ethanol [28]. Also several cancer cell cultures like PC12, ARM, 2B2, MCF-7/AZ and PL $\beta 2$ cell lines demonstrated significant inhibition of cell adhesion in the presence of $\mathrm{N}$ Cadherin antibody [29].

We showed that blocking of cell adhesion molecules with soluble peptide antagonists or antibodies can inhibit adhesion among cells, diminishing migration (and consequently aggregation) of neuronal cells. On PEI, blocking of membrane bound N-Cadherin was clearly more effective in inhibiting cell adhesion compared to N-CAM and L1 blocking. Formation of well sealing monolayers of cortical neurons is delayed by the presence of $\mathrm{N}$-Cadherin peptide and $\mathrm{N}$-Cadherin antibody (chapter 3). N-Cadherin antibody was also effective in blocking neuronneuron adhesion of cells cultured on fibronectin, PLL and laminin. None of the other blockers could inhibit neuron-neuron adhesion on fibronectin and laminin during the 144 hours of the experiments. The inhibitory effect on both PEI and PLL is present for 144 hours. This implies a continuous and steady effect of the added blockers during the 144 hours of the experiment. Most probably the biodegrability of fibronectin and laminin causes the temporary effect of cell-cell adhesion inhibition by the added blockers.

The difference in inhibition properties between N-Cadherin and N-CAM might be caused by a difference in strength of the homophilic bonds. Cadherin bonds are know to be stronger than any other known protein to protein bond, whereas NCAM bonds can be weakened by post-translational modification with polysialic acid (PSA) which reduces the adhesive properties of N-CAM [30]. This could explaining the different inhibitory properties of N-Cadherin and N-CAM.

L1 antibody and L1 protein had no effect on the impedance of cell covered electrodes when cells were cultured on either of the surface coatings. Immunocytological staining of cortical neurons used in the experiments (data not shown) indicated the presence of both N-CAM and N-Cadherin. However, the immuno-reactivity of cortical neurons for L1 was quite low. A low presence of membrane bound L1 is most probably the reason for detecting no inhibition of cellcell adhesion and aggregation during blocking with L1 peptide or antibody.

Addition of soluble CAM blockers, to neuronal cells that are cultured on immobilized CAMs substrates, can have two different effects. Since all of the 
applied CAMs show homophilic binding, competition between soluble CAMs and neuron-bound CAMs for binding to the immobilized CAMs substrate can be expected. Addition of soluble CAM peptide or antibody inhibits adhesion of neurons to immobilized CAM peptides and antibodies of the same kind (figure 2). For example, N-Cadherin antibody inhibits adhesion of neurons to immobilized NCaderin peptide or antibody (table 1). The neuron adhesive properties of immobilized N-Cadherin protein were inhibited more than those of immobilized NCadherin antibody when soluble N-Cadherin protein and anti-N-Cadherin antibody were present (table 1). The bonds between membrane bound N-Cadherin and immobilized N-Cadherin antibody are probably stable enough to overcome formation of new connections with soluble $\mathrm{N}$-Cadherin protein or antibody. The inhibition of cell-substrate adhesion can give interesting answers regarding competition mechanisms among CAM blockers, revealing a stronger or more stable antibody-protein bond compared to protein-proteins bonds. However, inhibition of both cell-substrate and cell-cell adhesion causes a very poor culturing environment, making a combination of soluble and immobilized CAMs of the same type useless. In several other combinations, in which soluble and immobilized CAMs are not of the same type, the aggregation of neurons can be inhibited. In the presence of both soluble $\mathrm{N}$-Cadherin protein and $\mathrm{N}$-Cadherin antibody aggregation of neurons on immobilized N-CAM antibody and N-CAM protein is inhibited. This study demonstrates the usefulness of immobilized cell adhesion molecules or their antibody counterparts as inhibitors of neuronal migration and aggregation in culture.

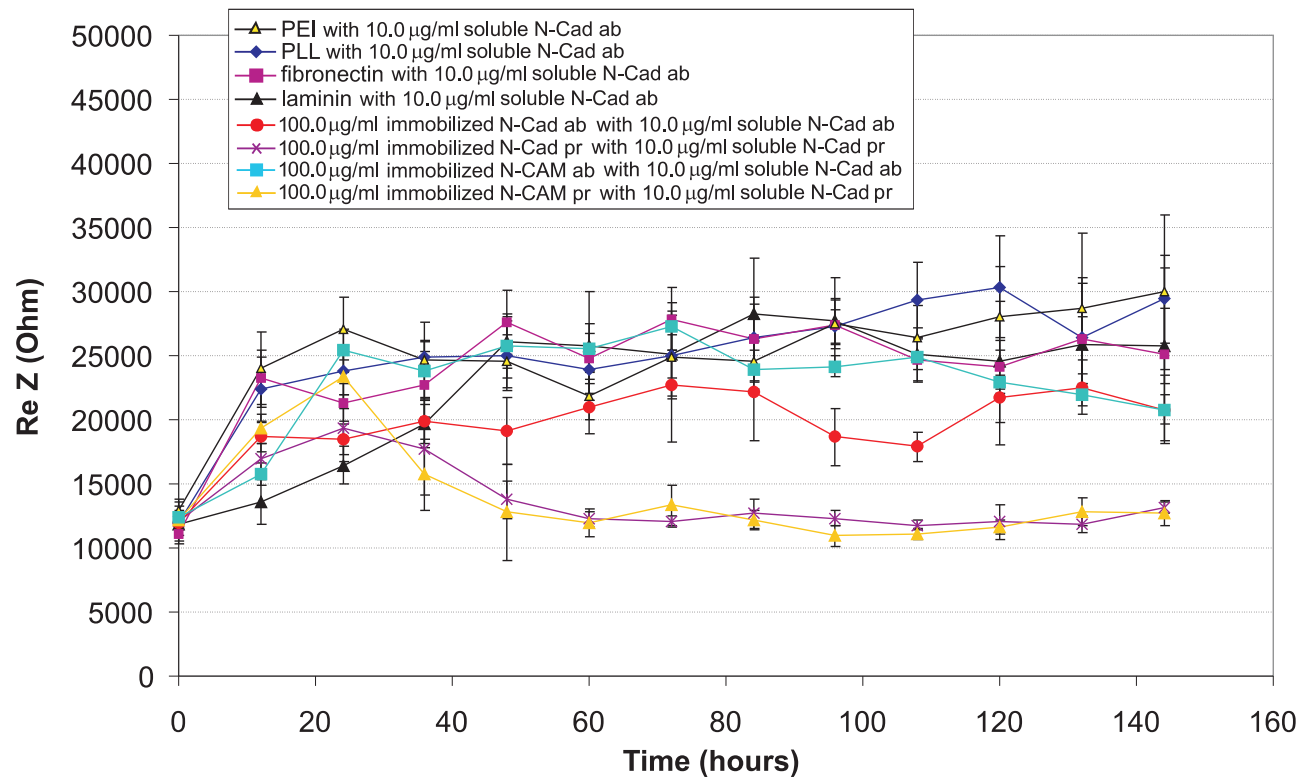


Figure 2. The real impedance during development of neuronal cultures on top of $7850 \mu \mathrm{m}^{2}$ gold electrodes measured at a frequency of $10 \mathrm{kHz}$. Comparison between PEI, Laminin, PLL, fibronectin, $\mathrm{N}$-Cadherin antibody, $\mathrm{N}$-Cadherin protein, N-CAM antibody and N-CAM protein as substrate coatings, but now with soluble CAM blockers. In this graphic the blockers with the strongest effect on the impedance are represented. $N=6$.

Table 1. Overview of the blocking effect of L1, N-Cadherin and NCAM (highest concentration peptides and antibodies) on neurons cultured on PEI, PLL, fibronectin and laminin, immobilized NCadherin antibody, immobilized $N$-Cadherin protein, immobilized $N$-CAM antibody and immobilized $N$-CAM protein $--=$ no effect, $+=$ moderate blocking effect, $++=$ strong blocking effect, $c . d .=$ cell death, $O=$ inhibition of cell-substrate adhesion. ("results from previous study, $N=6$ )

\begin{tabular}{l|ccccccc}
\hline $\begin{array}{l}\text { Substrate } \\
\downarrow\end{array}$ & $\begin{array}{c}\text { Blockers } \\
\rightarrow\end{array}$ & $\begin{array}{c}\text { L1 } \\
\text { antibody }\end{array}$ & $\begin{array}{c}\text { L1 } \\
\text { protein }\end{array}$ & $\begin{array}{c}\text { N-Cad } \\
\text { antibody }\end{array}$ & $\begin{array}{c}\text { N-Cad } \\
\text { protein }\end{array}$ & $\begin{array}{c}\text { N-CAM } \\
\text { antibody }\end{array}$ & $\begin{array}{c}\text { N-CAM } \\
\text { protein }\end{array}$ \\
\hline PEI & & - & - & ++ & + & - & c.d. \\
Fibronectin & - & - & ++ & + & + & - \\
PLL & - & - & + & c.d. & - & c.d. \\
Laminin & - & - & ++ & + & + & - \\
N-Cadherin antibody & - & - & O & O & - & c.d. \\
N-Cadherin protein & - & - & O & O & - & - \\
N-CAM antibody & - & - & + & + & O & O or c.d. \\
N-CAM protein & - & - & - & + & O & O or c.d. \\
\hline
\end{tabular}

\subsection{Cell Signalling}

Besides acting as physical anchors, N-CAM, N-Cadherin and L1 are also involved in transmembrane signalling, affecting the behaviour and fate of cells in several ways [31-34]. Soluble proteins bind to CAMs on the cell membrane in the same way as CAMs of adjacent cells bind to each other. The signal inducing properties of antibodies depend on to what extent antibodies can mimic homophilic binding between CAMs. Although binding to the same receptor, signaling events might be cancelled out by antibodies. Antibodies bind to antigens on CAMs, but it seems less likely that antibodies can induce a similar signalling effect, since their structure is completely different.

This could explain the different effects of N-CAM antibody and N-CAM protein on the culture's fate. The cell death of the neuronal cells at high concentrations caused by N-CAM peptide and in one case N-Cadherin peptide (in combination with PLL) during IS experiments could be specifically due to the fact that N-CAM and $\mathrm{N}-$ Cadherin antibody did not trigger a similar signal response like N-CAM and $\mathrm{N}$-Cadherin peptide did. This difference in signaling effect (or the lack of it) might not be valid for all antibodies (depending on the antigen position on the cell adhesion molecule). A study by Azizeh et al [35] revealed significant cell death 24 hours after addition of soluble anti-NCAM monoclonal antibodies $(3 \mu \mathrm{g} / \mathrm{ml})$, probably caused by a downstream signal transduction cascade that triggers programmed cell death.

In the aggregation assay cell death was also observed for the highest concentration of N-Cadherin protein and antibody. Cell death at high concentrations of these 
CAMs is most likely not the actual outcome of the signaling response under normal conditions, but rather a consequence of a signal cascade caused by the high concentration of CAM blockers.

\subsection{Recommendations}

Some important factors should be taken into account to improve and facilitate future investigation of cell-cell and cell-substrate adhesion using IS. This research was limited by the frequency range of the impedance setup, having a maximum of $20 \mathrm{kHz}$. For future research, higher frequencies might improve the sensitivity of applied electrodes. Also, for a better optical evaluation transparent microelectrodes made of indium tin oxide (ITO) might be an interesting option [36].

In this research project we investigated inhibition of neuronal cell migration and aggregation in vitro. All experiments were carried out during 144 hours, or 6 full days.

PEI demonstrated the best neuron adhesive properties when used as a substrate coating during these 6 days. In contrast to ECM proteins, PEI does not modulate neuronal processes like survival, neurite outhgrowth and differentiation [17-19]. However, the neuron adhesive properties of applied ECM protein substrates are moderate. N-Cadherin protein or antibody demonstrated much better adhesive properties compared to the ECM proteins. Furthermore, CAM binding is known to induce neurite outhgrowth and neuronal survival [31-34]. For preservation of a stable culturing topography the use of immobilized N-Cadherin protein or antibody is better than using laminin or fibronectin coatings. A study into the comparison of the neuronal processes, that are possibly promoted by substrate coatings, would be very helpful to indicate which coating fits a specific application. This would also point out whether immobilized N-Cadherin protein or antibody should be preferred over PEI.

The migration and aggregation of neuronal cells in case of PLL, laminin fibronectin or low concentrations of PEI coating can be inhibited for at least 6 days by the blocking of cell-cell adhesion molecules. Of all blockers applied, NCadherin antibody was most effective in preventing migration and aggregation of cortical neurons. For a stable culture (no migration or aggregation) a combination of a PEI substrate with N-Cadherin antibody as a blocker would be most appropriate. Nonetheless, CAM blocking with N-Cadherin was most effective on fibronectin and laminin coatings.

Prolonging experiments (weeks or even months) would provide interesting information on the long term effects of applied substrate coatings and CAM blockers. Long-term experiments could give important answers regarding electrical activity, connectivity, viability, dosage, etc. In case of prolonged experiments, ways of permanently inhibiting or terminating CAM function would be equally interesting. Permanent inhibition or termination of CAMs, by using techniques like 
gene knock-out [37], would eliminate some significant drawbacks of CAM blocking, like the continued addition of expensive blockers, fluctuations in concentrations of CAM blocker and unblocked CAMs.

\section{References}

[1] Giaever I and Keese C R 1986 Use of Electric Fields to Monitor the Dynamical Aspect of Cell Behavior in Tissue Culture IEEE Trans. Biomed. Eng. 33 242-247

[2] Bayarsaikhan M, Takino T, Gantulga D, Sato H, Ito T and Yoshioka K 2007 Regulation of N-cadherin-based cell-cell interaction by JSAP1 scaffold in PC12h cells Biochem. Biophys. Res. Commun. 353 2357-62.

[3] Wegener J, Giaever I and Keese C R 2000 Electric cell-substrate impedance sensing (ECIS) as a noninvasive means to monitor the kinetics of cell spreading to artificial surfaces Exp. Cell. Res. 259 158-66

[4] Dusseiller M R, Schlaepfer D, Koch M, Kroschewski R, Textor M 2005 An inverted

microcontact printing method on topographically structured polystyrene chips for arrayed micro-3-D culturing of single cells Biomaterials. 29 5917-25.

[5] Wang L, Murthy S K, Fowle W H, Barabino G A, Carrier R L 2009 Influence of micro-well biomimetic topography on intestinal epithelial Caco-2 cell phenotype Biomaterials. 30 6825-34

[6] Vogt A K, Lauer L, Knoll W, Offenhäusser A 2008 Micropatterned Substrates for the Growth of Functional Neuronal Networks of Defined Geometry Biotechnology Progress. 191562 -8

[7] Lakard S, Herlem G, Valles-Villareal N, Michel G, Propper A, Gharbi T and Fahys B 2005 Culture of neural cells on polymers coated surfaces for biosensor applications Bioelectrons and biosensors 20 1946-54

[8] Brewer G J, Deshmane S, Ponnusamy E 1998 Precocious axons and improved survival of rat hippocampal neurons on lysine-alanine polymer substrates J. Neurosci. Methods. 85 13-20.

[9] Ruardij T G, Goedbloed M H and Rutten W L C 2000 Adhesion and patterning of cortical neurons on polyethylenimine and fluorocarboncoated surfaces IEEE trans. biomed. eng. 47 1593-9

[10] Ruardij T G, van den Boogaart M A F and Rutten W L C 2002 Adhesion and growth of electrically-active cortical neurons on polyethyleneimine patterns microprinted on PEO-PPO-PEO triblockcopolymer-coated hydrophobic surfaces IEEE Trans. Nanobiosci. 1 1-8

[11] Ruardij T G, Goedbloed M H and Rutten W L C 2003 Long-term adhesion and survival of dissociated cortical neurons on miniaturized chemical patterns Med. Biol. Eng. Comp. 41 227-32 
[12] Corey J M, Feldman E L 2003 Substrate patterning: an emerging technology for the study of neuronal behavior Exp. Neurol. 184 Suppl 1:S89-96.

[13] Greve F, Frerker S, Bittermann A G, Burkhardt C, Hierlemann A, Hall H, Corey J M, Feldman E L 2007 Molecular design and characterization of the neuron-microelectrode array interface Biomaterials. 28 5246-58

[14] Azemi E, Stauffer W R, Gostock M S, Lagnaur CF, and Cui XT 2008 Surface immobilization of neuronal adhesion molecule L1 for improving the biocompatibility of chronic neuronal probes: In vitro characterization Acta biomater. 4 1208-17

[15] M. Lambert, F. Padilla and R.M. Mege 2000 Immobilized dimers of Ncadherin-Fc chimera mimic cadherin-mediated cell contact formation: contribution of both outside-in and inside out signals Journal of Cell Science 113 2207-19

[16] Sorribas H, Braun D, Leder L, Sonderegger P, Tiefenauer L 2000 Adhesion proteins for a thight neuron-electrode contact J. Neurosci. Meth. 104 13341

[17] Chen C S, Tan J and Tien J 2004 Mechanotransduction at cell-matrix and cell-cell contacts Ann. Rev. Biomed. Eng. 6 275-302

[18] Venstrom K A and Reichardt L F 1993 Extracellular matrix 2: Role of extracellular matrix

molecules and their receptors in the nervous system". FASEB J. 7 9961003.

[19] Smalheiser N R, Crain S M and Reid L M 1984 Laminin as a substrate for retinal axons in

Vitro Dev.. Brain Res. 12 136-140

[20] Bates C A, Becker C G, Miotke J A and Meyer R L 1999 Expression of polysialylated NCAM but not L1 or N-cadherin by regenerating adult mouse optic fibers in vitro Exp. Neurol. 155 128-39

[21] Kenwrick S, Watkins A and De Angelis E 2000 Neural cell recognition molecule L1: relating biological complexity to human disease mutations Hum. Mol. Genet. 9 879-86.

[22] Landmesser L, Dahm L, Schultz K and Rutishauser U 1988 Distinct roles for adhesion molecules during innervation of embryonic chick muscle Dev. Biol. 130 645-70

[23] Norgren R B Jr. and Brackenbury R 1993 Cell adhesion molecules and the migration of LHRH neurons during development Dev. biol. $160377-87$.

[24] Dahme M, Bartsch U, Martini R, Anliker B, Schachner M and Mantei N 1997 Disruption of the mouse L1 gene leads to malformations of the nervous system Nature Genet 17 346-9

[25] Cohen N R, Taylor J S H, Scott L B, Guillery R W, Soriano P and Furley A J W 1997 Errors in corticospinal axon guidance in mice lacking the neural cell adhesion molecule L1 Curr. Biol. 8 26-33 
[26] Kwon Y T, Gupta A, Zhou Y, Nikolic M, Tsai L H 2000 Regulation of Ncadherin-mediated adhesion by the p35-Cdk5 kinase Curr. Biol. 10 363-72.

[27] Gago N, Avellana-Adalid V, Evercooren A B, Schumacher M 2003 Control of cell survival and proliferation of postnatal PSA-NCAM $(+)$ progenitors Mol. Cell. Neurosci. 2 162-78.

[28] Wilkemeyer M F, Menkari C E, Spong C Y and Charness M E 2002 Peptide Antagonists of Ethanol Inhibition of L1-Mediated Cell-Cell Adhesion J. Pharmacol. Exp. Ther. 303 110-116

[29] Willems J, Bruyneel E, Noe V, Slegers H, Zwijsen A, Mege R M and Mareel M 1995

Cadherin-dependent cell aggregation is affected by decapeptide derived from rat

extracellular super-oxide dismutase FEBS Letters. 363 289-92.

[30] Rutishauser U, Acheson A, Hall A K, Mann D M and Sunshine J 1988 The neural cell adhesion molecule (NCAM) as a regulator of cell-cell interactions Science 240 53-7

[31] Skaper S D, Facci L, Williams G, Williams E, Walsh F S and Doherty P 2004 A dimeric version of the short N-cadherin binding motif HAVDI promotes neuronal cell survival by activating an N-cadherin/fibroblast growth factor receptor signalling cascade Mol. Cell. Neurosci. 26 17-23

[32] Ditlevsen D K, Køhler L B, Pedersen M V, Risell M, Kolkova K, Meyer M, Berezin V, Bock E 2003 The role of phosphatidylinositol 3-kinase in neural cell adhesion molecule-mediated neuronal differentiation and survival $J$. Neurochem. 84 546-56

[33] Chen S, Mantei N, Dong L, Schachner M 1999 Prevention of neuronal cell death by neural adhesion molecules L1 and CHL1 J. Neurobiol. 38 428-39

[34] Loers G, Chen S, Grumet M and Schachner M 2005 Signal transduction pathways implicated in neural recognition molecule L1 triggered neuroprotection and neuritogenesis $J$. Neurochem. 92 1463-76

[35] Azizeh B Y, Cribbs D H, Kreng V M and Cotman C W 1998 Cross-linking of NCAM receptors on neurons induces programmed cell death Brain Research. 796 20-6.

[36] Choi C K, Margraves C H, Jun S I, English A E, Rack P D and Kihm K D 2008 Opto-Electric Cellular Biosensor Using Optically Transparent Indium Tin Oxide (ITO) Electrodes Sensors 8 3257-70

[37] Kadowaki M, Nakamura S, Machon O, Krauss S, Radice G L, Takeichi M 2007 N-Cadherin mediates cortical organization in the mouse brain Dev. Biol. 304 22-33 


\section{Summary}

The goal of this study is to provide a tool for better control over aggregation of neuronal cells in culture. By enhancement of cell-substrate adhesion to artificial (flat electrode array) surfaces, accompanied by weakened neuronal cell-cell adhesion, we aim to inhibit neuronal aggregation and migration.

An improved control over cell-cell and cell-substrate adhesion in neuronal cultures would be important in the development of devices in which a selective and durable contact between 2D electrode systems and neural tissue is a necessity. An example of such a device is the 'cultured probe', an implantable electrode array pre-cultured with neurons.

In chapter 2 we investigated the applicability of electric impedance sensing (IS) for the monitoring of cell-cell adhesion in developing neuronal cultures. Four sizes of electrodes were compared. For all electrodes a clear effect of neuronal cell coverage on the electrode impedance was demonstrated. From the investigated frequency range $(5 \mathrm{~Hz}-20 \mathrm{kHz})$, the higher frequencies $(10$ and $20 \mathrm{kHz})$ showed to be most sensitive. On 7850 um $^{2}$ electrodes the increase of real impedance after cell coverage is over $250 \%$ at $10 \mathrm{kHz}$. Comparison of microscope-evaluation of cell coverage and cell spreading with simultaneous impedance measurements showed the superiority of the latter method.

IS showed to be a simple technique sensitive enough to detect small changes in developing cultures, which can not always be detected with microscopy and image analysis.

The combination of IS and microscopy was adopted for the investigation of cellcell adhesion in response to blocking of cell adhesion molecules. In chapter 3, antibodies and soluble extracellular domains of the cell adhesion molecules $\mathrm{N}$ CAM, N-Cadherin and L1 were used for the inhibition of cell-cell adhesion in neuronal cultures. These soluble molecules are able to block cell adhesion molecules located on neuronal cell membranes, therefore inhibiting neuronal cellcell adhesion and aggregation. First, the effect of the blockers on aggregation was investigated with microscopy in a 96 hour aggregation assay on a low adhesive substrate (and therefore accelerating aggregation of neurons). Especially the NCadherin protein and antibody showed to be effective in aggregation inhibition. Blocking of N-CAM and L1 revealed no inhibition of aggregation.

In a second experiment, impedance measurements were used to monitor the effect of CAM blockers on cell-cell adhesion among neuronal cells cultured on surfaces with relatively strong neuron adhesive properties. During 144 hours, the impedance of neuron-covered gold electrodes was monitored at a frequency of $10 \mathrm{kHz}$. Results from impedance correspond to those of the aggregation assays. Impedances of 
neuron covered electrodes were significantly lower in the presence of $\mathrm{N}$-Cadherin antibody and protein, indicating a less profound binding between adjacent neuron. The results from both the aggregation assays and the impedance measurements demonstrate the applicability of CAM blocking for diminishing cell-cell adhesion.

In chapter 3 we used polyethyleneimine (PEI) as a substrate coating. In chapter 4 we compared inhibition of cell-cell adhesion among neuronal cells cultured on several other substrates. Neurons were cultured on surfaces coated with laminin, fibronectin and poly-l-lysine (PLL). These three surface modificators show moderate neuron adhesive properties compared to PEI. However, laminin and fibronection are known to promote several cellular processes like proliferation, differentiation, axonal outgrowth and survival, making it interesting to inhibit aggregation on these substrate coatings.

The lower neuron adhesive forces of laminin, fibronectin and PLL cause formation of neuronal aggregates within a few days. However, in the presence of $\mathrm{N}$-Cadherin protein or antibody, aggregation of neurons was inhibited or stopped.

In chapter 5, we studied the neuron adhesive properties of surfaces with immobilized L1, NCAM and N-Cadherin protein or antibodies. L1, N-CAM and $\mathrm{N}$-Cadherin are also known to promote several cellular processes, like axonal guiding, neuronal tissue morphogenesis, tissue differentiation, regeneration and synaptic plasticity. Surfaces with immobilized N-CAM and N-Cadhering protein or antibodies show good neuron adhesive properties, but neuronal adhesion on L1 modified surfaces (both protein and antibodies) was very poor.

In the second part of chapter 5 we studied the effect of adding soluble CAMs to neurons cultured on immobilized CAM surfaces. Competition between soluble CAMs and immobilized CAMs of the same origin was observed, since all the applied CAMs bind homotypically. For example, the neuron adhesive properties of an immobilized N-Cadherin protein surface are poor in the presence of soluble $\mathrm{N}$ Cadherin protein or antibody. Neurons cultured on immobilized antibodies were less affected by addition of soluble CAM blockers of the same type compared to neurons cultured on immobilized proteins, indicating that antibody-protein bonds are more stable compared to protein-protein bonds.

The experimental results in this study show the applicability of soluble CAMs for the inhibition of neuronal cell-cell adhesion and aggregation in neuronal cultures on various types of culturing substrates. Aggregation of neuronal cells on PEI, PLL, laminin and fibronectin can be inhibited using soluble CAMs.

Also, soluble CAMs can be immobilized, resulting in specific neuron adhesive substrates. Immobilization of CAMs enables the study of competition mechanisms among CAMs. 


\section{Samenvatting}

Het doel van deze studie is het verbeteren van de controle over de aggregatie en migratie van neuronale cellen in kweek. Door het verbeteren van de adhesie van neuronale cellen aan artificiële oppervlakken, in combinatie met gereduceerde celceladhesie, hebben we geprobeerd neuronale aggregatie en - migratie tegen te gaan. Een betere controle over cel-cel- en cel-substraatadhesie is belangrijk voor de ontwikkeling van toepassingen waarbij selectieve en duurzame contacten tussen 2D elektrodesystemen en neuronaal weefsel van belang zijn. Een voorbeeld van een dergelijke toepassing is de 'cultured probe'; een implanteerbaar elektrodenarray, welke voorgekweekt is met neuronale cellen.

In hoofdstuk 2 hebben we gekeken naar de toepasbaarheid van impedantiemetingen voor het monitoren van cel-celadhesie in zich ontwikkelende neuronale kweken. Hierbij hebben we elektrodes van vier verschillende grootten met elkaar vergeleken. Voor alle formaten is een duidelijke toename van de impedantie, door bedekking van de elektrodes met neuronen, te zien. Van de onderzochte frequentiereeks $(5 \mathrm{~Hz}-20 \mathrm{kHz})$ laten de hogere frequenties (10 and $20 \mathrm{kHz}$ ) de hoogste gevoeligheid voor celbedekking van de elektrodes zien. Bij de $7850 \mathrm{um}^{2}$ elektrode is de toename van de impedantie meer dan 250\% bij $10 \mathrm{kHz}$. De vergelijking van microscopisch evalueren van de celdekking met impedantiemetingen laat zien dat de laatstgenoemde techniek de beste is. ''Impedance Sensing', (IS) is een eenvoudige techniek, die gevoelig genoeg is om kleine veranderingen in ontwikkelende kweken aan te tonen. Vaak zijn deze veranderingen niet te detecteren met microscopie en beeldanalyse.

De combinatie van IS en microscopie, uit hoofdstuk 2, is verder gebruikt om het effect van blokkeerders van celadhesiemoleculen (CAMs) op de cel-cel adhesie te bestuderen. In hoofdstuk 3 zijn antilichamen en de oplosbare extracellulaire domeinen van N-CAM, N-Cadherin and L1 toegepast als remmers van celadhesie. Deze oplosbare CAMs kunnen CAMs op celmembranen blokkeren en zo adhesie tussen neuronale cellen remmen (en daarmee ook aggregatie). Als eerste is het remmende effect van bovengenoemde CAMs onderzocht met microscopie, in een 96 uur durende aggregatie-assay, op een oppervlak waar neuronen matig aan hechten (waardoor neuronen dus sneller aggregeren). Vooral N-Cadherin proteïne en antilichamen blijken effectief in het remmen van aggregatie. Het blokkeren van $\mathrm{N}-\mathrm{CAM}$ en L1 had geen effect op neuronale aggregatie.

In een tweede experiment zijn impedantiemetingen gebruikt voor het bepalen van het effect van CAM-blokkers op cel-celadhesie. Ditmaal zijn de cellen gekweekt op een oppervlak dat neuronale cellen sterk bindt. Gedurende 144 uur is de impedantie van met cellen bedekte elektroden gemeten bij een frequentie van 10 
$\mathrm{kHz}$. De resultaten van het impedantie-experiment komen overeen met die van de aggregatie assays. De impedantie van met neuronen bedekte elektrodes lag beduidend lager in de aanwezigheid van $\mathrm{N}$-Cadherin-antilichaam en -proteïne, wat duidt op een minder goede adhesie tussen neuronale cellen. Alle resultaten van de aggregatie-assyas en de impedantiemetingen tonen de toepasbaarheid van CAMblokkers voor de vermindering van cel-cel adhesie aan.

In hoofdstuk 3 is polyethyleneimine (PEI) gebruikt als substraatcoating. In hoofdstuk 4 vergelijken we de inhibitie van cel-celadhesie in kweken op verschillende substraten. Neuronen zijn in dit experiment gekweekt op laminine-, fibronectine- en poly-L-lysine- ondergronden (PLL). Oppervlakken, gecoat met één van deze drie stoffen, laten een beperkte neuronadhesie zien. Echter, van laminine en fibronectine is bekend dat deze verschillende processen in neuronale cellen bevorderen, zoals proliferatie, differentiatie, uitgroei van axonen en de overlevingskansen. Dit maakt de inhibitie van aggregatie, op dergelijke kweekoppervlakken, met deze stoffen aantrekkelijk. De resultaten laten zien dat neuronen, gekweekt op laminine, fibronectine en PLL, binnen enkele dagen aggregeren. Echter, in de aanwezigheid van N-Cadherin-proteïne of -antilichaam wordt de aggregatie geremd.

In hoofdstuk 5 zijn de eerder gebruikte L1, NCAM en N-Cadherin toegepast voor de modificatie van kweekoppervlakken. Ook van L1, NCAM en N-Cadherin is bekend dat deze verschillende neuronale processen bevorderen, zoals: morphogenese, differentiatie, regeneratie en synaptische plasticiteit. Oppervlakken met geïmmobiliseerde N-CAM- en N-Cadherin-proteïne of -antilichaam laten een goede binding van neuronale cellen zien. De adhesie aan L1 proteïne of L1 antilichaam is daarentegen slecht.

In het tweede deel van hoofdstuk 5 hebben we het effect onderzocht van CAM blokkers op de cel-celadhesie van neuronen, gekweekt op substraten met geïmmobiliseerde CAMs. In dit experiment werd competitie van CAMs in oplossing en geïmmobiliseerde CAMs op het kweekoppervlak waargenomen. Zo zijn de neuron-adhesieve eigenschappen van geïmmobiliseerd N-Cadherin proteïne beduidend slechter in de aanwezigheid van vrije N-Cadherin-proteïnen, of antilichamen in de kweekvloeistof. De adhesie tussen neuronen en geïmmobiliseerde antilichamen wordt minder beïnvloed door vrije CAM-blokkers, dan de adhesie tussen neuronen en geïmmobiliseerde proteïnen.

De resultaten van de experimenten, in het hier beschreven onderzoek, laten de toepasbaarheid van CAMs als remmers van neuronale cel-celadhesie en aggregatie in neuronale kweken zien. Aggregatie van neuronale cellen op PEI, PLL, laminine en fibronectine kan worden geremd door de toevoeging van CAMs aan de kweekvloeistof. 
CAMs kunnen tevens worden geïmmobiliseerd voor het creëren van specifieke kweeksubstraten. Dergelijke kweeksubstraten kunnen ook worden gebruikt voor het bestuderen van competitiemechanismen tussen CAMs. 


\section{Dankwoord}

Het zou ondenkbaar zijn geweest dat dit proefschrift een einde (of een begin) zou hebben gehad zonder de hulp van anderen. Soms zat die hulp in iets kleins, maar soms ook in een grote en onmisbare inbreng voor mijn proefschrift. Mijn dank gaat uit naar alle mensen die een aandeel hebben gehad in dit boekje, of die hebben bijgedragen aan de nodige ontspanning en afleiding, tijdens, of na het werk.

Allereerst wil ik mijn dagelijkse begeleiders en promotoren, Wim Rutten en Enrico Marani, bedanken voor de kans die ze mij boden, om aan dit onderzoek te werken. De weg leek soms zonder einde, maar gelukkig is de eindstreep nu toch echt in zicht. Wim, bedankt voor al je tijd en energie, die je in mij en het proefschrift hebt gestoken de afgelopen jaren. Enrico, ten eerste mijn dank voor de wekelijkse aanvoer van immer piepvers materiaal, maar vooral voor je inzet als begeleider en de ondersteuning in moeilijke tijden.

André Poot, jou wil ik graag bedanken voor het proeflezen en verbeteren van mijn proefschrift, maar ook voor mijn allereerste kennismaking met de Universiteit Twente.

Dan zijn er natuurlijk de studenten die, vooral op experimenteel gebied, veel werk hebben verricht. Elisabeth Rozen, Richard Heerschop, Jasper van Weerd, lab Suus en Cees Middel. Jullie werk staat helaas niet in dit boekje, maar het voorbereidende werk was onmisbaar. Vooral het uitzoeken van de juiste blokkers en het uitzoeken van de fotobewerkingen heeft mij veel werk uit handen genomen.

Ook onmisbaar was de technische ondersteuning van Ed en Marcel. Ed, bedankt voor het aanpassen van de impedantie opstelling en natuurlijk voor alle afleveringen van Lost en Heroes. Marcel, jij bedankt voor de vele uren in de cleanroom. Zonder jouw vakwerk zou het nooit gelukt zijn.

Gedurende mijn tijd bij BSS heb ik ook heel wat kamergenoten "versleten". Eerst Marc van den Boogaart en Kathrin Zweers-Peter. Katrhin heeft mij de fijne kneepjes op het kweeklab bijgebracht, waarvoor mijn dank. Daarna kwamen Daniel en Ljuba bij me op de kamer. Heren, het was een onvergetelijke tijd!

Mijn enige echte room-moat is natuurlijk Martin. Je hebt het vier jaar met me uitgehouden. Bedankt dat je me als paranimf wilt bijstaan.

Verder zijn er nog de vele andere (oud)-collega's, die ik wil bedanken voor de gezellige tijd. Colleen, Dimitrios, Willem van Riel, Jeroen, Daphne, Peter, Eva, Joost, Irina en natuurlijk Wies, die ontelbare dingen voor me heeft geregeld.

Tot slot zijn er nog enkele mensen die ik graag apart zou willen bedanken. Paul, I also miss our confessions at the flowhood! Esther, de spannende verhalen over het gezamenlijke AOI avontuur en mijn deelname aan de "5 roses" had ik voor geen 
goud willen missen. Jan S., wij hebben veel samengewerkt en je hebt mij met ontzettend veel dingen geholpen, maar we hebben vooral veel gelachen. Dank!

Nadine, na meer dan 20 jaar ken je me als geen ander. Bergen en dalen, maar je hebt altijd achter me gestaan. Kus.

Remy. 
